Portland State University

PDXScholar

\title{
Evaluating Project Assessment Techniques for High- Profile Transportation Projects Development and Delivery: Case of State Departments of Transportation (DOTs) in the United States
}

Rafaa Ibrahim Khalifa

Portland State University

Follow this and additional works at: https://pdxscholar.library.pdx.edu/open_access_etds

Part of the Transportation Commons

Let us know how access to this document benefits you.

\section{Recommended Citation}

Khalifa, Rafaa Ibrahim, "Evaluating Project Assessment Techniques for High-Profile Transportation Projects Development and Delivery: Case of State Departments of Transportation (DOTs) in the United States" (2019). Dissertations and Theses. Paper 5109.

https://doi.org/10.15760/etd.6985

This Dissertation is brought to you for free and open access. It has been accepted for inclusion in Dissertations and Theses by an authorized administrator of PDXScholar. Please contact us if we can make this document more accessible: pdxscholar@pdx.edu. 
Evaluating Project Assessment Techniques for High-Profile Transportation Projects Development and Delivery: Case of State Departments of Transportation (DOTs) in the United States

by

Rafaa Ibrahim Khalifa

A dissertation submitted in partial fulfillment of the requirements for the degree of

\author{
Doctor of Philosophy \\ in \\ Technology Management
}
Dissertation Committee:
Tugrul Daim, Chair
Judith Estep
Leong Chan
Loren Lutzenhiser

Portland State University

2019 
(C) 2019 Rafaa Ibrahim Khalifa 


\begin{abstract}
Time delays and cost overruns in construction projects are generally due to factors such as inappropriate planning, design errors, unexpected site conditions, inadvisable tools selection, change scope, weather conditions, lack of resources, and other project changes. Time delays and cost overruns are of concern to most project managers, owners, and governments. These elements of time and cost are two of the critical defects that impact the construction project delivery. These defects can lead to project failures and to various negative issues like increasing in disagreements among the project team, the contractor, suppliers, and the owner.
\end{abstract}

State Departments of Transportation (DOTs) in the U.S. continue to spend heavily on roads, highways, and bridges construction, as well as development, maintenance, and expansion. This continued financial commitment reflects decades of commitment to improve the transportation service for safer and better use by the general public. Despite the notable efforts from most of the states to develop the transportation infrastructure, budget restrictions and lack of funds are some of the major challenges faced by DOTs.

Highway and bridge infrastructure has a high potential growth in the U.S. construction market. Well-organized highway and bridge project investment decision-making becomes increasingly crucial in the transportation sector. In this research, transportation is specified to highway and bridge projects, and it focused on high-profile projects. These projects are 
defined as high-cost projects, and are associated with higher project delivery risk (typically $\$ 100$ - \$500 million).

All states are working with their state transportation plan, listing the projects based on each state priorities and population growth. Proper planning leads to the right decision regarding selecting the best alternative within budget, and it must reflect certain core principles, including a comprehensive analysis. To facilitate such a decision process, decision makers need a trusted decision model that considers all important options and impacts. By using a decision model, decision-making will not be subjectively influenced to favor one option or group. The decision model becomes the primary tool for selecting the best option, based on its structure levels, perspectives, sub-criteria, and experts' input. Recently, there is an apparent need for a decision model to help DOTs evaluating their options. Effective project delivery assessment tools, techniques, or practices are strongly needed to improve transportation construction projects' performance.

The research objective is to develop a comprehensive decision model that can be used by project managers and their teams to choose the most effective project assessment technique for measuring the success of performance and outcomes related to the delivery of transportation projects. This research was focused on the assessment techniques that are used in the development phase within the transportation project lifecycle phases.

To this end, the research identified and screened the innovative assessment tools and techniques of project delivery that the transportation and other industries have used by reviewing numerous of academic literature and technical reports. Based on the review, 
value optimization elements such as cost, time, performance, risk, and resources were selected to be the primary evaluation criteria that lead to achieving the model objective. Also, the model sub-criteria were investigated and selected based on the literature review and direct discussion with some experts such as project managers, civil engineers, and value management consultants.

The outcome analysis of the results showed that in terms of objectives that performance efficiency was rated the highest importance with respect to the mission, while resources presented the lowest importance from an overall assessment point of view. The results showed that Alternative 4, the VE-RACRDAM technique, was ranked as the most important alternative among others followed by Alternative 5, while Alternative 2 was ranked the least important. A five scenarios analysis was applied to measure the sensitivity of the effects of changing the relative importance of the assessment criteria on alternatives' rankings. Results showed that Alternative 4 was maintained as the most effective assessment technique among the other alternatives in the five scenarios.

In the end, experts were asked to validate the final research results, and they confirmed that the results were appropriate and valid. The validity of the decision model and findings of this research contribute new insights into the transportation construction industry as the case of state departments of transportation. Also, the experts agreed that this decision model is generalizable and could be used in other industries. Therefore, the model significantly contributes to the project management knowledge, and construction project development and delivery success. 


\section{DEDICATION}

This dissertation is dedicated to:

The memory of my father, Ibrahim; my uncles, Mohsen and Khalifa; and My Father-in-Law, Ali; may Allah have mercy upon them. 


\section{ACKNOWLEDGEMENTS}

I always felt extraordinarily fortunate throughout my $\mathrm{Ph} . \mathrm{D}$. research to be able to extend my body of knowledge and learn from many great people. This research would not have been possible without the support and help of many individuals who contributed to and influenced my work in numerous ways. Thank you, all.

I wish to express my sincere thanks to my country (LIBYA) and the Ministry of Higher Education and Scientific Research, I express my appreciation for their financial support of my Ph.D. studies in the USA. Thank you, my country.

My most grateful and sincere thanks to Professor Tugrul U. Daim for his wise guidance throughout this research. He has always been there with valuable insights and challenges which played a significant role in my journey. Thank you, Dr. Daim.

I would like to express my deep appreciation to my dissertation committee members, Dr. Judith Estep, Dr. Leong Chan, and Dr. Loren Lutzenhiser for their constructive suggestions and continuous support over the past three years as I moved from the research idea to completed research. Thank you, my professors.

My gratitude is also extended to all faculty members, staff, and friends in the Engineering and Technology Management Department who had been like my second family during my Ph.D. studies. Thank you, all. 
I would like to acknowledge Robert Stewart and other individual project delivery professionals and their agencies, who participated in this research. I am grateful for their cooperation, advice and invaluable comments. Thank you, Rob and others.

I would like to express my heartfelt gratitude for my beloved great mother, Habiba; my darling sister, Samia; and my close friend and brother, Dr. Rashed. Their selfless love has been my driving force. I wish I could show them just how much I love and appreciate them. Thank you, my mother, my sister, and my brother.

Last but not least, I believe that words not enough to express my great gratitude for the role and help of my lovely wife, Maysoun during my Ph.D. research. I am especially indebted to her for being extremely understanding, supporting me patiently, and raising our lovely Kids, Ebrahim, Saif, and Alia, without enough help from me during years of my studies and hardship. Her unconditional support fueled my success. Thank you, my wife. 
TABLE OF CONTENTS

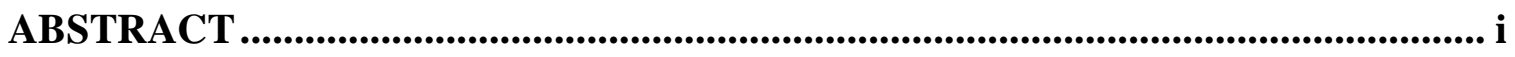

DEDICATION

ACKNOWLEDGEMENTS.........................................................................................................v

LIST OF TABLES........................................................................................... xii

LIST OF FIGURES.......................................................................................................................xiv

ABBREVIATIONS........................................................................................................... xvii

CHAPTER ONE: INTRODUCTION ........................................................................1

1.1 Research Background ....................................................................................................1

1.2 Research Problem and Motivation ......................................................................4

1.3 Research Gap ...........................................................................................................10

1.4 Research Scope ........................................................................................................12

1.5 The Dissertation Map...................................................................................................17

CHAPTER TWO: LITERATURE REVIEW .............................................................19

2.1 Project Cost and Schedule .........................................................................................19

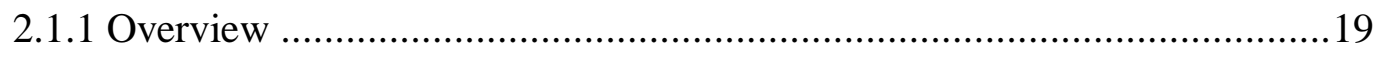

2.1.2 Over Budget and Schedule - Actual Cases ..............................................20

2.1.3 Projects Delay or Budget Overruns - Issues and Causes............................24

2.1.4 Project Success - On Budget and Time or Early Delivered .......................29

2.2 Value Optimization and Performance Measurement ........................................32

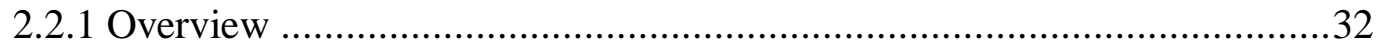

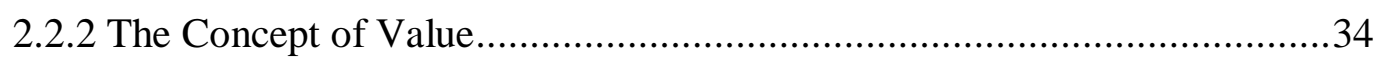

2.2.3 Research Approach regarding Value Optimization ....................................36

2.3 Project Development Process.................................................................................39

2.3.1 State Departments of Transportation (DOTs) Project Delivery ..................39

2.3.2 Comparison of DOTs Project Delivery Process ........................................40

2.3.3 Characteristics of Assessment Tools - Value Optimization Approach ........42 


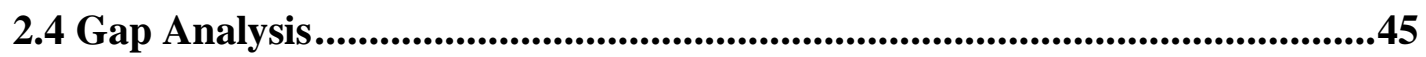

CHAPTER THREE: PROJECT MANAGEMENT TOOLS, TECHNIQUES, AND

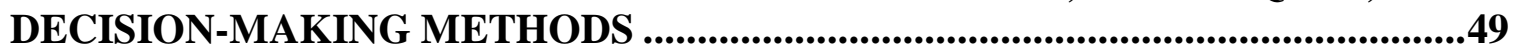

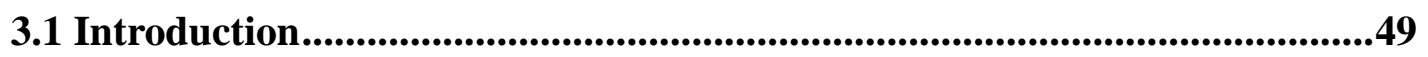

3.2 Managing Construction Projects Using Project Delivery Methods...............54

3.3 Managing Construction Projects by Contracting Methods.............................58

3.4 Managing Construction Projects by Support Tools and Techniques...........60

3.5 Overview of Multi-criteria Decision Models Leveraging Expert Opinion ..64

CHAPTER FOUR: RESEARCH APPROACH ...................................................75

4.1 Research Objective...................................................................................................75

4.2 Research Focus........................................................................................................77

4.3 Research Methodology ...............................................................................................80

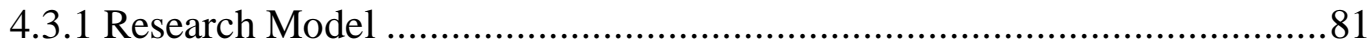

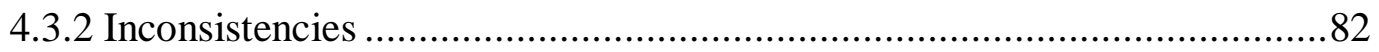

4.3.3 Disagreements and F-test with Hypotheses Testing ..................................84

4.3.3.1 The Interclass Correlation Coefficient (ICC) ..................................84

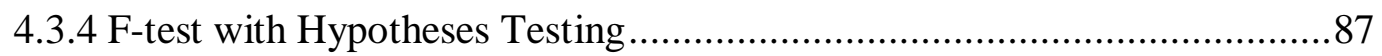

4.4 Sensitivity Analysis...............................................................................................88

4.5 Expert Panel Design ................................................................................................91

4.5.1 Experts Panel Forming and Administration .............................................91

4.5.2 Criteria for the Expert Selection ........................................................92

4.5.3 Expert Selection Procedures .................................................................93

CHAPTER FIVE: CASE STUDY BACKGROUND ..............................................95

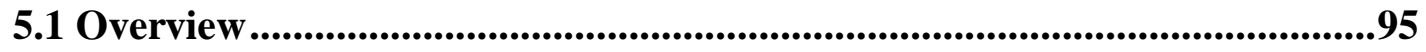

5.2 Project Assessment Techniques - What / Why is it Important? .....................95

5.3 Innovative Project Assessment Tools Selection for the DOTs.......................98

5.4 Tools Integration ..........................................................................................................99

CHAPTER SIX: CASE STUDY MODEL DEVELOPMENT ......................................102

6.1 Piloting the Model Development...........................................................................102 


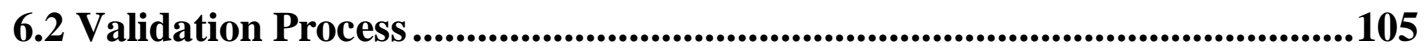

6.3 Quantification Process .....................................................................................107

6.4 Finalizing the Model Development and Implementation ...............................112

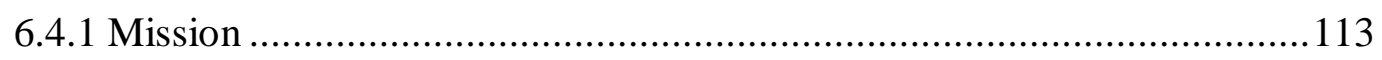

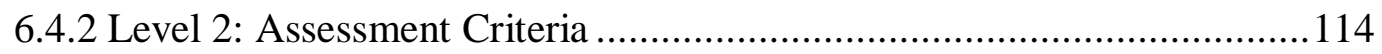

6.4.3 Level 3: Assessment Sub-criteria.......................................................115

6.4.4 Level 4: Alternatives - Project Assessment Techniques...........................119

6.5 Data Collection and Expert Panels Design ........................................................122

CHAPTER SEVEN: RESULTS AND DATA ANALYSIS .....................................129

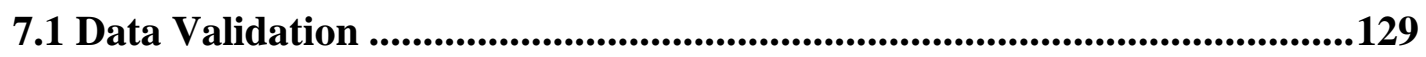

7.1.1 Analysis of Expert Panel (A1) Criteria Results - Level 2 ........................130

7.1.2 Analysis of Expert Panel (B1) Sub-criteria Results - Level 3 ..................132

7.2 Data Quantification.............................................................................................140

7.2.1 Analysis of Expert Panel (EP1) Criteria Results - Level 2 ........................141

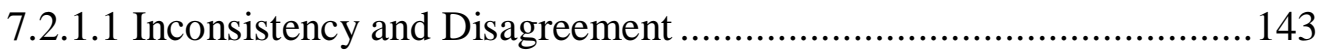

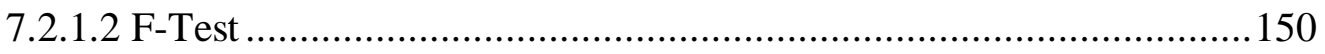

7.2.2 Analysis of Expert Panels Sub-criteria Results - Level 3...........................151

7.2.2.1 Expert Panel (EP2) Cost Sub-criteria ............................................152

7.2.2.2 Expert Panel (EP3) Schedule sub-criteria .......................................... 154

7.2.2.3 Expert Panel (EP4) Risk sub-criteria ..............................................156

7.2.2.4 Expert Panel (EP5) Performance sub-criteria .................................. 158

7.2.2.5 Expert Panel (EP6) Resources sub-criteria ...................................... 160

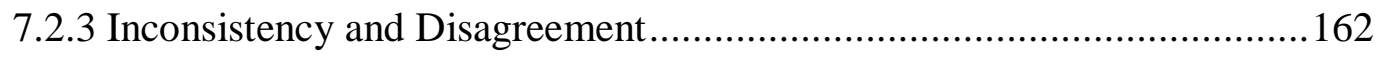

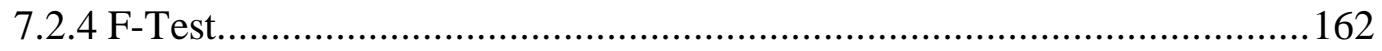

7.2.5 Analysis of Alternatives Panel Results - Level 4 …...............................166

7.2.5.1 Results of Alternatives with Cost Sub-criteria .................................. 166

7.2.5.2 Results of Alternatives with Schedule Sub-criteria ............................ 171

7.2.5.3 Results of Alternatives with Risk Sub-criteria .................................. 178

7.2.5.4 Results of Alternatives with Performance Sub-criteria ......................184 
7.2.5.5 Results of Alternatives with Resources Sub-criteria 191

7.2.6 Final Results of the Alternatives with Respect to the Mission .198

7.2.7 Inconsistency and Disagreement 199

7.2.8 F-Test 200

7.3 Scenario Analysis .202

7.3.1 Cost Reduction Scenario Analysis . .203

7.3.2 Schedule Acceleration Scenario Analysis .204

7.3.3 Risk Identification Scenario Analysis .206

7.3.4 Performance Efficiency Scenario Analysis .207

7.3.5 Resources Capability Scenario Analysis 208

7.4 Criterion-Related Validity .210

CHAPTER EIGHT: DISCUSSION 214

8.1 Data Validation ..............................................................................214

8.2 Data Quantification..............................................................................215

8.3 Recommendation of A New Systematic Project Assessment Process ........222

CHAPTER NINE: RESEARCH CONCLUSIONS ............................................226

9.1 Conclusions and Contributions.............................................................226

9.2 Limitations...........................................................................................231

9.3 Future Work

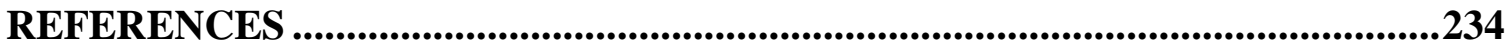

APPENDIX A: Research Instruments (RI1\& RI2) ..................................................258

Appendix A-1: Expert Invitation Templet - Validation................................258

Appendix A-2: Content Validity Survey ..................................................259

APPENDIX B: Research Instruments (RI3, RI4 \& RI5) .........................................260

Appendix B-1: Expert Invitation Templet - Quantification ...........................260

Appendix B-2: Content Quantify Process - HDM Software ............................261

Model Content - HDM Software Layout.......................................................261

Model Level 2 Criteria Quantification - HDM Software Layout.....................262 
Model Level 3 (COST) Quantification - HDM Software Layout ....................263

Model Level 3 (SCHEDULE) Quantification - HDM Software Layout...........263

Model Level 3 (RISK) Quantification - HDM Software Layout .....................263

Model Level 3 (PERFORMANCE) Quantification - HDM Software Layout...264

Model Level 3 (RESOURCES) Quantification - HDM Software Layout.........264

Model Level 4 Alternatives Quantification - HDM Software Layout...............265

APPENDIX C: Research Instruments (RI6) ..........................................................266

Appendix C-1: Expert Invitation Templet - Final Results Validation ...........266

Appendix C-2: Survey Instrument - Final Results Validation .......................267 


\section{LIST OF TABLES}

Table 1: Key Research Findings/Gaps in the Literature..........................................11

Table 2: State DOTs Project Development Process and Project Lifecycle .....................40

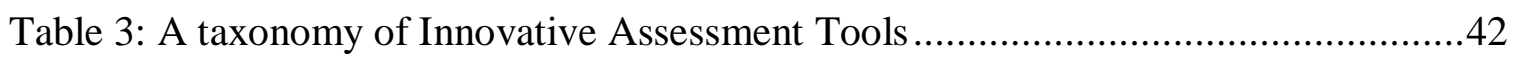

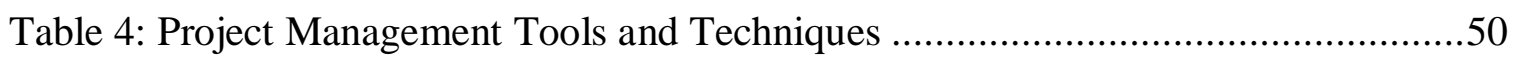

Table 5: Activities and Selection of PMTT in of Project Life Cycle Phases ..................54

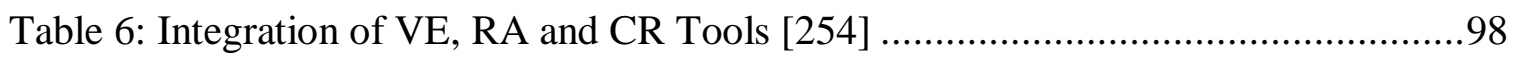

Table 7: Transportation Project Assessment Practices .................................................99

Table 8: Category of Expert's Panels in this Research ............................................ 123

Table 9: Sample of Distribution of Experts over Panels - Validation ......................... 124

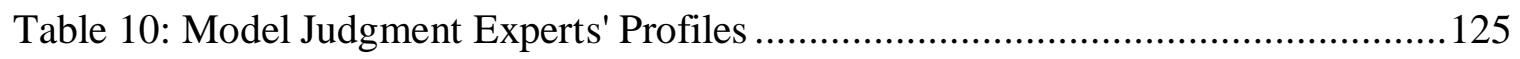

Table 11: Criteria Validation - Experts' Responses ............................................... 131

Table 12: The Experts Panel (B1) Feedback .................................................... 133

Table 13: The Final Decision Model Validation Results .......................................... 135

Table 14: Analysis of the Importance of Each Criterion to Alts. Selection ................... 142

Table 15: Orientation Table from HDM Numerical................................................ 145

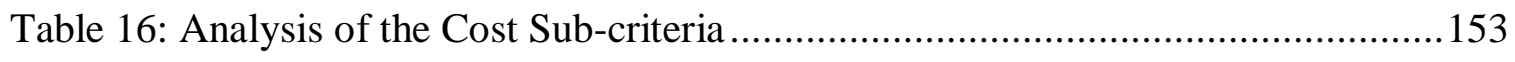

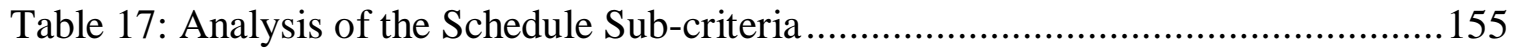

Table 18: Analysis of the Risk Sub-criteria ...................................................... 157

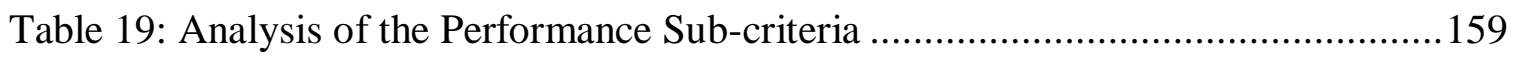

Table 20: Analysis of the Resources Sub-criteria ............................................. 161

Table 21: F-Test Values for all Sub-criteria Under Each Criterion .............................. 165

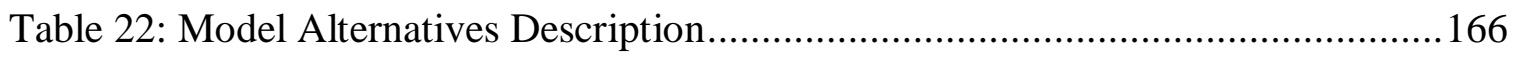

Table 23: Results of Alts. with Respect to Capital Cost........................................... 167

Table 24: Results of Alts. with Respect to Life-Cycle-Cost...................................... 169

Table 25: Results of Alts. with Respect to Support Costs ....................................... 170 
Table 26: Results of Alts. with Respect to Design \& Env. Analysis 172

Table 27: Results of Alts. with Respect to Right-of-Way Acquisition 174

Table 28: Results of Alts. with Respect to Tender \& Const. Duration 175

Table 29: Results of Alts. with Respect to Closeout Activities Duration 177

Table 30: Results of Alts. with Respect to Perf. Risk Impact.................................... 179

Table 31: Results of Alts. with Respect to Support Cost Risk Impact ......................... 182

Table 32: Results of Alts. with Respect to Schedule Risk Impact ............................. 183

Table 33: Results of Alts. with Respect to Project Scope ........................................ 185

Table 34: Results of Alts. with Respect to Needed Functions ................................... 187

Table 35: Results of Alts. with Respect to Commun. and Integ. Capabilities ................ 188

Table 36: Results of Alts. with Respect to Stakeholder Needs..................................190

Table 37: Results of Alts. with Respect to In-house Capability .................................. 192

Table 38: Results of Alts. with Respect to Ext. Consultant Needs ............................. 194

Table 39: Results of Alts. with Respect to Time Needs ............................................. 195

Table 40: Results of Alts. with Respect to Stakeholder Involvement .......................... 197

Table 41: Final Results of Alts. with Respect to Mission ........................................ 198

Table 42: Final Results of F-test and Disagreement ............................................201

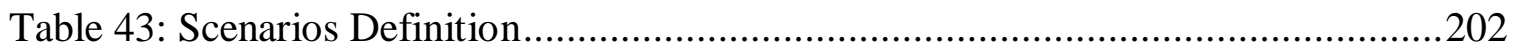

Table 44: Distribution Values of Variations Scenarios .........................................203

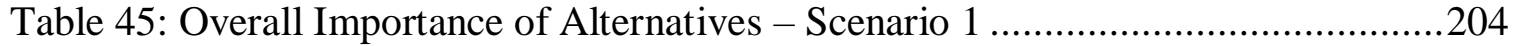

Table 46: Overall Importance of Alternatives - Scenario 2 ..................................206

Table 47: Overall Importance of Alternatives - Scenario 3 ...................................207

Table 48: Overall Importance of Alternatives - Scenario 4 ...................................208

Table 49: Overall Importance of Alternatives - Scenario 5 ...................................209 


\section{LIST OF FIGURES}

Figure 1: Highway and Street Construction- Adapted From [41] ...............................

Figure 2: Project Assessment Tools ...................................................................... 10

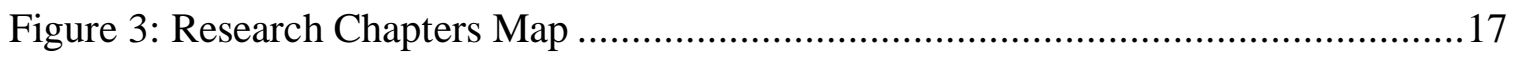

Figure 4: Comparison of Cost Overrun in Studied Projects- Adapted From [68] ...........23

Figure 5: Value Optimization Frame- Reproduced From [92] ...................................35

Figure 6: Five Elements of Value Optimization- Adapted From [104] .........................37

Figure 7: DB Process in Bridges Construction- Adapted From [162] .............................57

Figure 8: Multi-criteria Decision Process- Adapted From [183] ..................................64

Figure 9: CODT Project Lifecycle- Adapted From [27] ........................................ 78

Figure 10: Transportation Project LC / Design Phase- Adapted From [221] ..................79

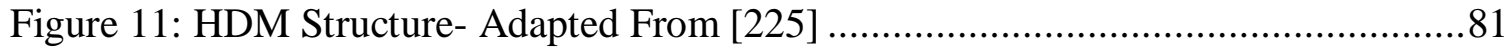

Figure 12: Selection Experts Procedures- Adapted From [251] ................................93

Figure 13: Timing of Conducting each Assessment Tool in Project Phases ..................97

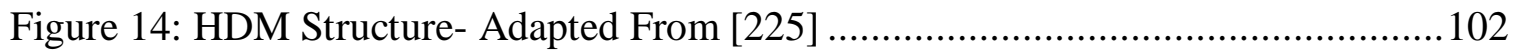

Figure 15: The Initial Decision Model for Evaluating Project Assessment Techniques. 104

Figure 16: Research Instrument (RI1 and RI2) Process ....................................... 105

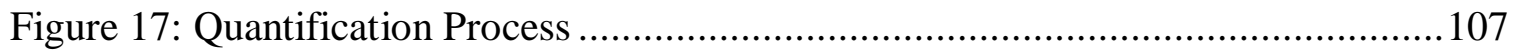

Figure 18: Research Instrument (RI3) Process .................................................. 108

Figure 19: Research Instrument (RI4) Process .................................................. 109

Figure 20: Research Instrument (RI5) Process ................................................. 110

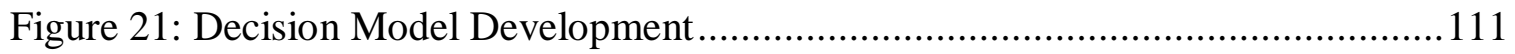

Figure 22: The Final Validation and Quantification Process................................... 113

Figure 23: Criteria Validation - Model Structure ................................................ 131

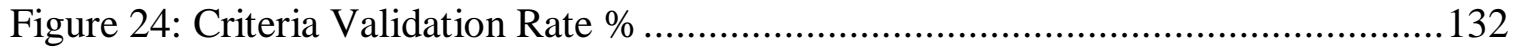

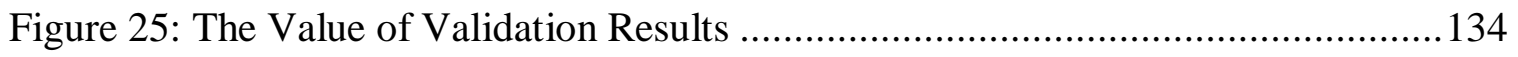


Figure 26: The Final Decision Model Validation Results ..............................................136

Figure 27: Final Alternatives' Validation Results......................................................136

Figure 28: The Final Decision Model Validation .......................................................137

Figure 29: The Hierarchal Decision Model for Evaluating Proj. Ass. Techniques .........139

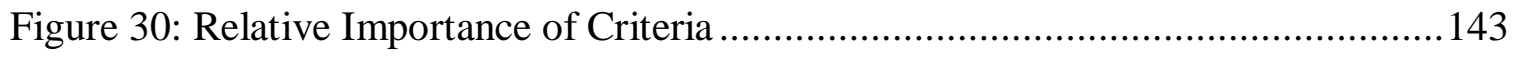

Figure 31: Inconsistency Threshold Limits at $\alpha=0.01$ to $\alpha=0.25$ [298] .....................149

Figure 32: Inconsistency Threshold for Five Variables ...............................................150

Figure 33: F-Test Values for Disagreements at the Criteria Level .................................151

Figure 34: Relative Importance of Cost Sub-criteria ...................................................153

Figure 35: Relative Importance of Schedule Sub-criteria .............................................155

Figure 36: Relative Importance of Risk Sub-criteria ……….....................................157

Figure 37: Relative Importance of Performance Sub-criteria ..........................................159

Figure 38: Relative Importance of Resources Sub-criteria............................................161

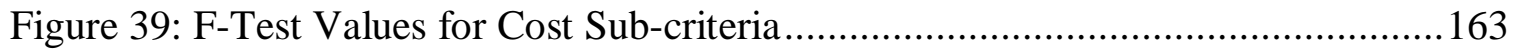

Figure 40: F-Test Values for Schedule Sub-criteria .................................................... 163

Figure 41: F-Test Values for Risk Sub-criteria ............................................................. 164

Figure 42: F-Test Values for Performance Sub-criteria ................................................164

Figure 43: F-Test Values for Resources Sub-criteria ...................................................165

Figure 44: Relative Importance of Alts. with Respect to Capital Cost ...........................168

Figure 45: Relative Importance of Alts. with Respect to Life-Cycle-Cost ......................169

Figure 46: Relative Importance of Alts. with Respect to Support Costs..........................171

Figure 47: Relative Importance of Alts. with Respect to Design \& Env. Analysis .........173

Figure 48: Relative Importance of Alts. with Respect to Right-of-Way Acquisition ..... 174

Figure 49: Relative Importance of Alts. with Respect to Tender \& Const. Duration ..... 176

Figure 50: Relative Importance of Alts. with Respect to Closeout Activities Duration .177

Figure 51: Relative Importance of Alts. with Respect to Perf. Risk Impact ...................179

Figure 52: Relative Importance of Alts. with Respect to Cost Risk Impact .....................181

Figure 53: Relative Importance of Alts. with Respect to Support Cost Risk Impact...... 182 
Figure 54: Relative Importance of Alts. with Respect to Schedule Risk Impact ............ 184

Figure 55: Relative Importance of Alts. with Respect to Project Scope ....................... 186

Figure 56: Relative Importance of Alts. with Respect to Needed Functions.................. 187

Figure 57: Relative Importance of Alts. with Respect to Commun. and Integ.............. 189

Figure 58: Relative Importance of Alts. with Respect to Stakeholder Needs................ 190

Figure 59: Relative Importance of Alts. with Respect to In-house Capability ............... 193

Figure 60: Relative Importance of Alts. with Respect to Ext. Consultant Needs ........... 194

Figure 61: Relative Importance of Alts. with Respect to Time Needs .........................196

Figure 62: Relative Importance of Alts. with Respect to Stakeholder Involvement....... 197

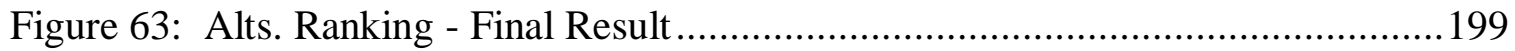

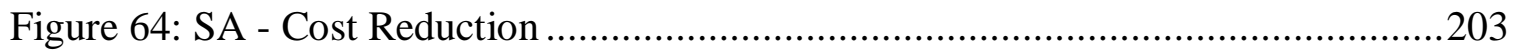

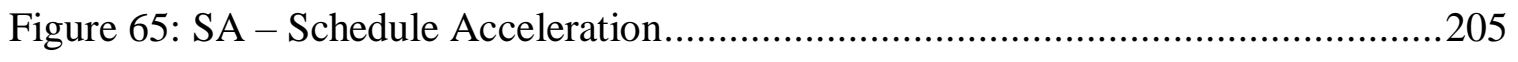

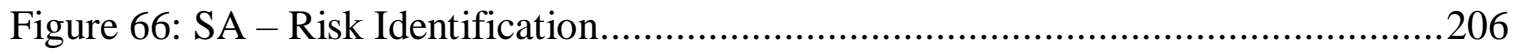

Figure 67: SA - Performance Efficiency ...........................................................207

Figure 68: SA - Resources Capability ..........................................................209

Figure 69: Project Execution Process - Adapted from Several Industries ...................229 


\section{ABBREVIATIONS}

\begin{tabular}{ll} 
AASHTO & American Association of State Highway and Transportation Officials \\
AHP & Analytic Hierarchy Process \\
AIA & American Institute of Architects \\
ANP & Analytic Network Process \\
ATCs & Alternative Technical Concepts \\
BLT & Build-Lease-Transfer \\
BOT & Build-Operate-Transfer \\
BOO & Build-Own-Operate \\
BOOT & Build-Own-Operate-Transfer \\
BTO & Build-Transfer-Operate \\
CEVP & Cost Estimate Validation Process \\
CE & Consultant Engineer/Civil Engineer \\
CDOT & Colorado Department of Transportation \\
CMR & Construction Manager-at-Risk \\
CR & Constructability Review \\
CRA & Cost Risk Assessment \\
CPM & Critical Path Method \\
DA & Decision Analysis \\
DB & Design-Build \\
DBB & Design-Bid-Build \\
DBFO & Design-Build-Finance-Operate \\
DBOM & Design-Build-Operate-Maintain \\
DEX & Decision Expert \\
DOT & Department of Transportation \\
\hline
\end{tabular}


ELECTRE Elimination et Choice Translating Reality

EP Expert Panel

EVM Earned Value Management

FWHA Federal Highway Administration

FMI Management Consulting and Investment Banking in U.S

GRA Grey Relational Analysis

HDM Hierarchical Decision Model

INDOT Indiana Department of Transportation

IPD Integrated Project Delivery

LCC Life-Cycle-Cost

LT Lease and Transfer

MCDA Multi-criteria Decision Analysis

NCHRP National Cooperative Highway Research Program

NHS National Highway System

NRC National Research Council

NPV Net Present Value

ODOT Oregon Department of Transportation

PERT Program Evaluation \& Review Technique

PD Project Delivery

PM Project Management

PMI Project Management Institute

PMBOK Project Management Body of Knowledge

PMS Project Management Software

PMTT Project Management Tools and Techniques

PPP Public Private Partnerships PROMET- $\quad$ Preference Ranking Organization Method for Enrichment Evaluations
HEE

Risk Analysis / Risk Management 


$\begin{array}{ll}\text { RI } & \text { Research Instrument } \\ \text { ROW } & \text { Right-of-Way } \\ \text { RSV } & \text { Root of the Sum of Variances } \\ \text { SAW } & \text { Simple Additive Weighting } \\ \text { SMART } & \text { Simple Multi-Attribute Rating Technique } \\ \text { TK } & \text { Turnkey } \\ \text { TOPSIS } & \text { Technique for the Order of Prioritization by Similarity to Ideal } \\ \text { TQM } & \text { Solution } \\ \text { TRB } & \text { Total Quality Management } \\ \text { VE } & \text { Value Engineering } \\ \text { VIKOR } & \text { VlseKriterijuska Optimizacija I Komoromisno Resenje } \\ \text { VMs } & \text { Value Metrics } \\ \text { VMS } & \text { Value Management Strategies } \\ \text { WBS } & \text { Work Breakdown Structure } \\ \text { WSDOT } & \text { Washington State Department of Transportation }\end{array}$




\section{CHAPTER ONE: INTRODUCTION}

\subsection{Research Background}

During the past decade, several existing and new project delivery methods, tools, and programs have improved construction project outcomes through aligning the project elements with project delivery value factors. This alignment has not only improved efficiency and reduced the project errors, but also enabled exploration of alternative approaches to market opportunities by maximizing projects' performance.

Cost growth has occurred on many major transportation projects such as highway and bridge projects. There is still a lack of real information and reasons for cost increases on DOTs major projects [1]. However, to deliver construction projects on time and within budget is still the primary concern for the project planners, project managers, and decision makers. For instance, the demand to deliver transportation projects in less time with limited budgets has driven each U.S. states' department of transportation to research, develop, and adapt innovative tools, methods, practices, processes, or programs for its construction projects.

Due to the high level of risk and uncertainty in most transportation projects, especially in the metropolises and towns that have a large population density, the selection of appropriate project alternatives or project delivery methods has been more challenging and has involved more complex decision making. Furthermore, research has been conducted 
on the performance of project delivery methods and applications in transportation and proved that there is a lack of comprehensive comparative approaches and a lack of adequate orientation toward the future to provide a sufficient basis for strategic decisions. The exploration of innovative project planning, value improving, and delivery tools or methods for transportation and other infrastructure projects is the result of the continuous need to develop project delivery strategies. Across the United States, state departments of transportation (DOTs) and other transportation agencies are seeking solutions and techniques to improve their projects delivery, management, operation, and organizational effectiveness. Their approach aims to maximize the benefits of time and cost savings by delivering transportation projects in a programs' strategy [2]. Most of them are actively researching the best tools, methods, practices, and programs to deliver their projects successfully. Recently, their efforts have been noticed, and have positively impacted and helped transportation agencies' decision makers and construction projects' teams to improve the project delivery process and outcome.

These improvements include integrating planning and assessment tools or programs during the project lifecycle phases. However, there is still a lack of understanding of how these tools or programs are interrelated, to what extent they have improved the value of the delivery of transportation projects, and how they are integrated to support each other [3]. There is still a lack of use of essential evaluation tools that help to assess the relative costs and benefits of alternative options of transportation projects in America [4]. Improved project value can be represented in different ways depending upon specific project needs. 
These improvements would include perspectives such as function, flexibility, expandability, maintainability, or reduced life-cycle cost (LCC) [5].

The National Cooperative Highway Research Program (NCHRP) Synthesis 504 demonstrates the benefits and challenges of a strategic approach to improve the delivery of transportation projects [2]. The main advantages include improving the acceleration of project delivery; reducing the project risk and cost uncertainty; increasing project performance efficiencies; controlling of project scope and duration; increasing the cooperation among the project stockholders including the contractors; providing the concept of effective management and innovation; and leveraging of project resources. On the other hand, the same report indicates to the challenges that use this approach, such as the lack of experience within the DOTs; resistance to change; lack of well trained and educated staff who are required to implement the new strategy; and effective government and community outreach [2].

Some DOTs are working hard to minimize the adverse impacts of their project construction operations. Their efforts have focused on the improvement of construction project performance by improving its execution within the budget and completing projects on time. Transportation agencies and federal organizations within the U.S. have started to consider the importance of measuring and evaluating projects' delivery by continuously developing the required policies and guidelines for the project assessment. 
Therefore, a unique decision model is strongly needed to evaluate the effectiveness of assessment tool alternatives while considering value optimization as a primary goal to maximize projects' performance within DOTs projects constructions.

Decision makers are willing to explore and evaluate several options before making their final decision based on the weighting score in each option [6]. The outcome of this research aims to help decision makers to select their choices with competing candidate criteria by using the decision model that developed in this context. Using the model, decision makers and their teams' decisions will lead to deliver their projects based on the value approach.

\subsection{Research Problem and Motivation}

Construction projects' decision makers are still debating about which project delivery system is the best. Previous studied and technical reports have addressed the selection of project delivery systems for construction projects. Despite the considerable number of these studies and reports that have been undertaken, cost and time overruns are still a pervasive problem. The vast majority of construction projects experience the same issue [7][8][9][10][11][12][13][14][15][16][17].

"Overrun is a problem in private as well as public sector projects, and things are not improving; overruns have stayed high and constant for the 70-year period for which comparable data exist. Geography doesn't seem to matter either; all countries and continents for which data are available suffer from overruns" [18]. 
For example, in Singapore, Beijing, Hong Kong, and Sydney construction industry indicated that nearly two-thirds of the construction projects suffered from cost overruns and more than half were delayed [19].

Despite much-gained knowledge in project management, delay and cost overruns are an inherent part of most construction projects. The report [20] stated that there are five causes of project delays and overruns; the most impactful factor is design errors, while scope change is ranked as one of the major reasons for most delays and cost overruns. Also, inappropriate procurement, the complexity of the project, and the post-execution phase have been identified as primary reasons for the delay and cost overrun in the project. Also, other researchers mentioned that the lack of experience of project type, project location, governmental delay, poor communication, and severe weather conditions are significant factors of the cost and time overrun [19][21]. Improper planning and slow decision making are also considered as important reasons for the delay and cost overrun [22].

Mensah suggested a solution to overcome the construction industry's current cost overruns and delays. He emphasized that this issue would be resolved if effective project management processes were to be implemented [23]. Tabtabai also confirms that the importance of project management and training skills are both an ideal solution to avoid cost and time overruns [24].

Government projects have a great deal of uncertainties that make them difficult to plan, implement, and manage effectively [25]. Furthermore, governments worldwide are now under increasing pressure to meet public needs within more restricted budgets [26][27]. 
Quantitative tools are mostly used to measure the project cost, while time analysis is a qualitative process. This process usually is not systematic [28].

In this subject, previous research indicate that the construction industry provides an opportunity to develop innovative decision making or support systems for project delivery. Different studies have been undertaken regarding how to control and measure the performance of construction projects in both public and private sectors [29][30][31]. However, Olawale and Sun identified some problems with the project control practices in the UK. They emphasized that there are a variety of tools that are used in project control with non-standard use. While many qualitative and quantitative tools are adapted but there is no systematic analysis implementing to complete the required actions [28].

The models or systems developed often do not present comprehensive solutions to help project managers making their final decisions based on multi-criteria perspectives. However, these systems assist project managers and decision-makers to better understand problems that lead to make the best decision [32][33].

In transportation construction projects, all modes of transportation are under extreme budgetary and community pressure to deliver projects on time and within budget. Transportation construction projects can be complex, and most projects are large scale. Highway and bridge projects need large investments which are often fraught with uncertainty and associated with higher project delivery risk [34]. The National Cooperative Highway Research Program (NCHRP), state DOTs, and other transportation agencies are working hard to develop and employ dynamic project management and decision-making 
tools to meet these twin goals, on time and within budget. On time and within budget can mean different things to the transportation agencies and their customers, whether public or private [35].

Project cost overrun or time delay can occur during any of the projects' main delivering phases. The lack of data on project completion in the U.S leads to arguments regarding the reasons of highway and bridge projects completion. Transportation agencies and organizations measure the extent and cause of cost overrun or time delay often as a high subjective [1][36]. However, statistics indicate that less than $50 \%$ of Oregon DOT projects completed within their originally contracted time of performance [37].

Recently, State DOTs spent and planned to spend a significant percentage of dollars as a commitment to building new and developed roads, bridges and highways [38]. Highway and street construction has a high potential growth in the U.S construction market [39]. FMI (a management consulting and investment banking in U.S) estimates that by 2020, the construction spending will reach $30 \%$ on transportation assets in U.S. [40]. State budgets have seen growth in recent years and much of highway and street construction spending is expected to occur in 2019 [41].

As shown in Figure 1, highway and street construction increased by $7 \%$ in 2015 to $\$ 90.6$ billion. FMI is expected to increase the construction growth by approximately two to four percent overall through 2022 [41]. The U.S. new government has promised to increase infrastructure spending, although there are still uncertain plan or actions at this time [39]. 


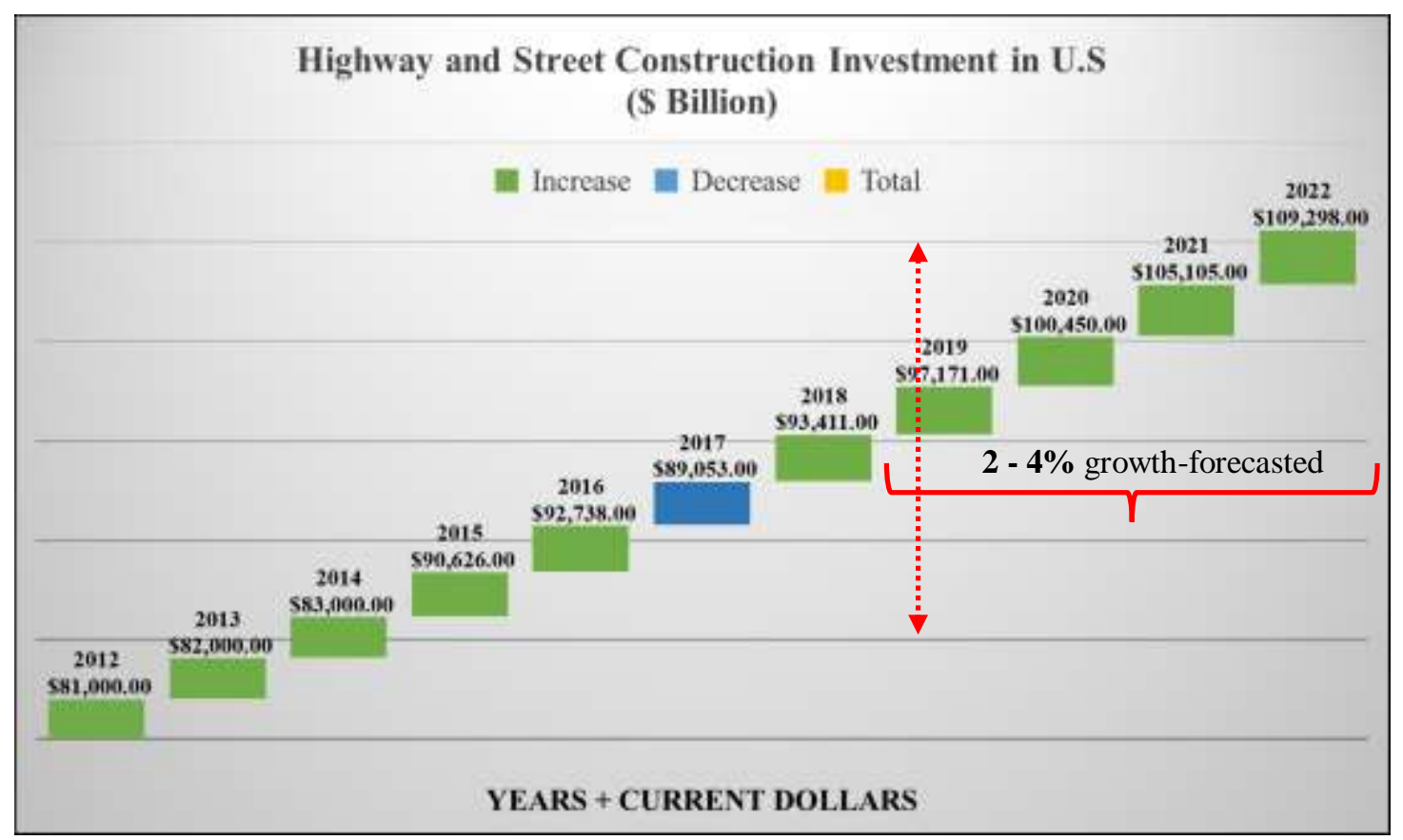

Figure 1: Highway and Street Construction- Adapted From [41]

About $\$ 163$ billion is needed annually for highway and bridges projects over the coming five years. However, due to the lack of funding only $\$ 105$ billion is being invested [40]. High investments are usually associated with high risk of projects delivery, most of the highway projects are considering a large project scale [42][34]. About 614,387 bridges in America, which are 50 years or older. The roads are often crowded and are becoming more dangers [43].

In America more than four million miles of roadways need about 170 billion in capital investment annually to improve its conditions and performance [44]. State Departments of Transportation (DOTs) estimated 101 billion in annual capital investment which are needed 
between now and 2028 to maintain all the highway network at their current condition. The U.S. roads' status is ranked at-risk classification (D), while bridges are required attention $(\mathrm{C}+)[43]$.

Wrong decisions during project's planning will have impact on the following project life cycle phases [29]. About half of unsuccessful projects are impacted by poor decisionmaking [45]. Completing the highway and bridge projects on schedule, within budget, and making acceptable standards becomes a complex challenge. Performance measures started to be more important for the DOT's needs. Planning is the key to meet various performance metrics depending on different perspectives [27]. New managerial, innovative assessment tools and methods accommodating with a high technology could allow DOTs decision makers to make balanced decisions resulting in smoother and quicker project delivery [46]. The project complexity assessments should be an essential part of the project development phase prior to full approval to proceed [47]. The research findings help to reduce the difficulty in taking the right decision by developing a unique decision model. The model aims to select the most effective project assessment technique (Figure 2) for measuring the success of outcomes related to the delivery of transportation projects. 


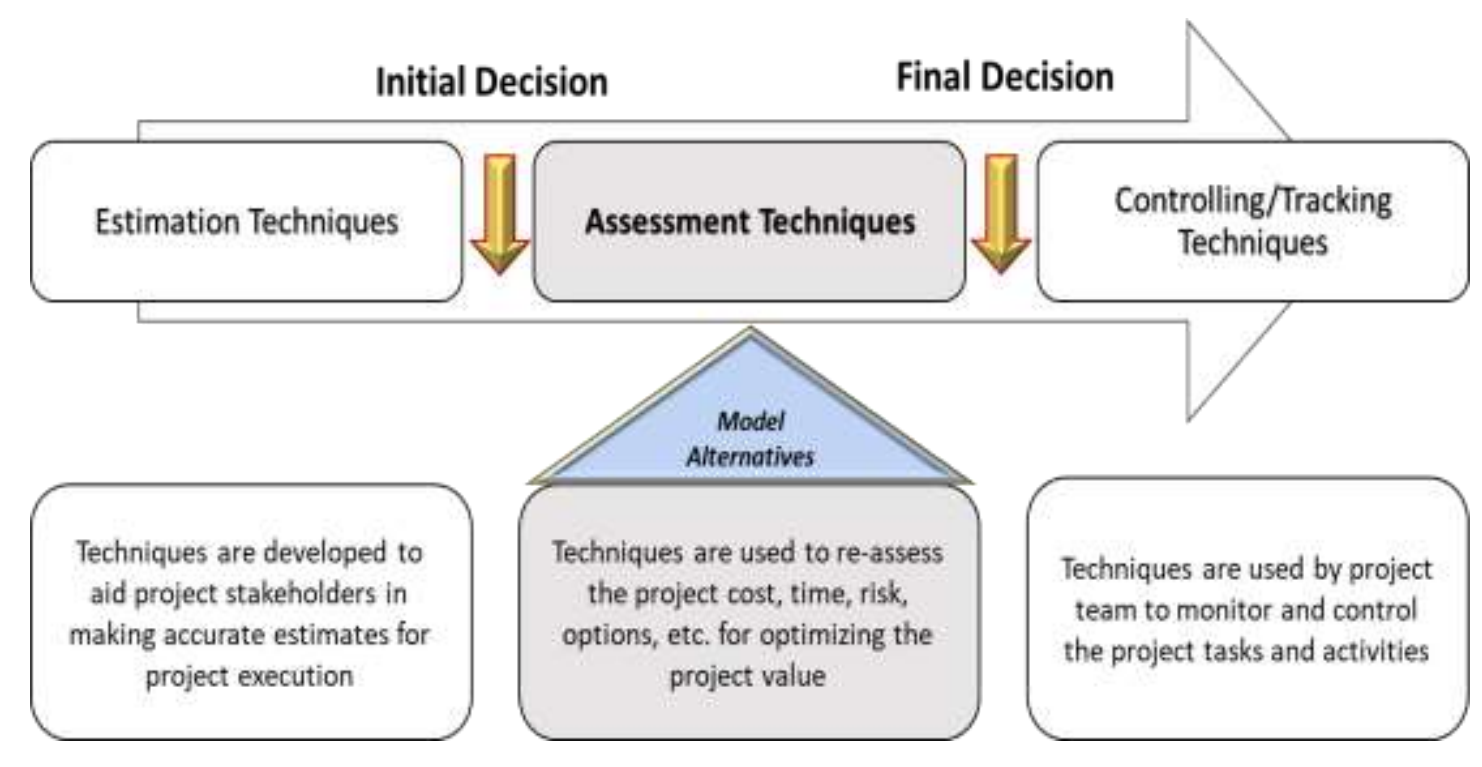

Figure 2: Project Assessment Tools

\subsection{Research Gap}

For this study, a comprehensive literature review was conducted to identify and investigate existing innovative assessment techniques and practices within the construction projects industry, especially in the public transportation sector. The research focused on what theory, methodology, or practices were embedded in these approaches; how these tools or techniques can be implemented in a particular industry; and how likely these tools or techniques could be applied to transportation project delivery for enhancing the project performance within acceptable a timeframe and within budget constraints. Based on the research findings, several research gaps have been identified. Table 1 summarizes three 
significant gaps that were selected to be the key research areas. Then, research questions were developed to help the decision makers bridge the research gaps.

Table 1: Key Research Findings/Gaps in the Literature

\begin{tabular}{|c|c|c|}
\hline No. & Gap Description & Reference \\
\hline 1 & $\begin{array}{l}\text { There is not a comprehensive multi- } \\
\text { perspective decision model for assessing the } \\
\text { effectiveness or selecting innovative } \\
\text { assessment tools, techniques, or practices. }\end{array}$ & $\begin{array}{l}\text { J. Barry Barker et al. } \\
\text { (2010)[46], } \\
\text { J. Yu et al (2012)[48], } \\
\text { S. Monghasemi et al. } \\
\text { (2015)[49], } \\
\text { K. Mela et al. (2012)[6], } \\
\text { J. Schuyler (1994)[50], } \\
\text { P. Russel (2014)[51], } \\
\text { D. Marcelo et al. (2016)[52] } \\
\text { D. Beale et al. (2017)[53] }\end{array}$ \\
\hline 2 & $\begin{array}{l}\text { There is not a specific study that is focusing } \\
\text { on the project assessment tools from value } \\
\text { optimization approach. Most studies have } \\
\text { specific objectives such as cost reduction, } \\
\text { schedule acceleration, environmental impact, } \\
\text { or safety. }\end{array}$ & $\begin{array}{l}\text { J. Yu et al. (2012)[48], } \\
\text { R. Stewart (2010)[54], } \\
\text { W. Ibbs et al. (2007)[55], } \\
\text { C. Wimmler et al. } \\
\text { (2015)[56], } \\
\text { Dooley et al. (2010)[57], } \\
\text { R. Sonmezand \& H. } \\
\text { Bettemir (2012)[58] } \\
\text { M. Bertoni (2017)[59] }\end{array}$ \\
\hline 3 & $\begin{array}{l}\text { Innovative assessment tools or techniques } \\
\text { are commonly disjointed and don't often } \\
\text { support each other. Therefore, an evaluation } \\
\text { process is required. }\end{array}$ & $\begin{array}{l}\text { K. Harrington (2015)[60], } \\
\text { Y. Olawale (2015) [28], } \\
\text { NCHRP Report } 466 \\
(2002)[61], \\
\text { NCHRP 504 (2017)[2] }\end{array}$ \\
\hline
\end{tabular}




\subsection{Research Scope}

The research identified the common use of existing innovative assessment tools, techniques, and programs within transportation projects. Then, a decision model was developed to evaluate some of these alternatives from five objectives (cost, schedule, risk, performance, and resources) including their associated sub-criteria.

Three goals are targeted as significant outcomes from this research. The first goal is to provide the needed decision model for transportation development and construction projects considering value-based perspectives such as risk, time, cost, performance, and resources. The second is to help the decision makers to optimize the project delivery value and outcome within the transportation infrastructure. The last goal is to enable transportation agencies and project teams to reduce the impact of time and scheduling constraints during the delivery of transportation projects.

The transportation industry is a large sector that contains many types of projects. This research focused on the development of highways and bridges projects. These projects are defined in this research as high-profile projects that require a significant construction budget and are associated with higher project delivery risk (typically $\$ 100$ - \$500 million).

Innovative assessment tools, techniques, and practices are used by the project team to evaluate the project performance in terms of the relevant measures of effectiveness such as cost, time delay,...etc. [34]. This research specific focused on innovative assessment techniques that are used to evaluate transportation construction projects during the 
development phase. The assessment tools and techniques are used to optimize the project value and outcomes. The following questions regarding these tools and techniques are covered during the literature review:

What are the most effective project assessment tools or techniques that are used in transportation development and construction?

Why are the tools or techniques used?

What do the tools or techniques do or create?

When should the tools or techniques be used?

What are examples or practices of the tools or techniques?

A set of selected project assessment techniques were chosen in this research to be candidates for the weighting process. The evaluation of various levels of criteria aimed to address which alternatives are more valuable than others.

This research used state Departments of Transportation (DOTs) as a case study. The scope is structured in main four phases as follows:

Phase 1, innovative assessment techniques were identified and screened within transportation projects and other industries that are used during the project life cycle, and that primarily meet the requirements of the project development phase. The process started to identify the various successes of transportation infrastructure development perspectives including common attributes that are employed in the project delivery decision-making 
during the development phase such as cost, time, risk, performance, resources. The process was carried out by reviewing literature from different academic papers and industry reports as a first step. The literature review focused on value approach assessment tools and techniques that are performed in the construction industry. These tools and techniques are used during the project life cycle and meet the requirements of the project development phase primarily. Then, three individual research papers are carried out as part of the Ph.D. independent studies requirement.

The literature reviews process was started in the first and second independent studies courses to identify and investigate innovative methods, tools, and techniques within the transportation sector and construction industry. The first independent study was used as a preliminary screening for collecting a full list of State Departments of Transportation (DOTs) in U.S. and other industries that commonly employ value methodology, risk management, and constructability review activities for the improvement of their projects and processes.

The second independent study focused on surveying the most common tools and practices within public transportation agencies regarding their currently performed assessment tools; how they are interrelated; and to what extent they are integrated and support each other. The survey results guided us in understanding the effectiveness of these assessment tools and techniques for measuring the success of outcomes relating to the delivery of transportation projects. 
In the last independent study, the collected list was narrowed down to the specific industries for the analysis process. The screened process targeted other sectors that most closely share commonalities with the transportation infrastructure industry. The collected list of other industries underwent a depth analysis to investigate its ability for improving the projects' and products' delivery and performance in these sectors. A number of criteria and factors were identified during the research, and most of them were relevant to the project delivery or product development such as cost, performance, time, risk, reliability, flexibility, sustainability, competitiveness, ... etc.

Phase 2, an initial Hierarchical Decision Model (HDM) was developed including evaluating criteria \& sub-criteria, and identified alternatives, and focused on the requirements of the highway and bridge projects in the development phase. In order to develop a unique model that considers the value optimization approach; this research focused on what theory; methodology; or practices that are embedded in this approach; how value assessment tools or techniques can be implemented in particular industry; and how likely these tools or techniques can be applied to the transportation project delivery for enhancing the project performance within acceptable cost and time.

Phase 3, the research expanded the literature review, created the final research model, and analyzed and discussed the research results. The most important stage in this phase was deciding on how the expert panels would be performed and administrated. Selecting experts is very critical to ensure the identification of relevant and qualified experts. In order to choose the best alternative, the experts were asked to discuss, identify, weight, and 
validate the model criteria, sub-criteria, and alternatives. Several methods were used to identify and select the experts in this research. The experts were from transportation agencies and other construction industries, and they were selected based on their qualifications and experience.

Phase 4, the final research findings were validated and discussed with experts and they expect the research results might make a significant contribution further to the project assessment practices. Finally, a new systematic project assessment process was suggested and discussed. The suggested process is integration of some tools into the assessment process that will improve the project assessment outcome and enhance the communication and the negotiation within the transportation project life cycle. 


\subsection{The Dissertation Map}

There are nine chapters in this dissertation. Included in this introduction chapter are the other chapters, and their aims as mentioned in Figure 3 below:

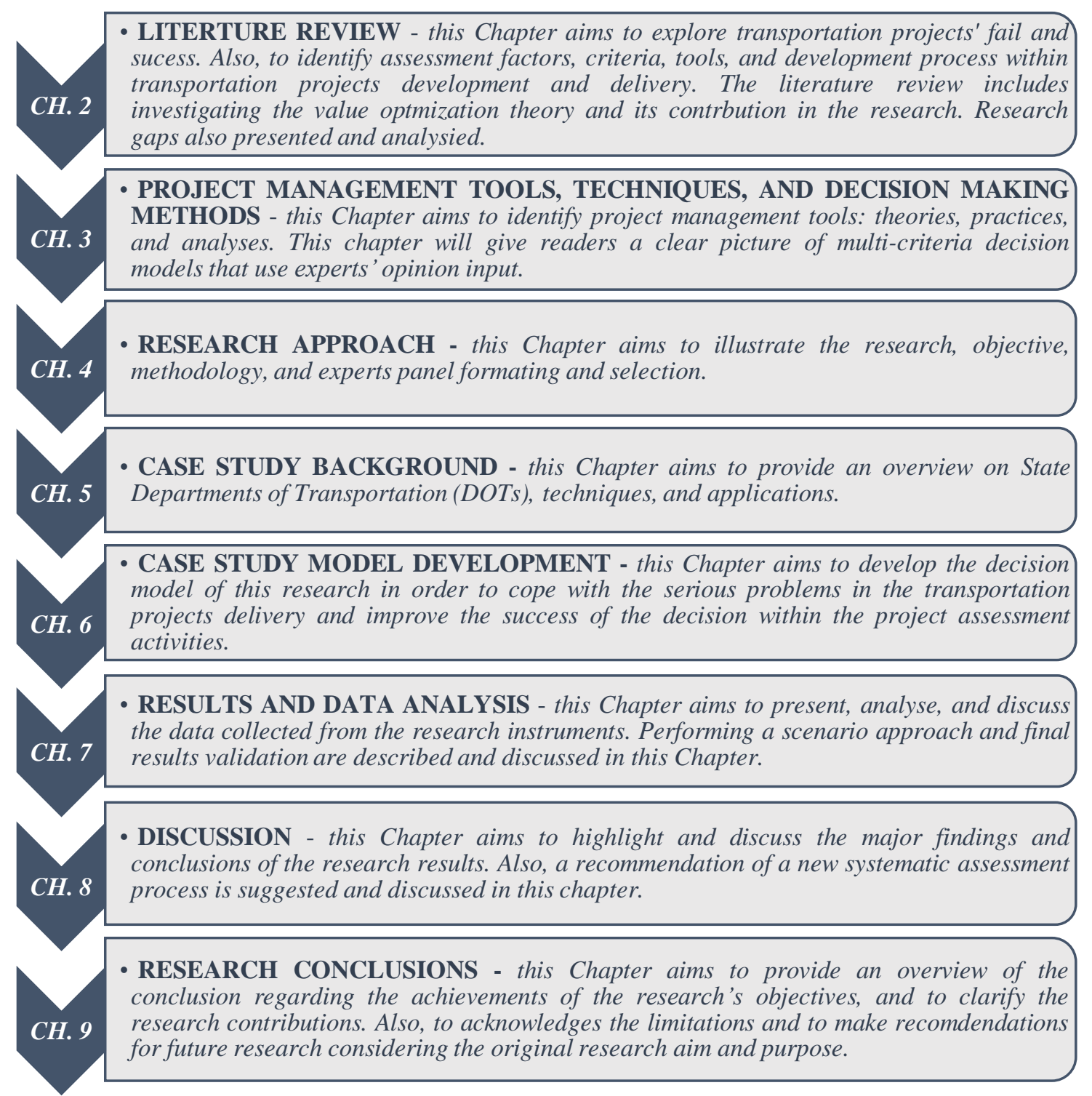

Figure 3: Research Chapters Map 


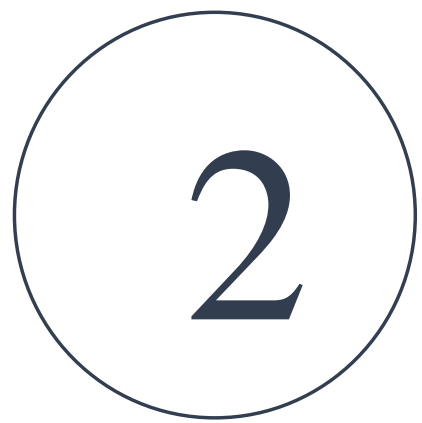

- LITERTURE REVIEW - this Chapter aims to explore transportation projects' fail and sucess. Also, to identify assessment factors, criteria, tools, and development process within transportation projects development and delivery. The literature review includes investigating the value optmization theory and its contrbution in the research. Research gaps also presented and analysied.

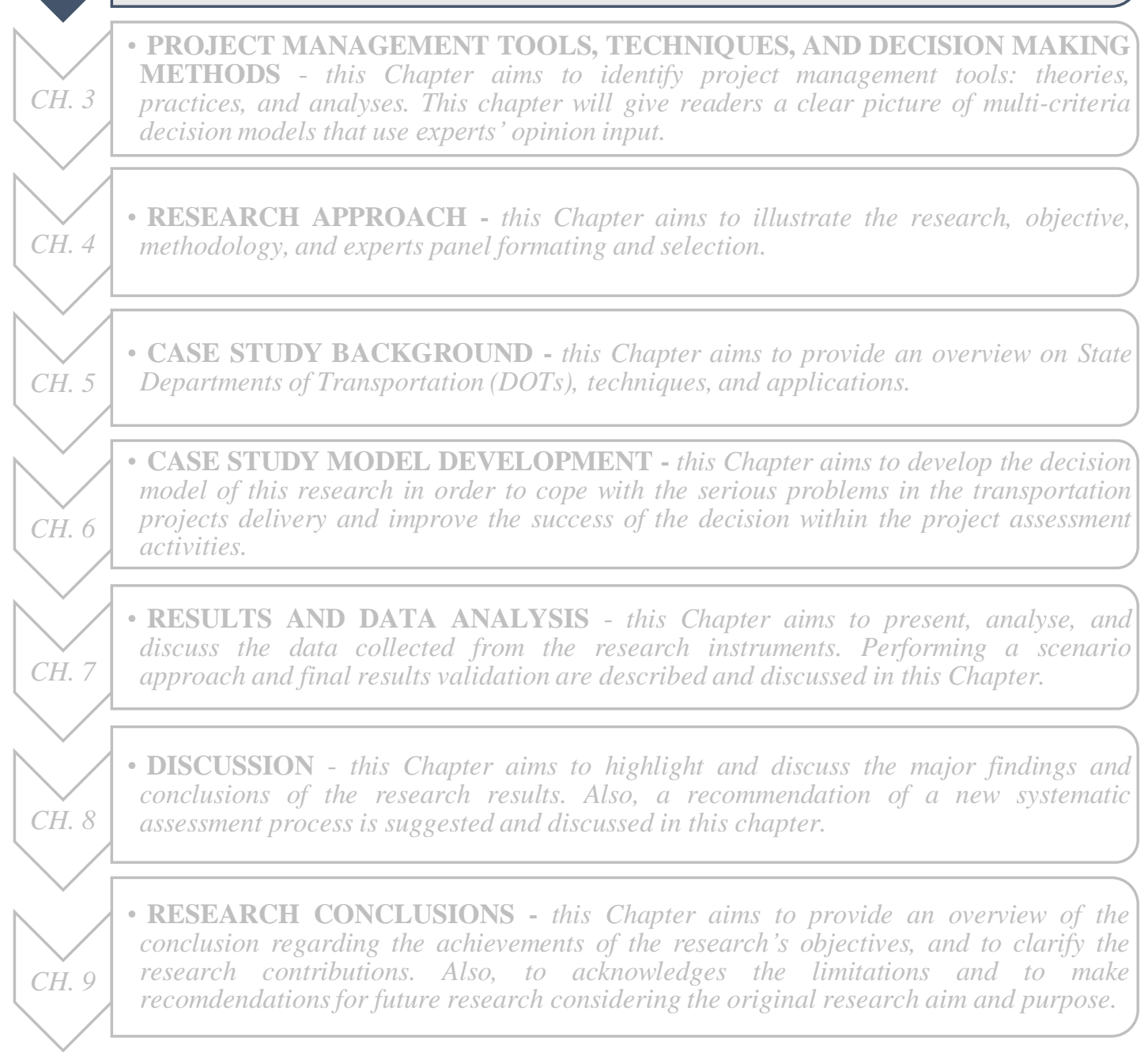




\section{CHAPTER TWO: LITERATURE REVIEW}

\subsection{Project Cost and Schedule}

\subsubsection{Overview}

Nowadays, all modes of transportation are under extreme budgetary and community pressure to deliver projects on time and within budget. Highway design and construction projects can be complicated, and most projects are large scale. Highway and bridge projects need large investments which are often fraught with uncertainty and associated with higher project delivery risk [35]. The National Cooperative Highway Research Program (NCHRP), State DOTs and other public and private companies in the transportation industry work hard to develop and employ dynamic project management and decisionmaking tools to meet these twin goals (on time and within budget). On time and within budget can mean different things to the transportation agencies and their customers, whether public or private [36]. Project cost overrun or time delay can occur during any of the projects' main delivering phases. The lack of data on project completion in the U.S leads to arguments regarding the reasons of highway and bridge projects completion. Transportation agencies and organizations measure the extent and cause of cost overrun or time delay often as a high subjective [37]. However, statistics indicate that less than 50\% of Oregon DOT projects are completed within their originally contracted time of performance [29]. About half of unsuccessful projects are impacted by poor decision- 
making [33]. Completing the highway and bridge projects on schedule, within budget, and making acceptable standards becomes a complex challenge. Performance measures started to be more important for the DOT's needs. Planning is the key to meet various performance metrics depending on different perspectives [9].

\subsubsection{Over Budget and Schedule - Actual Cases}

INDOT evaluated the extent of their highway and bridge projects in cooperation with the Federal Highway Administration. The assessment study aimed to analyze the cost overruns and time delays of INDOT projects. Also, the study aimed to develop a set of recommendations that could help INDOT to reduce the problem of cost overruns and time delays within the agency projects delivery. For comparison purpose, the study used a questionnaire instrument to collect and analyze the data from other states. The results of the survey showed that INDOT highway and bridges projects were determined as $4.5 \%$ as the overall rate for cost overrun amounts. The most interesting part of this study was 55\% of all INDOT contracts experienced cost overruns. With regards to schedule delay, the study found that $12 \%$ of the agency contracts experienced time delay with an average of 115 days per contract [62]. Finally, the study recommended for improving the management of INDOT projects in order to reduce the time and cost overrun.

The Verona Road Interchange Project, the city of Madison Wisconsin faced with delays and inflation over the past years. Four major state highway projects including a Madison artery have accumulated overruns in excess of $\$ 700$ million [63]. For example, the work 
on the Verona Road interchange on Madison's Beltline was running about \$130 million over the original estimated costs. The major factor in the increases was initial project estimates that did not sufficiently capture costs, some of these increases came from decision-making delays.

Boston, Massachusetts was suffering from a traffic problem. The city has a six-lane highway that ran through the center of downtown. These lanes were designed in 1959 to carry about 75,000 vehicles per day. However, in 1990 the same lanes carried upwards of 200,000 making it one of the most congested highways in the United States [64]. To overcome the above issue, the Massachusetts Department of Transportation launched one of the most expensive highway projects in the U.S.A, and it called Big Dig Boston. The project closed nine years late and was plagued by cost overruns. The Big Dig was planned to finish in 1998 at an estimated cost of $\$ 2.8$ billion. Due to, poor execution and use of substandard materials, the project was completed in 2007 , at the expense of over $\$ 14.6$ billion.

Another recent reconstruction project has hit the same problem; it is the Massachusetts city's Longfellow Bridge. The project was delayed by two-year because of complications associated with preserving the century-old structure. It announced in 2015, at the cost of \$255 million [65].

The new Sullivan Bridge in Washington is expected to cost $\$ 424,000$ million more than planned. The reason for cost overruns is related to a design error. The error wasn't 
discovered during the planning process. It addressed after the city accepted the bid for the bridge. The bridge designers didn't notice that the legal clearance of the trail surface [66].

The Springfield Interchange Improvement Project (SIIP) was one of the transportation megaprojects in the part of the Washington-DC metropolitan area. The project was divided into eight major stages with an estimated cost of $\$ 700$ million. The TIIP performed rather poorly in the early stage of the project regarding the cost. The project cost increased by more than $60 \%$, One of these projects was the junction of Interstates 95, 395, and 495 [67]. The risk management planning was not conducted in the project early stage. VDOT policy didn't consider risk management activity as required in the planning stage of their agency's projects. Also, political and management issues impacted negatively to the overall performance of the project delivery [68].

Actual cases from different countries; Ahbab [69] investigated in his thesis 28 large projects that impacted by the time and cost overruns. As shown in Figure 4 the author classified the size of projects into three categories, $75 \%$ that cost between $\$ 50$ and $500 \mathrm{~m}$, $14 \%$ of them are projects with total costs less than $\$ 50$ million, and the rest $11 \%$ are mega projects with more than $\$ 500$ million.

The largest investigated project was Shaanxi roads development project. The project constructed in China in the actual cost of $\$ 965.5$ million with $27.5 \%$ of cost overrun.

The second largest project was the Jamuna bridge project in Bangladesh. The project closed with $\$ 57.73$ million cost overrun which is $8.3 \%$ over the estimated cost. 
The third large project is the state rural roads project in Turkey. The project cost $\$ 750.9$ million with almost double of the predicted cost (about $56 \%$ cost overrun).

Reilly mentioned that there are several examples of projects with cost problems can demonstrate the extent and seriousness of the problem. The Jubilee line transit project in London, the project closed with two years late and $£ 1.4$ billion (67\%) over budget. The Channel Tunnel project was $£ 3.7$ billion (80\%) over budget. Denmark’s Great Belt Link project exceed 54\% over budget. Also, the Woodrow Wilson bridge bid reached about 72 $\%$ overestimate [68].

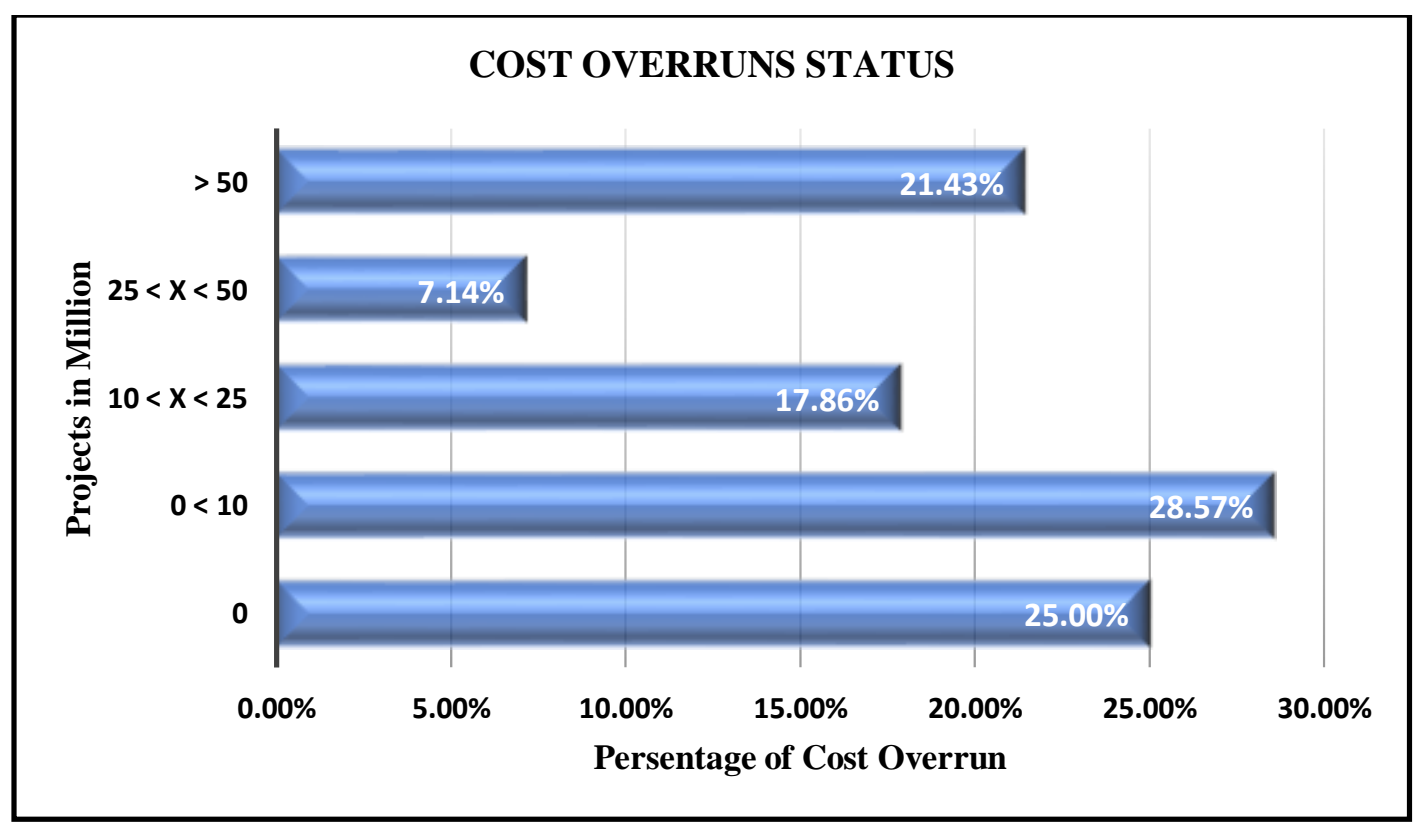

Figure 4: Comparison of Cost Overrun in Studied Projects- Adapted From [68]

The most critical factors that caused the cost overrun of the investigated projects were related to project management issues and poor cost estimating practices [69][20]. These 
factors such as: inaccurate initial project scope and cost estimate; poor supervision and inadequate site management; estimates reduced by mandate date or cost; and poor contract management.

\subsubsection{Projects Delay or Budget Overruns - Issues and Causes}

Despite much-gained knowledge in project management, delay and cost overruns are an inherent part of most construction projects. The study [19] stated that there are five causes of project delays and overruns; the most impactful factor is design errors, while scope change is ranked as one of the major reasons for most delays and cost overruns. Also, inappropriate procurement, the complexity of the project, and the post-execution phase have been identified as primary reasons for the delay and cost overrun in the project. Researchers mentioned that the lack of experience of project type, project location, governmental delay, poor communication, and severe weather conditions are significant factors of the cost and time overruns [21][69]. Large projects can, and do, experience large scope and schedule changes that affect the final cost. Most of the time these changes increase the overall cost [22]. Improper planning and slow decision making are also considered as important reasons for the delay and cost overrun [23].

Mensah [24] suggested a solution to overcome the construction industry's current cost overruns and delays. He emphasized that this issue would be resolved if effective project management processes were to be implemented. Tabtabai also confirms that the importance of project management and training skills are both an ideal solution to avoid cost and time overruns [25]. 
Government projects have a great deal of uncertainties that make them difficult to plan, implement, and manage effectively [26]. Furthermore, governments worldwide are now under increasing pressure to meet public needs within more restricted budgets [27][70].

Managing large-scale transportation infrastructure projects are challenging and associated with higher risks of project delivery. Various studies have addressed the issue of cost and time overruns in transportation infrastructure projects [71].

Flyvbjerg [71] presented in his study that how large are cost overruns in transportation projects. The most important conclusion of Flyvbjerg's study are:

- About $86 \%$ of the transportation infrastructure projects were impacted by cost escalations comparing with $14 \%$ had costs equal to or lower than the original forecasted costs.

- The overestimation costs are always lower than the size of the underestimation costs.

- Average of $45 \%$ of cost overruns addressed for rail projects, $34 \%$ in fixed links, and $20 \%$ in roads construction.

- Tunnels are larger projects in cost overruns (48\%) compared with $30 \%$ of bridges construction.

- Cost overruns were significant in most transportation projects in the world at average of $65 \%$. 
- The average cost escalation in bridges and tunnels was $26 \%$ in North America and $43 \%$ in Europe.

The same author [72] presented categorization of cost overrun causes and explanations. Most important categories of explanations were highlighted by some authorities and agreed with Flyvbjerg in his explanation. Four categories of explanations were distinguished as follows:

Technical explanations: Poor project design and incomplete estimations are the most important causes of cost overrun. Lack of experience could lead to poor project design, while incomplete estimations could be the result of the inadequate data that require during the initial and planning phase. Also, there are other costs overrun causes that might classify under the technical category such as scope change; inadequate decision-making process; poor planning process; and inappropriate organizational structure all are considering as causes of project cost overrun.

Economical explanations: Lack of resources; incentives; funding; and stakeholder support are considered as economic causes because they influence the extent of project cost overruns. For example, the lack of resources lead the decision-makers to choose between their projects.

Psychological explanations: This concept is based on planning error and optimism bias. People who involve in taking decisions with risky prospects, they tend to be risk-averse 
and have near relative to risk attitudes. Their cognitive bias leads to optimistic forecasts that usually cause cost overrun.

Political explanations: Cost estimates are manipulated because the behavior is determined based on advocacy rather than objectively. Organizational and political pressures cause wrong strategic implementation because estimates adjust to derive the most politically or organizational aspirations. Furthermore, the lack of information leads to poor decision because decision-makers are dependent on the information that received from the forecasts study, the poor decision causes cost overruns.

The schedule performance of transportation rehabilitation and construction projects is becoming increasingly concerned to decision-makers. For example, Departments of Transportation (DOTs), politicians, and economists have realized the severe implications of schedule overruns [73]. Due to, the pressure from the project owners the schedule performance has become the primary focus of the transportation infrastructure. DOTs decision-makers have recognized the negative impacts of delays on resource allocation and time-to-market. Therefore, they have started to push contractors to complete projects in record time. According to [72], the internal and external project environments are important factors in determining whether there will be a schedule overrun or not. These factors can be related to the physical site, socioeconomic climate or design. The author divided these factors into four main segments as follows:

- Physical site characteristics, which include climatic and seasonal conditions, Environmental complexity, noise restrictions, stochastic events, and traffic volume. 
- Design characteristics, which include design complexity, constructability, and utility work.

- Construction process characteristics, which include project management, equipment shipment delays, and conflict among project participants.

- Socioeconomic and political characteristics, which include political and safety concerns, and the right-of-way acquisition.

Another article [74] was searched further for the additional relevant subject, cost and schedule overrun in construction projects. A survey was carried out for some local construction projects in India. The analysis results found that the follows factors are most occurring problem responsible for time and cost overrun in construction projects:

- Slow decision making, and

- Design change,

- lack of fund,

- Lack of adequate planning,

- Extra claims,

- Political issues.

In the following section, the research also investigated some real cases which were delivered by transportation agencies and considered as successful projects delivery. 


\subsubsection{Project Success - On Budget and Time or Early Delivered}

The Sellwood Bridge [75] is 86 years old. It is located across the Willamette River in Portland, Oregon. The Sellwood bridge project was the largest project in Multnomah County's history that used construction manager and general contractor (CM/GC) project delivery alternative. The project construction began in December 2011 with an estimated cost of $\$ 229$ million. The project constructed by Sundt and Slayden Construction as General Contractors. The project team innovated a new approach or technique that led to saving about $\$ 5$ to $\$ 10$ million in construction costs. Also, the new innovative approach cut about a year off the schedule. The new innovative approach is the shoofly technique or detour bridge; it is used to keep traffic flowing throughout the project. Hydraulic jacks were used to lift the old bridge deck and truss and moving it to one side. Then, place it on a set of temporary piers and connecting it to temporary approach spans. This approach helped the construction team to keep the traffic continues flowing while the new bridge is constructed. The bridge construction was especially challenging and was considered as a highly complex operation. It was one of the longest bridge sections ever to be moved.

The project aimed to replace the old Sellwood Bridge with the new one and within its existing east and west corridor. The new bridge is planned to provide a structurally safe bridge and connections that help to accommodate multi-modal mobility needs [76]. The new Sellwood Bridge construction cost estimation was prepared based on conceptual design level data which provided a basis for cost comparisons between five alternatives (A, $\mathrm{B}, \mathrm{C}, \mathrm{D}$, and $\mathrm{E})$. The detailed cost data was presented during the preliminary design to 
select the best alternative. According to the total estimated construction cost for each alternative in the year 2012 dollars, the construction costs were expected between $\$ 280$ million and \$361 million [77]. The project team used some factors to prioritize and to select the best alternative of the new Sellwood Bridge. These factors are bridge closure; construction cost; ability to phase construction; bicyclists and pedestrians; transit; residential displacements; business displacements; maintenance of access to businesses and residences; park and recreational facility impacts; and regulated floodway [74].

Sellwood Bridge Project Overcoming Challenges [78]

- Continuous changes to the project by using CM/GC project delivery method.

- As a result of the scope changed several times, the major challenge was how to meet the project requirements during the design and construction activities.

- Because of the span sits in the middle of a bowl formed by an experienced landslide, the soil was even looser than expected and forcing a redesign.

- Problems drilling into the riverbed pushed costs higher.

- Managing the paperwork tracking for more than 200 sub-contractors.

The Most Success of the Sellwood Bridge Project [78]

- A full collaboration and partnership had been done between ODOT, Multnomah County, the City of Portland, and contractor and subcontractors during the project delivery. 
- The project team used an innovative shoofly approach that saved approximately $\$ 5$ to $\$ 10$ million in construction costs and cut about a year off the schedule.

TriMet's MAX West Side Expansion Project [79] is also a good example that considered as one of the success projects. TriMet is the owner and operator of five separate lines (red, green, blue, yellow, and orange lines) of max light rail and other transportation facilities. TriMet is serving about 97 stations in Portland, Oregon. The company has begun the service in mid of the 80s era. In July 1993, TriMet launched a Westside light rail extension project with an expected cost of $\$ 963$ million. The extension was about 18 miles (MAX Blue Line: 33 Miles' total) of alignment with a tripling of service. The expansion includes two significant projects; twin tunnel section through Portland's West Hills; each three miles long and about 21 feet in diameter. Also, underground station, only stop in the three-mile tunnel, which is servicing the City's Washington Park at deep of 260 feet below ground and it is the fifth-deepest park in the world[80][81][78]. The project connects Hillsboro, Beaverton and Portland City Center [82]. In 1998, the project completed on schedule and within budget. In the same year, September 98, the new extension line has started in service [79]. 


\subsection{Value Optimization and Performance Measurement}

\subsubsection{Overview}

Nowadays, selecting the best project alternative or making the right decision regarding an optimal solution in construction projects is complicated. Decision-makers face a significant challenge to reduce the conflict that can be often represented during the comparison process between many objectives [83]. Decision-makers and practitioners have used several multi-objective optimization tools and techniques to reduce the potential conflict between project objectives. A significant improvement in the overall cost and performance of construction projects could be achievable if value optimization and performance measurements are implemented [84]. Usually, the process uses to optimize the value or to measure the performance of the construction project delivery. The measurement is considered as a value gap analysis, which is the relationship between the objectives and the outcome between prior expectations and real performance [85]. The project decision makers are responsible for identifying the project gaps that illustrate the difference between the work done and the original plan. Their efforts are required to close all project gaps to achieve the project objectives [86]. Large gaps are usually associated with high risks that lead to inefficiency in project performance and cost and time overruns.

High-profile projects need a clear vision and formal project management knowledge. These projects are mostly owned and managed by governments. However, project costs and benefits in this category are difficult to measure [87]. This kind of projects has challenges regarding a long construction duration, a significant budget, many uncertainties, 
and several stakeholders involved. Moreover, governments now face a major challenge to meet public needs within limited or restricted budgets [25]. Historically, many projects have been failing to achieve their objectives or are terminated according to poor of performance [88]. Many studies have investigated project value and performance issues within governments. In large-scale government projects, project management approaches should be conducted with the project characteristics to reduce the impact of poor project performance [46]. Since the project team has started to face challenges with delivering their projects on time and within the budget, they are required to deal with advanced technology to manage their projects successfully.

Highway administrations and DOTs across the United States share the same objective of delivering high-quality transportation projects and programs [89]. They have started to use innovative technologies, processes, and tools in their project delivery to improve performance. The most significant challenge for the project selection is identifying the best from a set of possible alternatives. A systematic analysis of alternatives selection process is often made based on the individual project objective such as cost, time, quality...etc. Alternatives should be developed using the DOTs or FWHA design guidance. Each project has several options, and each alternative consists of a summary of the project information and objectives. The project team usually develops several competing ideas, and only one may be implemented [90]. The Evaluation Matrix is used to present the alternatives in the comparison process. This process helps to ensure that the impacts of each alternative are 
consistent. A screening of the best option should consider the purpose of this selection among all of the alternatives [54].

\subsubsection{The Concept of Value}

"Value is an expression of the relationship between the performance of a function, and the resources required to obtain it. Hence the term, best value, refers to the most efficient means to reliably accomplish a function that will meet the performance expectations of the customer" [91]. A project's success is measured by being efficient and creating value [54].

Stewart presents in his book [54] the concept of value optimization. He describes value optimization as an integration of four essential elements (see Figure 5) that are used to measure the project value. These elements are cost, time, risk, and performance. He also stated that project managers should maximize the relationship of these elements in order to achieve customer satisfaction and to optimize the project value. 


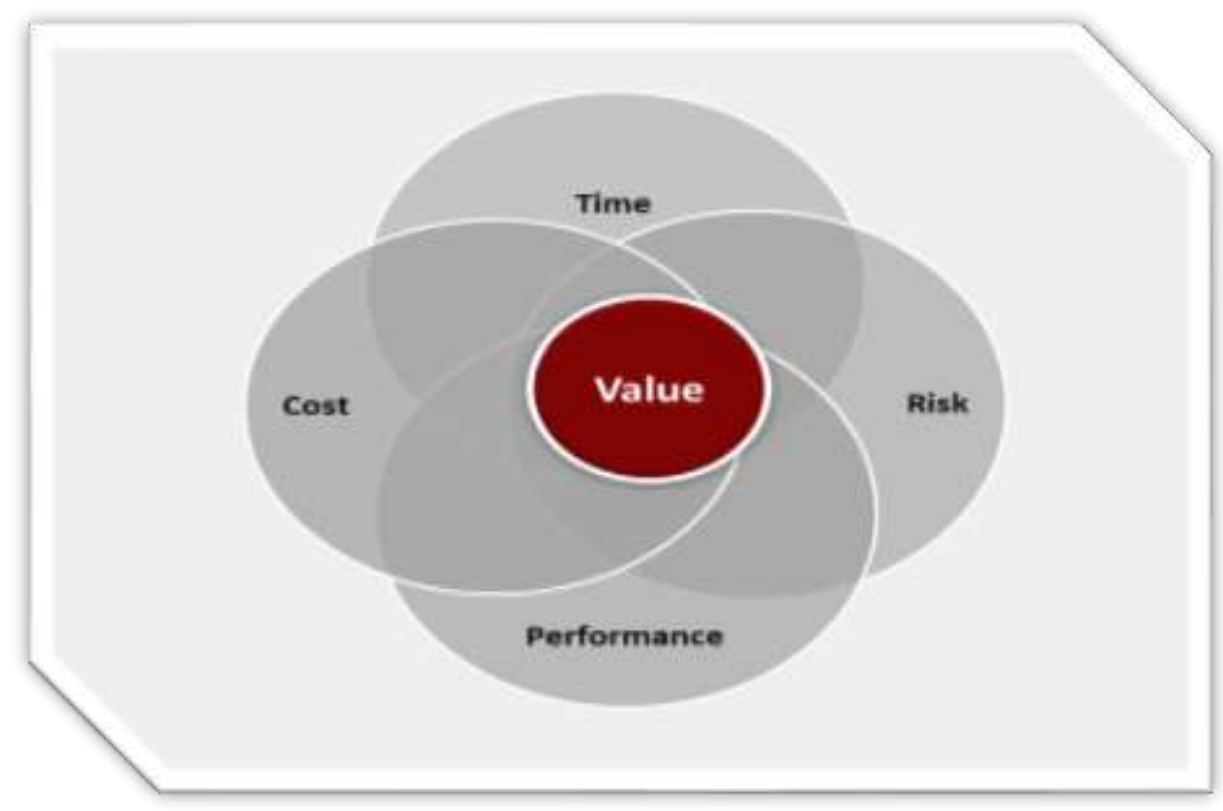

Figure 5: Value Optimization Frame- Reproduced From [92]

Several disciplines and management functions have been developed to improve project performance, and the research literature is growing in this field [93][94][94]. However, there is still limited research regarding the links between project management performance and the value that is gained from the project management activities [93].

Many practices are used to enhance project performance but, there is a lack of understanding about which practices are perceived as the most valuable. Practitioners use alternative methods and innovated tools to measure the day-by-day performance and value of their projects [95]. Project success is one of the important topics that is investigated by researchers in academia and industry. Some of them consider the success of a project as a unit in terms of meeting the project budget within the time frame and assess the overall 
quality of the work [96]. Project managers and project teams are required to define the parameters that help them to evaluate their project's performance. However, there is still no consensus as to the definition of project success, and there is apparent disagreement between academia and industry practitioners over how success is measured [97][54].

\subsubsection{Research Approach regarding Value Optimization}

Improving the project value is always related to the decreasing of project cost and increasing its performance. Improving value can be achieved by increasing the project performance while increasing its costs. Also, it can be achievable by decreasing the performance while reducing the costs [98]. In order to evaluate the relationship between the project cost and performance, specific techniques or combined assessment tools are required to measure the relative importance of cost and performance the project objectives.

Miles indicates that maximum value is achieved by the performance of the function with the least possible cost [99]. Some project management tools are used in the project development phase to measure the project cost, time, risk, performance, ....etc. The value measuring activity is performed to optimize the performance of projects and its deliverables for the lowest possible cost. The value-oriented tools are used to provide useful information for implementing rational decision-making processes [54]. 
Value is the outcome of the performance of a function and the resources that are required to achieve it [100]. Resources are considered as a significant element for value optimization [101][102][103][54].

This research maximized the strength of the developed comprehensive decision model by adding the element of resources to the original value optimization frame that is proposed in the Stewart book [54]. These five elements (see Figure 6) are included in the model assessment perspectives as Level 2. Experts are then asked to decide which perspectives or criteria are more important than the others. The model sub-criteria (Level 3) are selected based on the literature review and direct discussion with experts (i.e., DOT experts, project managers, civil engineers, and value management consultant).

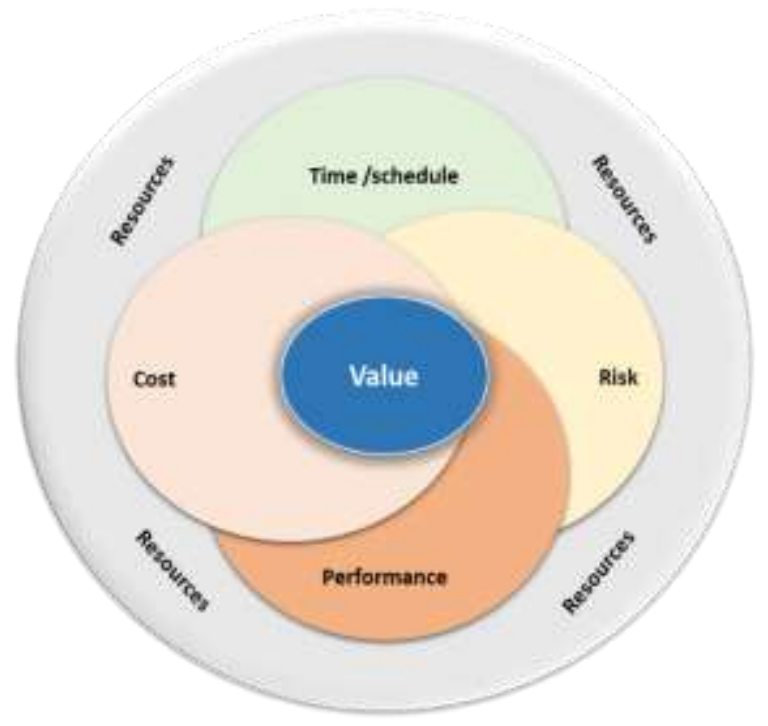

Figure 6: Five Elements of Value Optimization- Adapted From [104] 
A particular strategy was applied in this research as a guide to develop the model. The strategy was started with a literature review to explore the existing innovative assessment techniques and practices that help to measure the project value within public transportation agencies. Also, the effectiveness of using these techniques and tools within transportation agencies across the United States were investigated. Also, the research investigated these project delivery techniques in literature, including several keywords, criteria, factors, and terminology related to project management and innovative technology. These criteria were while searching the academic and industry databases. The research focused on what theory, methodology, or practices are embedded in these approaches, how these techniques can be implemented in a particular industry, and how likely these techniques can be applied to transportation project delivery in order to enhance the project performance and value within acceptable cost and time frame. 


\subsection{Project Development Process}

\subsubsection{State Departments of Transportation (DOTs) Project Delivery}

The NCHRP 19-11 (2015) research project [104] summarizes an outline of the literature content and recommendations on the suitability of the information to the application of project delivery for transportation projects. Some documents were reviewed to understand the state DOTs efforts regarding the project delivery activities including policies and guidance of project delivery within twelve state DOTs.

The research found that there is a high degree of inconsistency related to terminology interchangeability and the actual meaning. The project development and Lifecycle terms were used interchangeably in several of the documents reviewed. Project delivery refers to the combination or integration of Project Development and Project Management in the construction industry. The project development is used to illustrate the development of a construction project from the beginning to the end. The project lifecycle is a more generic term to describe project stages from the initial to the closing stage. Also, the scope was various between agencies, projects phases and tasks required during the project delivery process all appear different for the DOTs investigated. Some DOTs provide a very detailed project delivery process, and others have a unique process version.

As noticed in the NCHRP 19-11 research, many states have developed guidelines for their project delivery efforts. However, various levels of thoroughness in the guidelines and consistency of information were addressed from reviewing of the twelve DOTs. 


\subsubsection{Comparison of DOTs Project Delivery Process}

Table 2 summarizes the project delivery process including project development process and project lifecycle from twelve DOTS. The information in this table emphasizes the observations made above.

Table 2: State DOTs Project Development Process and Project Lifecycle

\begin{tabular}{|c|c|c|c|}
\hline State & $\begin{array}{l}\text { Project development process / Project life } \\
\text { cycle }\end{array}$ & $\begin{array}{l}\text { Title of the } \\
\text { literature/Report }\end{array}$ & $\begin{array}{l}\text { Date } \\
\text { of issue }\end{array}$ \\
\hline Florida DOT & $\begin{array}{l}\text { Critical topics include the following: } \\
\text { Planning } \\
\text { Project Development \& Environmental } \\
\text { Design } \\
\text { Right of Way (ROW) } \\
\text { Construction } \\
\text { Design-Build } \\
\text { Maintenance } \\
\text { Local Agency Program }\end{array}$ & $\begin{array}{l}\text { Project } \\
\text { Management } \\
\text { Handbook [105] }\end{array}$ & 2014 \\
\hline $\begin{array}{l}\text { Georgia } \\
\text { DOT }\end{array}$ & $\begin{array}{l}\text { Critical topics include: } \\
\text { Concept Stage } \\
\text { Preliminary Design } \\
\text { Final Design } \\
\text { Design Guideline Exceptions/Variances } \\
\text { Construction }\end{array}$ & $\begin{array}{l}\text { Project } \\
\text { Management } \\
\text { Handbook [106] }\end{array}$ & 2012 \\
\hline Oregon DOT & $\begin{array}{l}\text { Program Development } \\
\text { Project Development } \\
\text { Award Construction Contract } \\
\text { Construction Management } \\
\end{array}$ & $\begin{array}{l}\text { Project Delivery } \\
\text { Guide [107] }\end{array}$ & 2010 \\
\hline Utah DOT & $\begin{array}{l}\text { PD methods include: } \\
\text { Design Build (DB) } \\
\text { CMGC } \\
\text { Procurement Contract }\end{array}$ & $\begin{array}{l}\text { Project Manager } \\
\text { Guide [108] }\end{array}$ & 2013 \\
\hline $\begin{array}{l}\text { Montana } \\
\text { DOT }\end{array}$ & $\begin{array}{l}\text { The MDT adopts Adjusted Score Design- } \\
\text { Build Bid Process involving several tasks: } \\
\text { Project Identification } \\
\text { Development of the Design and } \\
\text { construction Criteria Package (DCCP) } \\
\text { Contract Number Assignment } \\
\text { Advertisement } \\
\text { Statement of Qualifications } \\
\text { Considerations for Request for } \\
\text { proposal Development } \\
\text { Guidelines for Request for Proposal }\end{array}$ & $\begin{array}{l}\text { Design Build } \\
\text { Guideline [109] }\end{array}$ & 2008 \\
\hline
\end{tabular}




\begin{tabular}{|c|c|c|c|}
\hline $\begin{array}{l}\text { Colorado } \\
\text { DOT }\end{array}$ & $\begin{array}{l}\text { Phase I: Pre-Project Budge. } \\
\text { Phase II: Design } \\
\text { Phase III: Construction }\end{array}$ & $\begin{array}{l}\text { CDOT Project } \\
\text { Development } \\
\text { Manual [110] }\end{array}$ & 2013 \\
\hline $\begin{array}{l}\text { Virginia } \\
\text { DOT }\end{array}$ & $\begin{array}{l}\text { Initiation Phase } \\
\text { Development Phase } \\
\text { Delivery Phase } \\
\text { Closeout Phase } \\
\end{array}$ & $\begin{array}{l}\text { Project } \\
\text { Management } \\
\text { Policy [111] }\end{array}$ & 2011 \\
\hline $\begin{array}{l}\text { New Jersey } \\
\text { DOT }\end{array}$ & $\begin{array}{l}\text { Problem Screening (PS) } \\
\text { Concept Development (CD) } \\
\text { Preliminary Engineering (PE) } \\
\text { Final Design (FD) } \\
\text { Construction (CON) }\end{array}$ & $\begin{array}{l}\text { Project } \\
\text { Customization } \\
\text { Guideline [112] }\end{array}$ & 2015 \\
\hline Nevada DOT & $\begin{array}{l}\text { Possible delivery methods include: } \\
\text { Design-Bid-Build } \\
\text { Construction Manager/General } \\
\text { Contractor (CMGC) } \\
\text { Design-Build (DB) } \\
\text { Design-Build-Operate-Maintain } \\
\text { (DBOM) } \\
\text { Design-Build-Finance-Operate (DBFO) } \\
\text { Build-Own-Operate } \\
\text { Outsourced Service Contract } \\
\text { Asset Management } \\
\text { Concession } \\
\text { Availability Concession } \\
\text { Transportation Facility Agreement } \\
\text { (TFDA) }\end{array}$ & $\begin{array}{l}\text { Project } \\
\text { Management } \\
\text { Guidelines 2 } \\
\text { Edition Working } \\
\text { Draft [113] }\end{array}$ & 2010 \\
\hline WSDOT & $\begin{array}{l}\text { Project identification as design-build } \\
\text { candidate } \\
\text { Project attribute assessment } \\
\text { Team formulation } \\
\text { Project scope definition } \\
\text { Data gathering } \\
\text { Final decision to use Design-Build } \\
\text { contracting } \\
\text { Request for Proposal preparation } \\
\text { Selection of Design-Builder } \\
\text { Administration of contract }\end{array}$ & $\begin{array}{l}\text { Guidebook for } \\
\text { Design-Build } \\
\text { Highway Project } \\
\text { Development } \\
\text { [114] }\end{array}$ & 2004 \\
\hline TxDOT & $\begin{array}{l}\text { Planning and Programming } \\
\text { Preliminary Design } \\
\text { Environmental } \\
\text { The Right of Way and Utilities } \\
\text { The preparation of PS\&E } \\
\text { Letting }\end{array}$ & $\begin{array}{l}\text { Project } \\
\text { Development } \\
\text { Process Manual } \\
{[115]}\end{array}$ & 2014 \\
\hline Caltrans & $\begin{array}{l}\text { Project Initiation Document } \\
\text { Permits \& Environmental Studies } \\
\text { Plans, Specifications, \& Estimates } \\
\text { (PS\&E) } \\
\text { Construction } \\
\text { Right of Way }\end{array}$ & $\begin{array}{l}\text { Caltrans Project } \\
\text { Management } \\
\text { Handbook } \\
5^{\text {th }} \text { Edition [116] }\end{array}$ & 2007 \\
\hline
\end{tabular}




\subsubsection{Characteristics of Assessment Tools - Value Optimization Approach}

Table 3 shows a taxonomy list of innovative assessment tools which were identified and collected during this research. The research explored the existing value engineering (VE); risk assessment (RA); constructability review (CR); value metrics/decision model (VMs); and cost estimation \& validation process currently (CEVP). These tools are currently applied to the delivery of transportation infrastructure projects and other construction industry. During the investigation process of the filtered list of innovative assessment tools; these tools were classified based on some criteria and factors that commonly use in the project delivery process. Four main criteria and factors were identified during the research and most of them were considered in the investigated innovation methods, tools, and techniques. The criteria and factors that were addressed in this research including cost, time, risk, performance/quality, flexibility, product reliability, sustainability, competitiveness, the willingness of adoption, and utility.

Table 3: A taxonomy of Innovative Assessment Tools

\begin{tabular}{|c|c|c|c|c|c|c|c|c|}
\hline \multirow{2}{*}{ Tool } & \multirow{2}{*}{ Industry } & \multirow{2}{*}{ Subject } & \multicolumn{6}{|c|}{ The tool uses to identify or assess the project; } \\
\hline & & & $\overrightarrow{\tilde{u}}$ & $\oiiint_{\Xi}$ & $\frac{4}{2}$ & 峁 & $\begin{array}{l}\vec{E} \\
\text { ț }\end{array}$ & References \\
\hline \multirow{6}{*}{$\frac{51}{>}$} & Construction & Ship Building & $\mathrm{O}$ & & & $\mathrm{O}$ & & [117] (2016) \\
\hline & Construction & Planning & $\mathrm{O}$ & $\mathrm{O}$ & & $\mathrm{O}$ & $\mathrm{O}$ & [118] (2011) \\
\hline & Construction & Railway & $\mathrm{O}$ & & & & $\mathrm{O}$ & [119] (2011) \\
\hline & Transportation & Development & $\mathrm{O}$ & $\mathrm{O}$ & & $\mathrm{O}$ & $\mathrm{O}$ & [120] (2014) \\
\hline & Construction & $\begin{array}{l}\text { Decision } \\
\text { Analysis }\end{array}$ & $\mathrm{O}$ & & & $\mathrm{O}$ & & [121] (2009) \\
\hline & Transportation & Planning & & & & $\mathrm{O}$ & & [122] (2010) \\
\hline
\end{tabular}




\begin{tabular}{|c|c|c|c|c|c|c|c|c|}
\hline & Value-knowledge & $\begin{array}{l}\text { Uncertainty } \\
\text { Modelling }\end{array}$ & $\mathrm{O}$ & $\mathrm{O}$ & $\mathrm{O}$ & $\mathrm{O}$ & & [123] (2012) \\
\hline & Transportation & $\begin{array}{c}\text { Policy \& } \\
\text { procedures }\end{array}$ & $\mathrm{O}$ & & & $\mathrm{O}$ & & [124] (2013) \\
\hline \multirow{9}{*}{ 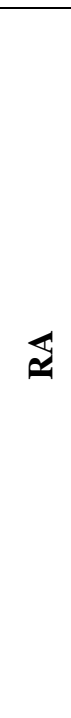 } & Construction & $\begin{array}{c}\text { Project } \\
\text { Management }\end{array}$ & $\mathrm{O}$ & $\mathrm{O}$ & $\mathrm{O}$ & $\mathrm{O}$ & & [125] (2013) \\
\hline & Construction & $\begin{array}{l}\text { Mega projects } \\
\text { investment }\end{array}$ & $\mathrm{O}$ & & $\mathrm{O}$ & $\mathrm{O}$ & & [126] (2016) \\
\hline & Construction & $\begin{array}{l}\text { Projects } \\
\text { selection }\end{array}$ & $\mathrm{O}$ & $\mathrm{O}$ & $\mathrm{O}$ & $\mathrm{O}$ & $\mathrm{O}$ & [127] (2014) \\
\hline & Construction & Highway & $\mathrm{O}$ & $\mathrm{O}$ & $\mathrm{O}$ & & $\mathrm{O}$ & [128] (2006) \\
\hline & Construction & $\begin{array}{l}\text { A knowledge- } \\
\text { based }\end{array}$ & $\mathrm{O}$ & & $\mathrm{O}$ & & & [129] (2014) \\
\hline & Transportation & $\begin{array}{c}\text { Risk } \\
\text { Management } \\
\end{array}$ & $\mathrm{O}$ & $\mathrm{O}$ & $\mathrm{O}$ & & & [130] (2012) \\
\hline & Transportation & Highway & $\mathrm{O}$ & $\mathrm{O}$ & $\mathrm{O}$ & & & [131] (2012) \\
\hline & Transportation & $\begin{array}{c}\text { Risk } \\
\text { Management }\end{array}$ & $\mathrm{O}$ & $\mathrm{O}$ & $\mathrm{O}$ & & $\mathrm{O}$ & [132] (2012) \\
\hline & Transportation & Construction & $\mathrm{O}$ & $\mathrm{O}$ & $\mathrm{O}$ & $\mathrm{O}$ & & [133] (2016) \\
\hline \multirow{9}{*}{$\widetilde{U}$} & Construction & Overview & $\mathrm{O}$ & $\mathrm{O}$ & & & & [134] (2010) \\
\hline & Transportation & Construction & $\mathrm{O}$ & $\mathrm{O}$ & $\mathrm{O}$ & & & [135] (2014) \\
\hline & Construction & $\begin{array}{c}\text { Building } \\
\text { performance }\end{array}$ & $\mathrm{O}$ & $\mathrm{O}$ & & $\mathrm{O}$ & $\mathrm{O}$ & [136] (2011) \\
\hline & Construction & Factors review & $\mathrm{O}$ & $\mathrm{O}$ & & $\mathrm{O}$ & & [137] (2011) \\
\hline & Construction & Guidebook & $\mathrm{O}$ & $\mathrm{O}$ & & $\mathrm{O}$ & & [138] (2010) \\
\hline & Transportation & Guide manual & $\mathrm{O}$ & $\mathrm{O}$ & & $\mathrm{O}$ & & [139] (2008) \\
\hline & Transportation & Design manual & $\mathrm{O}$ & $\mathrm{O}$ & & $\mathrm{O}$ & & [140] (2013) \\
\hline & Transportation & $\begin{array}{l}\text { Research } \\
\text { report }\end{array}$ & $\mathrm{O}$ & $\mathrm{O}$ & & & $\mathrm{O}$ & [141] (2012) \\
\hline & Transportation & $\begin{array}{l}\text { Constructabilit } \\
\text { y guide }\end{array}$ & $\mathrm{O}$ & $\mathrm{O}$ & & & & [142] (2010) \\
\hline \multirow{2}{*}{$\sum^{\infty}$} & Transportation & $\begin{array}{l}\text { Value Analysis } \\
\text { Guide }\end{array}$ & $\mathrm{O}$ & $\mathrm{O}$ & $\mathrm{O}$ & $\mathrm{O}$ & & [54] (2013) \\
\hline & General & $\begin{array}{l}\text { Value } \\
\text { Optimization }\end{array}$ & $\mathrm{O}$ & $\mathrm{O}$ & $\mathrm{O}$ & $\mathrm{O}$ & & [69] (2010) \\
\hline \multirow{3}{*}{$\sum_{\substack{x \\
0}}^{2}$} & Transportation & $\begin{array}{l}\text { Cost-Risk } \\
\text { estimation } \\
\text { process }\end{array}$ & $\mathrm{O}$ & $\mathrm{O}$ & $\mathrm{O}$ & & & [143] (2004) \\
\hline & Construction & $\begin{array}{l}\text { Infrastructure } \\
\text { projects }\end{array}$ & $\mathrm{O}$ & $\mathrm{O}$ & $\mathrm{O}$ & & & [144] (2004) \\
\hline & Transportation & \begin{tabular}{l}
\multicolumn{1}{c}{ Risk-Based } \\
Engineers \\
Estimate
\end{tabular} & $\mathrm{O}$ & $\mathrm{O}$ & $\mathrm{O}$ & & & [145] (2015) \\
\hline
\end{tabular}


Lack of funds, project complexity, and stakeholder involvement drive an ongoing need to increase innovation in project development and delivery. An innovative set of tools that help governments and companies is required to manage their projects more proactively and efficiently [37]. Some processes and tools contribute to stimulating innovation and progressive thinking. The demand for innovation increases, appropriate tools, and right decisions are strongly needed to deliver the projects efficiently [146][147]. Innovative tools help the project decision makers to plan and anticipate constraints at early project stages. Project planners and decision-makers should understand all perspectives and outcomes (i.e., technical, management, etc.) in a transportation construction project to make intelligent decisions. Also, they need a useful technique to help guide those decisions.

Therefore, the common innovated project assessment tools combined with VE to select the most effective technique were identified and used in this research. The main objective was to develop a comprehensive decision model for a value-based evaluation approach. The model findings aimed to choose the most effective alternative for measuring the success of outcomes related to the delivery of transportation projects. 


\subsection{Gap Analysis}

Gap 1: When several decision makers are involved in the same decision, the process of making the decision has the potential to be substantially more challenging [6]. All decisions that are formulated during the planning stage of construction projects have a significant impact on the project cost and performance. A decision at an early stage can lead to significant savings if multi-objective optimization is implemented, however, the best MCDM method has not been discovered yet [48]. Nowadays, in construction projects, there is increasing pressure on decision makers to search ways to minimize construction costs and time. Advanced models are needed for optimizing the multiple and conflicting objectives of project time, cost, and the effects on the environment [53]. Therefore, it is necessary to develop tools that have benefits that far exceed the effort practical [51]. Georgia DOT identified specific gaps that needed immediate attention, such as decision support tools and a performance-based approach using consistent criteria to guide their projects [52]. A set of tools is needed for the prioritization of alternatives [49]. Multicriterion decision-making approaches can help decision-makers to select the right solution among various potential optimal solutions in construction projects [50]. A value-based approach is needed. The drive for the selection of alternatives will be the effects of project cost and completion time [49]. A multi-criteria assessment approach is required to reach a solution with an acceptable degree of satisfaction [46]. New managerial, assessment tools and methods along with a high level of technology could allow DOTs decision makers to make balanced decisions resulting in smoother and quicker project delivery [58]. A 
developed decision model was developed in this research to evaluate the effectiveness of assessment tool alternatives while considering of some project delivery value perspectives that are related to highway construction projects. The model is standardized to assess a comprehensive range of project management tool alternatives that are required in different project delivery stages, and are based on the value optimization approach.

Gap 2: Researchers presented the decision analysis process to different industries and sectors (public and private) under different decision criteria perspectives. Most of previous studies presented specific objectives such as cost reduction, schedule acceleration, environmental impact, quality, or safety [48]. However, construction planners have to compromise on different aspects of projects [57]. The decision-makers' requirements including project problem characteristics are both considered as key influencers to select or develop the most appropriate approaches, systems, tools, or methods for making the right decision [56]. A variety of criteria needs to be applied to the evaluation or selection of alternatives. As of yet, no ideal set of criteria has been defined by research [59]. To increase the clarification of the risk and the lack of value consequences for operational decision-making, more investigation is required to identify the relation between factors at different levels of analysis [54].

Stewart emphasizes in his book Value Optimization for Project and Performance Management [55] that most decisions are based on one criterion. Some decision-makers focus on the project cost, time, or performance as critical elements to achieve an acceptable 
project outcome, whereas others refer to the importance of project size or impacts for making the right decision [54]. However, a balanced approach for multi-objective criteria is required to identify the relationship between cost, time, risk, performance, and resources to adjust them to optimize project value [28]. This research was followed the balanced approach to fill-in this gap by using the value optimization approach as an objective level in a multi-criteria decision support model.

Gap 3: Many qualitative and quantitative tools are used, but no systematic analyses are implemented to complete the required actions during the project assessment activities [2][60]. These tools or techniques may be combined based on project circumstances for assessing the uncertainty of projects' forecasts. An evaluation process is needed while innovative assessment techniques are commonly disjointed and don't often support each other [61]. To reduce the project delay, the integration of assessment tools is required. Integrated tools should be conducted concurrently rather than by a one by one process [148]. This research suggested a simple deployment and rollout process including the high ranked alternative that can be used as a project delivery assessment approach. 

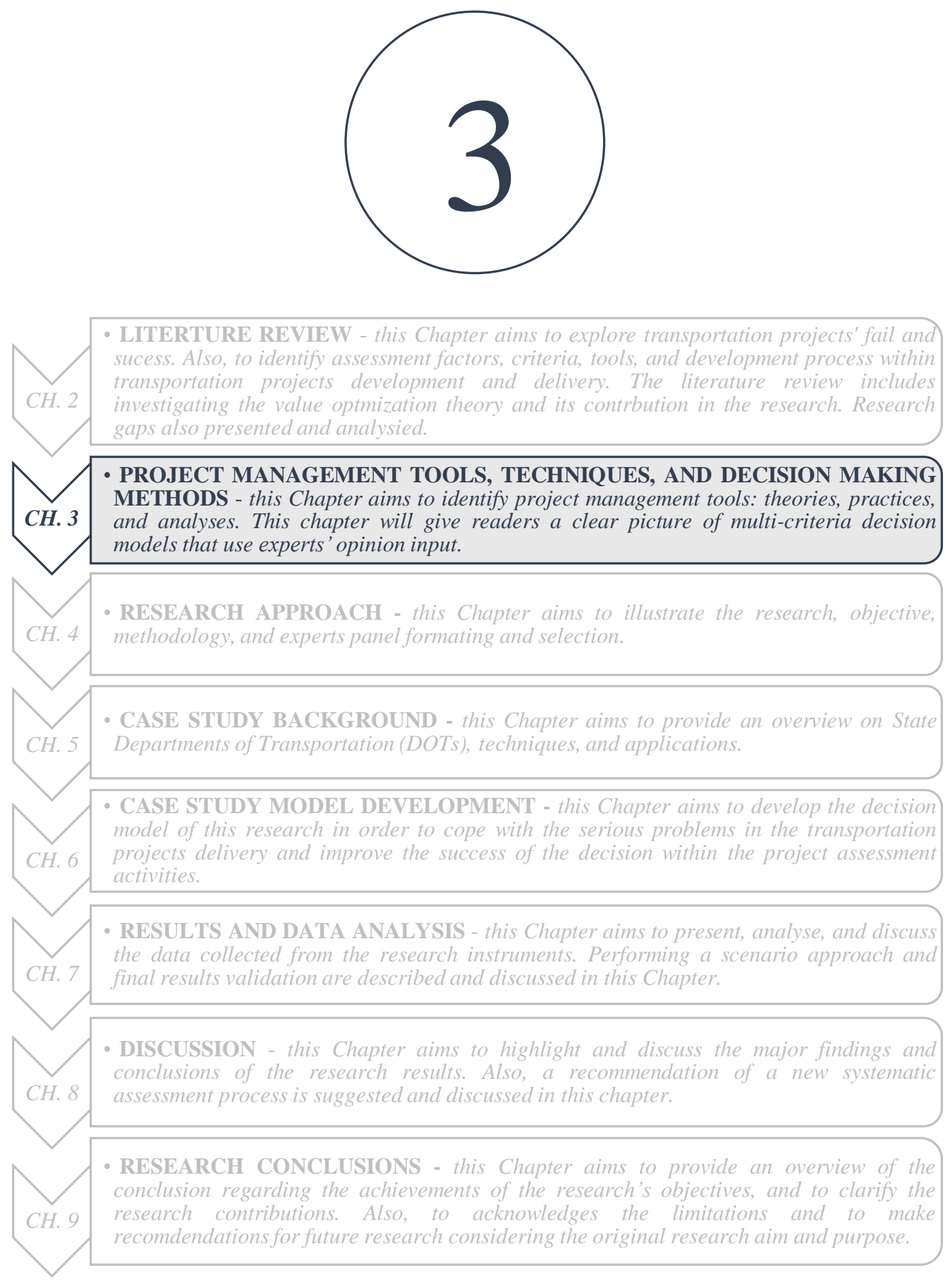


\section{CHAPTER THREE: PROJECT MANAGEMENT TOOLS, TECHNIQUES, AND DECISION-MAKING METHODS}

\subsection{Introduction}

Due to, the high level of risk and uncertainty in most construction projects, especially in the metropolises and towns that have a large population density, the selection of appropriate project management tools has been more challenging and involved complex decision making. Both individual organizations and practitioners in the field of project management are always working to develop their practices by examining the exciting and new innovated tools. Furthermore, some research has been conducted on the performance of project delivery tools, methods, and applications in the construction industry. The exploration of innovative project planning, management, value improving, and delivery tools or methods for transportation and other construction projects are the result of the insistent need to improve project delivery strategies rapidly. The current set of popular project management tools and techniques is more highly valued in high-scale construction projects, while it less highly valued for smaller projects. The most project valued tools can provide organizations with the guidance they need in developing and implementing project management tool and techniques.

Project Management Institute in PMBOK guide [149] identifies an overview of extensive set of project management tools and techniques. As shown in Table 4, these tools 
and techniques are considered valuable and applicable to most construction projects. The PMBOK guide indicates that the necessity of adapting practice to the particular situation by choosing which tools and techniques to employ within the construction industry. Thamhain [150] highlights the contribution of project management tools and techniques as a conditional to the project performance. Fortune [149] discusses the use of tools and techniques in relation to project success. Both [150] and [151] studies provide indepth concerning the varying levels of project management tools and techniques applications within the construction industry and others.

Table 4: Project Management Tools and Techniques

\begin{tabular}{|l|l|}
\hline \multirow{4}{*}{ Knowledge Area } & Tools and Techniques \\
\hline \multirow{5}{*}{ Integration Management } & Project plans \\
\cline { 2 - 3 } & Stakeholder analysis \\
\cline { 2 - 3 } & PM software \\
\cline { 2 - 2 } & Change control board \\
\cline { 2 - 3 } & Configuration management \\
\cline { 2 - 3 } & Project review meetings \\
\cline { 2 - 3 } & Project leadership \\
\cline { 2 - 3 } & Executive sponsorship \\
\cline { 2 - 3 } & Work authorization systems \\
\hline \multirow{5}{*}{ Scope Management } & Net present value \\
\cline { 2 - 3 } & Return of investment \\
\hline
\end{tabular}




\begin{tabular}{|c|c|}
\hline & Payback \\
\hline & Scope statement \\
\hline & Scope change control \\
\hline & Business cases \\
\hline & Weighted scoring models \\
\hline & Work breakdown structures \\
\hline & Requirements analysis \\
\hline & Gantt charts \\
\hline & Critical path analysis \\
\hline & Critical evaluation review techniques \\
\hline Time Management & Project network diagrams \\
\hline & Crashing \\
\hline & Fast tracking \\
\hline & Milestone reviews \\
\hline & Cost estimates \\
\hline & Cost management plan \\
\hline & Earned value management \\
\hline Cost Management & Project portfolio management \\
\hline & Financial software \\
\hline & Value engineering \\
\hline & Quality control chart \\
\hline & Six Sigma \\
\hline Quality Management & Quality audits \\
\hline & Pareto diagrams \\
\hline
\end{tabular}




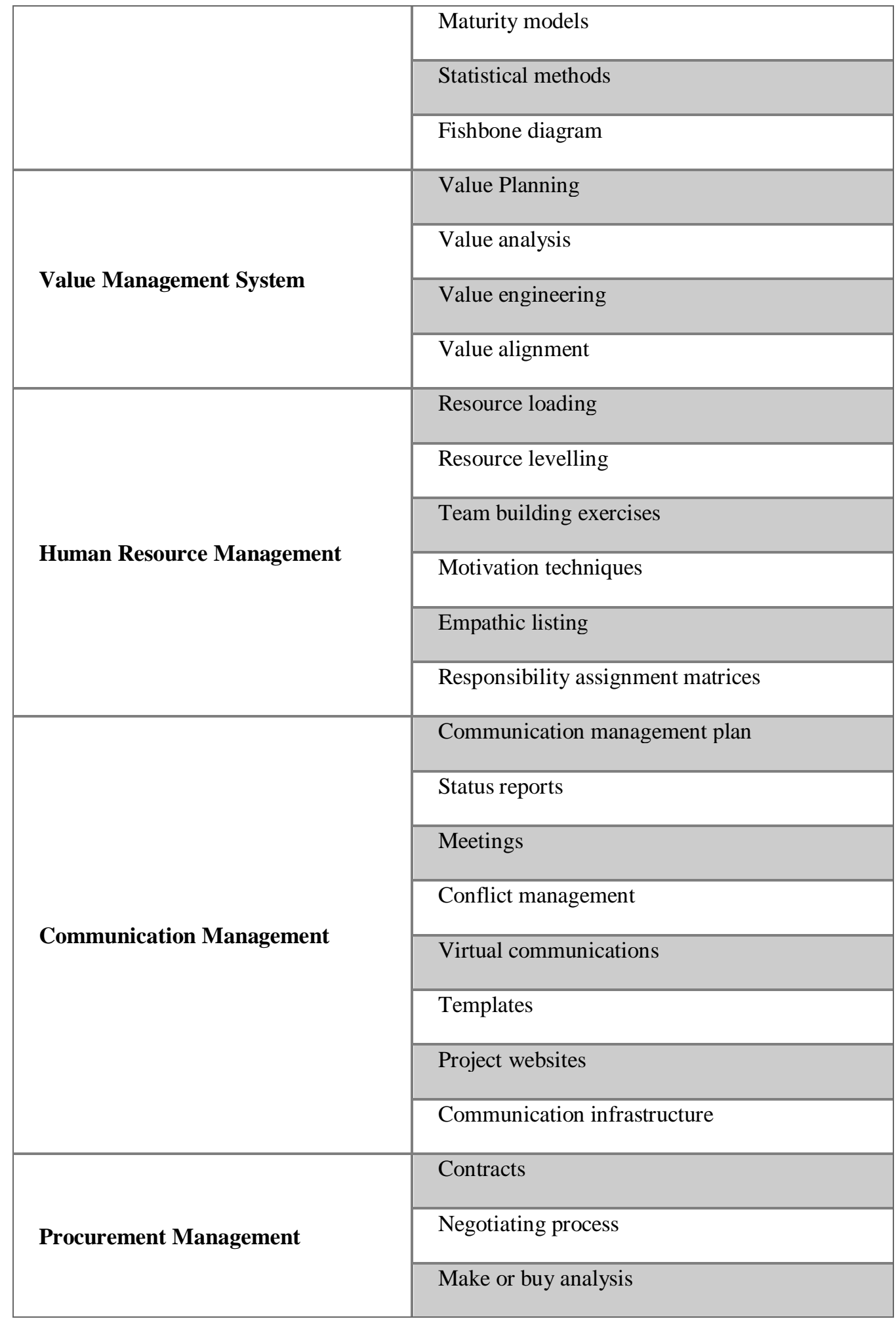




\begin{tabular}{|l|l|}
\hline \multirow{4}{*}{} & \multicolumn{1}{|l}{ Requests for proposals or quotes } \\
\cline { 2 - 3 } & Source selection \\
\cline { 2 - 3 } & E. procurement \\
\hline \multirow{5}{*}{ Risk Management } & Risk ranking \\
\cline { 2 - 3 } & Risk registration \\
\cline { 2 - 2 } & Risk assessment \\
\cline { 2 - 3 } & Probability and impact matrix \\
\cline { 2 - 3 } & Monte Carlo simulation \\
\cline { 2 - 3 } & Top-ten risk item \\
\cline { 2 - 3 } & Risk tracking \\
\hline & Constructability review \\
\hline
\end{tabular}

Each construction project classifies by a framework for looking at project dynamic over time, and the framework usually describes the project lifecycle. A generic project life cycle framework has four phases; conceptual, planning, execution, and termination. The project management tools and techniques differ across these phases. Based on the project objective and the activities in each phase, appropriate PM tools and techniques are identifying and selecting by the project manager and project team. Coombs [152] discusses the different of PM tools and techniques regarding their use in project phases and these tools and techniques metrics for project success. Table 5 shows examples of a proposition of the activities and the PM tools and techniques that may be used in each project phase. 
Table 5: Activities and Selection of PMTT in of Project Life Cycle Phases

\section{PROJECT PHASES}

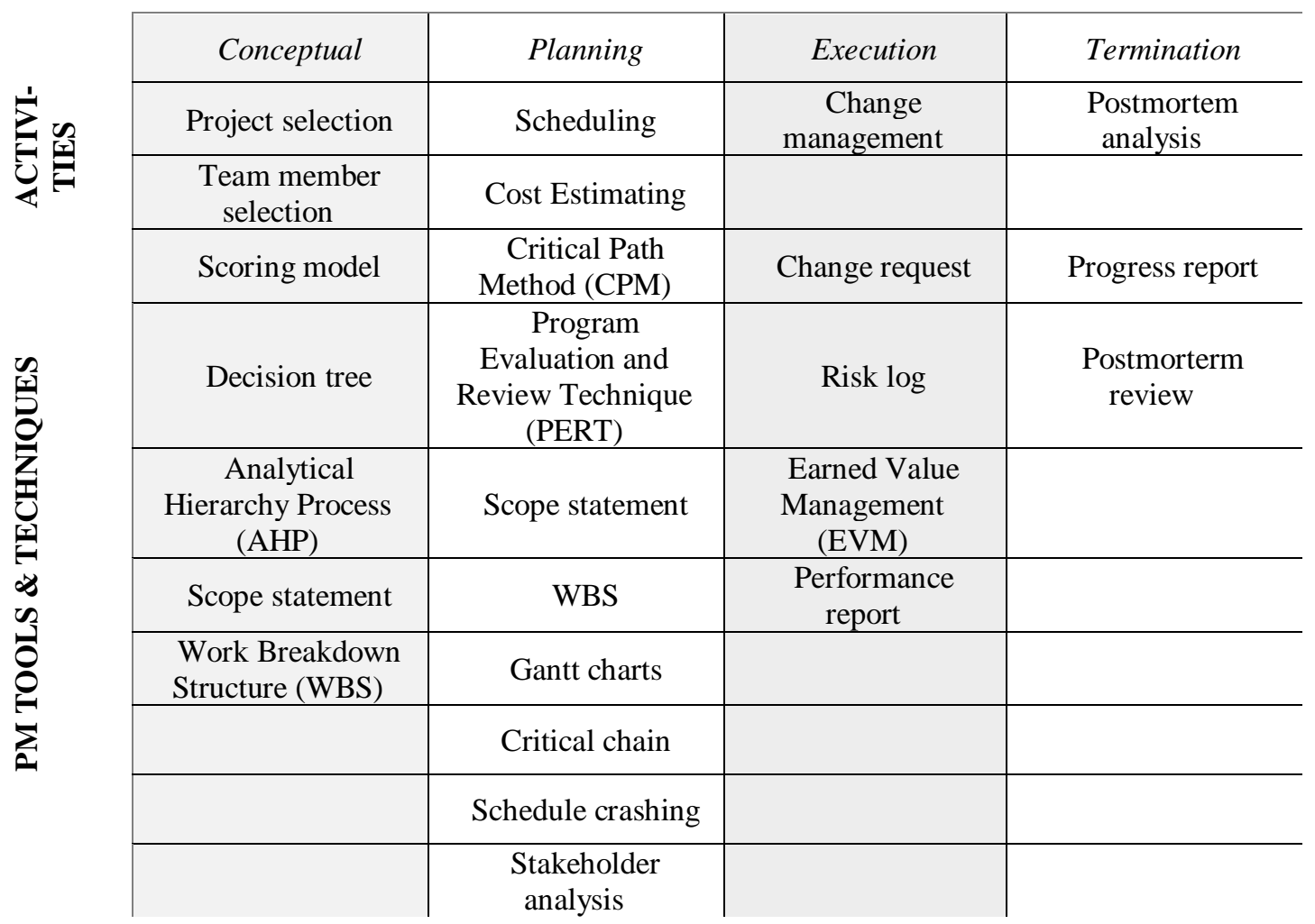

\subsection{Managing Construction Projects Using Project Delivery Methods}

Project delivery methods are continuously developing to reduce the project cost and time considering the project specific needs [153]. Suitable project delivery and contracting strategy would assign roles and responsibilities in a desirable way for the performance of project activities and facilitate the optimal performance of these activities with respect to owner's objectives [153]. The project delivery method is a process that respects to project scope, designers, constructors and various consultants [154]. A project delivery method 
associated with a procurement approach provide techniques for bidding, managing and specifying a project [153]. Three fundamental project delivery methods are considering by the Construction Industry Institute; Design-Bid-Build (DBB), Design-Build (DB), and Construction Manager-at-Risk (CMR).

The Design-Bid-Build (DBB) technique has a complete design before awarding the project which is increasing the certainty of the cost estimates. In this method, usually the owner and the bidder share and have the project engineer's estimate. Also, the owner can choose unit price bids as the payment method. DBB method has a significant advantage that allows the contractor to bid on unit prices rather than the total price. Touran [155] explains the use of DBB method, the contractor does not have the risk of fluctuating quantities, while the owner does not have to pay for constructor contingencies included in the bid because of quantity uncertainties. The DB technique provides a sole responsibility for both the design and construction of a project to one contractor as a single commitment [152]. In CMR method the coordination begins during the design phase between the construction manager at risk and the design engineer. However, in this method, the project owner has to sign two contracts one with the design engineer and the other with the construction manager. Both of $\mathrm{DB}$ and $\mathrm{CMR}$ engage the contractor earlier in the project lifecycle than with the DBB [156].

The [156] referred to a multitude of names for project delivery methods throughout the industry. For example; Project alliancing is the model for a new project delivery method that has recently emerged in the United States as an integrated project delivery method 
(IPD) [157]. The IPD defines by the American Institute of Architects (AIA) as a project delivery approach which integrates people, systems, and business structure into a process. The [158] and [159] pointed out in their studies to the integration delivery method in construction that the integration process of collaborative working practices, methods, and behaviors.

Academic research and industry reports introduce other methods that are using in different construction projects, and they prove its ability to reduce the project cost and time such as Design-Build-Operate-Maintain (DBOM). This method combines the design and construction responsibilities of design-build procurements with operations and maintenance. Design-Build-Finance-Operate (DBFO) also considers as an approach where responsibilities for designing, building, financing and operating are integrated and transferred together to private sector partners. Build-Own-Operate is retaining ownership while a private contractor constructs and operates the project.

There are also alternative delivery methods such as Public-Private Partnerships (PPP / P3s), and Alternative Technical Concepts (ATCs). According to [160] PPP is an umbrella term referring to a variety of collaborative that involving a significant number of individuals and organizations. PPP projects combine finance, operation, and maintenance with the more traditional DB project delivery approach. Projects that do not show all five characteristics such as design, build, finance, operate, and maintain are not characterized as PPP [161]. 
Figure 7 illustrates a flowchart of a sample Design-Build method that uses to accelerate transportation bridges construction. The key team members are shown in different colored boxes. The DB process combines both design and construction activities into one contract. The project design and construction are achieved by combined efforts of project's team and contractors with design engineers. Usually, some up-front project design is completed by the agency before the bidding process such as preliminary design, acquisition of RightOf-Way (ROW), and procurement of environmental permits [161].

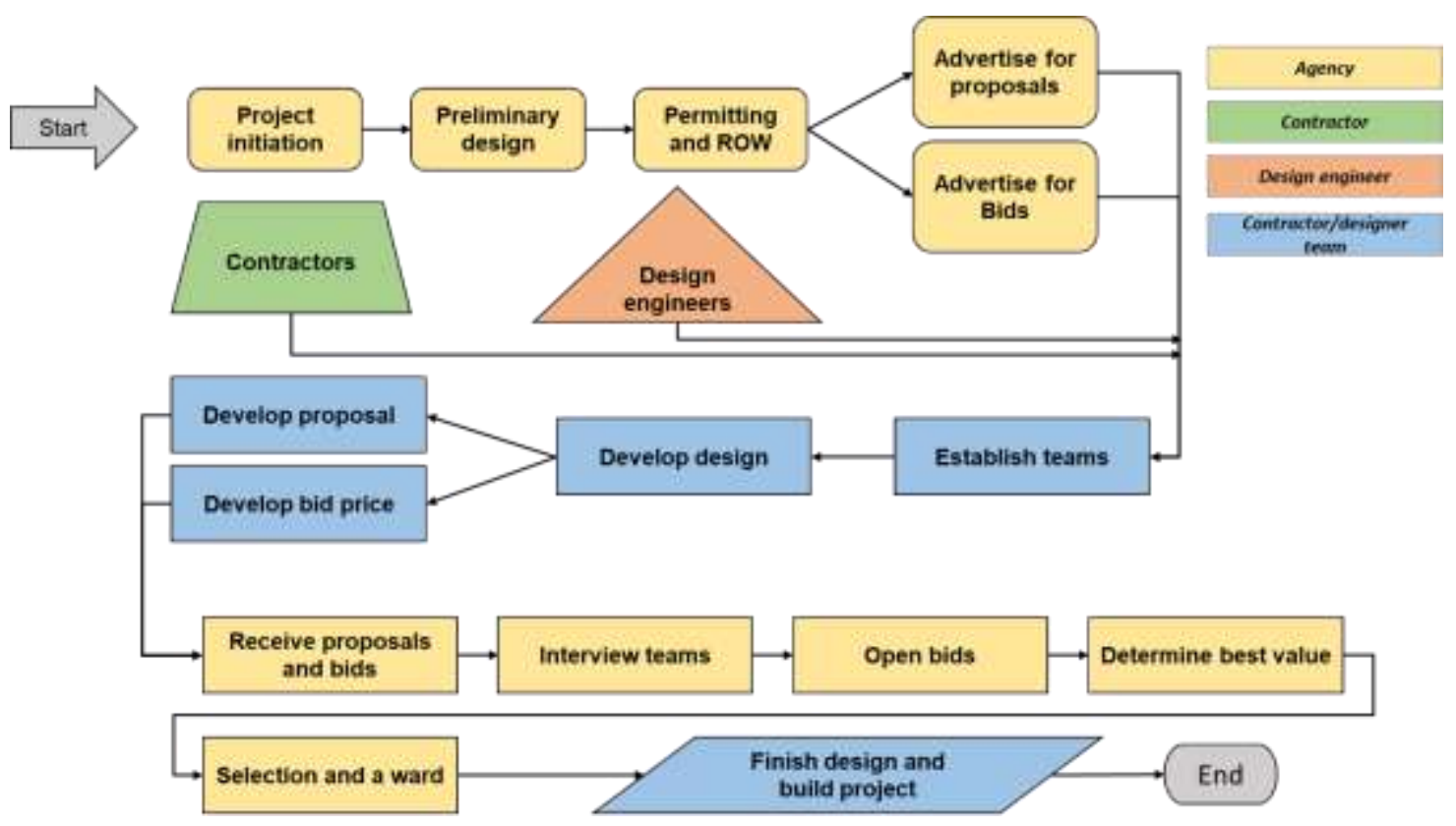

Figure 7: DB Process in Bridges Construction- Adapted From [162] 


\subsection{Managing Construction Projects by Contracting Methods}

Turnkey (TK): This model of contracting, which involves delivery of a complete system and extend the timescale of the project backward to pre-bid activities and forwards beyond the handover stage [163][164]. The [164] describes the turnkey as an approach involves the public and the private sector in delivering the project. The public sector is the ownership of the facility in this arrangement.

Build-Lease-Transfer (BLT): This technique is similar to the DB option, except that the facility is passed on to the public sector. The process occurs under a lease structure upon completion and acceptance of the facility [165].

Lease and Transfer (LT): In this category of arrangement, the leaseholder is responsible for operating and maintaining the infrastructure facility and services. However, usually, the operator is not required to make any significant investment. The duration of the leasing contract is typically for 10 to 20 years. It also depends on fixed facilities, which are leased out for a more extended period whereas mobile assets are a shorter duration [164].

Build-Transfer-Operate / Design-Build-Operate (BTO/DBO): In this model, the private sector designs and builds a facility for the public sector. Also, the private sector usually provides the financing for it. The new project is transferred to the project owner but the contractor who the responsible for operating the facility and recovers its investment in the project over a set number of years. The most common investment period of this model was between 25 to 30 years [166]. 
Build-Operate-Transfer (BOT): This approach is now gaining widespread popularity in developing countries. In this method, the private sector has to finance, design, build, operate, and maintain the project. Then, the project transfers to the owner (Government) after a specified concession period [167]. [167] Defines the BOT model as the government turns over development and initial operation to the private sector.

Build-Own-Operate-Transfer (BOOT): The developer in this model is usually who is the owner of the project or facility. The eventual no-cost transfer of the project or facility to the public sector would most likely be well after the economic life of the facility has expired, or at least not until the financing has been repaid [164]. In this model, after the contract period, it is handed to the public sector, it enables innovation and initiation from the private sector and is often associated with accelerated infrastructure construction and improved value for money [167].

The Build-Own-Operate (BOO): This method involves the greatest degree of private sector participation in the development of a new project or facility. Under this model, the sponsoring consortium finances the project and operates the facilities as the owner. BOO is not required to transfer the project or facilities back to the host government [164]. The government may contribute in some payment guarantee via long-term contracts, but any residual value of the project accrues to the private sector [153]. The arrangement of BOO involves a long-term supply contract with the client, who is charged accordingly for the services delivered [168]. 


\subsection{Managing Construction Projects by Support Tools and Techniques}

- Value Management (VM): In the project construction context, the value is the relationship between benefits, costs, and risks that are incurred for conducting project objectives. The VM framework is the balance of project stakeholder's benefits, resource efficiency, and the value for Money. VM is the link between strategic management and organizational project management. It is the accomplishment of the organization's strategies by projects or programs [54]. VM has existed under different names, such as Value Analysis (VA) and Value Engineering (VE) [169]. VE is the common term that uses in the construction project activity. It is a process for achieving the best project outcome by improving the project quality, safety, and reliability [54]. VE is usually applied in the analysis and design of a service/product [170]. The NCHRP Synthesis 352 defined the Value Engineering process as the Job Plan, defines a categorization of activities that are undertaken during a VE workshop. During the VE workshop, the VE team learns about the background issues, defines, and classifies the project (or product or process) functions. They identify creative ideas to provide the functions as first input. Then, they evaluate and develop the VE proposals to key decision makers. It is the focus on the functions that the project, product, or process must perform that sets Value Engineering separately from other quality-improvement or costreduction approaches [145]. 
- Risk Management (RM): It is one of the nine knowledge areas presented by the Project Management Institute [171]. RM in the construction project management context is a systematic way that uses to identify, analyze and respond to risks for achieving the project objectives [42]. RM process leads to identify, analyze and improve the construction project management processes including the efficient use of resources. Risk management comes as a response to specific questions during the project assessment activity. For example, what is the probability that this risk will occur? And what is the severity of the impact on the project if a risk is allowed to take place? [172]. In the construction projects, the risk analysis process is complicated because the nature of risk is usually affected by numerous factors such as human error, lack of data or information. Large investment scale of construction projects is always associated with higher risk [173]. The risk in construction projects is different than an issue, risk defines as an uncertain event, while the issue is a problem needs a solution by the project manager [174].

- Quality Management $(Q M)$ : Quality management has increasingly been adopted in construction projects to meet the needs of the final customer [175]. The Japanese defined the effective management of quality and productivity as total quality management (TQM), and it has been adopted and applied in the United States [176]. The Japanese adopt the TQM teachings for the experts to meet their needs in different industries. Construction companies have adapted the TQM method 
applied it to construction operations with minor modifications [177]. The TQM process is the contribution of all construction project parties [178].

- Constructability Review $(C R)$ : It is a formalized process whereby a project is evaluated to identify issues, errors, and omissions related to the construction of a project. A common definition of CR is defined by the Washington State Department of Transportation (WSDOT). They described CR as the property of a project in which errors and omissions on the contract plans and special provisions have been minimized and allow the contractor to construct a high-quality project that is biddable, buildable, and maintainable [179]. Many organizations consider constructability review, or CR, to be a process performed late in design. While CR should be performed before construction, it should also be considered during the earlier stages of project development. CR is both a quality and risk management process. This activity has been designed to help project teams systematically consider applicable constructability issues at various stages of project development. It draws upon research performed by the University of Kentucky and from several state departments of transportation to identify common areas of focus to uncover constructability issues. The importance of constructability to project success that it has motivated many state transportation agencies (STAs) to address it on their projects. While most STAs consider constructability in some manner as part of the 
project development process, however, only a small percentage have developed and implemented formal Constructability Review Processes (CRPs) [145].

- Project Management Software (PMS): Several PM softwares are developing to help project managers and their team to plan and manage the project tasks and resources. These tools may use in estimation, assessment, controlling, or management project activities. For example, the most common software is scheduling tools. Most of these tools are listed above [180] such as MS Project, Gantt Chart, the Program Evaluation Review Technique (PERT), Critical Path Method (CPM), or Primavera (P6)tool or technique. Scheduling tools are used to sequence project activities and assign dates and resources. Scheduling tools may include support for resource leveling, critical path, activity duration estimation, or activity cost accounting [181][182]. 


\subsection{Overview of Multi-criteria Decision Models Leveraging Expert Opinion}

Multi-Criteria Decision Making (MCDM) provides a strong decision making in domains. It helps to choose the best options with respect to many criteria and factors; the best alternative can be selected based on expert's input by weighting the criteria and then choose the optimum alternative using any multi-criteria decision-making techniques [183]. MCDM methods have four basic steps that support the making of more efficient, rational decisions:

- Structure the decision process, criteria formulation, alternative selection.

- Display trade-offs among criteria and determine the weight of each criterion.

- Apply value judgments concerning acceptable trade-offs and evaluation.

As shown in Figure 8 the process of evaluating results and make a decision [183].

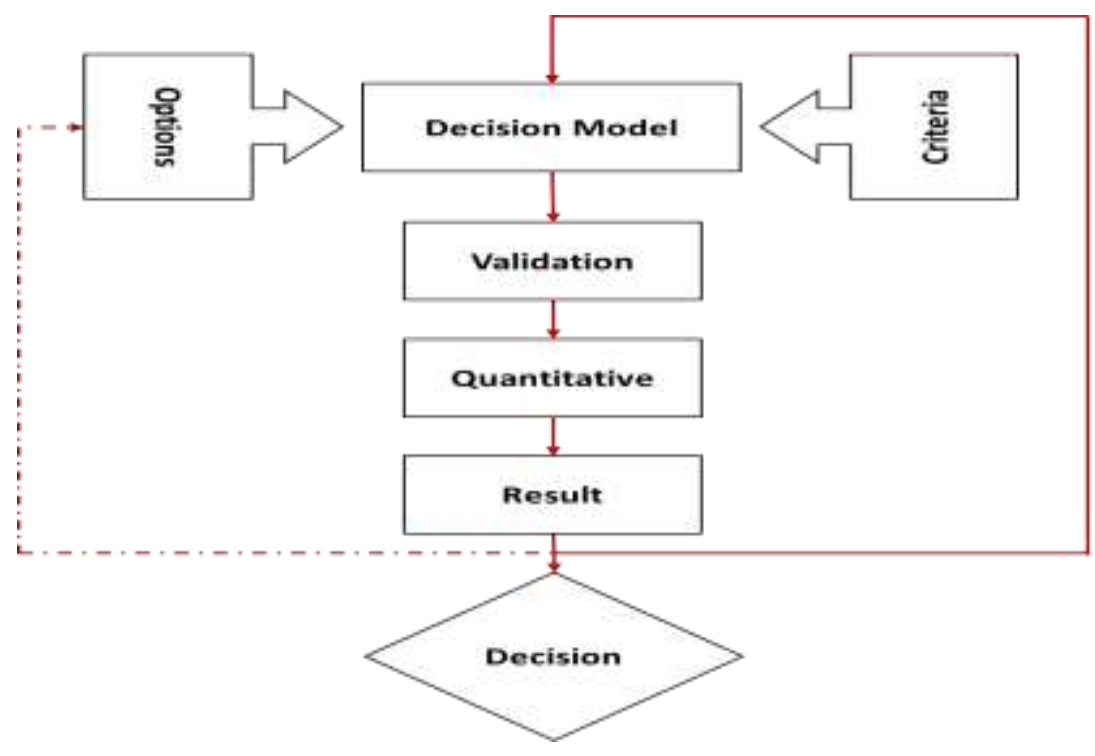

Figure 8: Multi-criteria Decision Process- Adapted From [183] 
The multi-criteria analysis is used to select the "best fitting" solution from distinct multi-attribute options [184]. For example; Delphi method is a technique for structuring systematic communications among a panel of experts. It uses as an opinion-taking procedure, and it is different from conventional face-to-face group integration [185].

In this research there are 12 multi-criteria decision methods, which depending on expert opinion were investigated from the literature review:

- The Hierarchical Decision Model (HDM)

- Analytic Hierarchy Process (AHP)

- Analytic Network Process (ANP)

- Technique for the Order of Prioritization by Similarity to Ideal Solution (TOPSIS)

- Simple Additive Weighting (SAW)

- Value Matrices (VM)

- Elimination et Choice Translating REality (ELECTRE)

- The VlseKriterijuska Optimizacija I Komoromisno Resenje (VIKOR)

- Preference Ranking Organization Method for Enrichment Evaluations (PROMETHEE)

- The Grey Relational Analysis (GRA)

- Simple Multi-Attribute Rating Technique (SMART)

- Decision EXpert (DEX) 
The Hierarchical Decision Model (HDM): The Hierarchical Decision Model (HDM) technique was developed by Professor Dunder Kocaoglu [186]. The model can be used as a network of relationships among decision hierarchies, where subjective judgments are provided in a comprehensive evaluation [187]. The HDM has adopted by decision makers in various industries [188][189][190]. HDM is used to quantify expert qualitative judgments and convert them to numerical values using a pair-wise comparison method. The HDM process likes other multi-criteria decision tools such as AHP. Its steps include structuring the decision problem into levels, followed by pairwise comparison among all variables, calculating the priorities of the objectives, and checking the consistency. The HDM process is more comfortable for the experts related to the relative and absolute preference [191]. HDM has the capability to divide the problem into smaller entities for making the decision more accurate. Also, the HDM has another advantage to screen and select alternatives, criteria, and sub-criteria in a significant number [185]. HDM helps to analysis the relationship between mission, objectives, and alternatives in a hierarchical structure. Also, it uses a pairwise comparison process to convert experts' qualitative input into numerical values.

Analytic Hierarchy Process (AHP): It is a decision-making method which developed by Thomas Saady [192]. AHP is a well-known technique that has been applied in academia and industry to select among competing alternatives in a multiobjective environment and others. It is designed based on the well-defined mathematical structure of consistent matrices and ability to generate true or 
approximate weights [193]. The method converts individual opinion into ratio-scale weights that are combined into linear additive weights for the associated alternatives. The final weights are used to rank and select the best alternative or option. The judgments are made in a pairwise process. The AHP method is flexible, intuitive and checks inconsistencies.

Analytic Network Process (ANP): This method is more general form of the AHP used in multi-criteria decision analysis. The ANP structures as a network, while AHP designed a mission as a decision problem into a hierarchy with a goal, decision criteria, and alternatives [182]. Both methods use pairwise comparisons to weight the components of the structure and select the best alternative based on the expert's opinion. ANP prediction process is accurate because feedback improves priorities [194].

Technique for the Order of Prioritization (TOPSIS): It is a simple ranking method application developed by Hwang and Yoon in 1981 which is an extension of the theory of ideal solutions developed by Zelen [195] in 1974. The chosen alternative should have the shortest distance from the ideal solution, while it should have the farthest distance from the negative-ideal solution [196]. The positive ideal solution leads to maximize the benefit criteria and minimizes the cost criteria, whereas the negative ideal solution is vice versa. TOPSIS is a technique that combines quantitative attribute such as price, time, distance, and soon; and qualitative attributes such as quality of the relationship, quality of assurance, reliability; and compares all alternatives together 
based on these attributes [197]. TOPSIS provides alternatives ranking, makes full use of attribute information, and does not require attribute preferences to be independent [198]. Fuzzy TOPSIS method is used to eliminate an unreasonably large number of pairwise comparisons and to solve MCDM problems [199].

Simple Additive Weighting (SAW): This method is well-known and most widely used MADM method [200]. SAW method is also known as the scoring method which it is one of the best and simplest types of multiple attribute decision-making method. The fundamental rationale of the SAW method is to get a weighted total whole of performance ratings of each alternative overall attributes[200]. SAW uses the expert opinion for criteria and alternatives weighting [201]. However, this method is often argued by some researchers and practitioners because of the unbalanced scale of estimations that use during its process and its inappropriateness of crisp ratio representation [54].

Value Matrices (VM): It is a new innovative combined MCDM and Value Analysis method, which was developed by Stweart (2010)[104]. It demonstrates the measures project value by correlating the performance of project scope and schedule to the project costs. This process is known as Value Metrics. The objective of this methodology is to prescribe a systematic, structured approach to study and optimize a project's scope, schedule, and cost. 
The VM method is working based on the following steps [202]:

- Identify the project performance attributes and requirements,

- Develop the hierarchy and impact of these attributes upon the project,

- Determine the baseline of the current project performance by evaluating and rating the effectiveness of the design concepts of the project,

- Identify the change in performance of alternatives by the value analysis study,

- Measure the aggregate effect of alternative concepts related to the baseline project's performance as a measure of overall value improvement.

All competing concepts are compared to the baseline concept for all attributes in order to compare and contrast the potential for value improvement. The matrix is essential for understanding the relationship of cost, performance, schedule, and value of the project baseline and of the concepts developed during the value analysis process. Comparing the performance and cost suggests which alternatives are potentially as good as or better than the project's baseline concept in terms of overall value. Comparison at the value index level indicates which alternatives have the best performance versus cost or provides the project with the best value. Using the Value Analysis aims to improve project value.

A simple way to think of value in terms of an equation is as follows (where time is equivalent to delivery/schedule): VALUE $=$ PERFORMANCE / COST 
Also, during the Value Metrics implementation, the value analysis team leader can input the data through multiple tabs in the spreadsheet as the following list of tabs:

- Performance Requirements

- Performance Attributes

- Priorities

- Alternative Performance

- Alternative Value

- Strategy Performance

- Strategy Value

Once the analysis completed, reports of the findings are automatically generated for the Performance Priorities; Alternative Performance Ratings; Alternative Performance Profile; Alternative Value Profile; Strategy Performance Profile; and Strategy Value Profile.

Elimination et Choice Translating REality (ELECTRE): This method is capable of handling discrete criteria that are both quantitative and qualitative in nature and provides a complete ordering of the alternatives. The origins of ELECTRE methods go back to 1965 at the European consultancy company SEMA, which is still active today. An atypical ELECTRE method was innovated to deal with the problem of highway design projects [203]. The method analysis is focused on the dominance relationship between alternatives. It is based on the outranking relations and exploitation notions of 
concordance [191]. The outranking method uses a pair-wise comparison between alternatives [204]. This approach allows using fuzzy analysis because of thresholds of indifference and preference. It can accept qualitative and quantitative criteria. However, ELECTRE is considered as a complicated method, because of the principles used in its process (determining the concordance and discordance matrices) [202]. The method updated and developed into six versions (ELECTRE I, II, III, IV, IS and TRI) [204][205].

The VlseKriterijuska Optimizacija I Komoromisno Resenje (VIKOR): It is a wellknown MCDM technique which emphasized on select and rank of alternatives sets of conflicting criteria. This method has been studied and developed by scholars in recent years. VIKOR was applied in several application areas [205]. There is a high motivation to categorize these methods across several areas and particular sub-areas. The method classified by studies into four groups: Utilizing, Integrated, Proposed, and Modified research [206]. The VIKOR technique was modified by Anvari, et al. (2014) [207][208].

Preference Ranking Organization Method (PROMETHEE): The Preference Ranking Organization Method for Enrichment Evaluations (PROMETHEE) has been developed since four decades ago. The essential elements of the PROMETHEE method were introduced by Professor Brans in 1982 [204]. The method uses pairwise comparisons to weight each alternative with respect to the selected criteria. These 
evaluations depend on and present as numerical data. PROMETHEE implementation requires two main actions [204]:

To weight the relative importance of the selected criteria by experts.

Then, comparing all alternatives with respect to the related criteria.

The PROMETHEE is most useful to solve complex problems by the project team, especially problems with several multi-criteria which involve a lot of human perceptions and judgments. The method is unique when important elements of the decision are difficult to quantify or compare. It is working from different perspectives [209][210]. So far, the method has developed twice PROMETHEE I \& II [211].

The Grey Relational Analysis (GRA): The GRA method is a comprehensive evaluation approach. It was developed in 1982 by a Chinese J. Deng who is a professor at Huazhong University of Science and Technology [212]. GRY has been widely used in various fields of science, especially in Asia because of its advantages in prediction, modeling, control, and decision-making [213]. GRA has the merit of comparing two sets of data by measuring the distance between two points. In order to keep the method merit, all the criteria are distributed in a single level to the decision algorithm. The weighting conversion from multiple levels to a single level of performance characteristics are recommended to be done if the original decision model is in the multi-level hierarchy structure [214]. 
Simple Multi-Attribute Rating Technique (SMART): It is perceived ease of use, it has been widely applied. Similar to AHP, SMART assumes ratio-scale weights [215]. In order to get weights using direct numerical ratio judgments of the relative importance of attributes. Subjects first rank-order the attributes in importance and assign a scale between $(0-10)$, ten to the least important attribute. Then, they judge how much more important each of the remaining attributes is in relation to the least important and assign weights in multiples of ten. Finally, the ratio weights are normalized [216].

Decision EXpert (DEX): It is a qualitative multi-criteria decision analysis (MCDA) method for decision making and is implemented in the DEX software. The method is focusing on the explanation and analysis of options. Its processes lead to better understood and justified decisions [217]. DEX is particularly well suited for decision problems that involve qualitative concepts and lots of expert judgment. However, it seems that the usefulness of DEX increases with the increasing difficulty, or complexity of the decision problem. The best results were achieved in problems that required large models, consisting of at least 15 attributes, and/or involving a large number of options. The DEX software can deal with ten up to several hundreds of options. However, DEX turned out to be unsuitable for problems that require accurate formal modeling, numerical simulation and/or optimization [147]. 

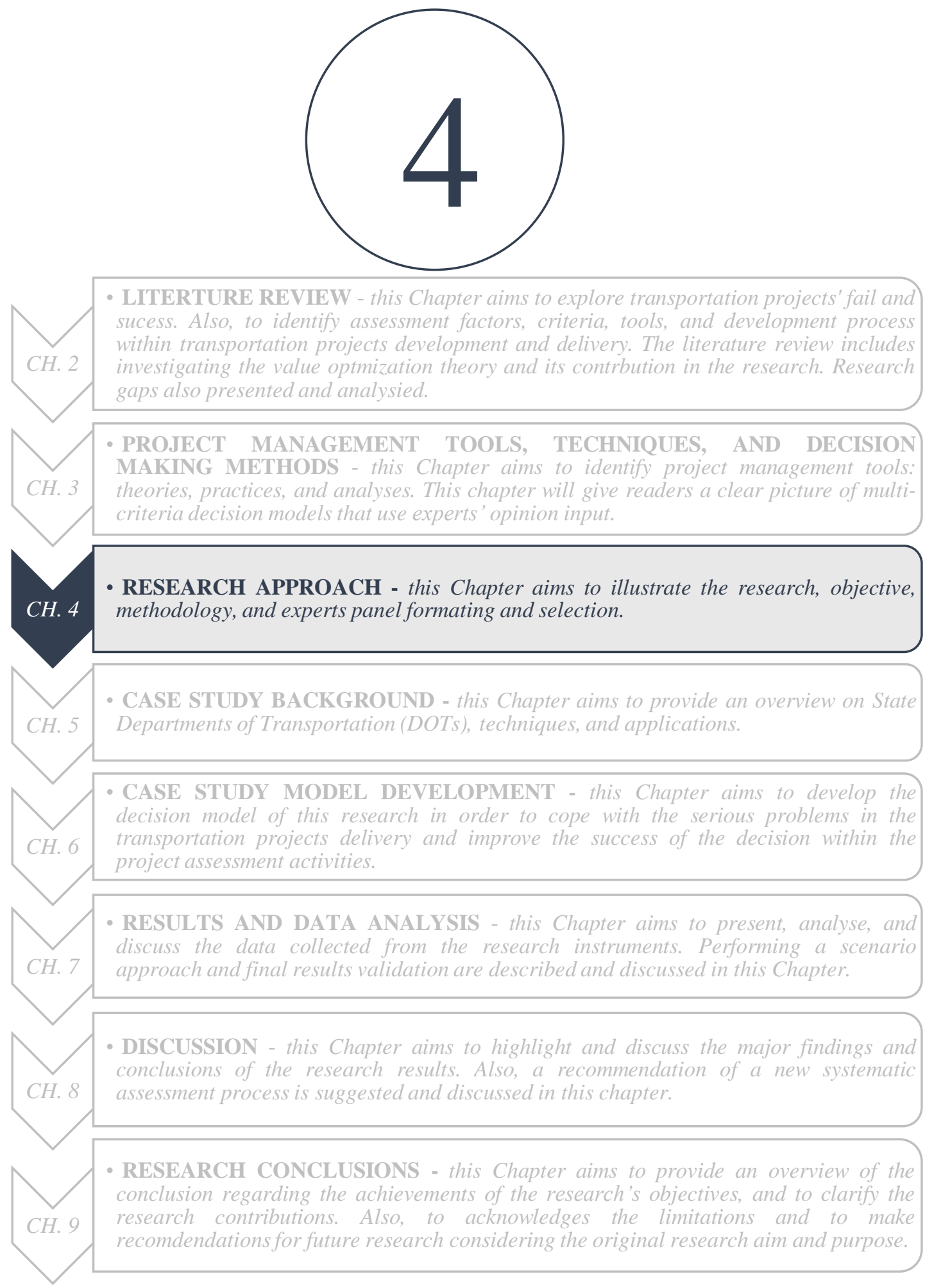


\section{CHAPTER FOUR: RESEARCH APPROACH}

\subsection{Research Objective}

This research aims to develop a comprehensive decision model for a value-based evaluation approach of the project assessment techniques for transportation projects development and delivery. The developed decision model will help to select the most effective alternative for measuring the success of outcomes related to the delivery of transportation projects. The common use of existing innovative assessment tools, methods, techniques, and practices within transportation projects have been investigated to design the model structure. The model is structured to evaluate some of the screened project assessment techniques from five perspectives (cost, time/schedule, risk, performance, and resources) including their associated sub-criteria. Furthermore, three high-level goals have been proposed to meet the research purpose as follows:

- The first goal is to provide the needed decision model for transportation development and construction projects considering value-based perspectives such as risk, time, cost, performance, resources...etc.

- The second goal is to help the decision makers to optimize the project delivery value and outcome within the transportation infrastructure.

- The third goal is to enable a reduction of time and schedule impacts during the delivery of transportation projects. 
The research is targeted to address the following research questions:

- What are the most common innovative assessment tools, techniques, or practices typically performed as activities or programs to minimize the project cost and delay of the construction project delivery process?

- What are the criteria for evaluating the innovative assessment tools from the project management, value optimization, and transportation project delivery perspective?

- Which assessment tool alternative has the highest effect on optimizing the transportation project delivery value and outcomes?

- To what extent can the developed model's results help in recommending a streamlined flowchart or process for transportation projects assessment?

- Could the developed model be generalizable to assess a wide range of project management toolkit alternatives? 


\subsection{Research Focus}

Several innovative assessment tools, methods, techniques, and practices are used by the project team to evaluate the project performance in terms of the relevant measures of effectiveness such as cost, time delay,..etc. [145]. This research focuses on project integrated assessment tools as potential techniques that can be used for optimizing the project value and outcomes. As mentioned in the introduction, some questions regarding these tools have been covered during the literature review process. A set of the selected assessment techniques is chosen to be candidates for the weighting process. The evaluation of various levels of criteria aims to help in identifying which alternatives are more valuable than others.

The PMBOK Guide defines ten knowledge areas that consist of methods, processes, and tools applicable to each stage for project delivery. These areas are integration, scope, time, cost, quality, human resource, communications, procurement, and stakeholder management [218]. The Project Management Institute (PMI) presents best practices to provide the right opportunity for applying the phased approach or lifecycle model to make project implementation success. A wide range of literature review has shown that there is an apparent variation among studies regarding the project planning stage [22]. Project planning and development are essential to the decision-making process [219]. In this research, some common project assessment techniques were identified and selected to be evaluated by experts through the developed decision model. These techniques are used in the development phases within the transportation project delivery. As shown in Figure 9, 
specifically, the research targets the latest developed project lifecycle process within the Colorado Department of Transportation (CDOT) [27]. Furthermore, the research is considered the information and data of development and design phases that are presented in the National Cooperative Highway Research Program, NCHRP 19-11, [220].

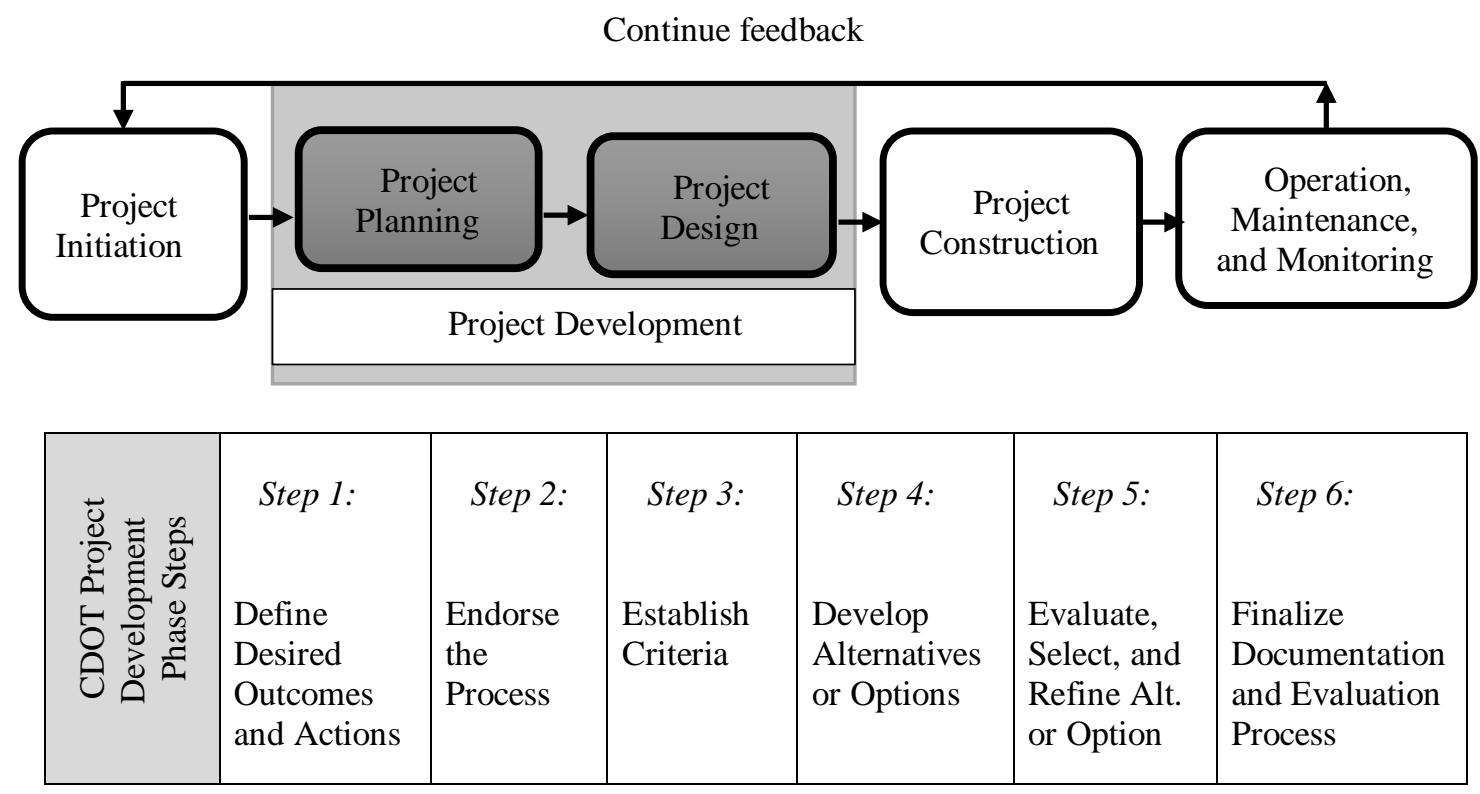

Figure 9: CODT Project Lifecycle- Adapted From [27]

Figure 10 represents a visual outline of how the value management practices align with a generic life cycle of transportation project delivery. It highlights key elements and provides a basic blueprint from which the NCHRP 19-11 research developed a comprehensive process. This process aims to assist transportation project teams in maximizing the value of their projects delivery. Therefore, this research leveraged the 
concept of transportation project life cycle and assessment activities to identify which project stage requires an assessment activity to reduce the cost and time of project delivery.

This research screened innovative assessment tools and techniques within transportation projects and other industries that are used during the project life cycle, and that primarily meets the requirements of the project development phase.

Also, the various successes of transportation infrastructure development perspectives including common attributes that are employed in the project delivery decision-making during the development phase such as cost, time, performance, risk...etc were identified and used in this research.

Finally, the high ranked alternative based on the developed model perspectives were identified, by focusing on the requirements of the highway and bridge projects at the development phase.

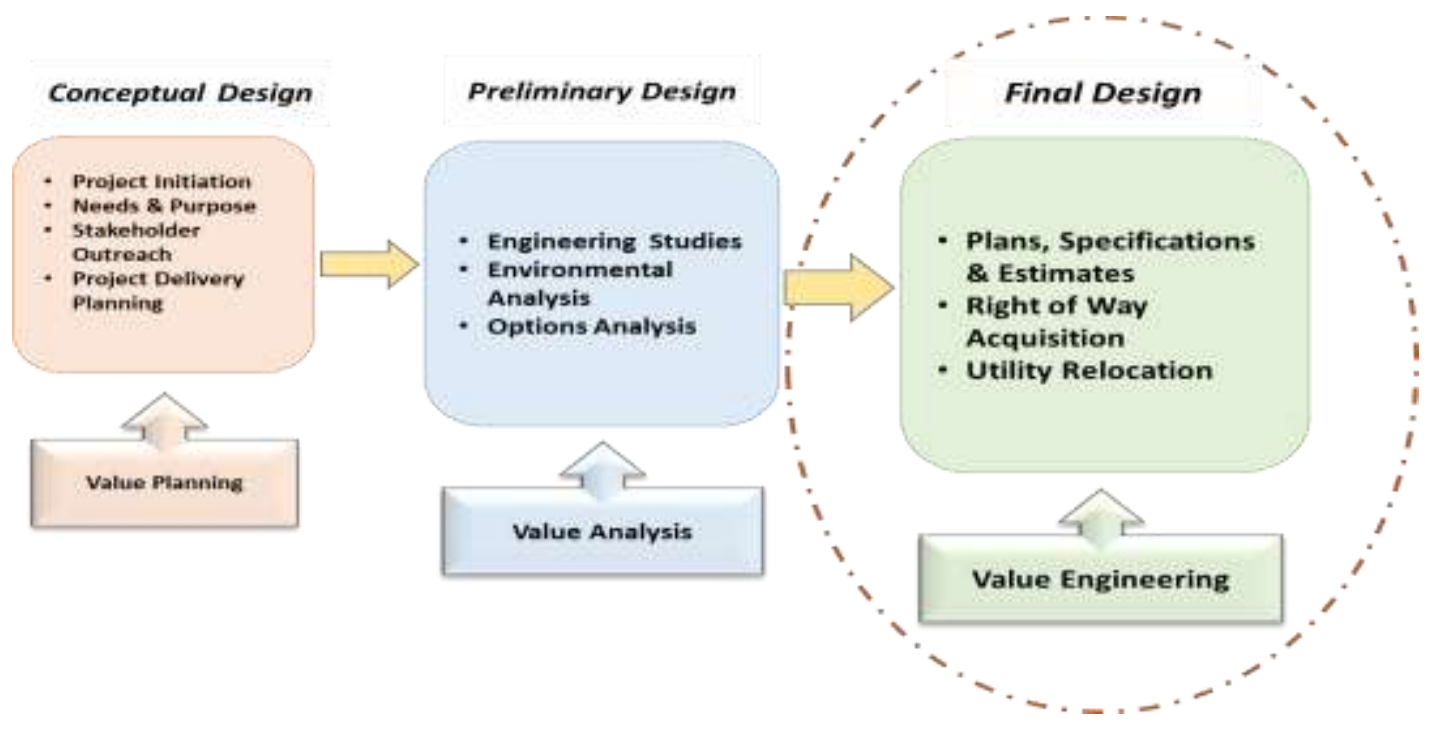

Figure 10: Transportation Project LC / Design Phase- Adapted From [221] 


\subsection{Research Methodology}

The design of the research structure is required to illustrate a clear approach before conducting the research activities. Dr. Greener defined the research design as "a grand plan of approach to the research topic"[222]. Justifying the research design elements are also important to understand the research design [223][224].

This research started with the literature review to identify and investigate existing innovative assessment tools, techniques, and practices within public transportation agencies and the effectiveness of using these techniques within some state DOTs. Several keywords were used to search academic and industry databases for literature on project delivery tools and techniques. Also, some criteria and terminology related to project management and innovative technology were used to identify and screen these tools and techniques. The research focused on what theory, methodology, or practices are embedded in these approaches, how these techniques can be implemented in a particular industry, and how likely these techniques can be applied to the transportation project delivery for enhancing the project performance within an acceptable cost and time frame. A hierarchy decision model (HDM) provides a systematic approach to develop priorities for alternatives based on the experts' judgments. A decision model is formulated in this research to include the evaluation of criteria and sub-criteria, to identify the high ranked alternatives based on the model perspectives, and to focus on the requirements of the highway and bridge project planning and development phase. The HDM is constructed to represent a decision problem, which it designs in hierarchy model levels as a mission including criteria, sub-criteria, and 
alternatives. In order to choose the best alternative, the experts were asked to discuss, identify, weigh, and validate the model criteria, sub-criteria, and alternatives.

\subsubsection{Research Model}

The HDM was used in this research as an evaluation model to identify the most effective assessment tools for optimizing the value and outcomes of the transportation infrastructure. HDM has the capability to divide the problem into smaller entities for making the decision more accurate. Also, the HDM has another advantge in that it can screen and select a large number of alternatives, criteria, and sub-criteria [185]. HDM helps to analyze the relationship between model mission, objectives, and alternatives in a hierarchical structure (Figure 11). Also, it uses a pairwise comparison process to convert experts' qualitative input into numerical values.

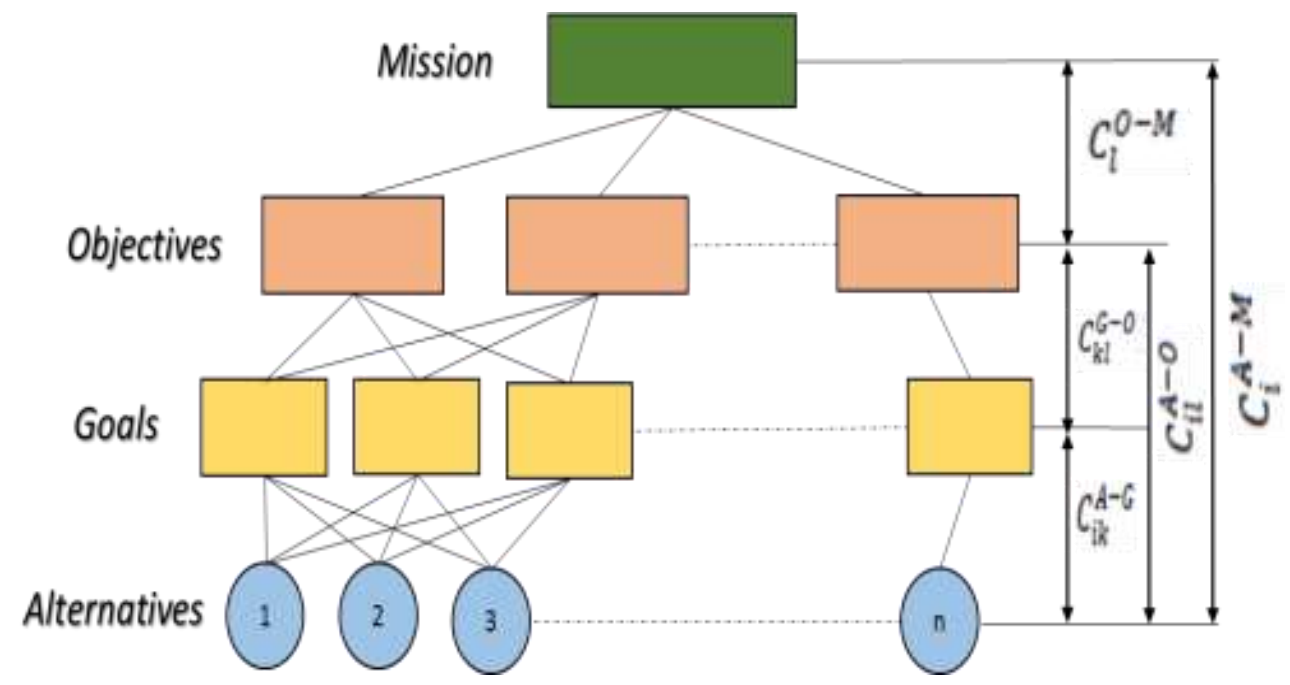

Figure 11: HDM Structure- Adapted From [225] 


\subsubsection{Inconsistencies}

Inconsistency is an unintentional error that occurs during the pairwise judgment process [226]. It is a gauge of how consistent, or reliable, the participant was in their assignments [227]. Inconsistency can also be defined as a disagreement within an individual's evaluation [228]. It is accepted value, if the inconsistency is between 0.0 and 0.1 for valid results [184][229][230]. However, an expert's judgments should be "consistent" over repeated times [231]. Furthermore, Neshati [232] emphasized in his dissertation that in order to reduce disagreements among experts, the weighting process of the model needs to be repetitive. Consistency is a necessary condition that the experts in a given field should agree about each other. This condition is sometimes accepted as a practical goal [233]. A large number of researchers have focused on inconsistency, and as a result, they have developed consistency measures [233]. The development refers to procedures which are used to adjust the inconsistent judgments.

For (n) elements, the constant sum calculations will result in a total of (n!) orientations with vector values represented by $(\mathrm{r} 1, \mathrm{r} 2 \ldots \mathrm{rn})$ for each. For example; if the expert thinks A is more likely than B and B is more likely than C. While at the same time, the same expert considers $\mathrm{C}$ to be more likely than $\mathrm{A}$, then the responses are considered "inconsistent." Therefore, each orientation is expected to have slightly different relative values assigned to each decision variable.

Inconsistency has a particular formula, and it can be determined as follows:

Let: $\mathrm{r}_{\mathrm{ij}}=$ relative value of the $\mathrm{i}^{\text {th }}$ element in the $\mathrm{j}^{\text {th }}$ orientation for an expert 
$\bar{r}_{i}=$ mean relative value of the ith element for that expert

$$
\bar{r}_{i}=\left(\frac{1}{n !}\right) \sum_{j=1}^{n !} r_{i j}
$$

The inconsistency of the $i^{\text {th }}$ element is:

$$
\text { Inconsistency }=\sqrt{\frac{1}{n !} \sum_{j=1}^{n !}\left(\bar{r}_{i}-r_{i j}\right)^{2}}
$$

For: $\quad \mathrm{i}=1,2, \ldots, \mathrm{n}$

$$
\mathrm{n}=\text { number of elements compared }
$$

$$
\text { Inconsistency }=\frac{1}{n} \sum_{i=1}^{n} \sqrt{\frac{1}{n !} \sum_{j=1}^{n !}\left(\bar{r}_{i}-r_{i j}\right)^{2}}
$$

A new calculation of inconsistency that has been recently developed by Abbas [234] using the sum of the root of variances instead of the standard deviations:

$\sigma_{i}^{2}=$ variance of the mean of the $\mathrm{i}^{\text {th }}$ decision element

$$
S V=\sqrt{\sum_{i=1}^{n} \sigma_{i}^{2}}
$$




\subsubsection{Disagreements and F-test with Hypotheses Testing}

In general, the disagreement is a result of the differences in knowledge or interest among experts. It comes from the differences in their subjective evaluations of the decision problems [227]. On the other hand, Estep [235] highlights in her dissertation the disagreement level, if the disagreement exceeds a value of 0.10 , the value of zero would imply complete agreement among the experts.

The interpretation of experts disagreement depends mostly upon the decision-making circumstance [229]. Analyzing and resolving disagreements among the experts is very import to achieve the decision-making objective. When the disagreement shows high, the weighting process should be re-examined. Therefore, to analyze the level of disagreements, two statistical methods can test disagreement between experts, The interclass correlation coefficient (ICC) and F-test with hypotheses testing [191][227] [184][236];-

\subsubsection{The Interclass Correlation Coefficient (ICC)}

- It is calculated to measure the degree to which $k$ experts are in agreement with one another on the ratings of $n$ subjects/criteria.

- The coefficient ICC may achieve the maximum of 1 when all experts assign the same mean values to the subjects that mean absolute agreement, or

- The value of $I C C$ is close to zero in case of a substantial difference between the mean judgment values among all experts. 
- If $I C C$ has a negative value, the negative correlation is generally considered as zero. It has been accepted that a $I C C>0.7$ indicates a strong agreement among the experts.

The ICC formulas illustrated below:

Terminology

ICC: Interclass correlation coefficient

MSBJ: $\quad$ Mean square between judges

SSBJ: $\quad$ Sum of square between judges

dfBJ: $\quad$ Degree of freedom between judges

MSBS: $\quad$ Mean square between judges

SSBS: $\quad$ Sum of square between judges

dfBS: $\quad$ Degree of freedom between judges

dfres: $\quad$ Degree of freedom residual

Si: $\quad$ Relative values of expert $\mathrm{i}$

$\mathrm{Xj}: \quad$ Relative values for subject $\mathrm{j}$

XT: Total of relative values for subject $\mathrm{j}$

$\mathrm{k}: \quad$ Number of judges

n: $\quad$ Number of subjects

SST: Total of sum of square between judges

MSR: $\quad$ Mean square residual

SSR: $\quad$ Sum of square residual 
Where:

$$
\begin{gathered}
I C C=\frac{M S B S-M S R}{M S B S+(k-1)+\frac{k(M S B)-M S R}{n}} \\
\mathrm{MSBJ}=\frac{S S B J}{d f_{B J}} \\
S S B J=\sum_{j=1}^{k}\left[\frac{\left(\sum X_{j}\right)^{2}}{n}\right]-\frac{\left(\sum X_{T}\right)^{2}}{n k} \\
\mathrm{MSBS}=\frac{S S B S}{d f_{B S}} \quad \\
S S B S=\sum_{i=1}^{n}\left[\frac{\left(\sum S_{i}\right)^{2}}{k}\right]-\frac{\left(\sum X_{T}\right)^{2}}{n k} \\
\mathrm{Df}_{B S}=\mathrm{n}-1
\end{gathered}
$$

$$
\mathrm{M} S R=\frac{S S R}{d f_{\text {res }}}
$$

$S S R=S S T-S S B J-S S B S$

$$
d f_{r e s}=\sum X_{T}^{2}-\frac{\left(\sum X_{T}\right)^{2}}{n k}
$$




\subsubsection{F-test with Hypotheses Testing}

The Cambridge Dictionary of Statistics, Fourth Edition, defines the F-test as a test for the equivalence of the variances between two experts or people having normal distributions. It is the ratio of the variances of a sample of observations taken from each [229]. The F-test uses the null hypothesis, which indicates to no association or significant disagreement among experts [227]. Estep [227] mentioned that the software offers all Fcalculation processes.

Terminology: $H O: \quad \mathrm{ICC}=0$

H1: It is not $\mathrm{HO}$

Where:

$$
F=\frac{M S B S}{M S R}
$$

- Based on the result of the pairwise comparison, F-value against F-critical value comparison, the null hypothesis can be accepted or rejected [229].

- H0 should be rejected when the F-value is greater than the F-critical value, which indicates to no statistically significant disagreement among the experts [237]. 


\subsection{Sensitivity Analysis}

Iskin [238] describes in his dissertation the importance of sensitivity analysis related to alternatives selection. He explains the usefulness of analysis where there is only one decision alternative that needs to be selected among others due to resource limitations. In this case, decision-makers want to explore those situations that could potentially alter the optimum solution.

Saaty [239] investigated the effect of uncertainty in judgment on the stability of the rank order of alternatives by using AHP. Then, Chen and Kocaoglu [191] developed the sensitivity analysis algorithm to study any changes in the HDM under different situations.

Several researchers [240][241][227][229][184][231][242][229] have utilized the sensitivity analysis method to analyze and measure the impacts of potential changes in the values at any level of the HDM.

The sensitivity analysis method has mathematical processes, which were developed based on a series of mathematical assumptions. The method is considered as an accurate and comprehensive method that is used to examine the impact of changes in different levels of HDM on the ranking of the alternatives [242].

The sensitivity analysis process has been demonstrated that when one contribution value changes, the other related ones will be changed. This change will be based on the original model ratio scale relationships [239]. 
The Sensitivity Analysis formulas illustrated below:

Let:

$A i$ : Alternatives and $M$ : Mission

$\operatorname{Cont}_{i}^{C-M}:$ Local contribution of the $\mathrm{L}^{\text {th }}$ criterion to the mission

Cont $k_{k l}^{S-C}:$ Local contribution of the $\mathrm{k}^{\text {th }}$ sub-criterion to the $\mathrm{L}^{\text {th }}$ criterion

Cont $_{i}^{A-M}:$ Overall contribution of $\mathrm{i}^{\text {th }}$ alternative to the mission

$\operatorname{Cont}_{i k}^{A-S} \quad:$ Local contribution of $\mathrm{i}^{\text {th }}$ alternative to the $\mathrm{K}^{\text {th }}$ sub-criterion

Cont $t_{i l}^{A-C}:$ Global contribution of $\mathrm{i}^{\text {th }}$ alternative to the $\mathrm{L}^{\text {th }}$ criteria

The analysis of perturbations introduced at the objective level, let $P_{l *}^{o}$ represent the perturbations imposed on one of the criterions $C_{i}^{C}$,

$$
-\operatorname{Cont}_{l *}^{C} \leq P_{l *}^{C} \leq 1-\operatorname{Cont}_{l *}^{C}
$$

Kocaoglu [243] emphasized that the original ranking of $A r$ and $A r+n$ will not change if,

$$
\lambda \geq P_{i}^{C} \cdot \lambda^{C}
$$

Where:

$$
\lambda=C_{r}^{A}-C_{r+n}^{A}
$$




$$
\begin{gathered}
\lambda^{C}=\operatorname{Cont}_{r+n, l *}^{A-C}-\operatorname{Cont}_{r l *}^{A}-\sum_{l=1, l \neq l *}^{L} \operatorname{Cont}_{r+n, l *}^{A-C} \cdot \frac{\operatorname{Cont}_{l}^{C}}{\sum_{l=1, l \neq l *}^{L} \operatorname{Cont}_{l}^{C}} \\
+\sum_{l=1, l \neq l *}^{L} \frac{\operatorname{Cont}_{r l}^{A-C}}{\sum_{l=1, l \neq l *}^{L} \operatorname{Cont}_{l}^{C}}
\end{gathered}
$$




\subsection{Expert Panel Design}

An expert panel is composed of experts from several segments of the transportation industry including some project managers from other sectors. However, identifying experts and forming panels is challenging. Selecting and forming the right expert panels are critical regarding the accuracy of the final result [244]. However, [245] justified that a significant contribution to the accuracy of the results should be limited to maximum of twelve experts per panel. While [246] pointed to literature that the Delphi group size depends on group dynamics for arriving at agreement among experts. The author refers to the actual size that is recommended in the previous studies, which is ten to eighteen experts per panel.

[247] [248] explained how to select expertise based on bias reduction. Between six and twelve experts are required per group of experts. Experts should be selected carefully when putting the domain in groups [224]. For choosing the best alternative, the experts will be asked to discuss, identify, weight, and validate the model perspectives and sub-criteria.

\subsubsection{Experts Panel Forming and Administration}

The data obtained from experts should be representative of their clear feedback. Therefore, to form a group of experts, qualified experts, create experts' database, group expert into panels were identified, and experts to the required panels were invited. In the next step, a particular process was considered to get reliable results such as using a proper tool or instrument for collecting the data from experts, processing a quantitative validation 
of the model resulting from the input of expert panels, and ensuring the secure and anonymous of the communication between expert panels.[248].

Experts and other professionals are usually busy. Therefore, prior planning is needed to ensure they have the availability for interviewing at appropriate times [249]. Also, some experts may be willing to discuss their ideas before submitting their opinions.

\subsubsection{Criteria for the Expert Selection}

The selection of experts is critical to ensure the identification of relevant and qualified experts. In general, experts should be chosen according to the following criteria:

- Expertise, knowledge, and experience [191][249]

- Availability and willingness to serve [191] [249]

- Technical credibility and independence [249]

- Skills working in committees and advisory panels [191]

- Absence of bias [241] 


\subsubsection{Expert Selection Procedures}

The expert selection procedures should be used to select specific individual experts. Complex decision-making problems need strong expert panels when quantitative data are not available [240][250]. Figure 12 shows how experts are selected to validate the decision model content and construct; the process is adapted and developed from Chitu (2004) [250].

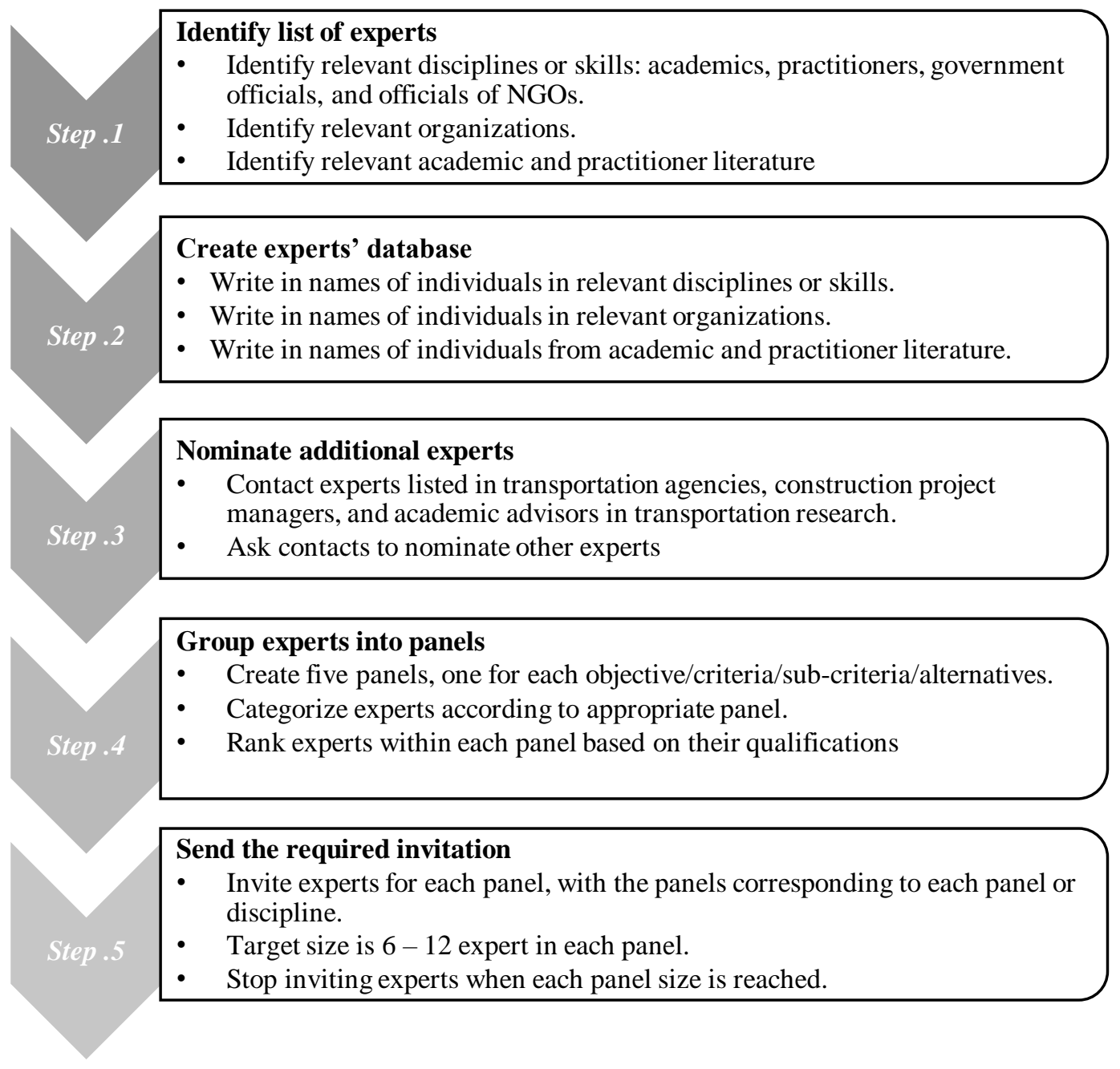

Figure 12: Selection Experts Procedures- Adapted From [251] 

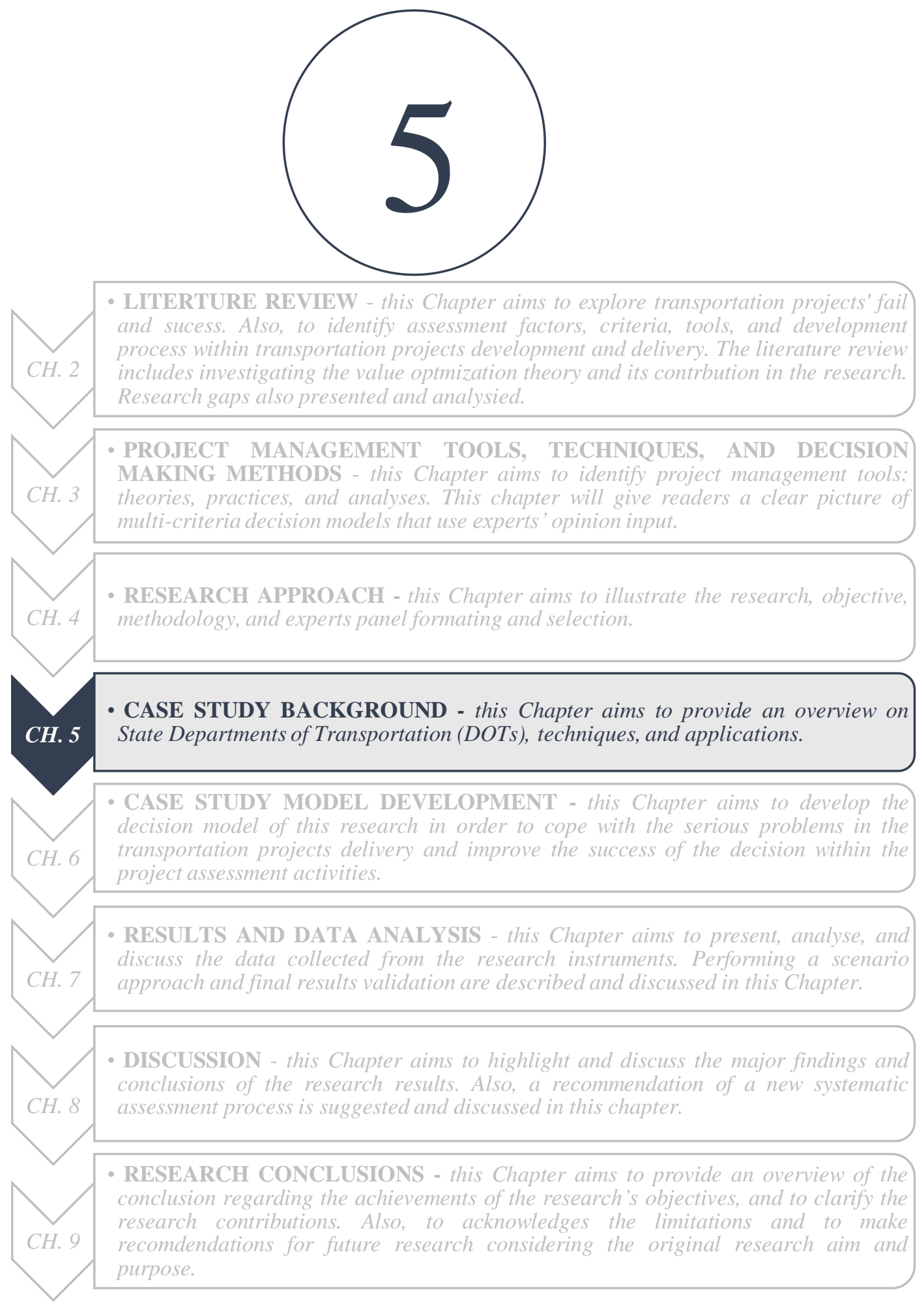


\section{CHAPTER FIVE: CASE STUDY BACKGROUND}

\subsection{Overview}

Research has been conducted on the performance of project delivery methods in transportation, and has proved that there is a lack of comprehensive comparative approaches combined with adequate orientation into the future to provide a sufficient basis for strategic decisions [252]. Therefore, the TRB, NRC, FHWA, AASHTO, and the individual states participating in the NCHRP have started to partner and cooperate with universities and private consulting companies to develop innovative techniques, tools, applications, or processes that reflect their own projects' circumstances and requirements. Some of the studies focus on the performance of specific assessment tools in projects development. Others researched on the features of these assessment tools to what level they are integrated with and support each other; the effectiveness of these programs; and the evaluation of current methods of measuring the success of outcomes (i.e., cost savings, performance benefits, risk reduction, accelerated delivery, etc.).

\subsection{Project Assessment Techniques - What / Why is it Important?}

DOT decision makers are always examining their assessment tools, practices, programs, process, and techniques for improvement and opportunities to be part of the 
overall public service plan [253]. In terms of the integration between tools such as VE, RA, or CR, NCHRP Synthesis 455 emphasizes that combination can be achieved in different ways [252]. To support the previous statement, [253][72] refer to the need to integrate these assessment tools with Risk Analysis (RA) and Risk Management (RM) process frameworks, and to apply them during the project development phases.

Several combinations of project tools or methods can be applied for the same project [254]. The NCHRP and DOTs are actively researching to improve the project delivery process and outcome. These improvements include integrating innovative assessment tools and techniques during the planning, design, or execution phase. However, there is still a lack of how these tools are interrelated, and to what extent they are integrated and support each other. The NCHRP 19-11 survey indicated that there is a clear variation in terms of how different U.S. State Departments of Transportation (DOTs) use project innovative assessment tools. The survey results were analyzed based on the response of 64 DOTs project delivery experts. The respondents were asked about the performance time of each tool during the project phases.

As shown in Figure 13, the majority of respondents (60\%) indicated that they perform VE studies during preliminary design. Nearly half $(45 \%)$ said that VE studies are conducted during final engineering, and about one quarter (28\%) said that VE studies are implemented during project planning and/or during engineering and analysis activities.

In the Risk Analysis survey, all respondents indicated that risk analysis is conducted during the preliminary design. The usage declines the further along in project delivery the 
agencies are. In this case, $75 \%$ of respondents use risk analysis in the planning stage, $67 \%$ use risk analysis during the final design, and $42 \%$ use risk analysis during construction.

The Constructability Review survey shows that $93 \%$ of respondents indicated that most constructability reviews are conducted on the final design, while $7 \%$ of respondents indicated that the constructability review is conducted during the planning stage, and the other $7 \%$ during the construction phase. The other $53 \%$ of respondents indicated that the constructability review is conducted during environment studies or the preliminary design [104].

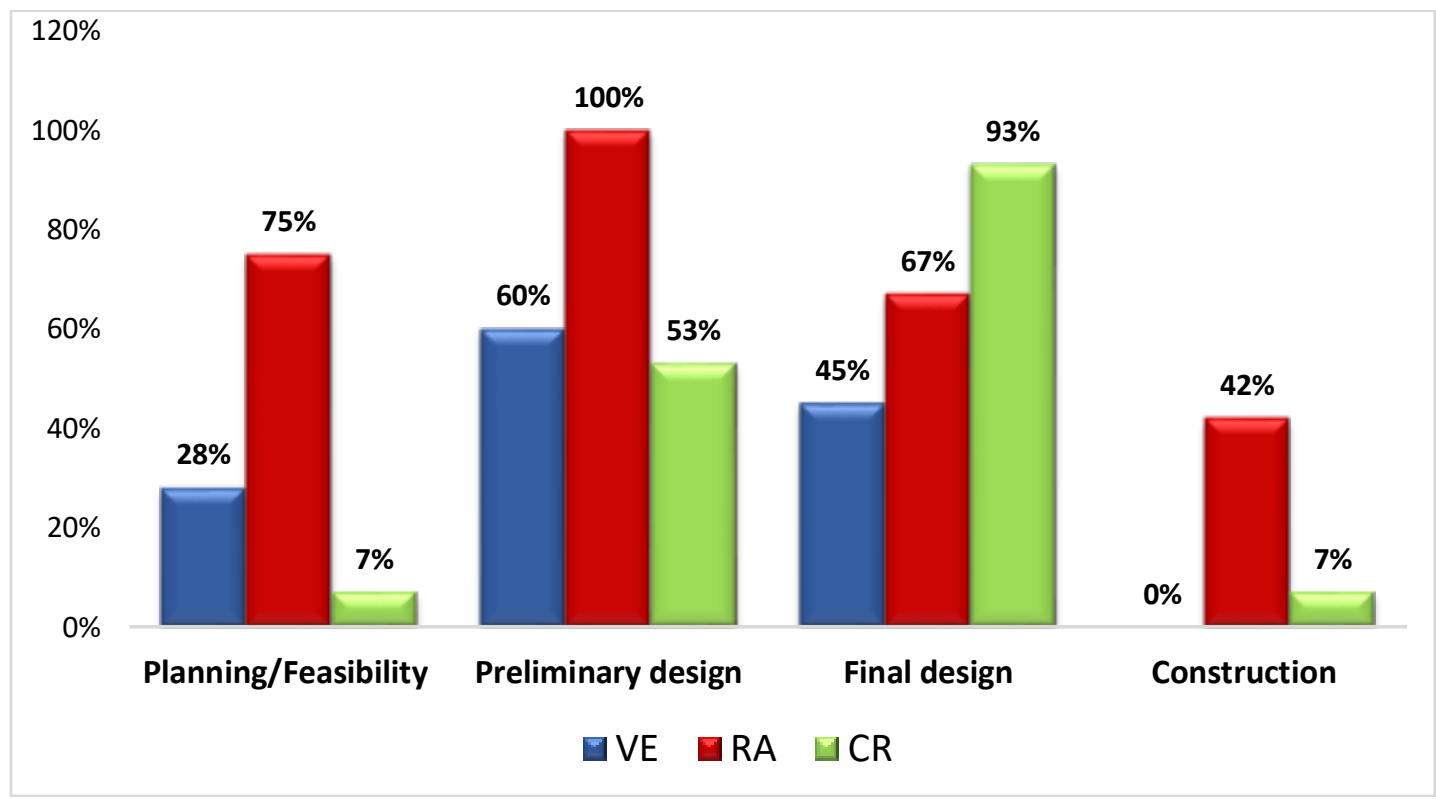

Figure 13: Timing of Conducting each Assessment Tool in Project Phases 
Also, the survey covered the features of project assessment tools, and to what level they are integrated with and support each other during project delivery. As shown in Table 6, $8 \%$ of respondents indicated that risk analysis was always performed in conjunction with VE. Another $42 \%$ of respondents stated that the Risk Analysis is sometimes performed with VE or that it is determined on a case-by-case basis. $27 \%$ of respondents stated that VE is performed with the Constructability Reviews, and the other $47 \%$ indicated that it is determined on a case-by-case [104].

Table 6: Integration of VE, RA and CR Tools [254]

\begin{tabular}{|c|c|c|c|c|}
\hline Tools & Always & Sometimes & Never & $\begin{array}{c}\text { Case-by-case } \\
\text { basis }\end{array}$ \\
\hline VE-RA & $8 \%$ & $42 \%$ & $8 \%$ & $42 \%$ \\
\hline VE-CR & $0 \%$ & $27 \%$ & $27 \%$ & $47 \%$ \\
\hline
\end{tabular}

\subsection{Innovative Project Assessment Tools Selection for the DOTs}

This research aimed to evaluate the effectiveness of five alternatives that are performed by several State Departments of Transportation and agencies for assessing their project delivery performance. The most effective alternative innovative project assessment techniques will be recommended to the DOT decision makers in order to optimize their projects' value and outcomes. 


\subsection{Tools Integration}

According to the research gap that is addressed by the literature review, there is still a lack of research about how project assessment tools are interrelated; to what extent they have improved the value of transportation projects delivery, and how they are integrated to support each other [85]. To reduce the project delay, the integration of assessment tools is required. The integrated tools should be conducted concurrently rather than through a one by one process [255].

A research question has been developed in this research with the purpose of addressing this gap. The answer to this question is presented in the discussion's chapter.

Table 7 illustrates some of the integration techniques that are currently used by DOTs to assess and improve the project delivery value and outcomes during the project life cycle. These techniques are used in the developed decision model as alternatives.

Table 7: Transportation Project Assessment Practices

\begin{tabular}{|c|l|}
\hline Technique & \multicolumn{1}{|c|}{ Description } \\
\hline $\begin{array}{c}\text { Value engineering combined } \\
\text { with risk assessment } \\
\text { (VE-RA) }\end{array}$ & $\begin{array}{l}\text { VE-RA is an interfacing risk assessment tool with a value } \\
\text { identified and mitigated by value analysis workshop team. This } \\
\text { engineering tool to improve the project value [256]. The combined } \\
\text { qualitative and quantitative risk analysis into a value analysis job } \\
\text { plan [255]. The advantage of this integration is that only a single } \\
\text { aspect of the project information will be needed for the value team } \\
\text { to address risk issues in value assessment study. Also, one single } \\
\text { team will be required to carry out the study on value and risk } \\
\text { assessment [257]. }\end{array}$ \\
\hline
\end{tabular}




\begin{tabular}{|c|c|}
\hline $\begin{array}{c}\text { Value engineering combined } \\
\text { with constructability review } \\
\text { (VE-CR) }\end{array}$ & $\begin{array}{c}\text { VE-CR is a combination between constructability review } \\
\text { activities and the value engineering job plan. The combination } \\
\text { improves the project performance by increasing the quality and/or } \\
\text { quantity of interaction between experienced construction team and } \\
\text { value study experts into the planning and design stages [224]. }\end{array}$ \\
$\begin{array}{c}\text { Value engineering combined } \\
\text { with the decision analysis model } \\
\text { (VE-DAM) }\end{array}$ & $\begin{array}{c}\text { The VE-DAM is a combination of multi-criteria decision Model } \\
\text { and value engineering. It measures the project value by correlating } \\
\text { the performance of project scope and schedule to the project costs } \\
\text { [54][258]. The VE-DAM leads to an improved and shared an } \\
\text { understanding of one of the project's key important issues for the } \\
\text { project and the community [120]. The objective of this technique } \\
\text { is to optimize a project's scope, schedule, and cost. }\end{array}$ \\
\hline $\begin{array}{c}\text { Value engineering combined } \\
\text { with risk assessment, } \\
\begin{array}{c}\text { constructability review, and } \\
\text { decision analysis model } \\
\text { (VE-RA-CR-DAM) }\end{array}\end{array}$ & $\begin{array}{l}\text { VE-RA-CR-DAM is a combination of risk assessment, } \\
\text { engineering study within the construction project. This } \\
\text { combination is used for improving project outcomes [259]. The } \\
\text { advantage of combining or integrating these tools is [143]: To } \\
\text { eliminate redundancy in activities; to enhance the communication } \\
\text { and collaboration among project assessment activities; to use the } \\
\text { same project information pack by the project assessment team; and } \\
\text { to ensure all project risk issues are addressed successfully. }\end{array}$ \\
$\begin{array}{c}\text { Value engineering combined } \\
\text { with cost estimate validations } \\
\text { process and risk assessment } \\
\text { (VE-CEVP-RA) }\end{array}$ & $\begin{array}{l}\text { The combination of the cost estimate validations process, risk } \\
\text { assessment, and value engineering lead to the evaluation of the } \\
\text { quality and completeness, including risk uncertainty, of the } \\
\text { estimated cost and schedule [295]. The CEVP process is a } \\
\text { technique that allows the project team to quantify risks explicitly, } \\
\text { and to develop more strategic risk management plans for the } \\
\text { clearly identified risk events [27]. }\end{array}$ \\
\hline
\end{tabular}



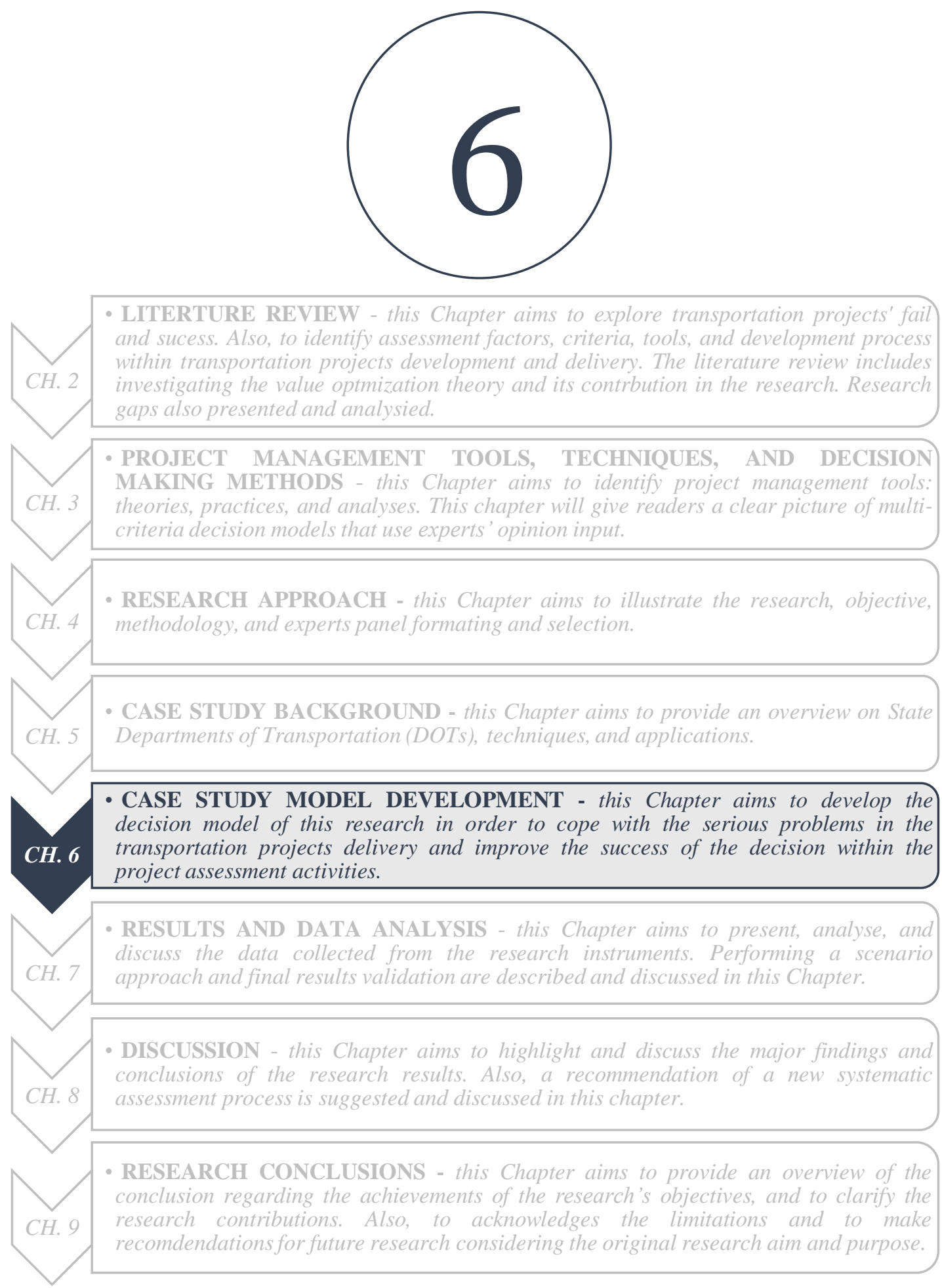


\section{CHAPTER SIX: CASE STUDY MODEL DEVELOPMENT}

\subsection{Piloting the Model Development}

As mentioned in Chapter 4, the Hierarchical Decision Model (HDM) technique is used as an evaluation model to identify the most effective assessment tools for optimizing the value and outcomes of the transportation infrastructure. HDM has the capability to divide the problem into smaller entities for making the decision more accurate. Also, the HDM has another advantage in that it can screen and select a large number of alternatives, criteria, and sub-criteria [185]. HDM helps to analyze the relationship between model mission, objectives, and alternatives in a hierarchical structure (Figure 14). Also, it uses a pairwise comparison process to convert experts' qualitative input into numerical values.

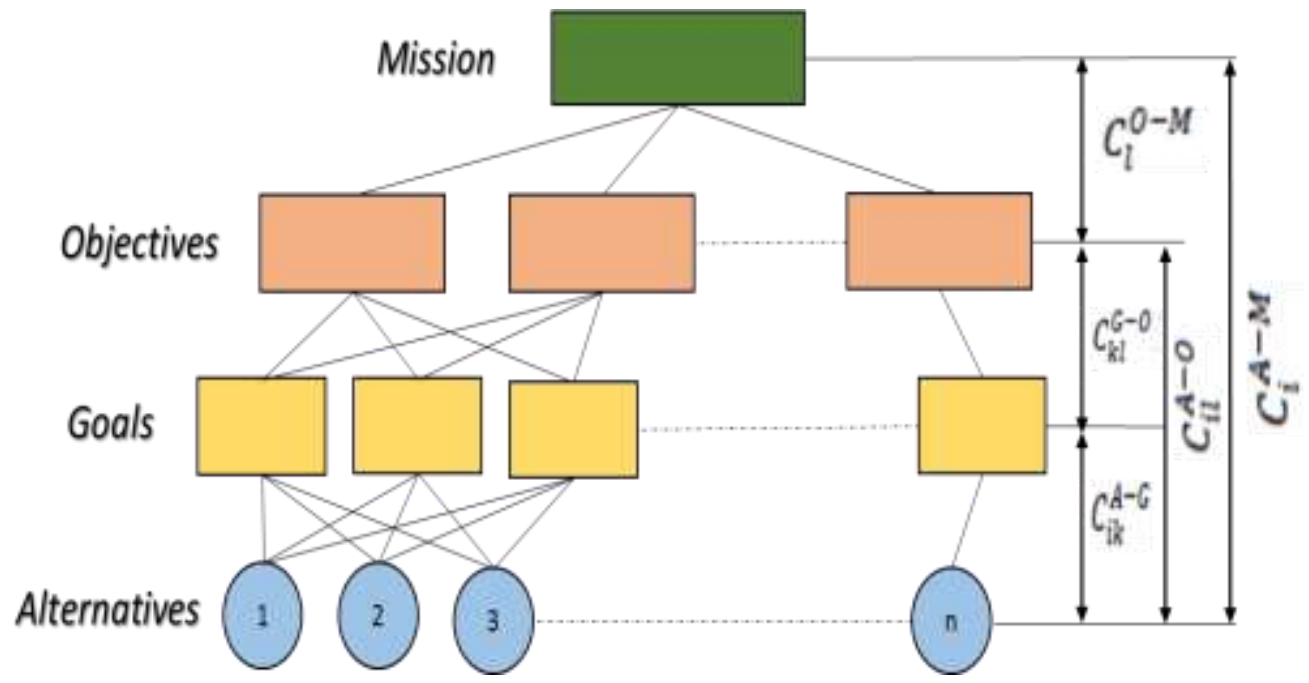

Figure 14: HDM Structure- Adapted From [225] 
In order to develop a unique model that considers the value optimization approach, this research focuses on what theory, methodology, or practices embedded in this approach. Also, it focuses on how project assessment techniques can be implemented in a particular industry, and how likely these techniques can be applied to transportation project delivery for enhancing the project performance within an acceptable cost and timeframe. This research maximizes the strength of the suggested comprehensive decision model by adding the element of resources to the original value optimization framework that is proposed in the Stewart book [249]. These five elements cost, time, risk, performance, and resources are included in the model assessment perspectives as Level 2. Experts in the field of transportation construction and project assessment were interviewed and asked to confirm the importance of using these elements for the proposed decision model. The Level 3, model sub-criteria are selected based on the literature review, and also from direct discussion with experts such as project managers, civil engineers, and value management consultants.

The pre-testing of the decision model needs to be carried out before being evaluated by the real experts. The objective of piloting the initial decision model is to detect possible shortcomings in the model structure. Bhattacherjee et al., (2017) indicates the importance of piloting to find out whether the proposed method or data collection will be able to achieve the research objectives [260].

In this research, the initial decision model and HDM process were tested by several of the DOT experts and Ph.D. students in technology management and civil engineering 
before approving the final model. In this step, volunteers who were named in this research as informal experts were asked to validate and quantify the initial model. Two web-based instruments of model contents were designed, and then tested by them for clarity and appropriateness. In order to find the best alternative, the informal experts were asked to discuss, identify, weigh, and validate the model's criteria and sub-criteria. The informal experts were comfortable using the HDM software. As shown in Figure 15, the initial decision model is formulated in this research to include the evaluation of the criteria and sub-criteria, to identify the high ranked alternatives based on the model objectives, and to focus on the requirements for the highway and bridge project development. It is constructed to represent a decision problem that needs to be solved in the model mission with respect to the criteria, sub-criteria, and alternatives.

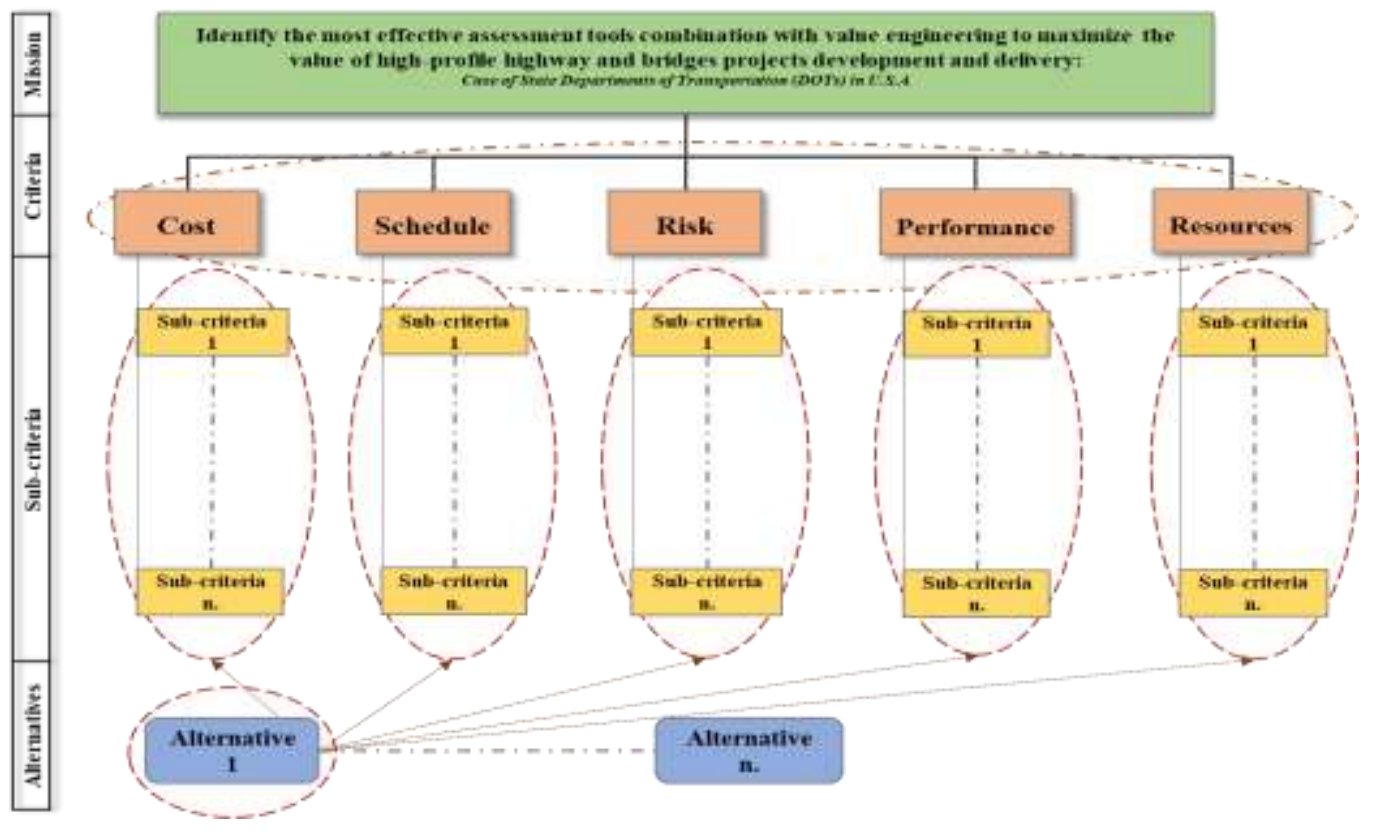

Figure 15: The Initial Decision Model for Evaluating Project Assessment Techniques 


\subsection{Validation Process}

A valid model can help make decisions based on real-world experience. The ease or difficulty of the validation process depends on the model structure. As shown below, the process is designed to be a simplification of reality. In this research, the process was started to validate the initial model based on informal expert panels. As shown in Figure 16, the validation process was divided between two research instruments (RI1 and RI2). In the initial validation process, two informal expert panels (Expert Panel, EP1 and EP2) were used to evaluate the model criteria and sub-criteria. In the final model, A1 and B1 real expert panels were targeted to revalidate the model criteria and sub-criteria (A1 for the criteria and B1 for the sub-criteria).

RI1 and RI2 were conducted using a web-based survey tool/Qualtrics. The initial model was sent to the informal EP1 for validation using research instrument one (RI1). The RI1 aimed to determine which criteria should and should not be included. The RI2 aimed to determined which, sub-criteria to include or not to include, and contributed to the model criteria in Level 2.

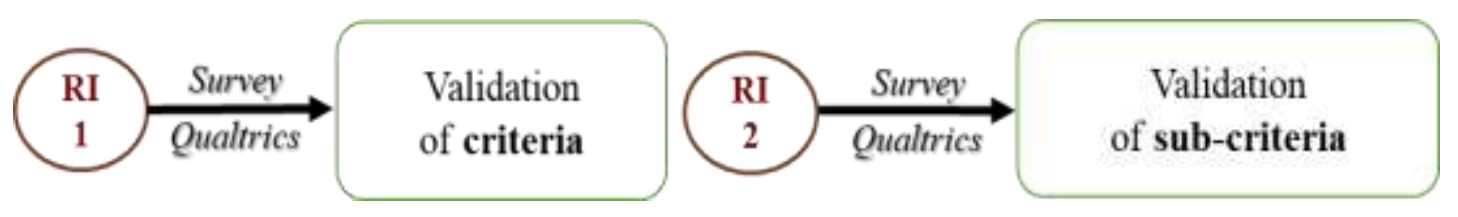

Figure 16: Research Instrument (RI1 and RI2) Process 
In the first round, nine out of twelve informal experts replied positively on the survey. They validated the model criteria (Level 2) as $100 \%$ acceptable. The parameter in the literature review is considered two-thirds as the acceptable limit for the experts' judgment. The second round targeted nine informal experts, 90\% replied "YES," and 10\% suggested to add or replace some sub-criteria (Level 3). EP2 contributed to the model criteria by selecting their options "YES" or "NO" based on their judgment.

To conclude,

- The informal Expert Panels (EP1 and EP2) were selected based on their qualification in engineering and project management.

- The validation process took several iterations.

- The validation process considered two-thirds of experts in agreement as the limit to include the criteria or sub-criteria in the initial model.

- All information regarding experts' invitation and research instruments templates are provided in Appendix A, B, and C. 


\subsection{Quantification Process}

After the model validation process had finished and was analyzed by RI1 and RI2, the initial decision model was finalized based on the two informal expert panels feedback (EP1 and EP2). Then, as shown in Figure 17, three research instruments (RI3, RI4, and RI5) for the model development were created, and were provided on the webpage using the developed HDM software. The decision model and its results will show its credibility if the experts accept its structure and contents [261]. To establish the credibility of the model, the experts should understand the model's objective and its contents. Also, the model process and reputation should be well known to them. By using pair-wise comparisons, the informal experts were asked to allocate a total of 100 points between each two criteria according to their relation to the model mission. Then, they were requested to quantify the sub-criteria according to the criteria, and in the last step, they quantified alternatives according to the sub-criteria.

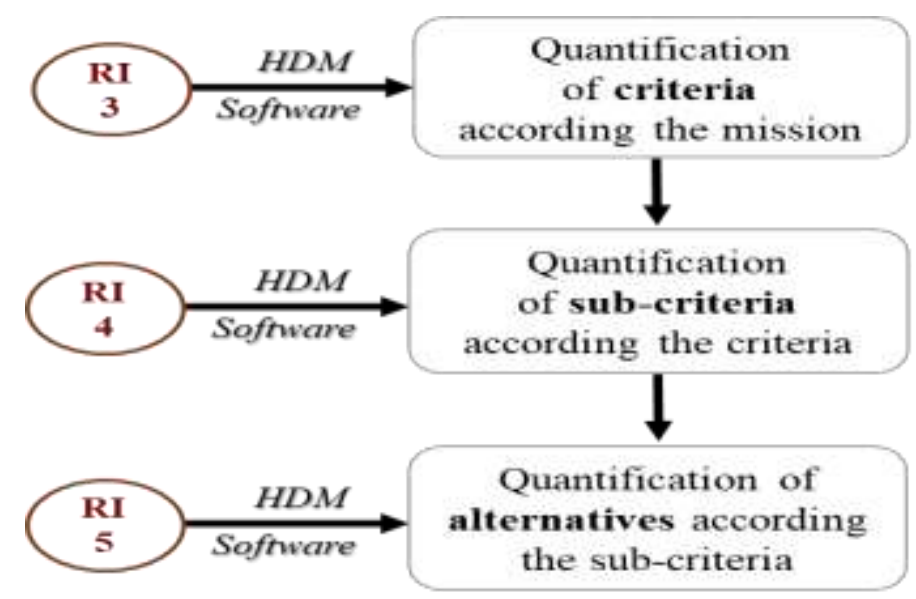

Figure 17: Quantification Process 
In the RI3-EP1, informal experts were asked to quantify the relative importance of each criterion regarding its contribution in evaluating the effectiveness of innovative assessment techniques in the transportation projects development as the decision model's mission, (see Figure 18). Based on their judgments, the relative priority of the model Level 2 (criteria) to the Level 1 (mission) and the inconsistency and disagreement level were obtained and considered in the final result analysis process to confirm the validity of the initial decision model.

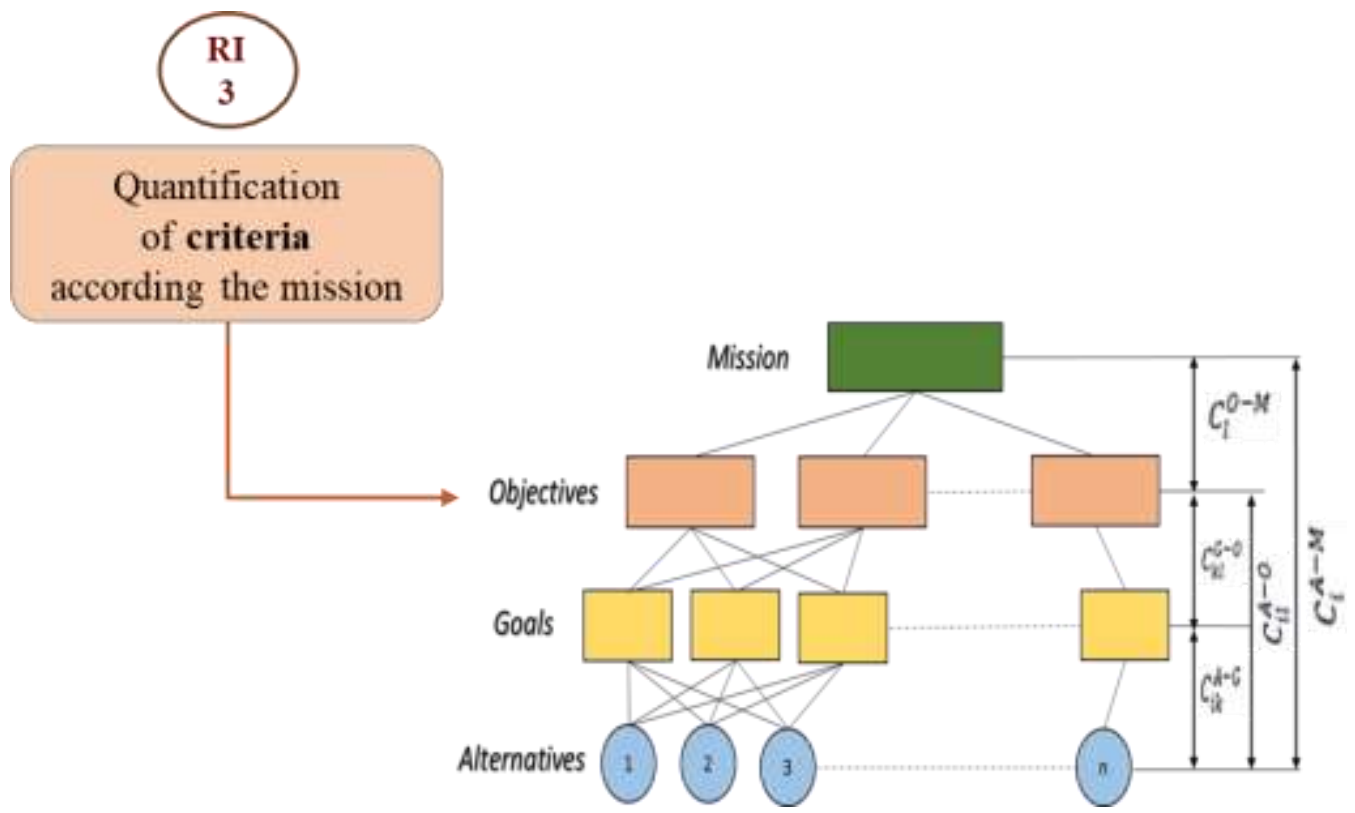

Figure 18: Research Instrument (RI3) Process

As shown in Figure 19, the RI4 was used to evaluate the model sub-criteria with respect to the criteria. At this stage, an email was sent to all volunteers thanking them for their support in validating and quantifying the previous instruments (RI1, RI2, and RI3). EP2 
used RI4 to base their judgments. The arithmetic mean was used to represent the relative ranking of the sub-criteria in the Level 3 of the model.

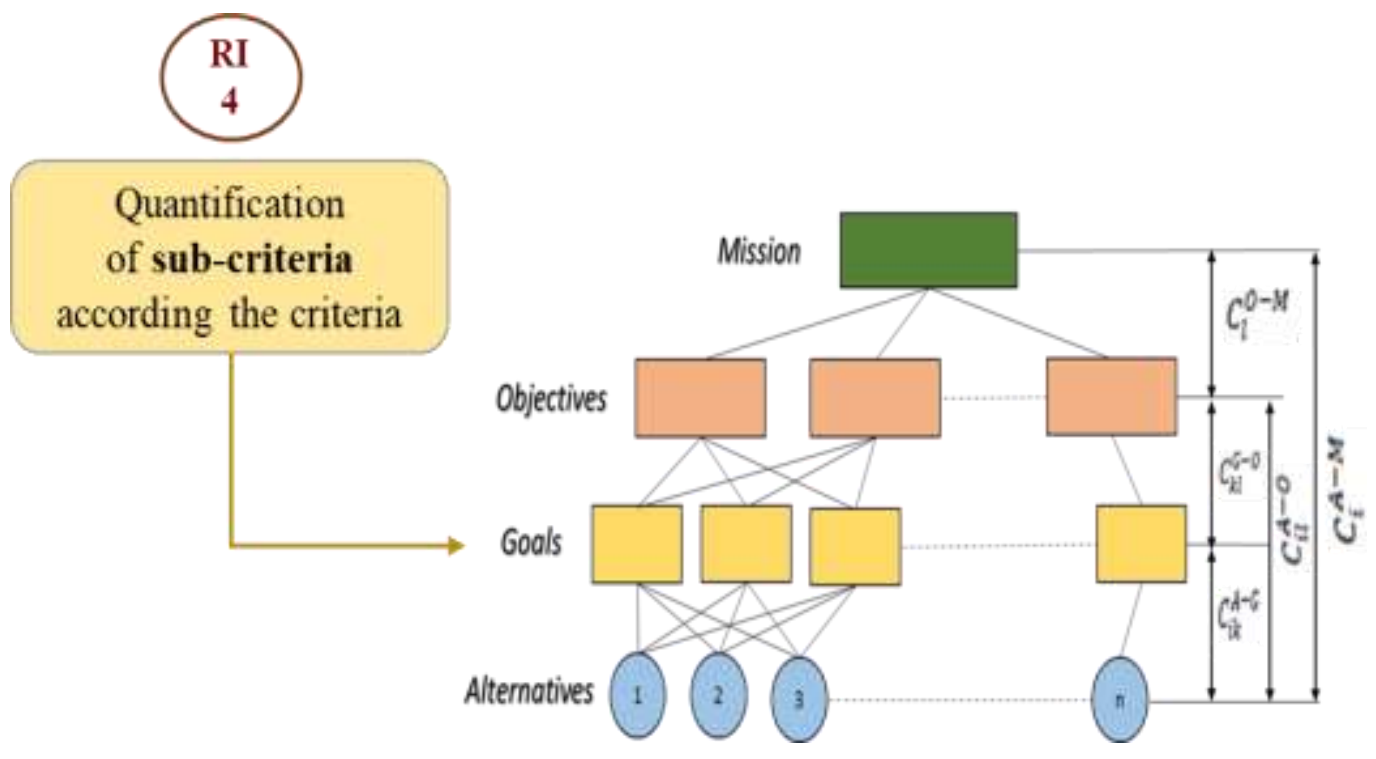

Figure 19: Research Instrument (RI4) Process

RI5 was the last step of the model quantification process (Figure 20). This instrument was used to evaluate the relative priorities of alternatives with respect to the sub-criteria. Again, EP2 was used to fulfill RI5 after they received an email that explained why they were selected to complete the last round of the quantification process. Based on quantification of their judgements, the arithmetic mean of the relative priority of alternatives in the sub-criteria (Level 4 to Level 3), and the inconsistency and disagreement 
level for the experts were obtained and analyzed. The last result showed the relative ranking of the alternatives.

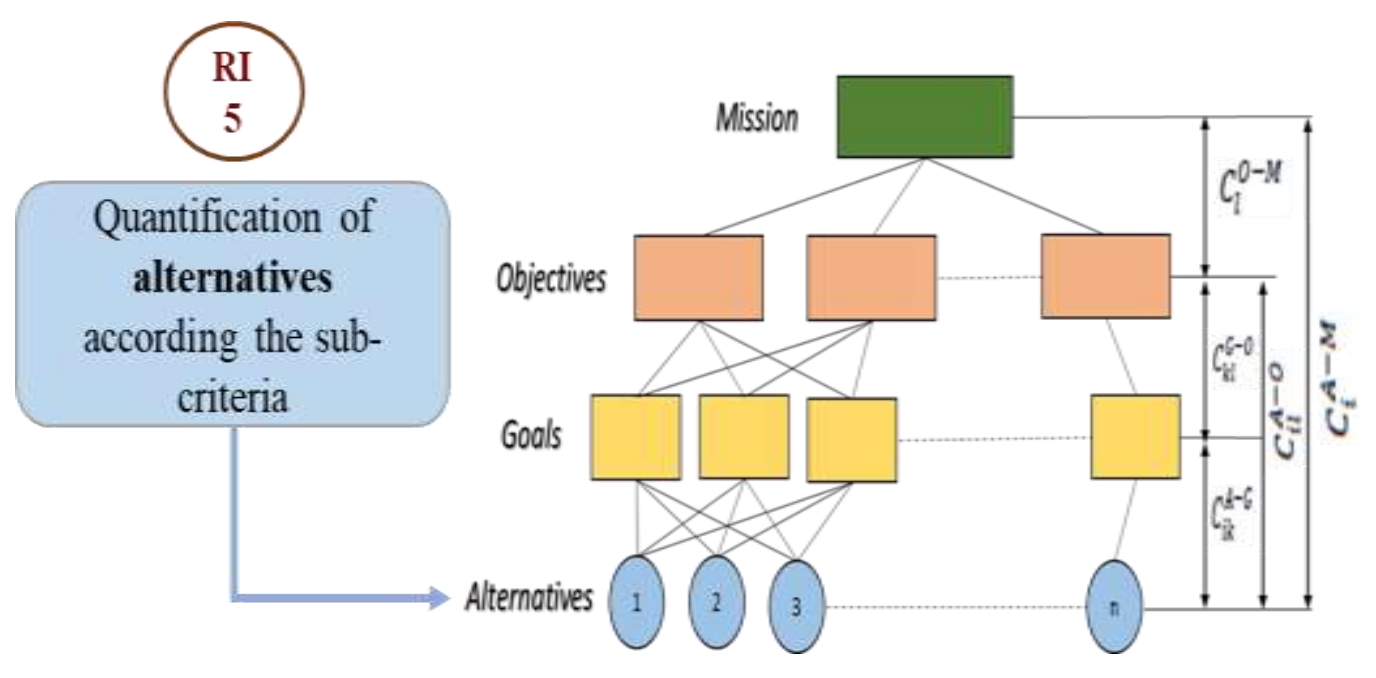

Figure 20: Research Instrument (RI5) Process

In the end, nine informal experts provided background information and valuable comments about the criteria and sub-criteria. They were allowed to add or replace any criteria or sub-criteria as they deemed appropriate. The initial model structure included criteria, sub-criteria, and alternatives. Their definitions were attached to the requested emails for the initial validation and quantification process during the first and second round. Then, the final structure of the decision model development was presented to the informal experts to get their final opinion before submitting the model to the real experts for finalizing and implementing the process (see Figure 21). 


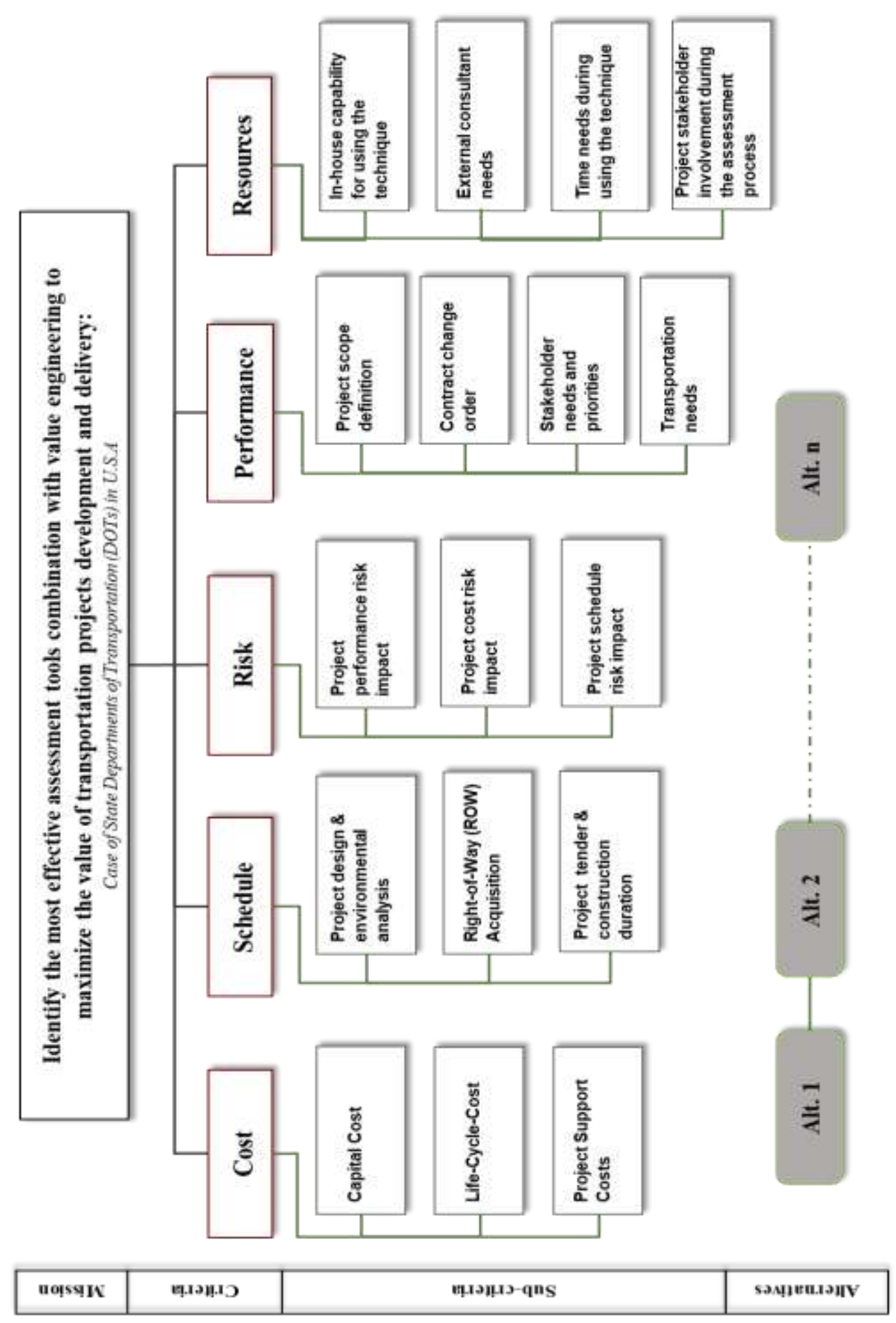

Figure 21: Decision Model Development 


\subsection{Finalizing the Model Development and Implementation}

As mentioned above, the reason for selecting the HDM in this research was because this decision model process is similar to other multi-criteria decision tools such as the AHP technique. Its steps include structuring the decision problem into levels, followed by a pairwise comparison among all variables, calculating the priorities of the objectives, and checking the consistency. The DOT experts were familiar with the AHP process. Chan [262] classifies the validation process in his dissertation into three major aspects: construct, content, and criterion-related validity. He also highlights the purpose of the model validation as the method to enhance the credibility of the research. Estep [227] emphasizes in her dissertation the importance of using a specific tool that incorporates qualitative and quantitative experts' feedback through the use of pairwise comparisons. She also refers to Kenny Phan's statement in his dissertation regarding the experts' comfortability and their decision making.

The previous process of the model validation and quantification that had been performed by the informal experts to develop a decision model was repeated on the real experts mainly from the transportation sector using the tested process in Figure 22. 


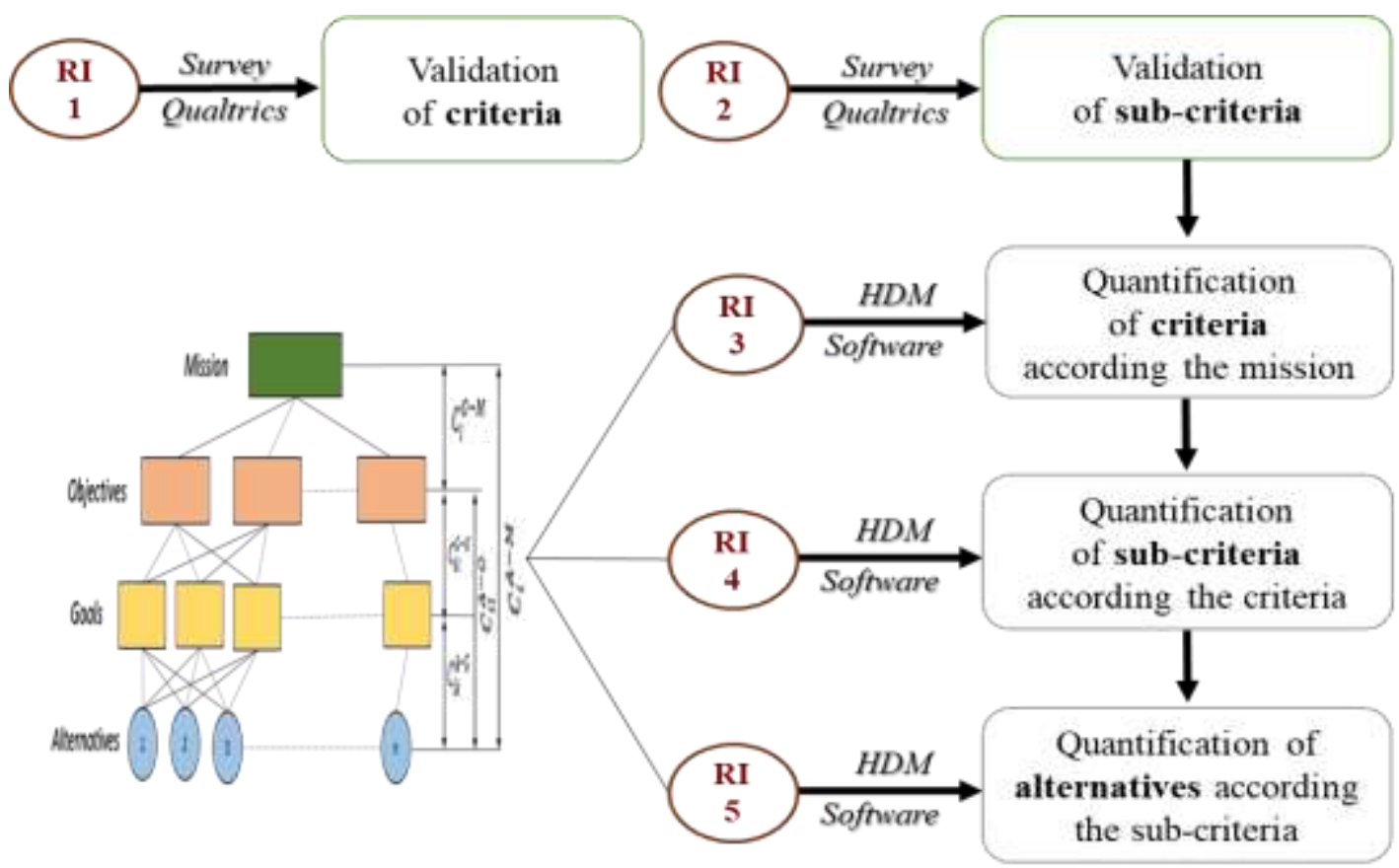

Figure 22: The Final Validation and Quantification Process

\subsubsection{Mission}

Innovative assessment tools, techniques, and practices were used by the project team to evaluate the project performance in terms of the relevant measures of effectiveness such as cost, time, risk, performance...etc. This level of the decision model describes the mission for the research. The mission is to identify the most effective assessment tools in combination with value engineering to maximize the value of transportation projects development and delivery. To achieve the research mission, a case study of DOTs is applied, and focused on high profile bridge and highway public projects in the transportation sector. 


\subsubsection{Level 2: Assessment Criteria}

- Achieve Project Cost Efficiency (Cost Criterion): This variable measures the importance of combined assessment tools with value engineering to achieve project cost efficiency. Cost includes all project expenditure (i.e. capital cost, life-cyclecost, and project support costs) [263][3][264][265][266].

- Accelerate Project Schedule (Schedule Criterion): This variable measures the importance of combined assessment tools with value engineering to accelerate the project delivery time. Schedule presents a project delivery time or schedule [267][268][269][270][271].

- Identify Project Risk (Risk Criterion): This variable measures the importance of combined assessment tools with value engineering to identify the project risk. Risk presents the impact that uncertainty can have on the project performance, cost, and time [272] [34][273][274][275].

- Enhance Project Performance (Performance Criterion): This variable measures the importance of combined assessment tools with value engineering to improve the project performance and outcomes. Performance represents the potential outcomes that lead to improving the project value, and achieving the needed functions such as traffic operations, safety, reliability, and environmental impacts [276][277][278][279][280]. 
- Resources Availability (Resources Criterion): Resources represent the different resources that are required to perform and support the project, as well as assessment activities for the completion of a project [224][281].

\subsubsection{Level 3: Assessment Sub-criteria}

- Cost:

- Reducing Capital Cost: This variable measures the importance of reducing the project capital cost that covers project land acquisition, the design process, the right-of-way, and construction [282].

- Offering Life-Cycle-Cost Reduction: This variable measures the importance of maintaining low project LCC. The Project LLC cost including the capital, maintenance, operations, replacement and/or rehabilitation costs [283].

- Minimizing Project Support Costs: This variable measures the importance of identifying or maintaining low future support costs that cover staff/consultants needed to deliver the project [284].

- Schedule:

- Accelerating Project Design \& Environmental Analysis: This variable measures the importance of developing and analyzing the project design options, and scheduling alternatives to identify opportunities for accelerating a project's completion [285]. 
- Accelerating Right-of-Way (ROW) Acquisition: This variable measures the importance of accelerating the timeframe needed for right-of-way or another land acquisition during the development of the project design, which includes acquisition needs in the complete design documents [286].

- Accelerating Project Tender \& Construction Duration: This variable measures the importance of accelerating the tendering and construction time by introducing new options and solutions to mitigate the period of tendering process and the on-site time required for construction activities [259].

- Accelerating Project Closeout Activities Duration: This variable measures the importance of accelerating project closeout activities time. These are the time/activities needed after construction is complete to close out the project (funding, settling claims, etc.) [287].

- Risk:

- Identifying Project Performance Risk Impact: This variable measures the importance of identifying the performance risks that are related to the project construction. Risks that could affect the long-term quality or performance of the project as it relates to its functions [122].

- Identifying Project Cost Risk Impact: This variable measures the importance of identifying the cost risk that is represented in the project construction and rightof-way costs, not in support costs [90]. 
- Identifying Project Support Costs Risk Impact: This variable measures the importance of identifying the support costs risk that cover staff/consultants needed to deliver the project [283][54].

○ Identifying Project Schedule Risk Impact: This variable measures the importance of identifying schedule risks that could potentially impact project delivery time and schedule [178].

- Performance:

○ Refining the Project Scope: This variable measures the importance of defining the project scope, goals, and metrics that are consistent with the plans and policies of the state and local community [90].

- Improving Project Needed Functions: This variable measures the importance of enhancing traffic operations, safety, constructability, and project reliability. It includes minimizing Right-Of-Way (ROW) and environmental impacts [288].

○ Offering Communication and Integration Capabilities: This variable measures the importance of enhancing communications and sharing data between assessment activities. Also, it includes providing integration capabilities with other project tools, process, methods, or techniques [289].

○ Determining Stakeholder Needs: This variable measures the importance of determining and quantifying the relative value of the performance of different 
perspectives on community interests, needs, and expectations for the project services that include identifying specific transportation needs [290] [291].

- Resources:

○ In-house Capability: In-house capability refers to the project team or agency staff abilities to take responsibility for applying the assessment activities professionally [127].

- External Consultant Needs: Experience with the assessment activity requires experts with specialized skills not available in-house within DOTs or other public agencies [292].

- Time Needs during using the Technique: The duration that is required for executing the project assessment activity by the integrated tools [265][293].

- Project Stakeholder Involvement: The complete involvement or lack of participation by the project owner or stakeholder in the project assessment activity or support the assessment team [287][294]. 


\subsubsection{Level 4: Alternatives - Project Assessment Techniques}

- Risk Assessment combined with Value Engineering (VE-RA):

The VE-RA is a combination of a risk assessment tool with a value engineering tool to improve the project value [255]. The combined process of VE-RA is used to analyze the project risks that are identified and mitigated by the value analysis workshop team. This combination demonstrates a step-by-step process for integrating a qualitative and quantitative risk analysis into a value analysis job plan [256]. The advantage of this combination is that single project information will be needed for the value team to address risk issues in value assessment study. Also, one single team will be required to carry out the study on value and risk assessment [255].

- Constructability Review combined with Value Engineering (VE-CR):

The VE-CR is a combination of constructability review activities and a value engineering job plan. The combination improves the project performance by increasing the quality and/or quantity of interaction between an experienced construction team and value study experts into the planning and design stages [257]. Also, the VE-CR provides an effective interaction between project designers, engineers, and construction team from the early phase of the project. The VE-CR technique can significantly offer a project more 
cost-effectiveness keep it on schedule, and achieve better quality including the safety of project delivery process [295].

- $\quad$ A Decision Analysis Model combined with Value Engineering (VE-DAM):

The VE-DAM is a combination of a multi-criteria decision model and value engineering. It measures the project value by correlating the performance of the project scope and schedule to the project costs [54][258]. The VE-DAM technique leads to an improved and shared understanding of one of the project's key important issues for the project and the community [120]. The objective of this technique is to optimize a project's scope, schedule, and cost.

- Risk Assessment, Constructability Review, and Decision Analysis Model combined with Value Engineering (VE-RACRDAM):

The VE-RACRDM technique is a combination of risk assessment, constructability review, and a decision analysis model with value engineering. This technique is used for improving project outcomes [289]. The advantage of combining these tools is to eliminate redundancy in activities, to enhance the communication and collaboration among project assessment activities, to use the same project information pack by the project assessment team, and to ensure all project risk issues are addressed successfully [143]. 
- Cost Estimate Validations Process and Risk Assessment combined with Value Engineering (VE-CEVPRA):

The VE-CEVPRA technique allows the project team to quantify risks explicitly, and to develop more strategic risk management plans for the clearly identified risk events. The combination of the cost estimate validations process, risk assessment, and value engineering lead to the evaluation of the quality and completeness, including risk uncertainty, of the estimated cost and schedule [295]. Also, it offers the creation of an environment conducive to a critical evaluation of the project and its characteristics, as well as to identify new opportunities [69]. 


\subsection{Data Collection and Expert Panels Design}

A total of sixty-two experts from the transportation and construction industry including some experts from academia participated in the final validation and quantification process. Twenty-four experts were accepted and validated the model, while forty-eight experts submitted their judgments of the decision model. It should be noted that some experts repeated their names in more than one category because they perform multi-project assessment activities within their departments. A list of experts' contacts from state departments of transportation (DOTs) and other transportation agencies was collected to be the primary source for the experts' selection and contacts. The list was collected and used in the NCHRP 19-11research project and published paper activity [296]. Also, experts from different industries were also considered to be added to the list based on their qualifications and experience in the project management and project assessment activity. Other methods such as the snowball sampling technique, LinkedIn, and recommendations were used to identify and select the research expert panels.

As described in Chapter 4, a five-step procedure was used for the forming and administration of the experts' panel. As shown in Table 8, each group had six to twelve experts. It is critical to identify and select relevant and qualified experts. As recommended in previous research [191][297], experts should be chosen according to the following criteria:

- Expertise, knowledge, and experience, and 
- Availability and willingness to serve;

- Technical credibility and independence;

- Skills working in committees and advisory panels;

- Absence of bias.

Table 8: Category of Expert's Panels in this Research

\begin{tabular}{|c|c|c|c|c|}
\hline \multirow{2}{*}{$\begin{array}{l}\text { Panel } \\
\text { No. }\end{array}$} & \multicolumn{2}{|c|}{ Panel Focus } & \multirow[b]{2}{*}{ Field of Expertise } & \multirow{2}{*}{$\begin{array}{l}\text { Pane } \\
\text { size }\end{array}$} \\
\hline & Step .1 & Step .2 & & \\
\hline $\begin{array}{l}\text { Panel } \\
\text { (A1) }\end{array}$ & \multicolumn{2}{|l|}{ Criteria validation } & $\begin{array}{l}\text { Project Managers } \\
\text { Value Management } \\
\text { Consultant }\end{array}$ & 8 \\
\hline $\begin{array}{l}\text { Panel } \\
(\mathrm{B} 1)\end{array}$ & \multicolumn{2}{|c|}{ Sub-criteria and alts. validation } & $\begin{array}{l}\text { Project Engineers } \\
\text { Tools Expertise } \\
\end{array}$ & 8 \\
\hline $\begin{array}{l}\text { Panel } \\
(1)\end{array}$ & \multicolumn{2}{|c|}{$\begin{array}{l}\text { Evaluate the relative importance of criteria with } \\
\text { respect to the mission }\end{array}$} & $\begin{array}{l}\text { Project Managers } \\
\text { Project Planners }\end{array}$ & 8 \\
\hline $\begin{array}{l}\text { Panel } \\
(2)\end{array}$ & $\begin{array}{l}\text { Evaluate relative } \\
\text { priorities for sub- } \\
\text { criteria with respect to } \\
\text { the cost criterion }\end{array}$ & $\begin{array}{l}\text { Evaluate relative } \\
\text { priorities for the decision } \\
\text { alternatives with respect } \\
\text { to the cost sub-criteria }\end{array}$ & $\begin{array}{l}\text { Project Finance } \\
\text { Specialists } \\
\text { Project Planners } \\
\text { Project Engineers }\end{array}$ & $6-12$ \\
\hline $\begin{array}{l}\text { Panel } \\
(3)\end{array}$ & $\begin{array}{l}\text { Evaluate relative } \\
\text { priorities for sub- } \\
\text { criteria with respect to } \\
\text { the schedule criterion }\end{array}$ & $\begin{array}{l}\text { Evaluate relative } \\
\text { priorities for the decision } \\
\text { alternatives with respect } \\
\text { to the schedule sub- } \\
\text { criteria }\end{array}$ & $\begin{array}{l}\text { Project Tracking } \\
\text { Specialists } \\
\text { Project Planners }\end{array}$ & $6-12$ \\
\hline $\begin{array}{l}\text { Panel } \\
(4)\end{array}$ & $\begin{array}{l}\text { Evaluate relative } \\
\text { priorities for sub- } \\
\text { criteria with respect to } \\
\text { the risk criterion }\end{array}$ & $\begin{array}{l}\text { Evaluate relative } \\
\text { priorities for the decision } \\
\text { alternatives with respect } \\
\text { to the risk sub-criteria }\end{array}$ & $\begin{array}{l}\text { Risk Management } \\
\text { Specialists } \\
\text { Constructability } \\
\text { Review Specialists }\end{array}$ & $6-12$ \\
\hline $\begin{array}{l}\text { Panel } \\
(5)\end{array}$ & $\begin{array}{l}\text { Evaluate relative } \\
\text { priorities for sub- } \\
\text { criteria with respect to } \\
\text { the performance } \\
\text { criterion }\end{array}$ & $\begin{array}{l}\text { Evaluate relative } \\
\text { priorities for the decision } \\
\text { alternatives with respect } \\
\text { to the performance sub- } \\
\text { criteria }\end{array}$ & $\begin{array}{l}\text { Value Engineering } \\
\text { Specialists } \\
\text { Value Management } \\
\text { Consultant }\end{array}$ & $6-12$ \\
\hline
\end{tabular}




\begin{tabular}{|c|l|l|l|c|}
\hline $\begin{array}{l}\text { Panel } \\
(6)\end{array}$ & $\begin{array}{l}\text { Evaluate relative } \\
\text { priorities for sub- } \\
\text { criteria with respect to } \\
\text { the resources criterion }\end{array}$ & $\begin{array}{l}\text { Evaluate relative } \\
\text { priorities for the decision } \\
\text { alternatives with respect } \\
\text { to the resources sub- } \\
\text { criteria }\end{array}$ & $\begin{array}{l}\text { Project Managers } \\
\text { Project Design and } \\
\text { Policy Managers } \\
\text { Project Engineers }\end{array}$ & $6-12$ \\
\hline
\end{tabular}

Experts were selected and distributed into five categories according to their field of expertise within their respective State Departments of Transportation (DOTs) and other transportation agencies. Previous research has shown that more than twelve experts do not significantly contribute to the accuracy of the results [237]. The final experts were distributed into six panels including alternatives based on their response to the first invitation email. As shown in Table 9, a sample of the panel distribution pattern showed some experts repeated their names in more than one category because they are accountable to perform multi-project assessment activities within their departments.

Table 9: Sample of Distribution of Experts over Panels - Validation

\begin{tabular}{|c|c|c|c|c|c|c|c|}
\hline Expert & Criteria & $C 1$ & $C 2$ & $C 3$ & $C 4$ & C5 & Alts. \\
\hline $\operatorname{Exp} 1$ & $\mathrm{x}$ & $\mathrm{x}$ & $\mathrm{x}$ & $\mathrm{x}$ & $\mathrm{x}$ & $\mathrm{x}$ & $\mathrm{x}$ \\
\hline $\operatorname{Exp} 2$ & $\mathrm{x}$ & & & & $\mathrm{x}$ & $\mathrm{x}$ & \\
\hline $\operatorname{Exp} 3$ & & $\mathrm{x}$ & $\mathrm{x}$ & & & & \\
\hline $\operatorname{Exp} 4$ & & & & & $\mathrm{x}$ & $\mathrm{x}$ & $\mathrm{x}$ \\
\hline $\operatorname{Exp} 5$ & & $\mathrm{x}$ & $\mathrm{x}$ & & & & \\
\hline $\operatorname{Exp} 6$ & $\mathrm{x}$ & & & $\mathrm{x}$ & & & \\
\hline $\operatorname{Exp} 7$ & $\mathrm{x}$ & & & & $\mathrm{x}$ & $\mathrm{x}$ & \\
\hline $\operatorname{Exp} 8$ & & & & & $\mathrm{x}$ & $\mathrm{x}$ & \\
\hline $\operatorname{Exp} 9$ & & $\mathrm{x}$ & $\mathrm{x}$ & & & & \\
\hline $\operatorname{Exp} 10$ & $\mathrm{x}$ & & & $\mathrm{x}$ & & & \\
\hline $\operatorname{Exp} 11$ & & & & & $\mathrm{x}$ & $\mathrm{x}$ & \\
\hline $\operatorname{Exp} 12$ & $\mathrm{x}$ & & & & & & \\
\hline $\operatorname{Exp} 13$ & $\mathrm{x}$ & $\mathrm{x}$ & $\mathrm{x}$ & & & & \\
\hline $\operatorname{Exp} 14$ & $\mathrm{x}$ & $\mathrm{x}$ & $\mathrm{x}$ & & & & \\
\hline $\operatorname{Exp} 15$ & $\mathrm{x}$ & & & $\mathrm{x}$ & & & \\
\hline $\operatorname{Exp} 16$ & & & & $\mathrm{x}$ & & & \\
\hline
\end{tabular}




\begin{tabular}{|c|c|c|c|c|c|c|c|}
$\operatorname{Exp} 17$ & & & & $\mathrm{x}$ & $\mathrm{x}$ & \\
\hline $\operatorname{Exp} 18$ & & & & & $\mathrm{x}$ & $\mathrm{x}$ & $\mathrm{x}$ \\
\hline $\operatorname{Exp} 19$ & & & & $\mathrm{x}$ & & & $\mathrm{x}$ \\
\hline $\operatorname{Exp} 20$ & & $\mathrm{x}$ & $\mathrm{x}$ & & & & \\
\hline $\operatorname{Exp} 21$ & & $\mathrm{x}$ & $\mathrm{x}$ & & & & $\mathrm{x}$ \\
\hline $\operatorname{Exp} 22$ & $\mathrm{x}$ & & & $\mathrm{x}$ & & & \\
\hline $\operatorname{Exp} 23$ & & & & $\mathrm{x}$ & & & $\mathrm{x}$ \\
\hline $\operatorname{Exp} 24$ & & & & $\mathrm{x}$ & & & $\mathrm{x}$ \\
\hline
\end{tabular}

The experts' list was used for the model validation and quantification (Table 10).

Table 10: Model Judgment Experts' Profiles

\begin{tabular}{|l|c|l|l|}
\hline Expert & Panel No. & \multicolumn{1}{|c|}{ Affiliation } & \multicolumn{1}{|c|}{ Sector } \\
\hline Exp-v1 & A1\&B1 & VM Consultation & Private \\
\hline Exp-v2 & A1\&B2 & University - PM & Government \\
\hline Exp-v3 & A1 & Transportation & Government \\
\hline Exp-v4 & A1\&B2 & Transportation & Government \\
\hline Exp-v5 & A1 & Road Service & Government \\
\hline Exp-v6 & A1 & Shell - G. Management & Private \\
\hline Exp-v7 & A1 & Consultation - GM & Private \\
\hline Exp-v8 & A1 & Transportation & Government \\
\hline Exp-v9 & A1 & Transportation & Government \\
\hline Exp-v10 & A1 & Shell - PM & Government \\
\hline Exp-v11 & A1\&B2 & Transportation - PM & Government \\
\hline Exp-v12 & A1 & University - QHSE & Private \\
\hline Exp-v13 & A1 & Communication & Government \\
\hline Exp-v14 & A1 & Management Solutions & Private \\
\hline Exp-v15 & A1 & Consultation Management & Government \\
\hline Exp-v16 & A1\&B2 & Transportation & Government \\
\hline Exp-v17 & A1\&B2 & Transportation & Government \\
\hline Exp-v18 & A1\&B2 & Transportation - VE & Government \\
\hline Exp-v19 & A1\&B2 & Transportation - VE & Government \\
\hline Exp-v20 & A1 & Transportation & Government \\
\hline Exp-v21 & A1 & Transportation - VE & Government \\
\hline Exp-v22 & A1\&B2 & University - Management & Government \\
\hline Exp-v23 & A1\&B2 & Transportation - VE & Government \\
\hline Exp-v24 & A1\&B2 & Transportation - RM & Povernment \\
\hline Exp1 & P1 & VM Consultant, PMP \\
\hline
\end{tabular}




\begin{tabular}{|c|c|c|c|}
\hline Exp 2 & $\mathrm{P} 1$ & International Management Consultant & Private \\
\hline Exp 3 & $\mathrm{P} 1$ & $\begin{array}{l}\text { Sustainable Development Projects } \\
\text { Consultant }\end{array}$ & Private \\
\hline Exp 4 & P1 & Transportation - Project Delivery Lead & Government \\
\hline Exp 5 & $\mathrm{P} 1$ & Transportation - Project Manager & Government \\
\hline Exp 6 & $\mathrm{P} 1$ & $\begin{array}{l}\text { Transportation - Engineer of } \\
\text { Construction }\end{array}$ & Government \\
\hline Exp 7 & $\mathrm{P} 1$ & Construction Planner & Utilities \\
\hline Exp 8 & $\mathrm{P} 1$ & Transportation - Construction Supervisor & Utilities \\
\hline Exp 9 & $\mathrm{P} 1$ & QHSE Consultant & Academia \\
\hline Exp 10 & $\mathrm{P} 1$ & Procurement Specialist & Academia \\
\hline Exp 11 & $\mathrm{P} 2$ & Transportation - Cost Estimate Specialist & Government \\
\hline Exp 12 & $\mathrm{P} 2$ & Transportation - Quality Engineer & Government \\
\hline Exp 13 & $\mathrm{P} 2$ & Consultant Engineer & Private \\
\hline Exp 14 & $\mathrm{P} 2$ & $\begin{array}{l}\text { Assistant Professor CATSS, } \\
\text { Transportation and Air Quality Program } \\
\text { Director }\end{array}$ & Academia \\
\hline Exp 15 & $\mathrm{P} 2$ & $\begin{array}{l}\text { Transportation - Cost Management } \\
\text { Engineer }\end{array}$ & Government \\
\hline Exp 16 & $\mathrm{P} 2$ & $\begin{array}{l}\text { Transportation - Risk Management } \\
\text { Specialist }\end{array}$ & Government \\
\hline Exp 17 & $\mathrm{P} 2$ & $\begin{array}{l}\text { Transportation - Letting Preparation } \\
\text { Engineer }\end{array}$ & Utilities \\
\hline Exp 18 & $\mathrm{P} 2$ & Transportation - Value Engineer & Government \\
\hline Exp 19 & $\mathrm{P} 2$ & Transportation - Quality Engineer & Government \\
\hline Exp 20 & P3 & $\begin{array}{l}\text { Transportation - Project Development } \\
\text { Engineer }\end{array}$ & Government \\
\hline Exp 8 & $\mathrm{P} 3$ & Civil Engineer & Private \\
\hline Exp 21 & P3 & Transportation - Civil Engineer & Private \\
\hline Exp 22 & P3 & $\begin{array}{l}\text { Transportation - Constructability Review } \\
\text { Coordinator }\end{array}$ & Private \\
\hline Exp 23 & $\mathrm{P} 3$ & Regional Construction Engineer & Government \\
\hline Exp 24 & P3 & Transportation - Team Leader & Government \\
\hline Exp 25 & $\mathrm{P} 3$ & Transportation - Innovations Engineer & Government \\
\hline Exp 26 & $\mathrm{P} 3$ & Constructability Review Coordinator & Government \\
\hline Exp 27 & P3 & Transportation - Technical Engineer & Government \\
\hline Exp 28 & $\mathrm{P} 3$ & Transportation Engineer & Government \\
\hline Exp 29 & $\mathrm{P} 3$ & $\begin{array}{l}\text { Transportation - Constructability Review } \\
\text { Coordinator }\end{array}$ & Government \\
\hline Exp 5 & P4 & Transportation - Project Manager & Government \\
\hline Exp 30 & $\mathrm{P} 4$ & Civil Engineer & Government \\
\hline Exp 31 & $\mathrm{P} 4$ & Civil Engineer & Private \\
\hline Exp 32 & P4 & $\begin{array}{l}\text { Transportation - Risk Management } \\
\text { Coordinator }\end{array}$ & Government \\
\hline
\end{tabular}




\begin{tabular}{|c|c|c|c|}
\hline $\operatorname{Exp} 33$ & P4 & $\begin{array}{l}\text { Transportation - State Value } \\
\text { Management Engineer }\end{array}$ & Government \\
\hline Exp 34 & $\mathrm{P} 4$ & Transportation - Manger & Government \\
\hline $\operatorname{Exp} 35$ & P4 & $\begin{array}{l}\text { Transportation - Risk Management } \\
\text { Coordinator }\end{array}$ & Government \\
\hline $\operatorname{Exp} 36$ & P4 & $\begin{array}{l}\text { Transportation - Planning Program } \\
\text { Manager }\end{array}$ & Government \\
\hline Exp 37 & $\mathrm{P} 4$ & Transportation - Project Manager & Government \\
\hline \multicolumn{4}{|l|}{ Exp 38} \\
\hline Exp 39 & P4 & $\begin{array}{l}\text { Transportation - Project Assessment } \\
\text { Specialist }\end{array}$ & Government \\
\hline $\operatorname{Exp} 40$ & $\mathrm{P} 4$ & Transportation - Project Manager & Government \\
\hline Exp 13 & $\mathrm{P} 5$ & Consultant Engineer & Private \\
\hline Exp 41 & P5 & Transportation - Value Engineer & Government \\
\hline Exp 42 & P5 & Transportation - Project Manager & Government \\
\hline Exp 43 & $\mathrm{P} 5$ & Transportation - VE Manager & Government \\
\hline Exp 44 & $\mathrm{P} 5$ & Transportation - VE Coordinator & Government \\
\hline Exp 45 & $\mathrm{P} 5$ & Transportation - Value Engineer & Government \\
\hline $\operatorname{Exp} 46$ & $\mathrm{P} 5$ & Transportation - Project Manager & Government \\
\hline $\operatorname{Exp} 47$ & P5 & Transportation - Value Engineer & Government \\
\hline Exp 48 & P5 & Transportation - Value Engineer & Government \\
\hline $\operatorname{Exp} 49$ & P5 & $\begin{array}{l}\text { Transportation - Value Engineering } \\
\text { Coordinator }\end{array}$ & Government \\
\hline Exp 50 & P6 & Transportation - VE Coordinator & Private \\
\hline Exp 44 & P6 & Transportation - VE Coordinator & Government \\
\hline Exp 41 & P6 & Transportation - Value Engineer & Government \\
\hline Exp 42 & P6 & Transportation - Value Engineer & Government \\
\hline \multicolumn{4}{|l|}{ Exp 43} \\
\hline $\operatorname{Exp} 44$ & P6 & Transportation - Value Engineer & Government \\
\hline $\operatorname{Exp} 45$ & P6 & $\begin{array}{l}\text { Transportation - Value Engineering } \\
\text { Coordinator }\end{array}$ & Government \\
\hline Exp 46 & $\mathrm{P} 6$ & Transportation - Value Engineer & Government \\
\hline
\end{tabular}



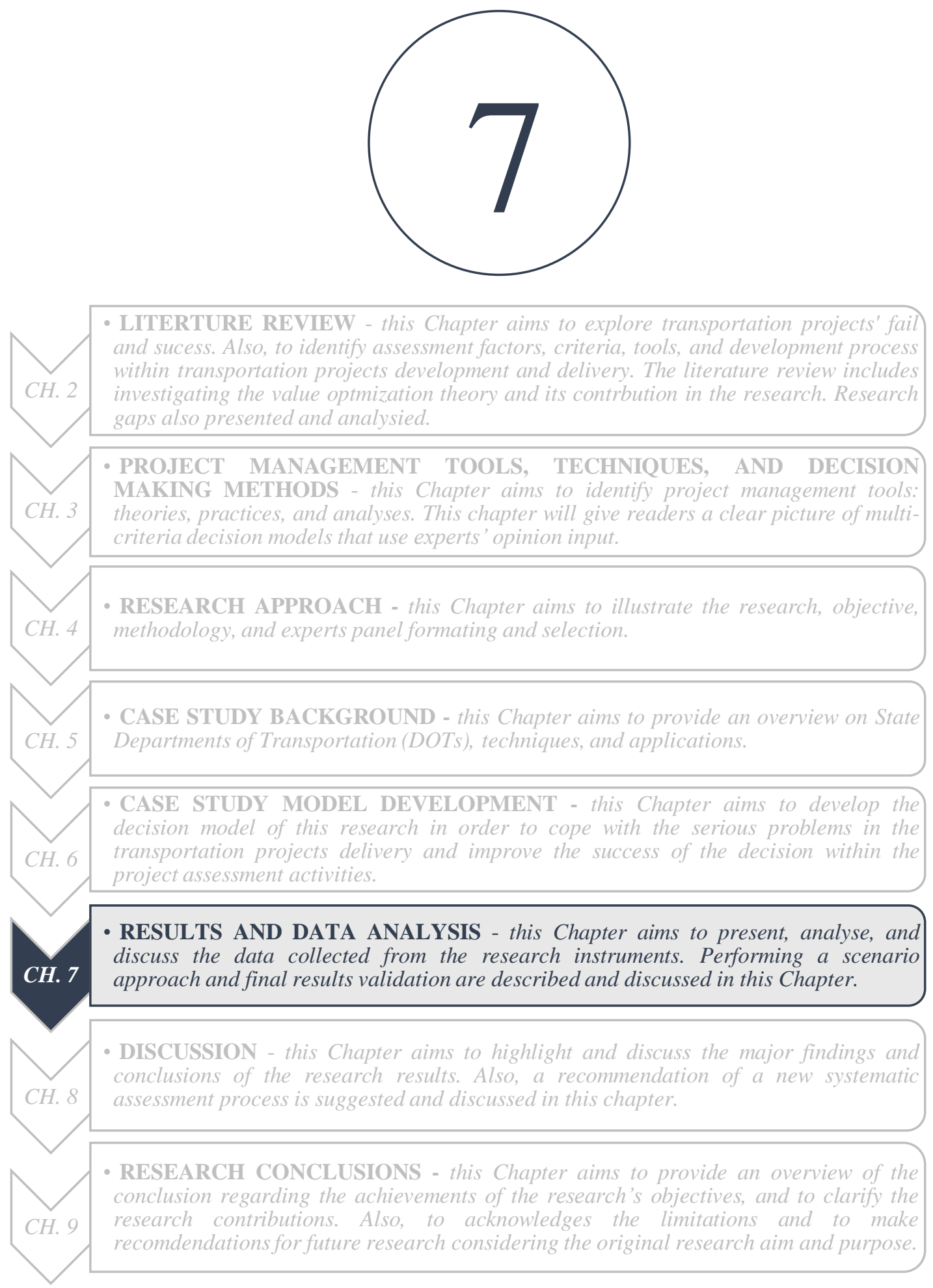


\section{CHAPTER SEVEN: RESULTS AND DATA ANALYSIS}

\subsection{Data Validation}

In the previous Chapter, the pre-testing and finalized decision model structure were discussed in detail. Validation and quantification processes were carried out based on the concept of design and assessment approach that is present in theory, methodology, research, and practices. The validated model's criteria, sub-criteria, and alternatives have been identified, and were presented in the final decision model, which has been revised to suit the needs of current project assessment activities. The validating process involved developing two separate questionnaires with a Yes or No question pattern. A two-thirds $(67 \%)$ agreement was adopted to accept or reject each criterion in the model. According to expert panels distribution, each expert was asked to answer a single common question for specific model elements 'Please click 'Yes' or 'No' for each criterion, sub-criteria, or alternatives" to indicate whether those elements are appropriate or not to be used in the model.

The unique decision model, which has been developed for this research, is considered to be generalized and established through actual applications and implementations in construction projects development within different sectors.

This chapter presents and analyses the data and feedback collected from experts in order to validate and quantify the final decision model, and to achieve the research 
objective. As mentioned in the previous chapter, sixty-two experts from the transportation and construction industry including some experts from academia were selected and participated in the model validation and quantification process. Two panels (A1 \& B2) were designed to gather the validated judgments from twenty-four experts, and the other six panels (P1 - P6) that included fifty experts that were collected and structured to quantify the contribution of the model criteria with respect to the mission. Two experts were omitted from the qualification process because they didn't submit their final judgment. Some experts provided valuable comments about the criteria, sub-criteria, and alternatives. All experts were allowed to add or replace any criteria or sub-criteria as appropriate.

In the validation process, two experts' panels were asked to use the online survey questionnaire link that included instructions about the research objective and the research decision model. Then, the six experts' panels members, in the quantification process, were asked to use the Hierarchical Decision Model (HDM) software online to quantify the model elements that effect the project assessment methods selection.

\subsubsection{Analysis of Expert Panel (A1) Criteria Results - Level 2}

Testing the model structure was important to demonstrate its validity and applicability. In this stage, experts were invited to validate the model criteria at Level 2 in black as shown in Figure 23. Then, the data were gathered from the expert panel (A1) regarding the criteria validation by using the Qualtrics tool (Research Instruments RI1). Table 11 below shows the contribution results from expert panel (A1). 


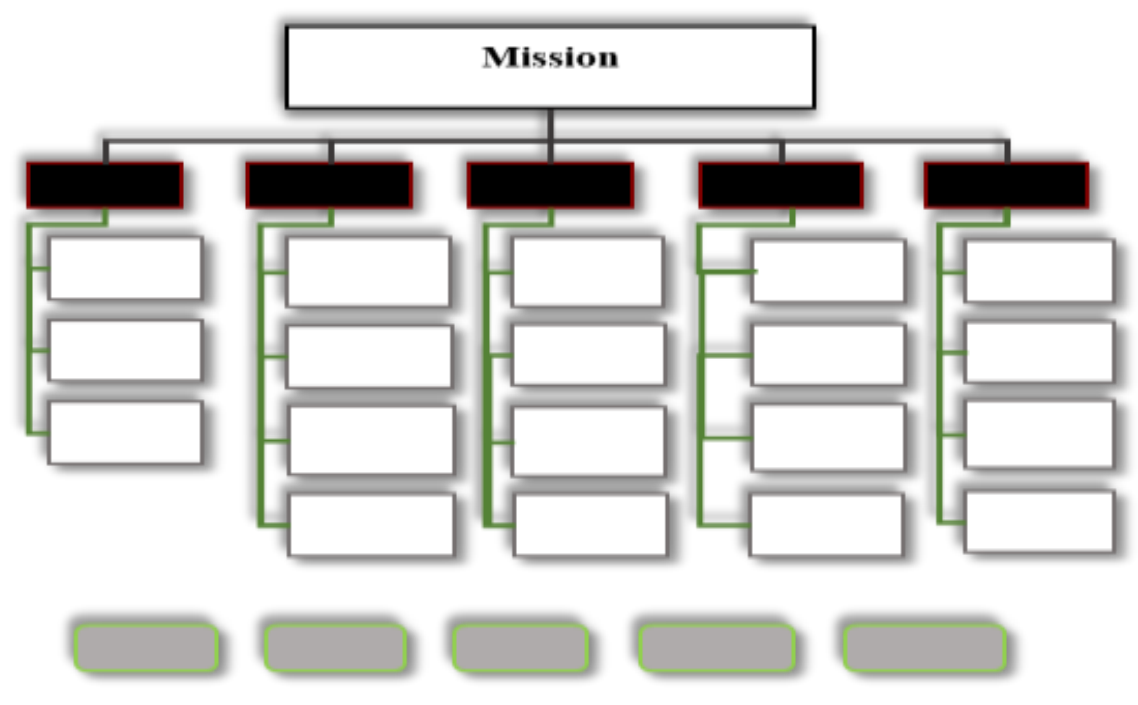

Figure 23: Criteria Validation - Model Structure

All experts agreed that the model Level 2 criteria, cost, schedule, and resources, were appropriate for assessing project assessment techniques. Risk and performance criterion were rejected by two experts, one expert rejected the risk criterion, and another expert rejected the performance criterion. The risk criterion was justified by one expert as a success attribute that should be included under the cost and schedule. Another expert indicated the importance of considering the performance criterion to the cost and risk, and he also recommended to include the performance under each cost and risk criterion.

Table 11: Criteria Validation - Experts' Responses

\begin{tabular}{|c|c|c|c|c|c|c|}
\hline$\#$ & Criteria & Yes & Percent & No & Percent & Total \\
\hline 1 & Cost & 10 & $100.00 \%$ & 0 & $0.00 \%$ & 10 \\
\hline 2 & Time & 10 & $100.00 \%$ & 0 & $0.00 \%$ & 10 \\
\hline 3 & Risk & 9 & $90.00 \%$ & 1 & $10.00 \%$ & 10 \\
\hline 4 & Performance & 9 & $90.00 \%$ & 1 & $10.00 \%$ & 10 \\
\hline 5 & Resources & 10 & $100.00 \%$ & 0 & $0.00 \%$ & 10 \\
\hline
\end{tabular}


The green bars, in Figure 24 below, indicate to the rate of model criteria validation results. The five criteria were accepted by the majority of experts, and considered as valid criteria for use in developing the model within the acceptance rate of agreement. The cost, time, and resources indicate at $100 \%$ acceptance while risk and performance indicate at $90 \%$

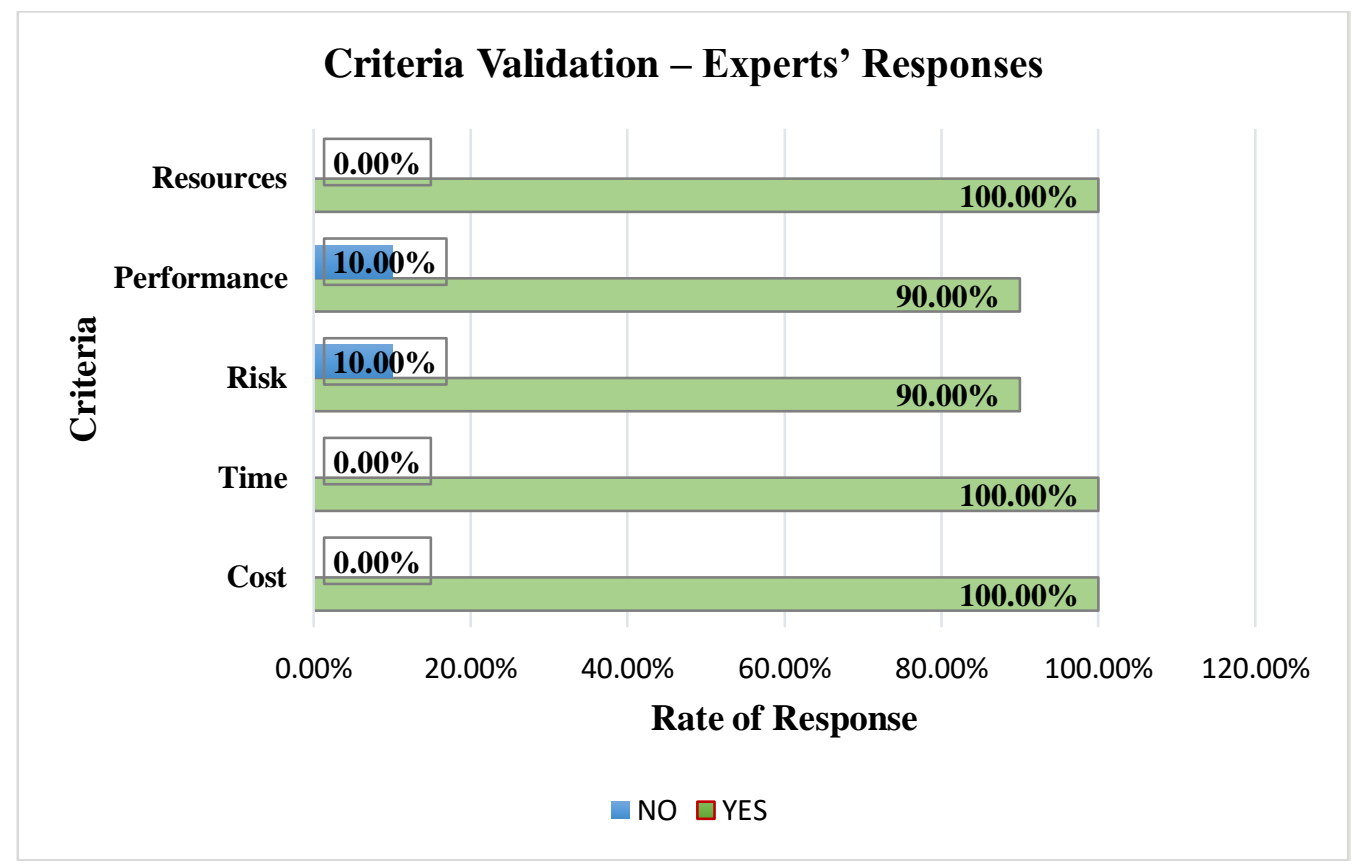

Figure 24: Criteria Validation Rate \%

\subsubsection{Analysis of Expert Panel (B1) Sub-criteria Results - Level 3}

Table 12 below illustrates the contribution results from the expert panel (B1) on Level 3. Estep in her Ph.D. dissertation indicates the rate of experts' acceptance agreement. She 
mentioned that each selected decision element was properly validated and considered when a two-thirds majority is achieved. [227].

The expert panel (B1) were asked to use the Qualtrics tool (Research Instruments RI2) to validate the model sub-criteria at Level 3 . At this stage, the experts were selected based on their attention and response to the previous invitation that put them at the top. Their response on the online survey was definitely encouraging because they accepted most of the suggested sub-criteria. The validation rate was above 90\%, the majority said YES, while a few experts were suggested to reject, add, or replace some sub-criteria.

Table 12: The Experts Panel (B1) Feedback

\begin{tabular}{|l|c|c|c|c|}
\hline Sub-criteria & Yes & No & $\%$ & Total \\
\hline Capital Cost & 8 & 0 & $100.00 \%$ & 8 \\
\hline Life-Cycle-Cost & 8 & 0 & $100.00 \%$ & 8 \\
\hline Project Support Costs & 7 & 1 & $87.50 \%$ & 8 \\
\hline Project Design \& Environmental Analysis & 7 & 1 & $87.50 \%$ & 8 \\
\hline Right-of-Way (ROW) Acquisition & 8 & 0 & $100.00 \%$ & 8 \\
\hline Project Tender \& Construction Duration & 8 & 0 & $100.00 \%$ & 8 \\
\hline Project Performance Risk Impact & 9 & 0 & $100.00 \%$ & 9 \\
\hline Project Cost Risk Impact & 9 & 0 & $100.00 \%$ & 9 \\
\hline Project Schedule Risk Impact & 9 & 0 & $100.00 \%$ & 9 \\
\hline Project Scope Definition & 8 & 0 & $100.00 \%$ & 8 \\
\hline Contract Change Order & 3 & 5 & $37.50 \%$ & 8 \\
\hline Stakeholder Needs and Priorities & 7 & 1 & $87.50 \%$ & 8 \\
\hline Transportation Needs & 8 & 0 & $100.00 \%$ & 8 \\
\hline In-house Capability for using the Tool & 8 & 0 & $100.00 \%$ & 8 \\
\hline External Consultant Needs & 7 & 1 & $87.50 \%$ & 8 \\
\hline Time Needs During Using the Tool & 7 & 1 & $87.50 \%$ & 8 \\
\hline Project Stakeholder Involvement & 8 & 0 & $100.00 \%$ & 8 \\
\hline
\end{tabular}


As shown in Figure 25, five out of eight experts said 'NO' on the contract change order attribute under the performance criteria. The contract change order attribute did not meet the two thirds of experts' agreement, so it was omitted from the model.

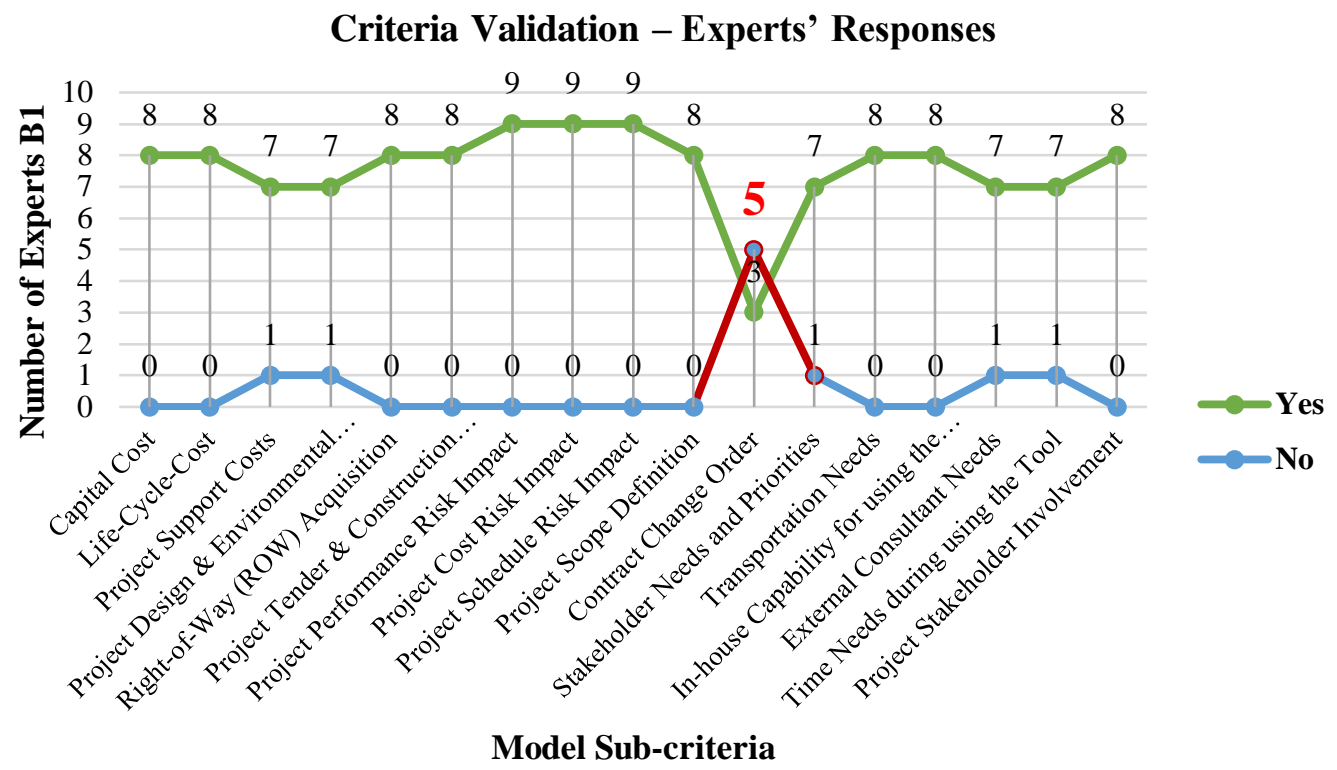

Figure 25: The Value of Validation Results

Table 13 and Figure 26 demonstrate the final decision model validation results. Four new sub-criteria were suggested by experts to strengthen the model. Improving Project Needed Functions, Offering Communication, and Integration Capabilities attributes were validated and added to the model under the performance criteria. Identifying Project Schedule Risk Impact was validated, and added under the risk. The same process was applied to the Accelerating Project Closeout Activities Duration, which was allocated under the schedule criteria. Based on the experts' feedback, the Identifying Expectations of Different Groups of Stakeholders attribute was married with Identifying Transportation 
Needs. The experts' feedback were valuable and acceptable. They clarified the importance of marrying these attributes to measure the performance of different perspectives based on community interests, needs, and expectations including identifying specific transportation needs.

Table 13: The Final Decision Model Validation Results

\begin{tabular}{|l|c|c|c|c|}
\hline \multicolumn{1}{|c|}{ Sub-crite ria } & Yes & No & \% & Total \\
\hline Reducing Capital Cost & $\mathbf{8}$ & 0 & $\mathbf{1 0 0 . 0 0 \%}$ & 8 \\
\hline Offering Life-Cycle-Cost Reduction & $\mathbf{8}$ & 0 & $\mathbf{1 0 0 . 0 0 \%}$ & 8 \\
\hline Minimizing Project Support Costs & $\mathbf{7}$ & 1 & $\mathbf{8 7 . 5 0 \%}$ & 8 \\
\hline $\begin{array}{l}\text { Accelerating Project Design \& } \\
\text { Environmental Analysis }\end{array}$ & $\mathbf{7}$ & 1 & $\mathbf{8 7 . 5 0 \%}$ & 8 \\
\hline $\begin{array}{l}\text { Accelerating Right-of-Way (ROW) } \\
\text { Acquisition }\end{array}$ & $\mathbf{8}$ & 0 & $\mathbf{1 0 0 . 0 0 \%}$ & 8 \\
\hline $\begin{array}{l}\text { Accelerating Project Tender \& } \\
\text { Construction Duration }\end{array}$ & $\mathbf{8}$ & 0 & $\mathbf{1 0 0 . 0 0 \%}$ & 8 \\
\hline $\begin{array}{l}\text { Accelerating Project Closeout Activities } \\
\text { Duration }\end{array}$ & $\mathbf{9}$ & 0 & $\mathbf{1 0 0 . 0 0 \%}$ & 9 \\
\hline $\begin{array}{l}\text { Identifying Project Performance Risk } \\
\text { Impact }\end{array}$ & $\mathbf{9}$ & 0 & $\mathbf{1 0 0 . 0 0 \%}$ & 9 \\
\hline Identifying Project Cost Risk Impact & $\mathbf{9}$ & 0 & $\mathbf{1 0 0 . 0 0 \%}$ & 9 \\
\hline $\begin{array}{l}\text { Identifying Project Support Costs Risk } \\
\text { Impact }\end{array}$ & $\mathbf{8}$ & 0 & $\mathbf{1 0 0 . 0 0 \%}$ & 8 \\
\hline Identifying Project Schedule Risk Impact & $\mathbf{8}$ & 0 & $\mathbf{1 0 0 . 0 0 \%}$ & 8 \\
\hline Refining the Project Scope & $\mathbf{8}$ & 0 & $\mathbf{1 0 0 . 0 0 \%}$ & 8 \\
\hline Improving Project Needed Functions & $\mathbf{7}$ & 1 & $\mathbf{8 7 . 5 0 \%}$ & 8 \\
\hline $\begin{array}{l}\text { Offering Communication and Integration } \\
\text { Capabilities }\end{array}$ & $\mathbf{8}$ & 0 & $\mathbf{1 0 0 . 0 0 \%}$ & 8 \\
\hline Identifying Transportation Needs & $\mathbf{8}$ & 0 & $\mathbf{1 0 0 . 0 0 \%}$ & 8 \\
\hline In-house Capability & $\mathbf{8}$ & 0 & $\mathbf{1 0 0 . 0 0 \%}$ & 8 \\
\hline External Consultant Needs & $\mathbf{8}$ & 0 & $\mathbf{1 0 0 . 0 0 \%}$ & 8 \\
\hline Time Needs during using the Technique & $\mathbf{8}$ & 0 & $\mathbf{1 0 0 . 0 0 \%}$ & 8 \\
\hline Project Stakeholder Involvement & $\mathbf{8}$ & $\mathbf{1 0 0 . 0 0 \%}$ & 8 \\
\hline
\end{tabular}




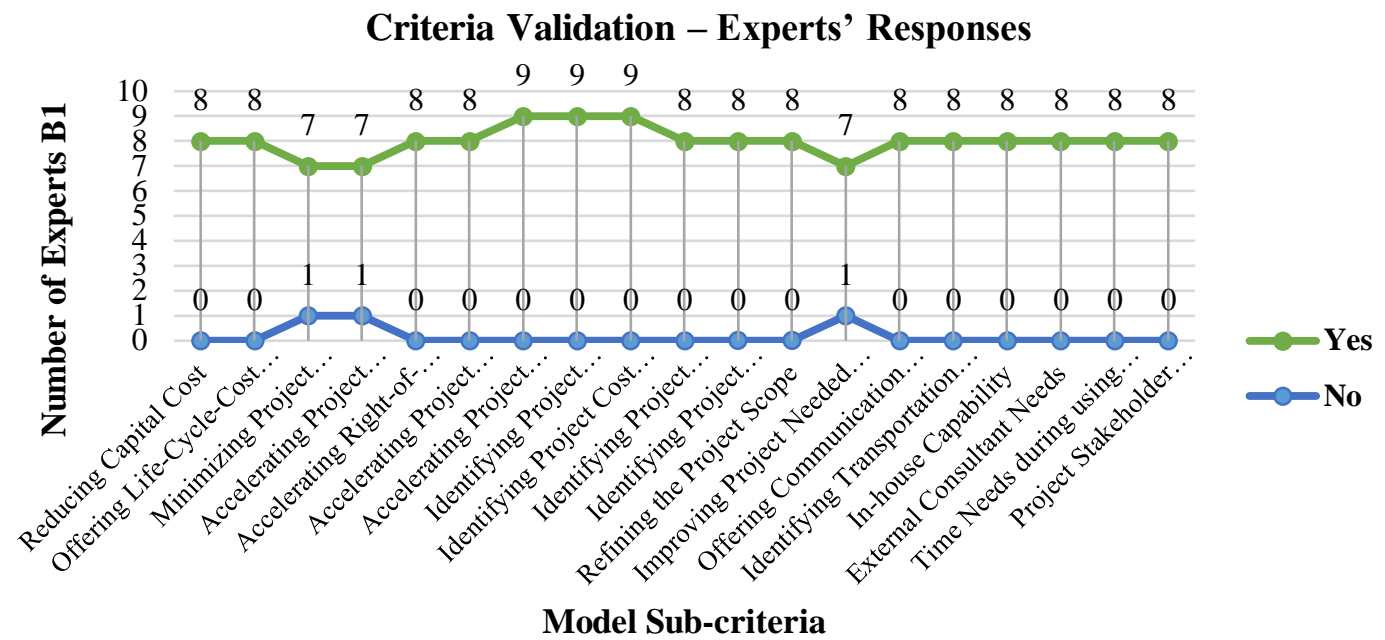

Figure 26: The Final Decision Model Validation Results

The same process was used to validate the five project assessment techniques (alternatives) with respect to the model sub-criteria and criteria. As shown in Figure 27, all respondents agreed on the proposed alternatives to be included in the model, so the result rate is considered as $100 \%$ acceptance.

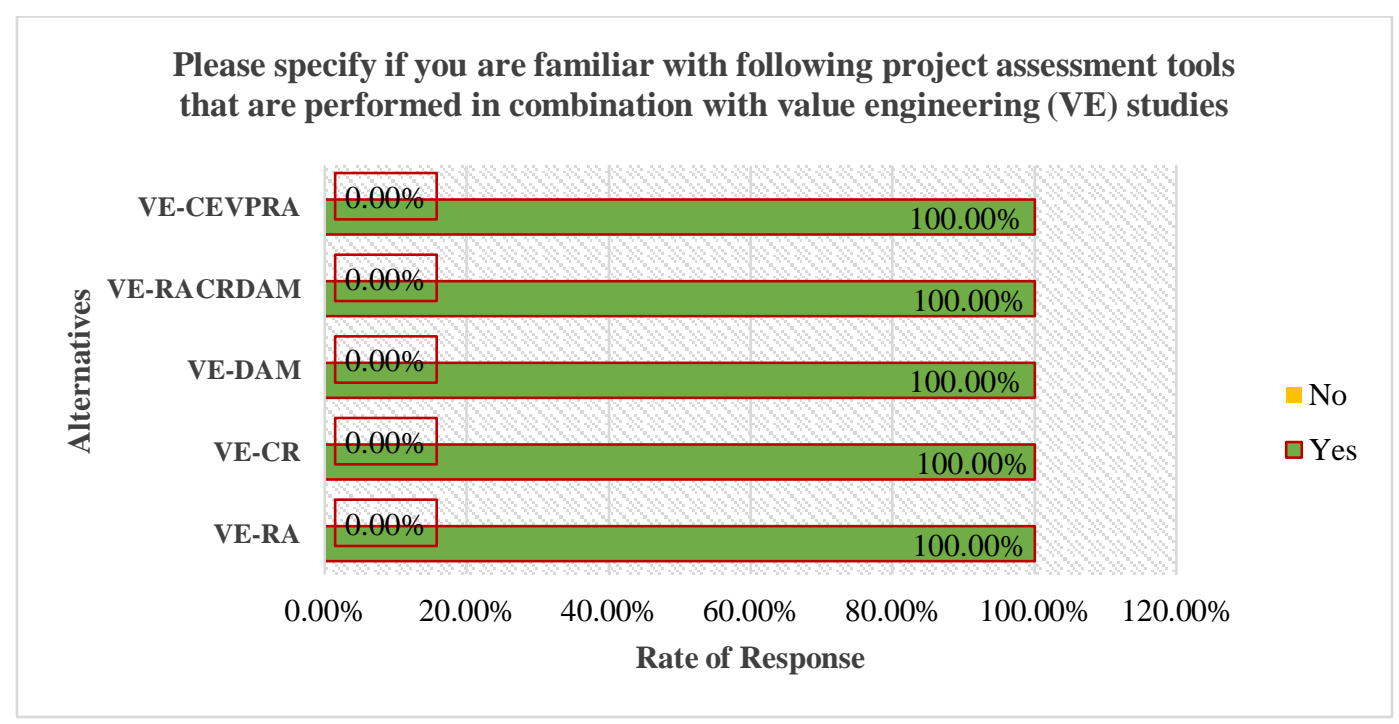

Figure 27: Final Alternatives' Validation Results 
The final experts' feedback was very encouraging and informative (see Figure 28). Therefore, the final results of the model validation were accepted because the agreement was reached.

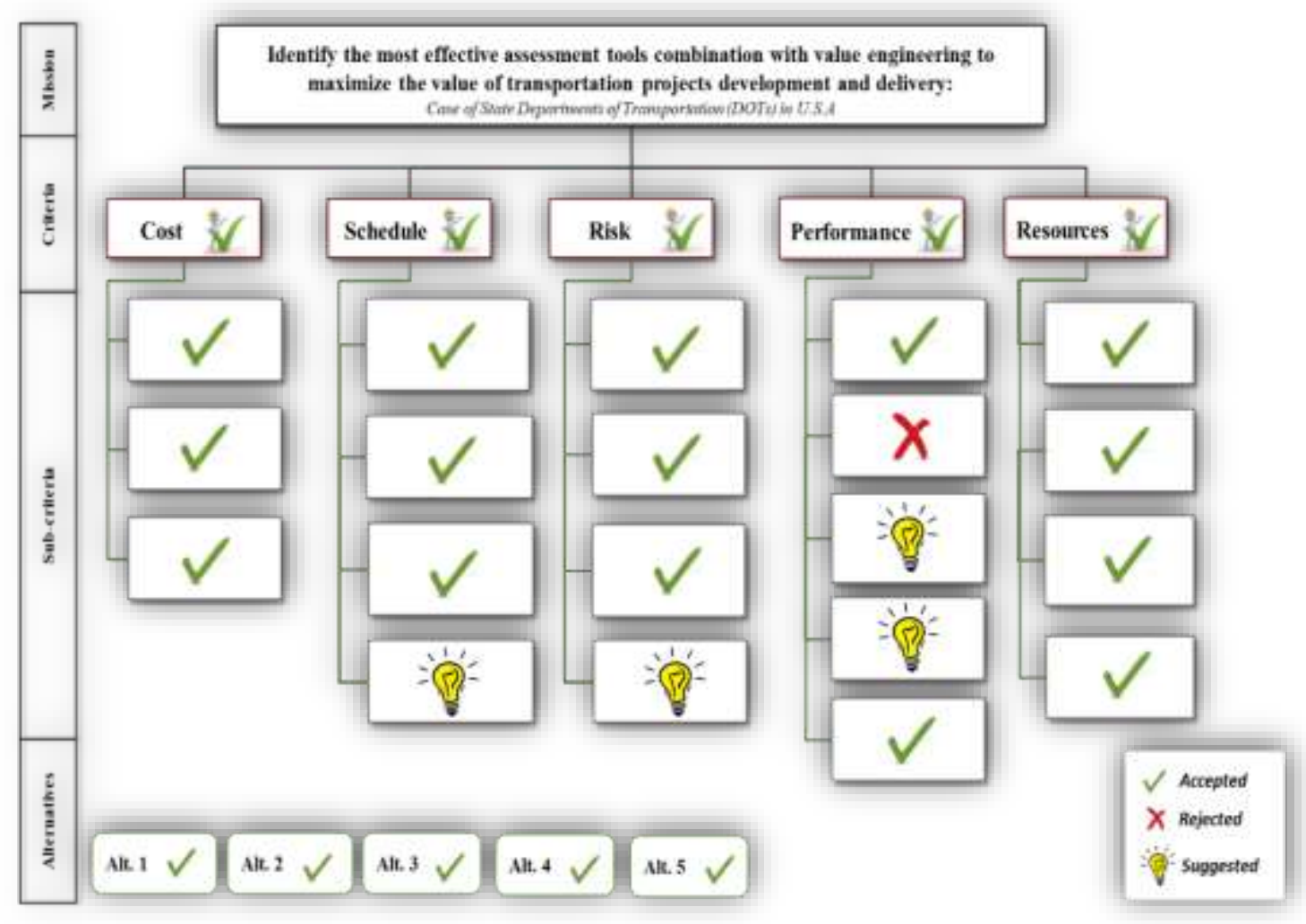

Figure 28: The Final Decision Model Validation

As proposed in this research, the decision model considered many aspects affecting the project assessment activities during the delivery process within the transportation projects construction. Selecting the right expert panels helped to create a unique decision model that might be also generalized and used for other project construction sectors. As shown in Figure 29, after a group agreement was achieved, the initial decision model was revised 
and included the model elements definition with respect to the research goal that was mentioned in the mission (Identify the most effective assessment tools combination with value engineering to maximize the value of high-profile highway and bridges projects development and delivery). 


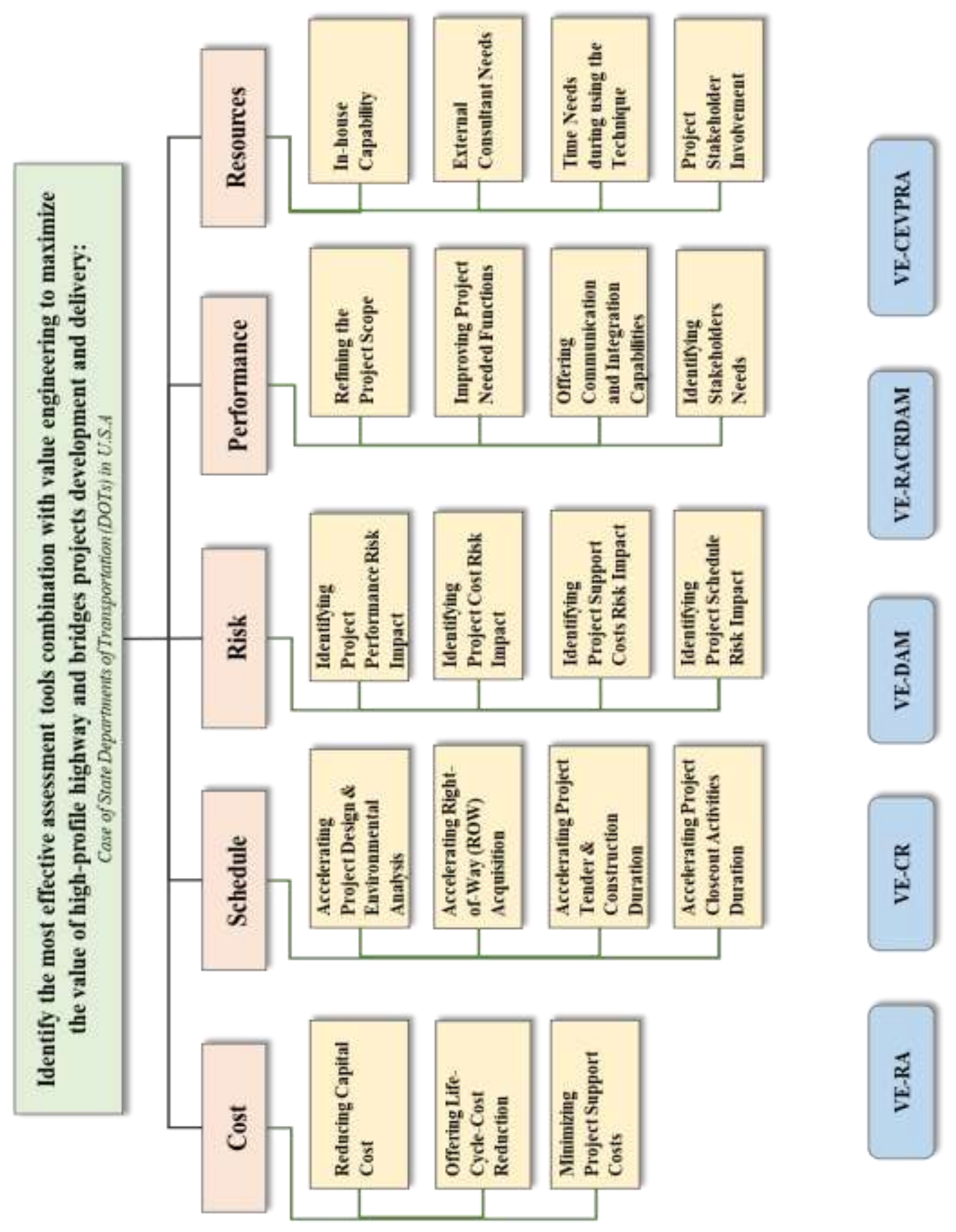

\begin{tabular}{|c|c|c|c|}
\hline nọss!W & 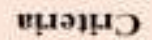 & ецวџз-qns & 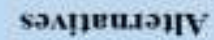 \\
\hline
\end{tabular}

Figure 29: The Hierarchal Decision Model for Evaluating Proj. Ass. Techniques 


\subsection{Data Quantification}

This section illustrates the judgment quantification results from six expert panels (EP1, EP2, EP3, EP4, EP5, and EP6), and demonstrates their inconsistencies and groups of disagreement for each expert in the panel. The strategic panel (EP1) was dedicated to performing the quantification of the model Level 2 (criteria) with respect to the mission (Level 1), and to fulfill the shortages on other panels. EP2 through EP6 were assigned to perform pairwise comparisons model sub-criteria under the cost, schedule, risk, performance, and resources criterion, respectively. In addition, EP2 through EP6 were asked to quantify relative priorities for the decision alternatives with respect to each assigned panel sub-criteria. The HDM software was used to calculate the experts' input. As explained in the previous chapter, the quantification process was divided into three research instruments (RI3, RI4, and RI5). RI3 was used by the expert panel EP1, while RI4 and RI5 were used by EP2, EP3, EP4, EP5, and EP6.

In this stage, the experts were selected carefully based on their qualification and experience in engineering and project management. Therefore, the results were usable and acceptable because the inconsistency measure was less than or close to (0.1) [184][229][230]. Also, the last combined disagreement among experts was very optimistic. However, Expert 4 had an inconsistency at Level 2 (criteria) at value of 1.1. Therefore, in order to check if the Expert 4's judgments were ok, a calculation of his inconsistency level was performed using Abaas's calculations of the RSV [298], after which it was compared with the acceptable threshold, as shown below in this section. 
According to the HDM software results, the F-test determined the critical value at level $\alpha$ of $(0.01,0.05,0.025$, and 0.1$)$ as desired levels to confirm how significant the level of agreement was statistically. The F-value calculation is supposed to be higher than F-critical to reject the null hypothesis. In this research, the F-test result showed at Level 2 of criteria, the in-house capability sub-criteria that was there is not reliable because it fails to explain identical or close judgments with no variance. However, Abotah (2014) argued that there is a variation of distribution between the F-test and input data because the F-test assumes normal distribution while the data does not [191]. As the disagreement measure was acceptable (less than 0.1 ), the F-test calculation was collected, and will be presented later in this chapter, but will be ignored in the discussion chapter.

\subsubsection{Analysis of Expert Panel (EP1) Criteria Results - Level 2}

Panel EP1 consisted of 10 participants. They were asked to evaluate the model criteria (Level 2) with respect to the mission (Level 1). The experts were given the option to quantify the relative importance of each criterion in terms of its contribution to evaluate the effectiveness of project assessment techniques in transportation projects development and delivery. The mean of EP1 is shown in Table 14. The color boxes show the maximum and minimum expert judgments for each criterion. The green indicates to the highest weight among all criteria in Level 2, and the orange shows the lowest. The performance was rated as the highest at 0.24 among other criteria while resources presented as the least important at 0.14 from an overall assessment point of view. The individual expert's 
judgments were among the acceptable range. The inconsistency level among nine out of ten experts was acceptable between 0 to 0.05 . Exp 4 showed inconsistency among others at Level of 1.1. Therefore, in order to check if the Exp 4's judgments were ok, a calculation of his inconsistency level was performed using Abaas's calculations [298].It was then compared with the acceptable threshold, as explained in the inconsistency. Overall, the results showed that the mean level of disagreement was 0.072 between all experts in the EP1, below the value of 0.1. Therefore, the group disagreement is accepted.

Table 14: Analysis of the Importance of Each Criterion to Alts. Selection

\begin{tabular}{|llllllc|}
\hline Expert & Cost & Schedule & Risk & Performance & Resources & Inconsistency \\
\hline Exp 1 & 0.17 & 0.18 & 0.27 & 0.21 & 0.17 & 0 \\
Exp 2 & 0.11 & 0.17 & 0.28 & 0.25 & 0.19 & 0.01 \\
Exp 3 & 0.23 & 0.23 & 0.3 & 0.18 & 0.07 & 0.02 \\
Exp 4 & 0.04 & 0.28 & 0.1 & 0.42 & 0.16 & 0.11 \\
Exp 5 & 0.48 & 0.1 & 0.21 & 0.13 & 0.08 & 0.04 \\
Exp 6 & 0.14 & 0.22 & 0.21 & 0.26 & 0.17 & 0.01 \\
Exp 7 & 0.24 & 0.24 & 0.24 & 0.19 & 0.1 & 0.02 \\
Exp 8 & 0.21 & 0.17 & 0.1 & 0.3 & 0.22 & 0.04 \\
Exp 9 & 0.2 & 0.21 & 0.2 & 0.31 & 0.07 & 0.1 \\
Exp 10 & 0.26 & 0.07 & 0.4 & 0.14 & 0.14 & 0.05 \\
\hline Mean & 0.21 & 0.19 & 0.23 & 0.24 & 0.14 & \\
\hline Minimum & 0.04 & 0.07 & 0.1 & 0.13 & 0.07 & \\
Maximum & 0.48 & 0.28 & 0.4 & 0.42 & 0.22 & \\
Std. & 0.11 & 0.06 & 0.09 & 0.08 & 0.05 & 0.072 \\
Deviation & & & & & & \\
Disagreement & & & & & & \\
\hline
\end{tabular}

Figure 30 shows the opinion level of each expert regarding the importance of each criterion to the project assessment techniques selection. 


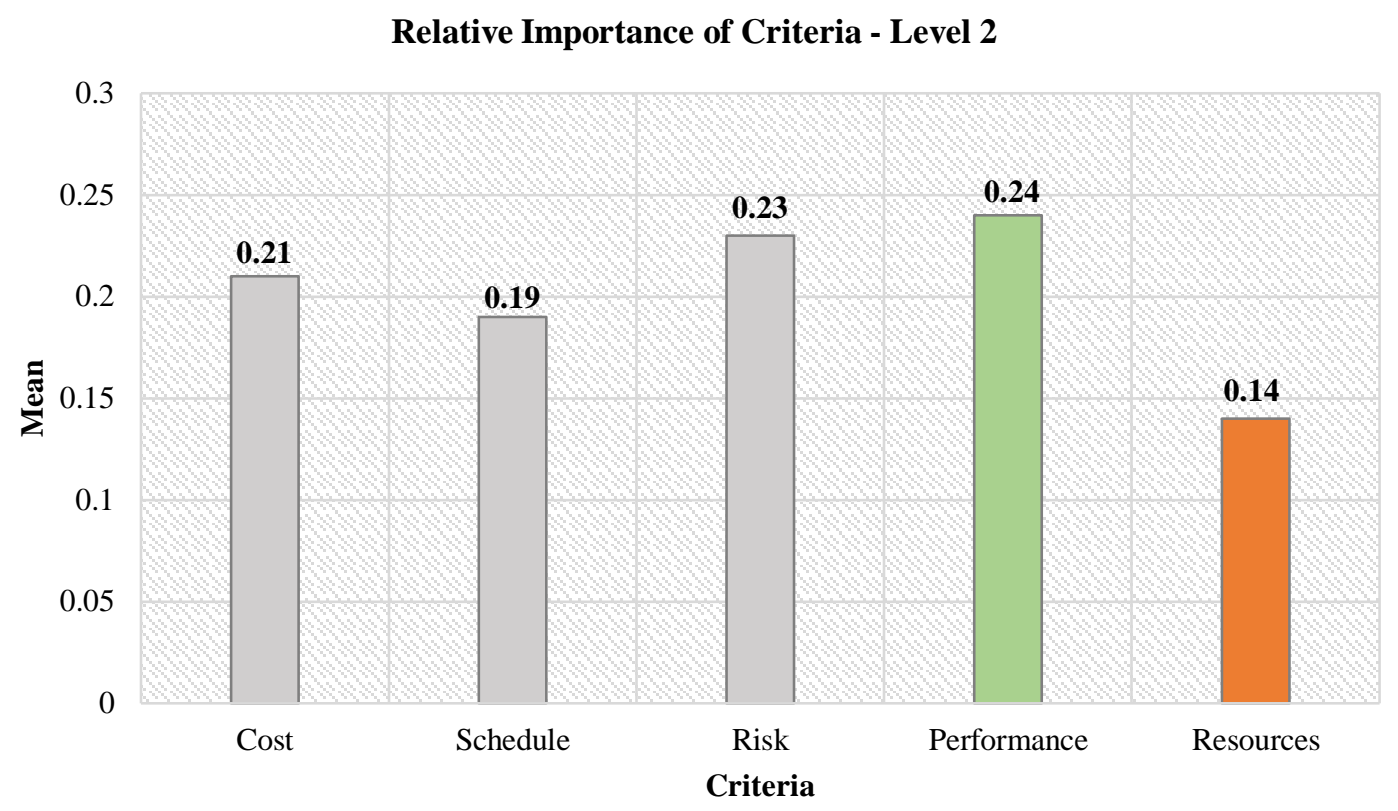

Figure 30: Relative Importance of Criteria

\subsubsection{Inconsistency and Disagreement}

The inconsistency level among nine out of ten experts was acceptable between 0 to 0.05. The Exp 4 showed inconsistency among others at Level of 1.1. Therefore, in order to check if the Exp 4's judgments were ok, a calculation of his inconsistency level was performed using Abaas's last calculations development (RSV) [298]. It was then compared with the acceptable threshold (the acceptable limits of the RSV vary as $\mathrm{n}$ varies as the $\alpha$ level varies) as shown in Figure 31. The original inconsistency method used the 0.1 thresholds regardless of the number of elements. The RSV was employed to investigate whether they were considered consistent by the RSV inconsistency measure. The original measure was conservative for $n \geq 5$. In order to calculate the RSV, matrixes A, B, C, D, 
and $\mathrm{E}$ were created for 120 orientations, and considered the five variables (criteria - Level 2). Each variable was evaluated $n$ factorial times, once for each orientation. As shown in Table 15, fifty orientations were selected; normalization of values was performed; means and standard deviations were collected; and then the final values were applied in the RSV formula, as demonstrated below. 
Table 15: Orientation Table from HDM Numerical

Before Normalization

Normalized Values

\begin{tabular}{|c|c|c|c|c|c|c|c|c|c|c|c|c|}
\hline$\#$ & Orientation & A & B & $\mathrm{C}$ & $\mathrm{D}$ & $\mathrm{E}$ & Sum & A & B & $\mathrm{C}$ & $\mathrm{D}$ & $\mathrm{E}$ \\
\hline 1 & AEBDC & 0.33 & 0.94 & 1.00 & 9.24 & 0.75 & 12.26 & 0.0269 & 0.0767 & 0.0816 & 0.7537 & 0.0612 \\
\hline 2 & ACEDB & 0.67 & 1.00 & 0.70 & 2.14 & 0.43 & 4.94 & 0.1356 & 0.2024 & 0.1417 & 0.4332 & 0.0870 \\
\hline 3 & ADBCE & 0.10 & 5.00 & 0.70 & 2.14 & 1.00 & 8.94 & 0.0112 & 0.5593 & 0.0783 & 0.2394 & 0.1119 \\
\hline 4 & ACDEB & 0.67 & 1.00 & 0.35 & 4.23 & 0.75 & 7.00 & 0.0957 & 0.1429 & 0.0500 & 0.6043 & 0.1071 \\
\hline 5 & ABCED & 0.23 & 5.00 & 0.70 & 1.00 & 0.43 & 7.36 & 0.0313 & 0.6793 & 0.0951 & 0.1359 & 0.0584 \\
\hline 6 & ADCEB & 0.10 & 1.00 & 0.70 & 9.24 & 0.75 & 11.79 & 0.0085 & 0.0848 & 0.0594 & 0.7837 & 0.0636 \\
\hline 7 & ABDEC & 0.23 & 0.94 & 1.00 & 4.23 & 1.87 & 8.27 & 0.0278 & 0.1137 & 0.1209 & 0.5115 & 0.2261 \\
\hline 8 & AEDCB & 0.33 & 1.00 & 0.58 & 9.24 & 0.43 & 11.58 & 0.0285 & 0.0864 & 0.0501 & 0.7979 & 0.0371 \\
\hline 9 & ADEBC & 0.10 & 5.00 & 1.00 & 4.23 & 0.75 & 11.08 & 0.0090 & 0.4513 & 0.0903 & 0.3818 & 0.0677 \\
\hline 10 & AECDB & 0.33 & 1.00 & 0.35 & 2.14 & 1.87 & 5.69 & 0.0580 & 0.1757 & 0.0615 & 0.3761 & 0.3286 \\
\hline 11 & BECDA & 1.00 & 2.42 & 0.35 & 13.42 & 1.87 & 19.06 & 0.0525 & 0.1270 & 0.0184 & 0.7041 & 0.0981 \\
\hline 12 & BDCAE & 0.33 & 0.94 & 3.47 & 9.24 & 1.00 & 14.98 & 0.0220 & 0.0628 & 0.2316 & 0.6168 & 0.0668 \\
\hline 13 & BCADE & 0.10 & 5.00 & 3.47 & 4.23 & 1.00 & 13.80 & 0.0072 & 0.3623 & 0.2514 & 0.3065 & 0.0725 \\
\hline 14 & BDECA & 1.00 & 0.94 & 3.47 & 4.23 & 1.87 & 11.51 & 0.0869 & 0.0817 & 0.3015 & 0.3675 & 0.1625 \\
\hline 15 & BACDE & 0.67 & 15.55 & 0.35 & 4.23 & 1.00 & 21.80 & 0.0307 & 0.7133 & 0.0161 & 0.1940 & 0.0459 \\
\hline 16 & BCAED & 0.33 & 5.00 & 3.47 & 1.00 & 0.43 & 10.23 & 0.0323 & 0.4888 & 0.3392 & 0.0978 & 0.0420 \\
\hline 17 & BADEC & 0.10 & 15.55 & 1.00 & 4.23 & 1.87 & 22.75 & 0.0044 & 0.6835 & 0.0440 & 0.1859 & 0.0822 \\
\hline 18 & BDACE & 0.67 & 0.94 & 0.70 & 13.42 & 1.00 & 16.73 & 0.0400 & 0.0562 & 0.0418 & 0.8022 & 0.0598 \\
\hline
\end{tabular}

品 


\begin{tabular}{|c|c|c|c|c|c|c|c|c|c|c|c|c|}
\hline 19 & BCDAE & 0.33 & 5.00 & 0.35 & 13.42 & 1.00 & 20.10 & 0.0164 & 0.2488 & 0.0174 & 0.6677 & 0.0498 \\
\hline 20 & BADCE & 0.10 & 15.55 & 0.70 & 9.24 & 1.00 & 26.59 & 0.0038 & 0.5848 & 0.0263 & 0.3475 & 0.0376 \\
\hline 21 & CBDAE & 0.33 & 0.94 & 0.58 & 13.42 & 1.00 & 16.27 & 0.0203 & 0.0578 & 0.0356 & 0.8248 & 0.0615 \\
\hline 22 & CBEAD & 0.10 & 2.42 & 0.58 & 1.00 & 5.36 & 9.46 & 0.0106 & 0.2558 & 0.0613 & 0.1057 & 0.5666 \\
\hline 23 & CEABD & 0.23 & 0.94 & 0.70 & 1.00 & 5.36 & 8.23 & 0.0279 & 0.1142 & 0.0851 & 0.1215 & 0.6513 \\
\hline 24 & CEDBA & 1.00 & 15.55 & 0.70 & 2.14 & 0.43 & 19.82 & 0.0505 & 0.7846 & 0.0353 & 0.1080 & 0.0217 \\
\hline 25 & CBEDA & 1.00 & 2.42 & 0.58 & 13.42 & 0.43 & 17.85 & 0.0560 & 0.1356 & 0.0325 & 0.7518 & 0.0241 \\
\hline 26 & CBADE & 0.10 & 15.55 & 0.58 & 4.23 & 1.00 & 21.46 & 0.0047 & 0.7246 & 0.0270 & 0.1971 & 0.0466 \\
\hline 27 & CEBAD & 0.10 & 15.55 & 0.70 & 1.00 & 0.75 & 18.10 & 0.0055 & 0.8591 & 0.0387 & 0.0552 & 0.0414 \\
\hline 28 & CBAED & 0.33 & 15.55 & 0.58 & 1.00 & 0.43 & 17.89 & 0.0184 & 0.8692 & 0.0324 & 0.0559 & 0.0240 \\
\hline 29 & CADEB & 4.23 & 1.00 & 3.47 & 4.23 & 0.75 & 13.68 & 0.3092 & 0.0731 & 0.2537 & 0.3092 & 0.0548 \\
\hline 30 & CBDEA & 1.00 & 0.94 & 0.58 & 4.23 & 5.36 & 12.11 & 0.0826 & 0.0776 & 0.0479 & 0.3493 & 0.4426 \\
\hline 31 & DEACB & 0.67 & 1.00 & 0.58 & 4.23 & 5.36 & 11.84 & 0.0566 & 0.0845 & 0.0490 & 0.3573 & 0.4527 \\
\hline 32 & DECAB & 0.23 & 1.00 & 3.47 & 4.23 & 1.87 & 10.80 & 0.0213 & 0.0926 & 0.3213 & 0.3917 & 0.1731 \\
\hline 33 & DBECA & 1.00 & 2.42 & 3.47 & 2.14 & 1.87 & 10.90 & 0.0917 & 0.2220 & 0.3183 & 0.1963 & 0.1716 \\
\hline 34 & DEBAC & 0.67 & 15.55 & 1.00 & 4.23 & 0.75 & 22.20 & 0.0302 & 0.7005 & 0.0450 & 0.1905 & 0.0338 \\
\hline 35 & DABCE & 0.23 & 5.00 & 0.70 & 13.42 & 1.00 & 20.35 & 0.0113 & 0.2457 & 0.0344 & 0.6595 & 0.0491 \\
\hline 36 & DCEAB & 0.23 & 1.00 & 0.70 & 9.24 & 5.36 & 16.53 & 0.0139 & 0.0605 & 0.0423 & 0.5590 & 0.3243 \\
\hline 37 & DBCEA & 1.00 & 5.00 & 0.70 & 2.14 & 5.36 & 14.20 & 0.0704 & 0.3521 & 0.0493 & 0.1507 & 0.3775 \\
\hline 38 & DBCAE & 0.33 & 5.00 & 3.47 & 2.14 & 1.00 & 11.94 & 0.0276 & 0.4188 & 0.2906 & 0.1792 & 0.0838 \\
\hline 39 & DABEC & 0.23 & 2.42 & 1.00 & 13.42 & 1.87 & 18.94 & 0.0121 & 0.1278 & 0.0528 & 0.7086 & 0.0987 \\
\hline 40 & DCAEB & 0.33 & 1.00 & 3.47 & 9.24 & 0.75 & 14.79 & 0.0223 & 0.0676 & 0.2346 & 0.6247 & 0.0507 \\
\hline
\end{tabular}

古 


\begin{tabular}{|c|c|c|c|c|c|c|c|c|c|c|c|c|}
\hline 41 & EBCDA & 1.00 & 5.00 & 0.35 & 13.42 & 0.75 & 20.52 & 0.0487 & 0.2437 & 0.0171 & 0.6540 & 0.0365 \\
\hline 42 & EBCAD & 0.10 & 5.00 & 3.47 & 1.00 & 0.75 & 10.32 & 0.0097 & 0.4845 & 0.3362 & 0.0969 & 0.0727 \\
\hline 43 & EBDAC & 0.67 & 0.94 & 1.00 & 13.42 & 0.75 & 16.78 & 0.0399 & 0.0560 & 0.0596 & 0.7998 & 0.0447 \\
\hline 44 & EDCBA & 1.00 & 15.55 & 0.58 & 9.24 & 0.43 & 26.80 & 0.0373 & 0.5802 & 0.0216 & 0.3448 & 0.0160 \\
\hline 45 & EACBD & 0.67 & 0.94 & 0.58 & 1.00 & 5.36 & 8.55 & 0.0784 & 0.1099 & 0.0678 & 0.1170 & 0.6269 \\
\hline 46 & EADCB & 0.10 & 1.00 & 0.58 & 9.24 & 5.36 & 16.28 & 0.0061 & 0.0614 & 0.0356 & 0.5676 & 0.3292 \\
\hline 47 & ECBDA & 1.00 & 0.94 & 0.58 & 13.42 & 1.87 & 17.81 & 0.0561 & 0.0528 & 0.0326 & 0.7535 & 0.1050 \\
\hline 48 & EADBC & 0.10 & 5.00 & 1.00 & 2.14 & 5.36 & 13.60 & 0.0074 & 0.3676 & 0.0735 & 0.1574 & 0.3941 \\
\hline 49 & EBACD & 0.67 & 15.55 & 0.35 & 1.00 & 0.75 & 18.32 & 0.0366 & 0.8488 & 0.0191 & 0.0546 & 0.0409 \\
\hline 50 & ECDBA & 1.00 & 15.55 & 0.35 & 2.14 & 1.87 & 20.91 & 0.0478 & 0.7437 & 0.0167 & 0.1023 & 0.0894 \\
\hline & & & & & & & Mean & 0.04080 & 0.31707 & 0.09767 & 0.39702 & 0.14743 \\
\hline & & & & & & & Variance & 0.00233 & 0.07354 & 0.01020 & 0.06624 & 0.02775 \\
\hline & & & & & & & $\begin{array}{l}\text { Standard } \\
\text { division }\end{array}$ & 0.04822 & 0.27119 & 0.10098 & 0.25736 & 0.16657 \\
\hline
\end{tabular}


"RSV is the square root of the sum of variances while the current measure is the average standard deviation" [298].

Expert 4 - inconsistency calculation using standard division (HDM software):

$$
\begin{aligned}
& \text { Inconsistency }=\frac{1}{n} \sum_{i=1}^{n} \sqrt{\frac{1}{n !} \sum_{j=1}^{n !}\left(\bar{r}_{i}-r_{i j}\right)^{2}} \\
& \text { Inconsistency }=\sqrt{\frac{1}{5}}\left[(0.04822)^{2}+(0.27119)^{2}+(0.10098)^{2}+(0.25736)^{2}+\right. \\
& \left.(0.16657)^{2}\right] \\
& \text { Inconsistency }=\sqrt{\frac{1}{5}}(0.1799) \\
& \text { Inconsistency }=0.17
\end{aligned}
$$

Expert 4 - inconsistency calculation using RSV (Abba's New Calculation):

$$
\begin{aligned}
& R S V=\sqrt{ } \sum_{1}^{n} \sigma 2 n \\
& R S V=\sqrt{ } 0.00233+\sqrt{ } 0.07354+\sqrt{ } 0.01020+\sqrt{ } 0.06624+\sqrt{ } 0.02775 \\
& R S V=\sqrt{ } 0.18005 \\
& R S V=0.42
\end{aligned}
$$




\begin{tabular}{|c|c|c|c|c|c|c|c|c|c|c|}
\hline \multirow[b]{2}{*}{ Percentile $(\alpha)$} & \multicolumn{10}{|c|}{ Number of variables } \\
\hline & 3 & 4 & 5 & 6 & 7 & 8 & 9 & 10 & 11 & 12 \\
\hline 0.01 & 0.0001 & 0.0183 & 0.1495 & 0.3012 & 0.4249 & 0.5100 & 0.5723 & 0.6170 & 0.6521 & 0.6500 \\
\hline 0.02 & 0.0002 & 0.0418 & 0.1934 & 0.3462 & 0.4620 & 0.5400 & 0.5961 & 0.6371 & 0.6690 & 0.6945 \\
\hline 0.03 & 0.0005 & 0.0596 & 0.2230 & 0.3745 & 0.4847 & 0.5581 & 0.6105 & 0.6493 & 0.6793 & 0.7034 \\
\hline 0.04 & 0.0009 & 0.0748 & 0.2460 & 0.3955 & 0.5012 & 0.5713 & 0.6211 & 0.6582 & 0.6868 & 0.7100 \\
\hline 0.05 & 0.0014 & 0.0884 & 0.2651 & 0.4124 & 0.5143 & 0.5818 & 0.6295 & 0.6653 & 0.6928 & 0.7152 \\
\hline 0.06 & 0.0021 & 0.1008 & 0.2816 & 0.4266 & 0.5253 & 0.5904 & 0.6365 & 0.6712 & 0.6978 & 0.7196 \\
\hline 0.07 & 0.0028 & 0.1124 & 0.2963 & 0.4390 & 0.5347 & 0.5979 & 0.6425 & 0.6763 & 0.7022 & 0.7234 \\
\hline 0.08 & 0.0037 & 0.1233 & 0.3095 & 0.4499 & 0.5430 & 0.6045 & 0.6478 & 0.6807 & 0.7060 & 0.7267 \\
\hline 0.09 & 0.0046 & 0.1337 & 0.3215 & 0.4597 & 0.5505 & 0.6104 & 0.6526 & 0.6348 & 0.7095 & 0.7298 \\
\hline 0.10 & 0.0057 & 0.1437 & 0.3327 & 0.4686 & 0.5572 & 0.6157 & 0.6569 & 0.6884 & 0.7126 & 0.7325 \\
\hline 0.11 & 0.0069 & 0.1532 & 0.3430 & 0.4769 & 0.5634 & 0.6206 & 0.6609 & 0.6918 & 0.7155 & 0.7350 \\
\hline 0.12 & 0.0083 & 0.1625 & 0.3528 & 0.4845 & 0.5691 & 0.6252 & 0.6646 & 0.6949 & 0.7182 & 0.7374 \\
\hline 0.13 & 0.0097 & 0.1714 & 0.3620 & 0.4916 & 0.5745 & 0.6294 & 0.6681 & 0.6978 & 0.7207 & 0.7396 \\
\hline 0.14 & 0.0113 & 0.1801 & 0.3706 & 0.4983 & 0.5795 & 0.6334 & 0.6713 & 0.7005 & 0.7231 & 0.7417 \\
\hline 0.15 & 0.0129 & 0.1886 & 0.3789 & 0.5047 & 0.5842 & 0.6371 & 0.6743 & 0.7031 & 0.7253 & 0.7436 \\
\hline 0.16 & 0.0147 & 0.1969 & 0.3858 & 0.5106 & 0.5887 & 0.6406 & 0.6772 & 0.7056 & 0.7274 & 0.7455 \\
\hline 0.17 & 0.0166 & 0.2050 & 0.3944 & 0.5163 & 0.5929 & 0.6440 & 0.6200 & 0.7079 & 0.7294 & 0.7473 \\
\hline 0.18 & 0.0187 & 0.2129 & 0.4016 & 0.5218 & 0.5970 & 0.6472 & 0.6826 & 0.7101 & 0.7313 & 0.7490 \\
\hline 0.19 & 0.0207 & 0.2207 & 0.4086 & 0.5270 & 0.6009 & 0.6502 & 0.6851 & 0.7122 & 0.7332 & 0.7506 \\
\hline 0.20 & 0.0230 & 0.2283 & 0.4154 & 0.5320 & 0.6046 & 0.6532 & 0.6875 & 0.7143 & 0.7350 & 0.7521 \\
\hline 0.21 & 0.0254 & 0.2359 & 0.4219 & 0.5368 & 0.6081 & 0.6560 & 0.6899 & 0.7163 & 0.7367 & 0.7537 \\
\hline 0.22 & 0.0281 & 0.2433 & 0.4282 & 0.5414 & 0.6116 & 0.6587 & 0.6921 & 0.7182 & 0.7383 & 0.7551 \\
\hline 0.23 & 0.0306 & 0.2506 & 0.4343 & 0.5459 & 0.6149 & 0.6614 & 0.6943 & 0.7200 & 0.7399 & 0.7565 \\
\hline 0.24 & 0.0334 & 0.2578 & 0.4403 & 0.5502 & 0.6181 & 0.6639 & 0.6964 & 0.7218 & 0.7415 & 0.7579 \\
\hline 0.25 & 0.0363 & 0.2648 & 0.4461 & 0.5544 & 0.6212 & 0.6664 & 0.6984 & 0.7235 & 0.7430 & 0.7592 \\
\hline
\end{tabular}

Figure 31: Inconsistency Threshold Limits at $\alpha=0.01$ to $\alpha=0.25$ [298]

As shown in Figure 32, the inconsistency using the RSV calculation showed that the result is 0.42 . The value of $\operatorname{RSV}(0.42)$ for $n=5$ corresponds to $\alpha=0.21$. This value represents a somewhat high inconsistency [298]. It means there is 0.21 probability that there is randomness in the judgments [299] provided by Expert 4 on the criteria in Level 2. This judgment is based on the threshold limits that are presented by Abbas [298]. Yildiz, $\mathrm{B}$ (2018), in his dissertation, emphasizes that (at $\alpha=0.21$ ) if there is no change in the level's priorities, the relative weights of the inconsistency level might be negligible. The Exp 4's input was removed in order to test its impact on the criteria priorities. The new calculation 
showed that there was no change in the priorities. Therefore, Expert 4's input was not omitted from the calculation, and was used in the following processes.

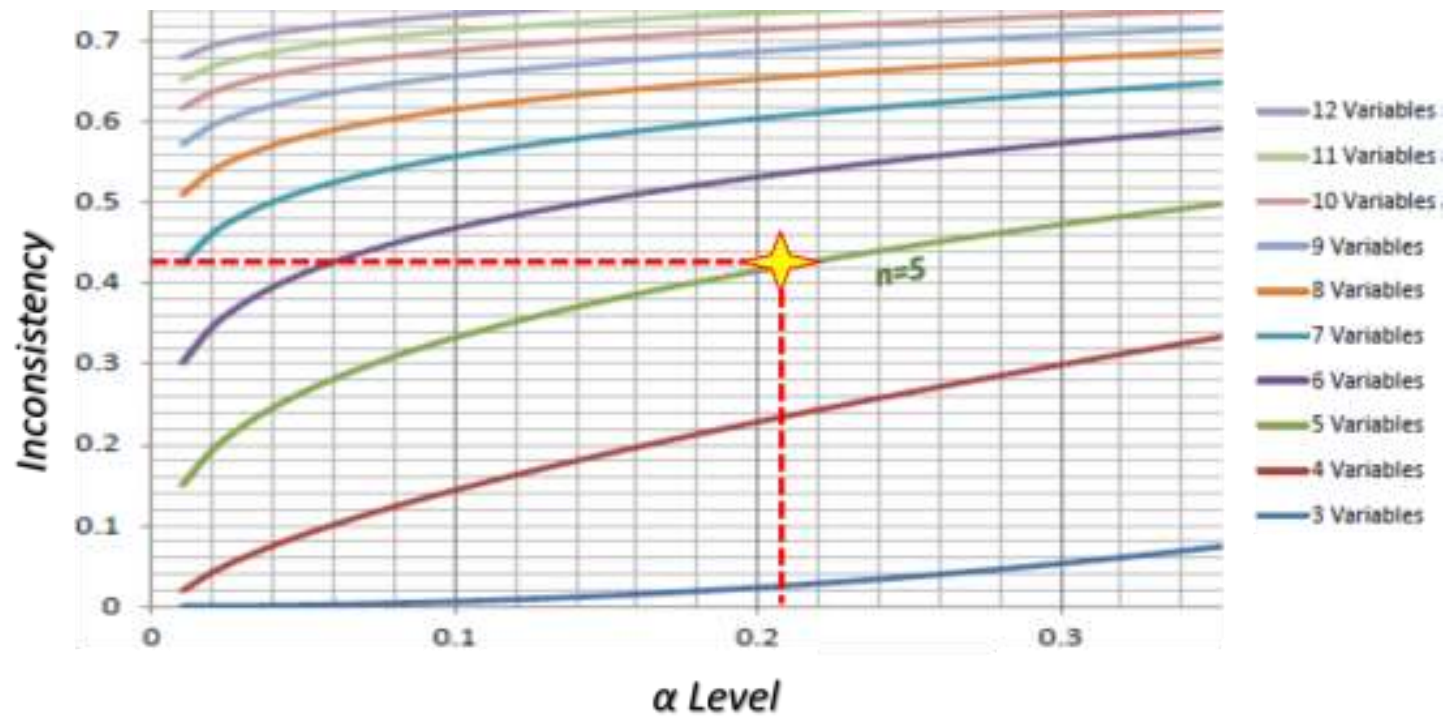

Figure 32: Inconsistency Threshold for Five Variables

Overall, the results showed that the mean level of disagreement was 0.072 between all experts in the EP1, which is below the value of 0.1 . Therefore, the group disagreement is accepted.

\subsubsection{F-Test}

An F-test was also utilized to analyze disagreement among experts. The criteria level was tested to approve if there were any significant arguments among them. Different experts assigned different values; however, the disagreements in the panel were measured and tested for statistical significance [299]. Figure 33 shows the F-Test values for disagreements at the criteria level. 


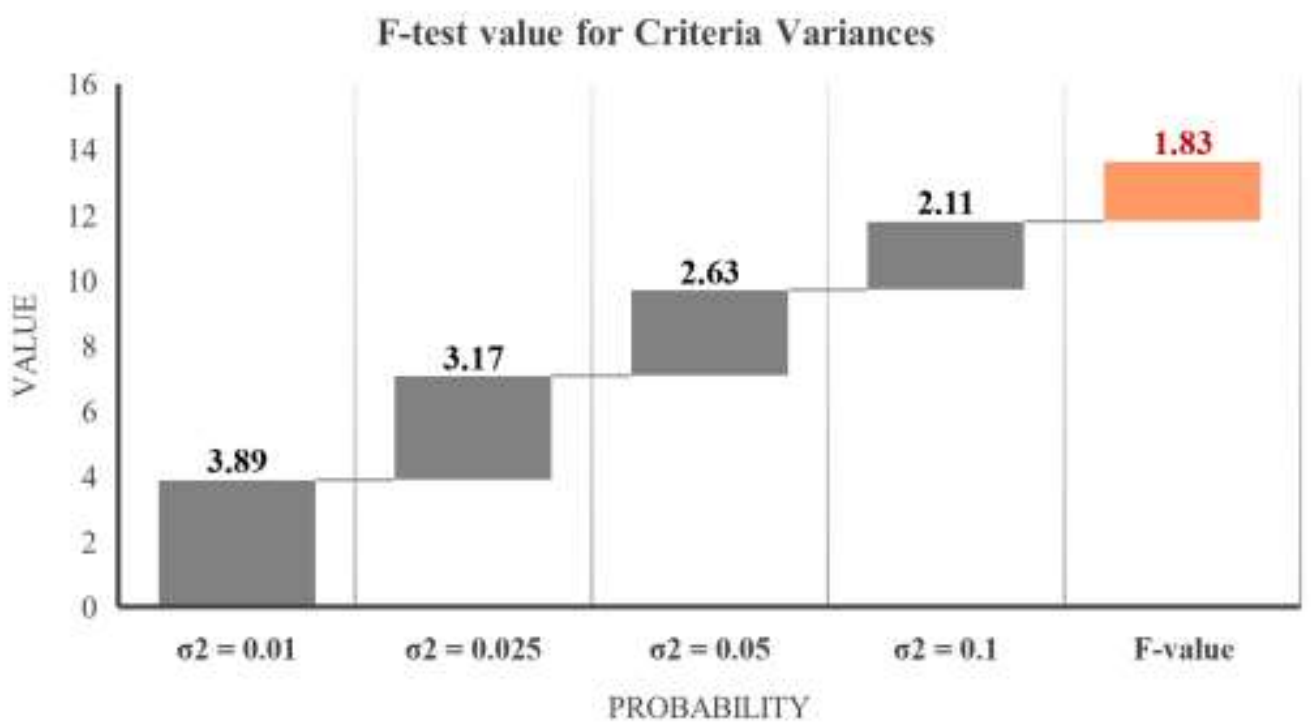

Figure 33: F-Test Values for Disagreements at the Criteria Level

The F-Test value is 1.83 for criteria Level 2. The null hypothesis cannot be rejected at 0.1 level. There is strong disagreement at the criteria level. The impact of Exp 4's judgments inconsistency was determined not to have an impact on the overall rank of criteria level. An extra calculation of his inconsistency level was performed using Abaas's last calculations development (RSV) to assess his impact on the whole criteria priorities. The new inconsistency indicated to $8.4 \%$, which is below the maximum fixed $10 \%$ threshold.

\subsubsection{Analysis of Expert Panels Sub-criteria Results - Level 3}

In this stage, forty-eight experts were invited to participated in assessing the relative contribution of nineteen sub-criteria of the main five criteria. All experts had knowledge 
and experience in project management and the transportation industry. They gave their judgment on the decision model elements using the HDM software. The RI4 was used by EP2, EP3, EP4, EP5, and EP6 to quantify the model sub-criteria (Level 3) with respect to the criteria (Level 2). The overall results of the comparison were acceptable among expert panels in this stage, and the disagreement level was less than 0.1 in each panel.

\subsubsection{Expert Panel (EP2) Cost Sub-criteria}

Three sub-criteria (Reducing Capital Cost, Offering Life-Cycle-Cost Reduction, and Minimizing Project Support Costs) were evaluated by nine experts in the EP2. The experts were asked to assess the relative contribution of the three sub-criteria to the cost criterion using pair-wise comparison through HDM software (RI4).

As shown in Table 16, the green box indicates the highest weight among the three subcriteria under the Cost criterion. The outcome analysis of EP2 results in Figure 34 shows that Capital Cost is rated at the highest value at 0.52 while Project Support Costs shows as the lowest at 0.23 . The individual expert's judgments were among the acceptable range. 
Table 16: Analysis of the Cost Sub-criteria

\begin{tabular}{|lcccc|}
\hline Cost & Capital Cost & $\begin{array}{c}\text { Life-Cycle-Cost } \\
\text { (LCC) }\end{array}$ & $\begin{array}{c}\text { Project } \\
\text { Support Costs }\end{array}$ & Inconsistency \\
\hline Exp 11 & 0.59 & 0.24 & 0.16 & 0.01 \\
Exp 12 & 0.48 & 0.29 & 0.24 & 0.01 \\
Exp 13 & 0.51 & 0.23 & 0.26 & 0.02 \\
Exp 14 & 0.35 & 0.42 & 0.23 & 0.01 \\
Exp 15 & 0.72 & 0.12 & 0.15 & 0 \\
Exp 16 & 0.58 & 0.14 & 0.28 & 0.04 \\
Exp 17 & 0.59 & 0.15 & 0.26 & 0.02 \\
Exp 18 & 0.55 & 0.19 & 0.26 & 0 \\
Exp 19 & 0.33 & 0.41 & 0.26 & 0.01 \\
\hline Mean & 0.52 & 0.24 & 0.23 & \\
\hline Minimum & 0.33 & 0.12 & 0.15 & \\
Maximum & 0.72 & 0.42 & 0.28 & \\
Std. & 0.12 & 0.1 & 0.04 & 0.081 \\
Deviation & & & & \\
Disagreement & & & & \\
\hline
\end{tabular}

Relative Importance of Cost Sub-criteria - Level 3

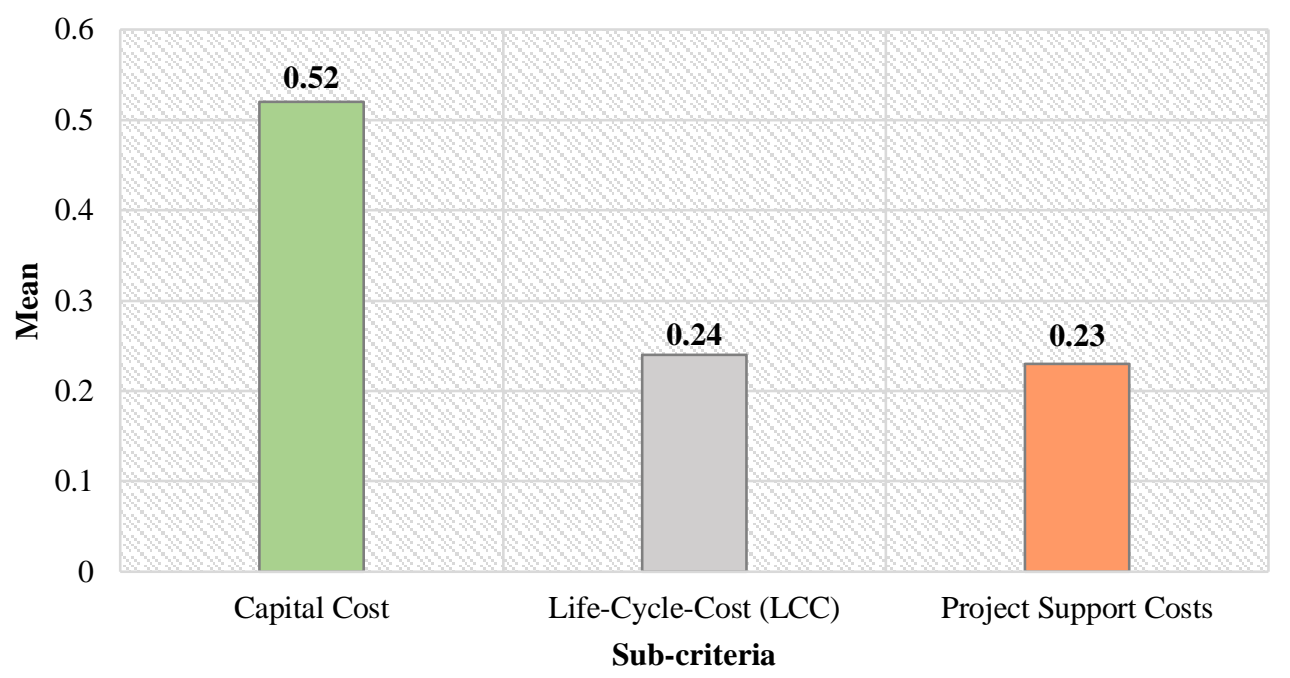

Figure 34: Relative Importance of Cost Sub-criteria 


\subsubsection{Expert Panel (EP3) Schedule sub-criteria}

Four sub-criteria (Project Design \& Environmental Analysis, Right-of-Way (ROW) Acquisition, Project Tender \& Construction Duration, and Project Closeout Activities Duration) were evaluated by eleven experts in the EP3. The experts were asked to assess the relative contribution of the four sub-criteria to the Schedule criterion using pair-wise comparison through HDM software (RI4). As shown in Table 17, the green indicates the highest weight among the four sub-criteria under the Schedule criterion. The outcome analysis of EP3 results in Figure 35 shows that the Project Design \& Environmental Analysis was rated at the highest value at 0.39 while Project Closeout Activities Duration showed the lowest at 0.14 . The individual expert's judgments were among the acceptable range. 
Table 17: Analysis of the Schedule Sub-criteria

\begin{tabular}{|lcclcc|}
\hline Schedule & $\begin{array}{c}\text { Project } \\
\text { Design \& } \\
\text { Environmental } \\
\text { Analysis }\end{array}$ & $\begin{array}{c}\text { Right-of- } \\
\text { Way (ROW) } \\
\text { Acquisition }\end{array}$ & $\begin{array}{l}\text { Project } \\
\text { Tender \& } \\
\text { Construction } \\
\text { Duration }\end{array}$ & $\begin{array}{c}\text { Project } \\
\text { Closeout } \\
\text { Activities } \\
\text { Duration }\end{array}$ & Inconsistency \\
\hline Exp 20 & 0.33 & 0.24 & 0.22 & 0.21 & 0 \\
Exp 8 & 0.33 & 0.28 & 0.26 & 0.13 & 0.01 \\
Exp 21 & 0.38 & 0.25 & 0.21 & 0.16 & 0.07 \\
Exp 22 & 0.41 & 0.34 & 0.15 & 0.1 & 0.01 \\
Exp 23 & 0.59 & 0.23 & 0.1 & 0.08 & 0.01 \\
Exp 24 & 0.32 & 0.25 & 0.23 & 0.19 & 0.01 \\
Exp 25 & 0.34 & 0.28 & 0.22 & 0.16 & 0.02 \\
Exp 26 & 0.31 & 0.27 & 0.24 & 0.17 & 0.02 \\
Exp 27 & 0.32 & 0.29 & 0.24 & 0.15 & 0.01 \\
Exp 28 & 0.57 & 0.16 & 0.18 & 0.08 & 0.04 \\
Exp 29 & 0.36 & 0.16 & 0.36 & 0.12 & 0.01 \\
\hline Mean & 0.39 & 0.25 & 0.22 & 0.14 & \\
\hline Minimum & 0.31 & 0.16 & 0.1 & 0.08 & \\
Maximum & 0.59 & 0.34 & 0.36 & 0.21 & \\
Std. & 0.1 & 0.05 & 0.06 & 0.04 & 0.057 \\
Deviation & & & & & \\
Disagreement & & & & & \\
\hline
\end{tabular}

Relative Importance of Schedual Sub-criteria - Level 3

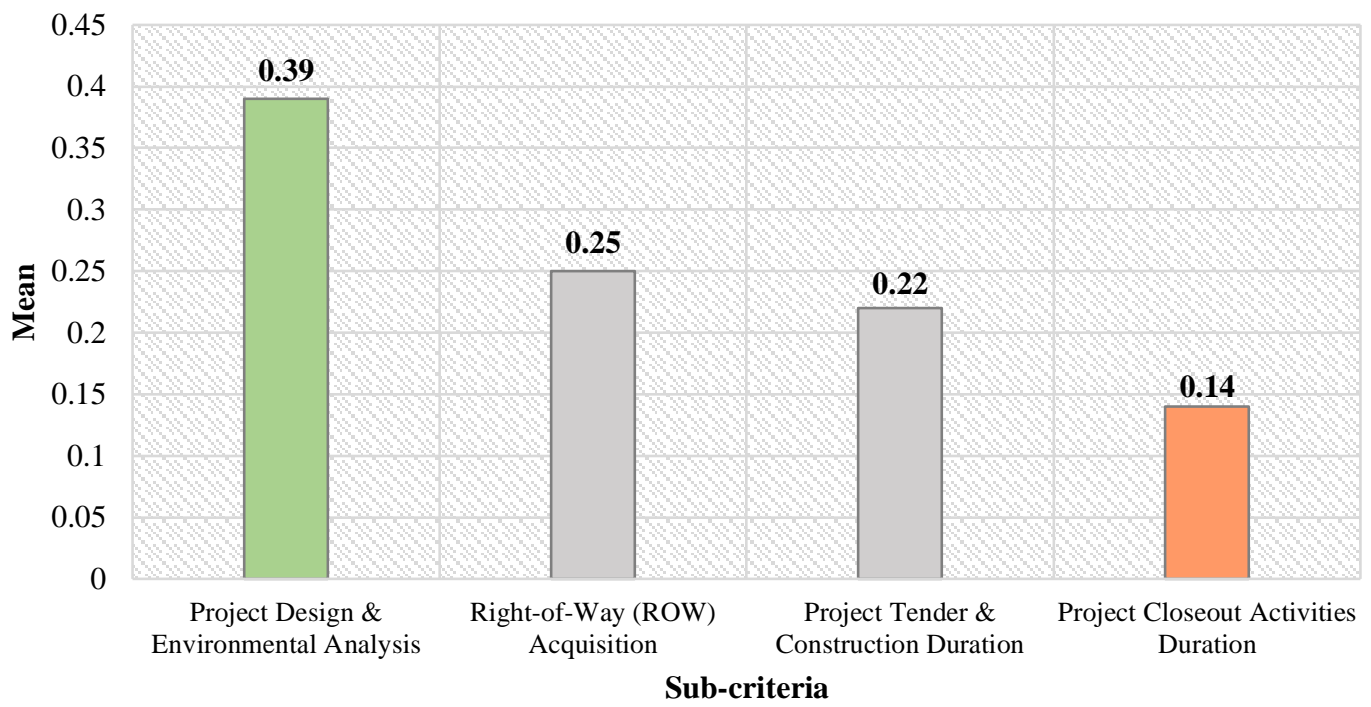

Figure 35: Relative Importance of Schedule Sub-criteria 


\subsubsection{Expert Panel (EP4) Risk sub-criteria}

Four sub-criteria (Identifying Project Performance Risk Impact, Project Cost Risk Impact, Project Support Costs Risk Impact, and Project Schedule Risk Impact) were evaluated by twelve experts in the EP4. Expert 38 was omitted from the qualification process because he didn't submit his final judgments. The experts were asked to assess the relative contribution of the four sub-criteria to the Risk criterion using pair-wise comparison through HDM software (RI4). As shown in Table 18, the green box indicates the highest weight among the four sub-criteria under the Risk criterion. The outcome analysis of EP4 results in Figure 36 show that the Project Cost Risk Impact was rated the highest value at 0.31 while Project Support Costs Risk Impact show the lowest at 0.18 . The individual expert's judgments were among the acceptable range. 
Table 18: Analysis of the Risk Sub-criteria

\begin{tabular}{|lccccc|}
\hline Risk & $\begin{array}{c}\text { Project } \\
\text { Performance } \\
\text { Risk Impact }\end{array}$ & $\begin{array}{c}\text { Project Cost } \\
\text { Risk Impact }\end{array}$ & $\begin{array}{c}\text { Project } \\
\text { Support Costs } \\
\text { Risk Impact }\end{array}$ & $\begin{array}{c}\text { Project } \\
\text { Schedule } \\
\text { Risk Impact }\end{array}$ & Inconsistency \\
\hline Exp 5 & 0.22 & 0.3 & 0.29 & 0.2 & 0.01 \\
Exp 30 & 0.38 & 0.22 & 0.19 & 0.2 & 0.03 \\
Exp 31 & 0.28 & 0.27 & 0.18 & 0.27 & 0 \\
Exp 32 & 0.31 & 0.27 & 0.17 & 0.24 & 0 \\
Exp 33 & 0.27 & 0.27 & 0.17 & 0.28 & 0.03 \\
Exp 34 & 0.25 & 0.29 & 0.21 & 0.25 & 0 \\
Exp 35 & 0.25 & 0.4 & 0.16 & 0.19 & 0.02 \\
Exp 36 & 0.26 & 0.38 & 0.17 & 0.19 & 0.03 \\
Exp 37 & 0.2 & 0.28 & 0.17 & 0.35 & 0.02 \\
Exp 39 & 0.28 & 0.27 & 0.19 & 0.27 & 0 \\
Exp 40 & 0.23 & 0.47 & 0.09 & 0.21 & 0.04 \\
\hline Mean & 0.27 & 0.31 & 0.18 & 0.24 & \\
\hline Minimum & 0.2 & 0.22 & 0.09 & 0.19 & \\
Maximum & 0.38 & 0.47 & 0.29 & 0.35 & \\
Std. & 0.05 & 0.07 & 0.04 & 0.05 & 0.048 \\
Deviation & & & & & \\
Disagreement & & & & & \\
\hline
\end{tabular}

Relative Importance of Risk Sub-criteria - Level 3

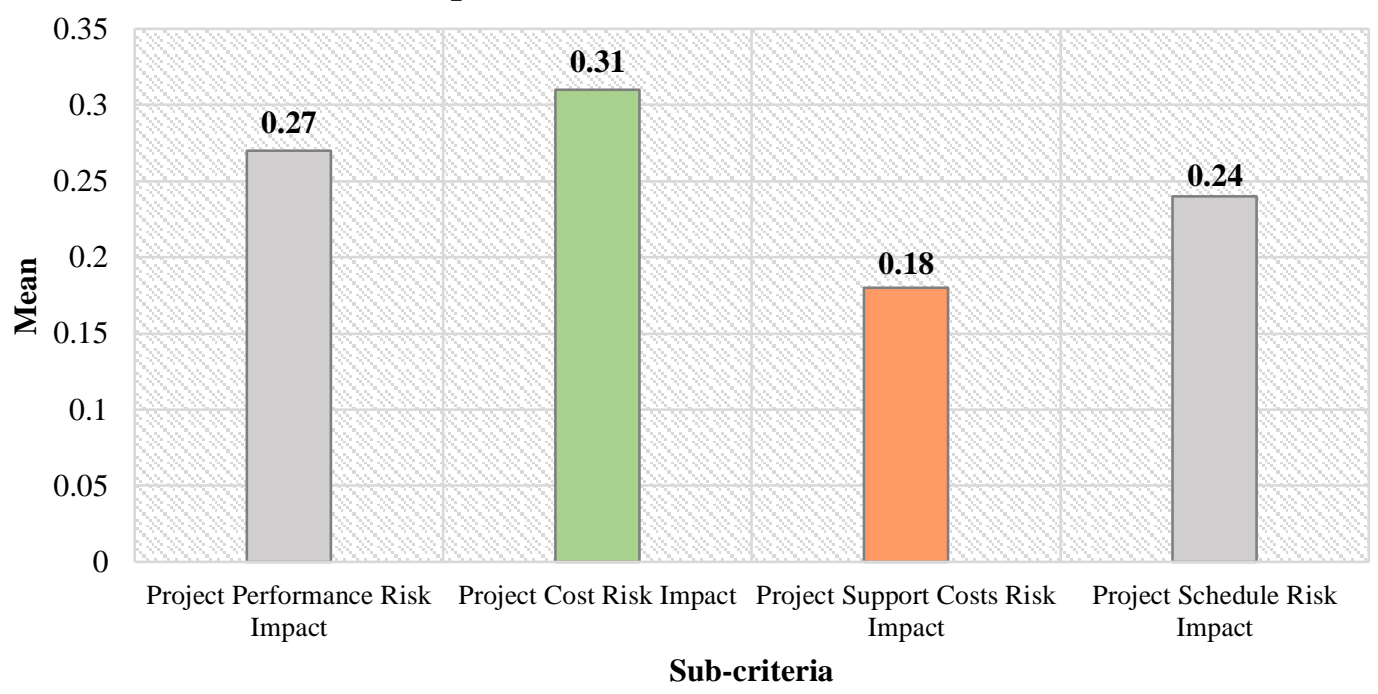

Figure 36: Relative Importance of Risk Sub-criteria 


\subsubsection{Expert Panel (EP5) Performance sub-criteria}

Four sub-criteria (Project Scope, Project Needed Functions, Communication and Integration Capabilities, and Stakeholder Needs) were evaluated by ten experts in the EP5. The experts were asked to assess the relative contribution of the four sub-criteria to the Performance criterion using pair-wise comparison through HDM software (RI4).

As shown in Table 19, the green indicates to the highest weight among the four subcriteria under the performance criterion. The outcome analysis of EP5 results in Figure 37 showed that the Project Needed Functions was rated at the highest value at 0.34 while Project Scope showed the lowest at 0.2. The individual expert's judgments were among the acceptable range. 
Table 19: Analysis of the Performance Sub-criteria

\begin{tabular}{|lccccc|}
\hline Performance & $\begin{array}{c}\text { Project } \\
\text { Scope }\end{array}$ & $\begin{array}{c}\text { Project } \\
\text { Needed } \\
\text { Functions }\end{array}$ & $\begin{array}{c}\text { Communication } \\
\text { and Integration } \\
\text { Capabilities }\end{array}$ & $\begin{array}{c}\text { Stakeholder } \\
\text { Needs }\end{array}$ & Inconsistency \\
\hline Exp 13 & 0.23 & 0.3 & 0.28 & 0.2 & 0.01 \\
Exp 41 & 0.19 & 0.39 & 0.15 & 0.27 & 0.03 \\
Exp 42 & 0.17 & 0.33 & 0.2 & 0.3 & 0.03 \\
Exp 43 & 0.2 & 0.3 & 0.2 & 0.31 & 0.03 \\
Exp 44 & 0.13 & 0.38 & 0.19 & 0.3 & 0 \\
Exp 45 & 0.2 & 0.33 & 0.18 & 0.29 & 0.01 \\
Exp 46 & 0.22 & 0.32 & 0.24 & 0.22 & 0.02 \\
Exp 47 & 0.17 & 0.47 & 0.14 & 0.22 & 0.02 \\
Exp 48 & 0.23 & 0.29 & 0.24 & 0.25 & 0.02 \\
Exp 49 & 0.25 & 0.24 & 0.27 & 0.23 & 0.06 \\
\hline Mean & 0.2 & 0.34 & 0.21 & 0.26 & \\
\hline Minimum & 0.13 & 0.24 & 0.14 & 0.2 & \\
Maximum & 0.25 & 0.47 & 0.28 & 0.31 & \\
Std. & 0.03 & 0.06 & 0.05 & 0.04 & \\
Deviation & & & & & 0.042 \\
Disagreement & & & & & \\
\hline
\end{tabular}

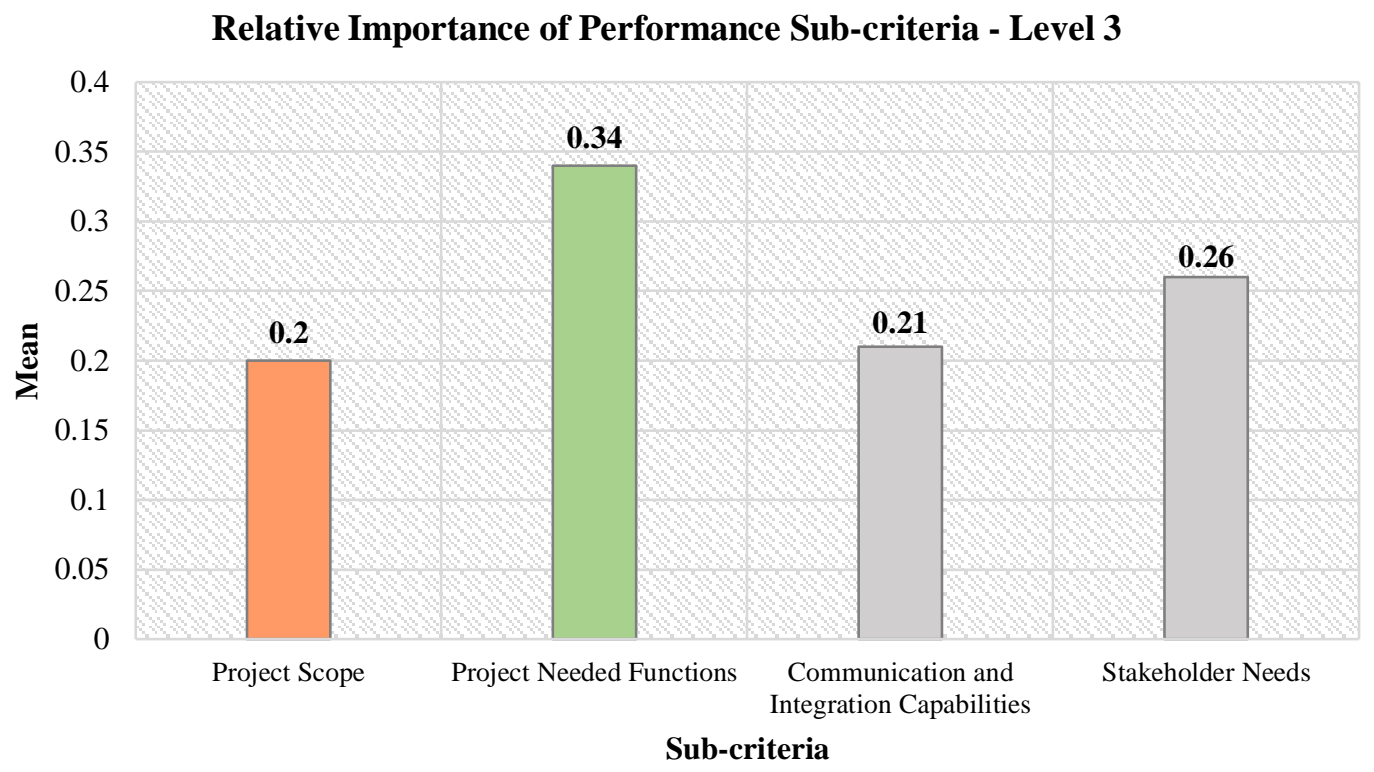

Figure 37: Relative Importance of Performance Sub-criteria 


\subsubsection{Expert Panel (EP6) Resources sub-criteria}

Four sub-criteria (In-house Capability, External Consultant Needs, Time Needs during using the Technique, and Project Stakeholder Involvement) were evaluated by eight experts in the EP6. Exp 43 was omitted from the qualification process because he didn't submit his final judgments. The experts were asked to assess the relative contribution of the four sub-criteria to the Resources criterion using pair-wise comparison through HDM software (RI4).

As shown in Table 20, the green box indicates the highest weight among the four subcriteria under the Resources criterion. The outcome analysis of EP6 results in Figure 38 shows that In-house Capability criterion was rated at the highest value at 0.42 while External Consultant Needs was rated the lowest at 0.17 . The individual expert's judgments were among the acceptable range. 
Table 20: Analysis of the Resources Sub-criteria

\begin{tabular}{|lccccc|}
\hline Resources & $\begin{array}{c}\text { In-house } \\
\text { Capability }\end{array}$ & $\begin{array}{c}\text { External } \\
\text { Consultant } \\
\text { Needs }\end{array}$ & $\begin{array}{c}\text { Time Needs } \\
\text { during using } \\
\text { the Technique }\end{array}$ & $\begin{array}{c}\text { Project } \\
\text { Stakeholder } \\
\text { Involvement }\end{array}$ & Inconsistency \\
\hline Exp 50 & 0.47 & 0.16 & 0.14 & 0.23 & 0.01 \\
Exp 44 & 0.28 & 0.27 & 0.21 & 0.24 & 0 \\
Exp 41 & 0.58 & 0.12 & 0.16 & 0.14 & 0.02 \\
Exp 42 & 0.36 & 0.21 & 0.19 & 0.24 & 0.06 \\
Exp 44 & 0.52 & 0.1 & 0.26 & 0.11 & 0.03 \\
Exp 45 & 0.3 & 0.2 & 0.29 & 0.21 & 0.01 \\
Exp 46 & 0.4 & 0.15 & 0.2 & 0.25 & 0.01 \\
\hline Mean & 0.42 & 0.17 & 0.21 & 0.2 & \\
\hline Minimum & 0.28 & 0.1 & 0.14 & 0.11 & \\
Maximum & 0.58 & 0.27 & 0.29 & 0.25 & \\
Std. & 0.1 & 0.05 & 0.05 & 0.05 & \\
Deviation & & & & & 0.064 \\
Disagreement & & & & & \\
\hline
\end{tabular}

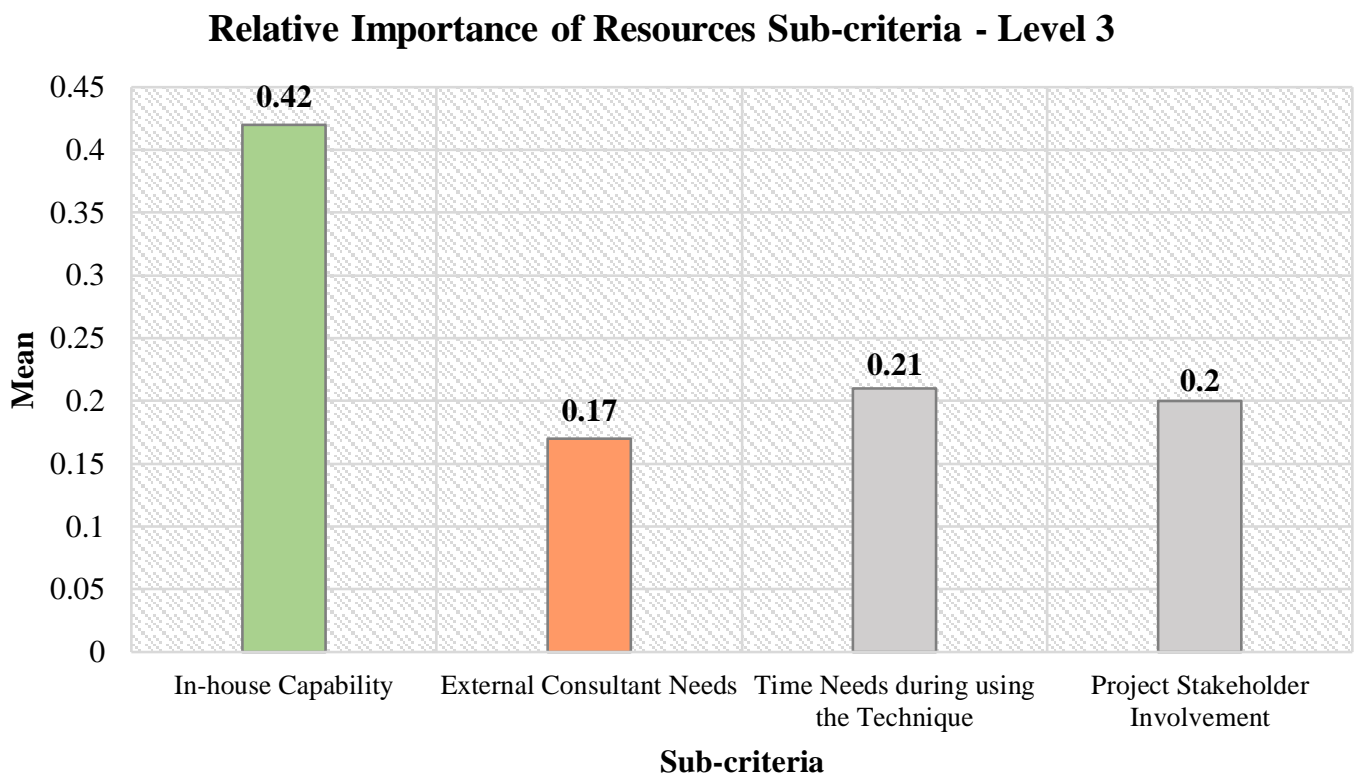

Figure 38: Relative Importance of Resources Sub-criteria 


\subsubsection{Inconsistency and Disagreement}

The research defined the inconsistency for the Hierarchical Decision Model (HDM) as the Root of the Sum of Variances (RSV) of the known number of decision variables [298]. The inconsistency value can be determined by calculating the square root of the sum of variances of the means of number variables [300]. In this Level 3, the individual inconsistency was acceptable for all sub-criteria. All results indicate that the inconsistency level was less than 0.10 . The disagreement at this level is measured among nineteen subcriteria with respect to the five criteria. The Cost, Schedule, Risk, Performance, and Resources sub-criteria received low disagreement level $(0.081,0.057,0.048,0.042$, and 0.064 , respectively). Since the acceptable limit for disagreement is 0.1 , these values are considered an acceptable level of disagreement.

\subsubsection{F-Test}

F-test was used as a secondary measure for disagreement at the sub-criteria level to analyze disagreement among experts. The F-test value was 16.36 for Cost, 18.4 for Schedule, 7.83 for Risk, 12.59 for Performance, and 11.98 for Resources sub-criteria. Since the computed F-value was significantly higher than F-critical, the null hypothesis was rejected [184]. In this research, the F-test confirmed that there was no statistically significant difference among the experts in panels EP2, EP3, EP4, EP5 and EP6 regarding Level 3 with respect to Level 2. Therefore, the null hypothesis was still rejected at 0.1 . 
The F-test results for each criterion are shown in Figure 39 through 43, and summarized in Table 21.

Figure 39 shows the disagreement among experts at Cost sub-criteria.

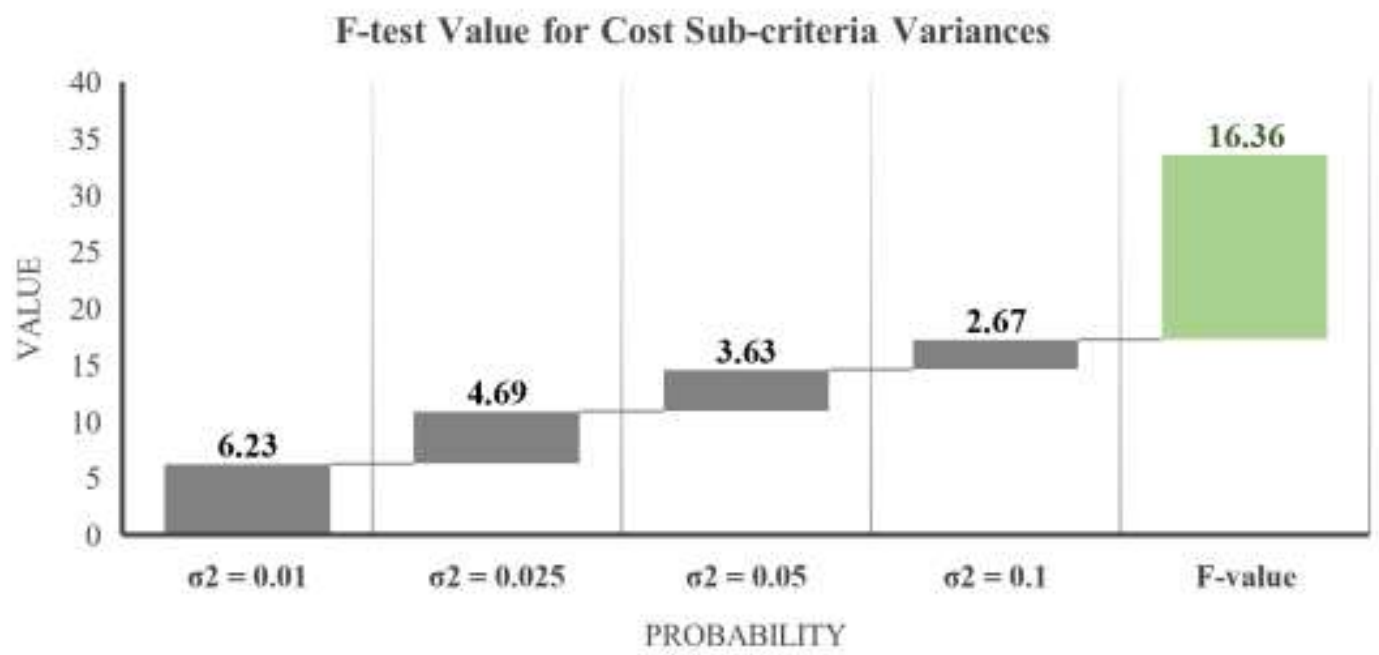

Figure 39: F-Test Values for Cost Sub-criteria

Figure 40 shows the disagreement among experts at Schedule sub-criteria.

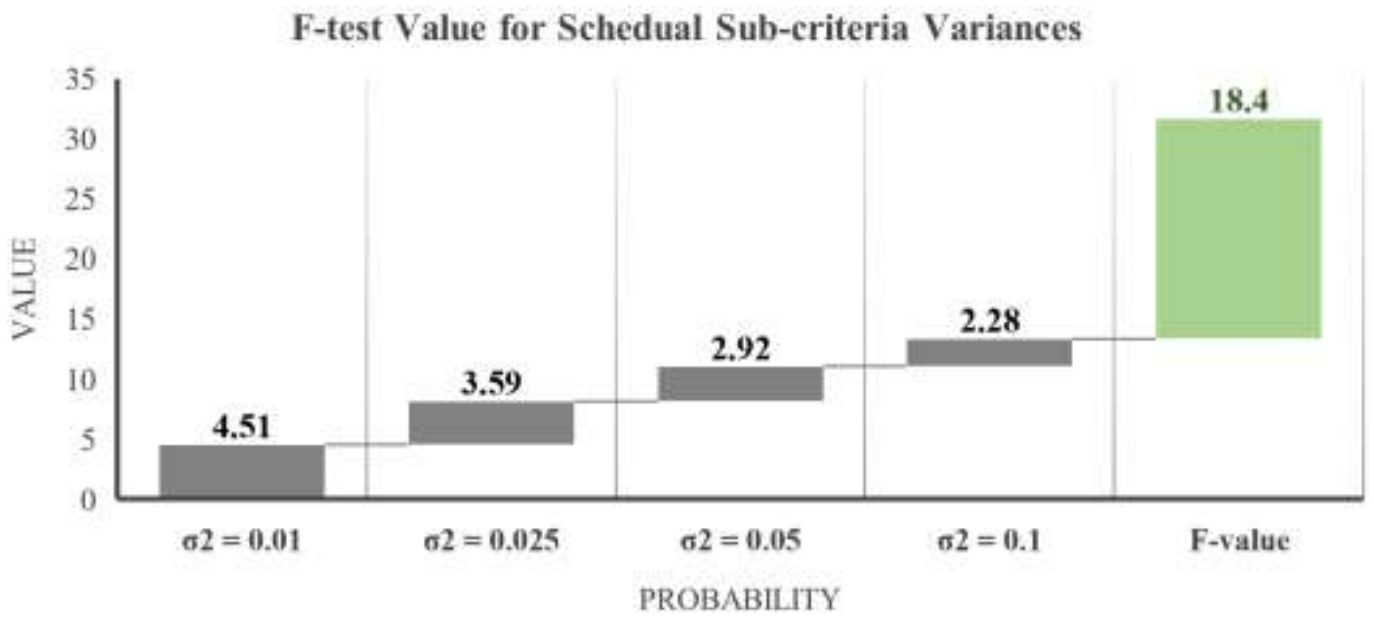

Figure 40: F-Test Values for Schedule Sub-criteria 
Figure 41 shows the disagreement among experts at Risk sub-criteria.

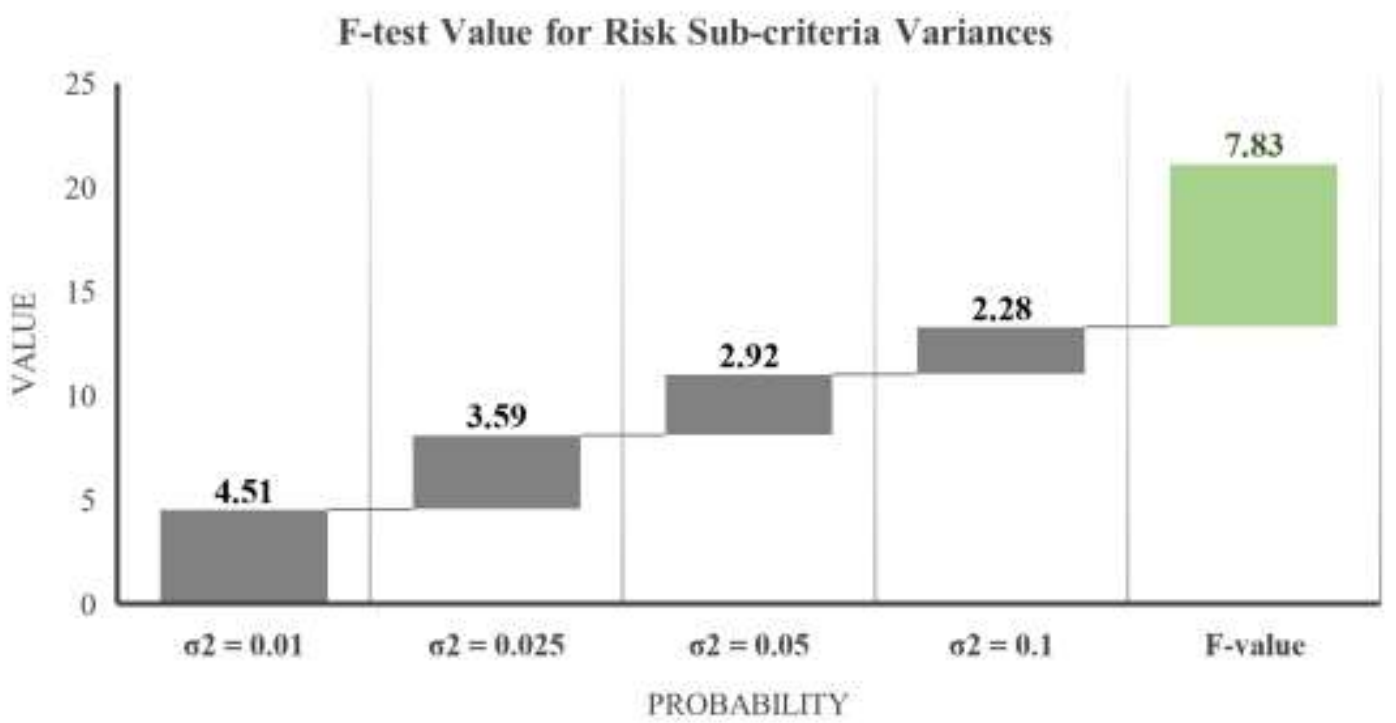

Figure 41: F-Test Values for Risk Sub-criteria

Figure 42 shows the disagreement among experts at Performance sub-criteria.

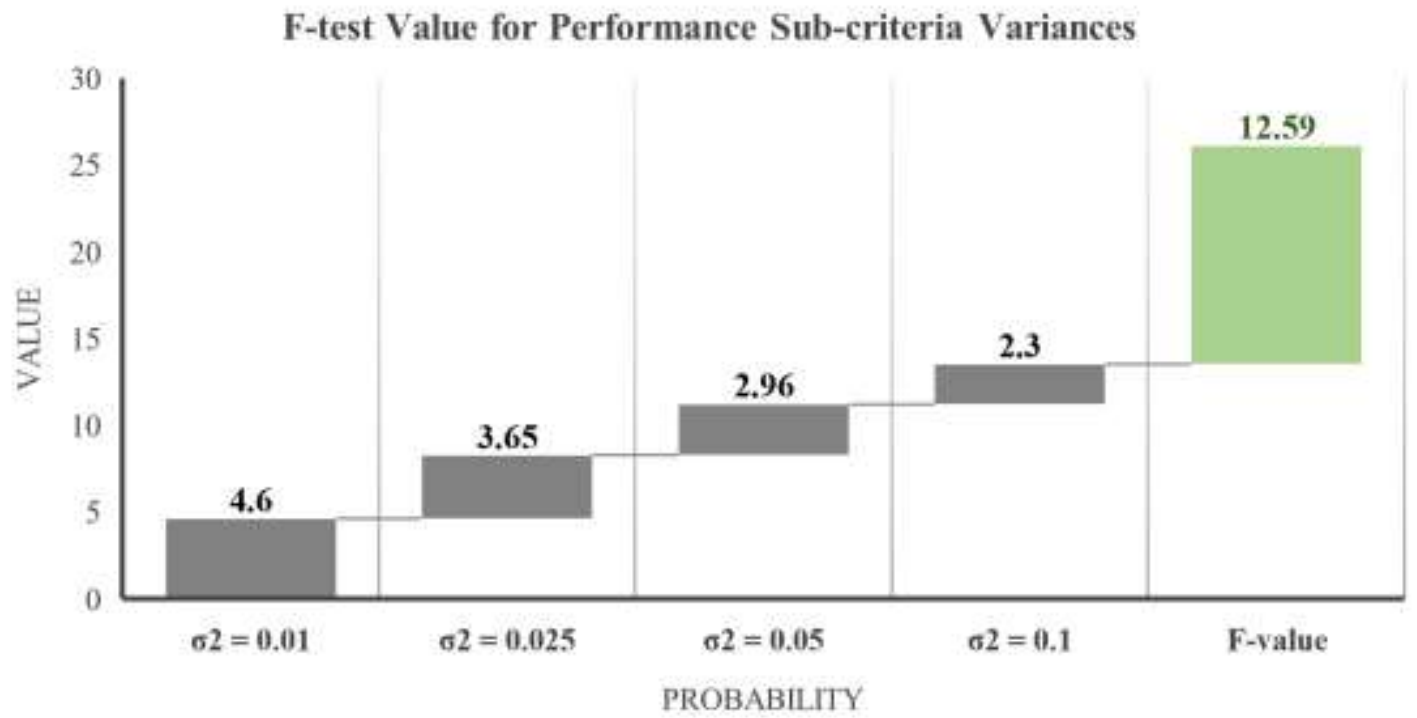

Figure 42: F-Test Values for Performance Sub-criteria 
Figure 43 shows the disagreement among experts at Resources sub-criteria.

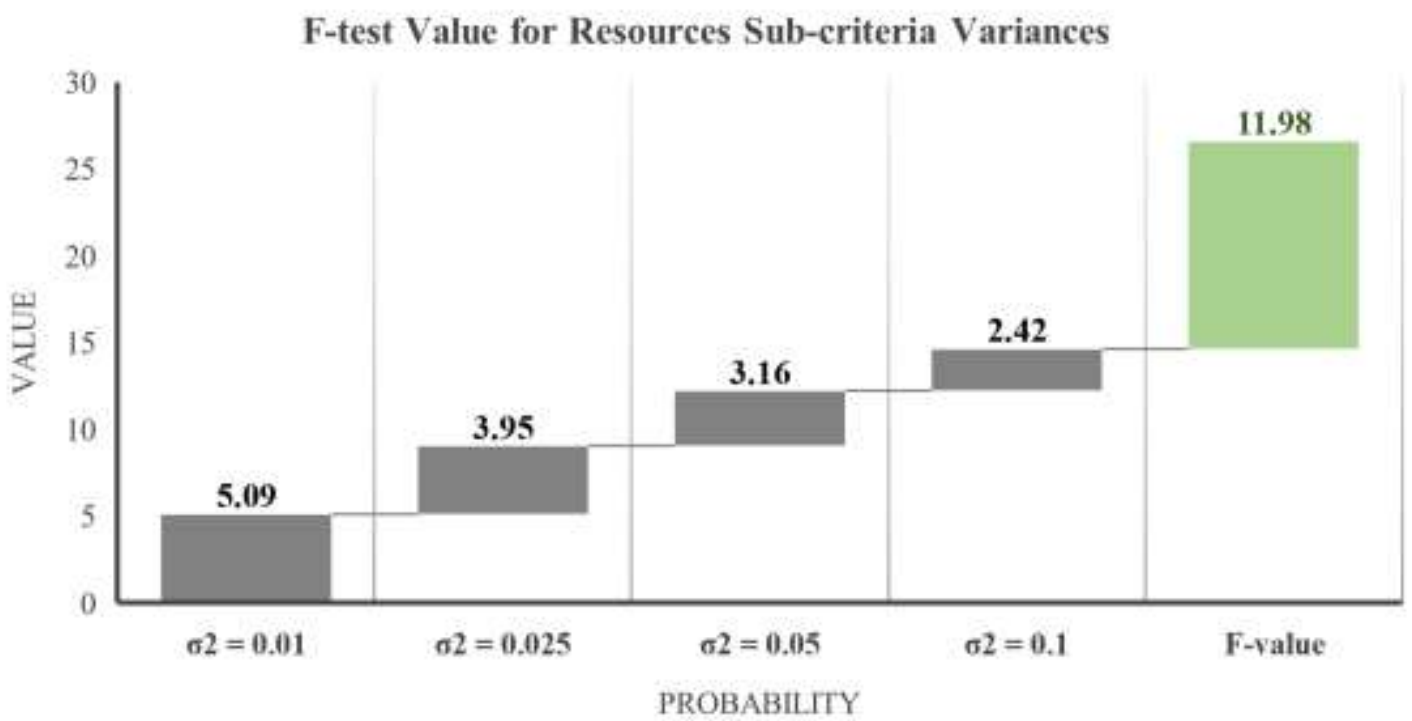

Figure 43: F-Test Values for Resources Sub-criteria

Table 21 shows the final results of disagreement among experts at all sub-criteria under each criterion in Level 2.

Table 21: F-Test Values for all Sub-criteria Under Each Criterion

\begin{tabular}{|l|c|c|c|c|c|}
\hline Sub-criteria & $\sigma 2=0.01$ & $\sigma 2=0.025$ & $\sigma 2=0.05$ & $\sigma 2=0.1$ & F-value \\
\hline Cost & 6.23 & 4.69 & 3.63 & 2.67 & 16.36 \\
Schedule & 4.51 & 3.59 & 2.92 & 2.28 & 18.4 \\
Risk & 4.51 & 3.59 & 2.92 & 2.28 & 7.83 \\
Performance & 4.6 & 3.65 & 2.96 & 2.3 & 12.59 \\
Resources & 5.09 & 3.95 & 3.16 & 2.42 & 11.98 \\
\hline
\end{tabular}




\subsubsection{Analysis of Alternatives Panel Results - Level 4}

In Step 2, the RI5 was used by EP2, EP3, EP4, EP5, and EP6 to evaluate and quantify the relative priorities of alternatives with respect to the sub-criteria. Same expert panels who performed the model quantification process in RI4 they were asked again to fulfill RI5 for evaluating the model Level 4 with respect to Level 3. Table 22 below shows the model alternatives and its descriptions that sent and assessed by expert panels (EP2 through EP6).

Table 22: Model Alternatives Description

\section{ALTERNATIVE ACRONYM DESCRIPTION}

\begin{tabular}{|c|c|c|}
\hline ALT. 1 & VE-RA & Risk Assessment combined with Value Engineering \\
\hline ALT. 2 & VE-CR & $\begin{array}{l}\text { Constructability Review combined with Value } \\
\text { Engineering }\end{array}$ \\
\hline ALT. 3 & VE-DAM & $\begin{array}{l}\text { A Decision Analysis Model combined with Value } \\
\text { Engineering }\end{array}$ \\
\hline ALT. 4 & $\begin{array}{l}\text { VE- } \\
\text { RACRDAM }\end{array}$ & $\begin{array}{l}\text { Risk Assessment, Constructability Review, and Decision } \\
\text { Analysis Model combined with Value Engineering }\end{array}$ \\
\hline ALT. 5 & VE-CEVPRA & $\begin{array}{l}\text { Cost Estimate Validations Process and Risk Assessment } \\
\text { combined with Value Engineering }\end{array}$ \\
\hline
\end{tabular}

\subsubsection{Results of Alternatives with Cost Sub-criteria}

EP2 evaluated and rated the relative importance of alternatives with respect to the Cost sub-criteria (Reducing Capital Cost, Offering Life-Cycle-Cost Reduction, and Minimizing Project Support Costs) using the research instrument RI5. The arithmetic means of the experts' judgments for the relative importance of considered alternatives with respect of each criterion are shown in Table 23 through 25 and Figure 44 through 46. The green color of each table and figure indicates the highest rank of the best-selected alternative with respect to each Cost criterion, and the orange color indicates the lowest importance. The 
results indicate that the Alt.4 was ranked the most important option among others with respect to the three Cost sub-criteria, and the Alt.3 was ranked the least importance option. In the Capital Cost criterion, as shown in Table 23 and Figure 44, the VE-RACRDAM technique was ranked the highest relative importance with a value of 0.37 . The VECEVPRA was ranked the second most effective alternative (0.23), while the VE-DAM was rated the least importance technique with the ranking value of 0.12 .

Table 23: Results of Alts. with Respect to Capital Cost

\begin{tabular}{|lcccccc|}
\hline Capital Cost & VE- RA & VE- CR & $\begin{array}{r}\text { VE- } \\
\text { DAM }\end{array}$ & $\begin{array}{r}\text { VE- } \\
\text { RACR } \\
\text { \& DAM }\end{array}$ & $\begin{array}{r}\text { VE- } \\
\text { CEVP } \\
\text { \& RA }\end{array}$ & Inconsistency \\
\hline Exp 11 & 0.07 & 0.13 & 0.23 & 0.43 & 0.14 & 0.06 \\
Exp 12 & 0.13 & 0.14 & 0.12 & 0.36 & 0.25 & 0.03 \\
Exp 13 & 0.19 & 0.15 & 0.12 & 0.42 & 0.12 & 0.02 \\
Exp 14 & 0.21 & 0.12 & 0.14 & 0.34 & 0.19 & 0.02 \\
Exp 15 & 0.13 & 0.12 & 0.1 & 0.45 & 0.2 & 0.02 \\
Exp 16 & 0.13 & 0.08 & 0.09 & 0.28 & 0.42 & 0.05 \\
Exp 17 & 0.2 & 0.21 & 0.11 & 0.22 & 0.27 & 0.05 \\
Exp 18 & 0.14 & 0.11 & 0.1 & 0.42 & 0.24 & 0 \\
Exp 19 & 0.14 & 0.1 & 0.1 & 0.43 & 0.22 & 0.02 \\
\hline Mean & 0.15 & 0.13 & 0.12 & 0.37 & 0.23 & \\
\hline Minimum & 0.07 & 0.08 & 0.09 & 0.22 & 0.12 & \\
Maximum & 0.21 & 0.21 & 0.23 & 0.45 & 0.42 & \\
Std. & 0.04 & 0.03 & 0.04 & 0.07 & 0.08 & \\
Deviation & & & & & & 0.051 \\
Disagreement & & & & & & \\
\hline
\end{tabular}




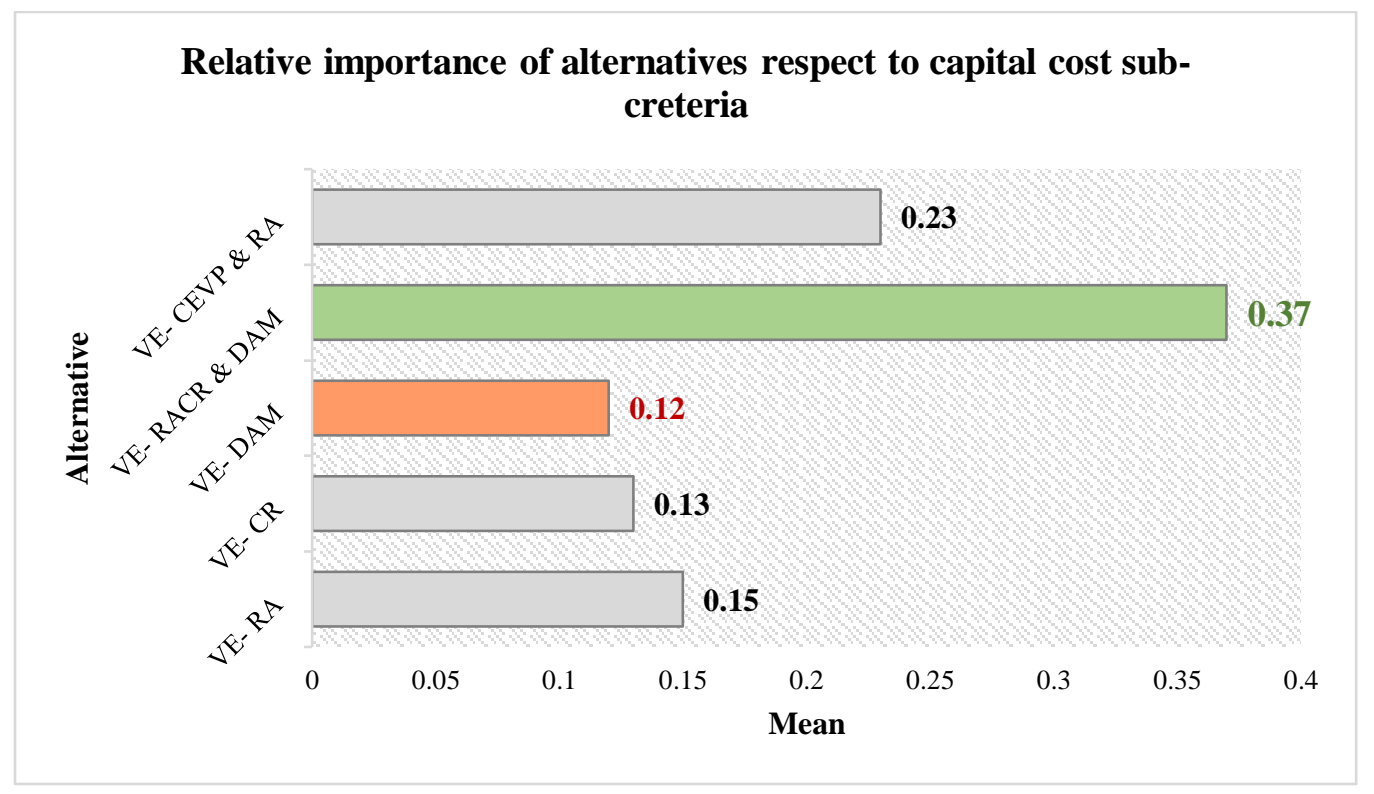

Figure 44: Relative Importance of Alts. with Respect to Capital Cost

In the Life-Cycle-Cost criterion, as shown in Table 24 and Figure 45, the VERACRDAM technique was also ranked the highest relative importance with a value of 0.36. The VE-CEVPRA was ranked the second most effective alternative $(0.21)$, while the VE-DAM was rated the least importance technique with the ranking value of 0.12 . 
Table 24: Results of Alts. with Respect to Life-Cycle-Cost

\begin{tabular}{|lcccccc|}
\hline $\begin{array}{c}\text { Life-Cycle- } \\
\text { Cost (LCC) }\end{array}$ & VE- RA & VE- CR & $\begin{array}{r}\text { VE- } \\
\text { DAM }\end{array}$ & $\begin{array}{c}\text { VE- } \\
\text { RACR } \\
\text { \& DAM }\end{array}$ & $\begin{array}{r}\text { VE- } \\
\text { CEVP } \\
\text { \& RA }\end{array}$ & Inconsistency \\
\hline Exp 11 & 0.15 & 0.14 & 0.22 & 0.35 & 0.15 & 0.09 \\
Exp 12 & 0.14 & 0.12 & 0.1 & 0.42 & 0.23 & 0.02 \\
Exp 13 & 0.2 & 0.14 & 0.11 & 0.41 & 0.14 & 0.03 \\
Exp 14 & 0.16 & 0.14 & 0.15 & 0.33 & 0.22 & 0 \\
Exp 15 & 0.14 & 0.13 & 0.13 & 0.38 & 0.21 & 0.01 \\
Exp 16 & 0.1 & 0.09 & 0.05 & 0.36 & 0.4 & 0.07 \\
Exp 17 & 0.22 & 0.28 & 0.09 & 0.3 & 0.11 & 0.07 \\
Exp 18 & 0.19 & 0.13 & 0.12 & 0.32 & 0.25 & 0.01 \\
Exp 19 & 0.17 & 0.15 & 0.15 & 0.33 & 0.2 & 0 \\
\hline Mean & 0.16 & 0.15 & 0.12 & 0.36 & 0.21 & \\
\hline Minimum & 0.1 & 0.09 & 0.05 & 0.3 & 0.11 & \\
Maximum & 0.22 & 0.28 & 0.22 & 0.42 & 0.4 & \\
Std. & 0.03 & 0.05 & 0.04 & 0.04 & 0.08 & \\
Deviation & & & & & & 0.044 \\
Disagreement & & & & & & \\
\hline
\end{tabular}

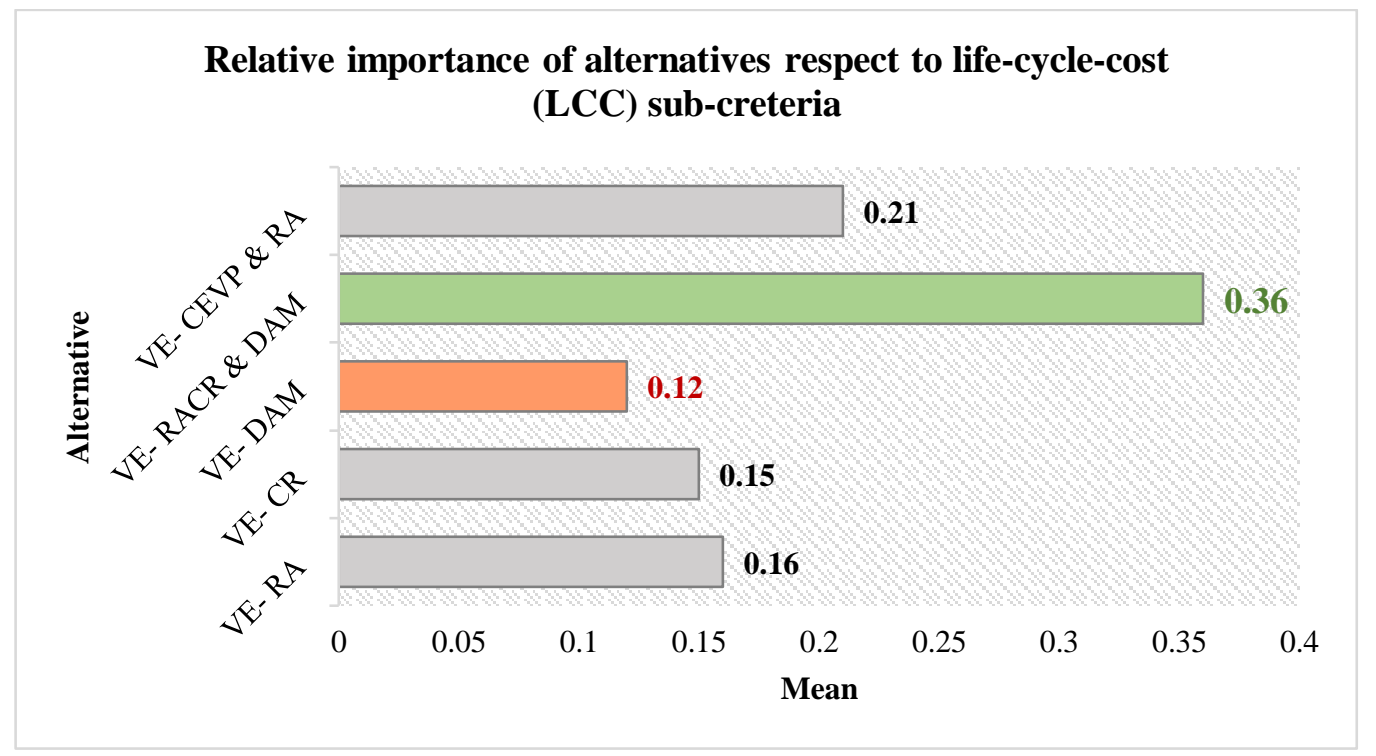

Figure 45: Relative Importance of Alts. with Respect to Life-Cycle-Cost 
In the Project Support Costs criterion, as shown in Table 25 and Figure 46, the VERACRDAM technique was also ranked the highest relative importance with a value of 0.31. The VE-CEVPRA was ranked the second most effective alternative (0.2), while the VE-DAM was rated the least importance technique with the ranking value of 0.15 .

Table 25: Results of Alts. with Respect to Support Costs

\begin{tabular}{|lcccccc|}
\hline $\begin{array}{l}\text { Project } \\
\text { Support Costs }\end{array}$ & VE- RA & VE- CR & $\begin{array}{r}\text { VE- } \\
\text { DAM }\end{array}$ & $\begin{array}{r}\text { VE- } \\
\text { RACR } \\
\text { \& DAM }\end{array}$ & $\begin{array}{r}\text { VE- } \\
\text { CEVP } \\
\text { \& RA }\end{array}$ & Inconsistency \\
\hline Exp 11 & 0.11 & 0.18 & 0.27 & 0.3 & 0.14 & 0.02 \\
Exp 12 & 0.14 & 0.14 & 0.14 & 0.32 & 0.25 & 0.02 \\
Exp 13 & 0.2 & 0.17 & 0.16 & 0.29 & 0.17 & 0.01 \\
Exp 14 & 0.14 & 0.17 & 0.15 & 0.32 & 0.22 & 0.04 \\
Exp 15 & 0.21 & 0.12 & 0.12 & 0.32 & 0.23 & 0.02 \\
Exp 16 & 0.18 & 0.16 & 0.09 & 0.28 & 0.28 & 0.07 \\
Exp 17 & 0.25 & 0.19 & 0.11 & 0.29 & 0.16 & 0.04 \\
Exp 18 & 0.18 & 0.19 & 0.16 & 0.29 & 0.18 & 0 \\
Exp 19 & 0.2 & 0.17 & 0.14 & 0.34 & 0.14 & 0.02 \\
\hline Mean & 0.18 & 0.17 & 0.15 & 0.31 & 0.2 & \\
\hline Minimum & 0.11 & 0.12 & 0.09 & 0.28 & 0.14 & \\
Maximum & 0.25 & 0.19 & 0.27 & 0.34 & 0.28 & \\
Std. & 0.04 & 0.02 & 0.05 & 0.02 & 0.05 & \\
Deviation & & & & & & 0.034 \\
Disagreement & & & & & & \\
\hline
\end{tabular}




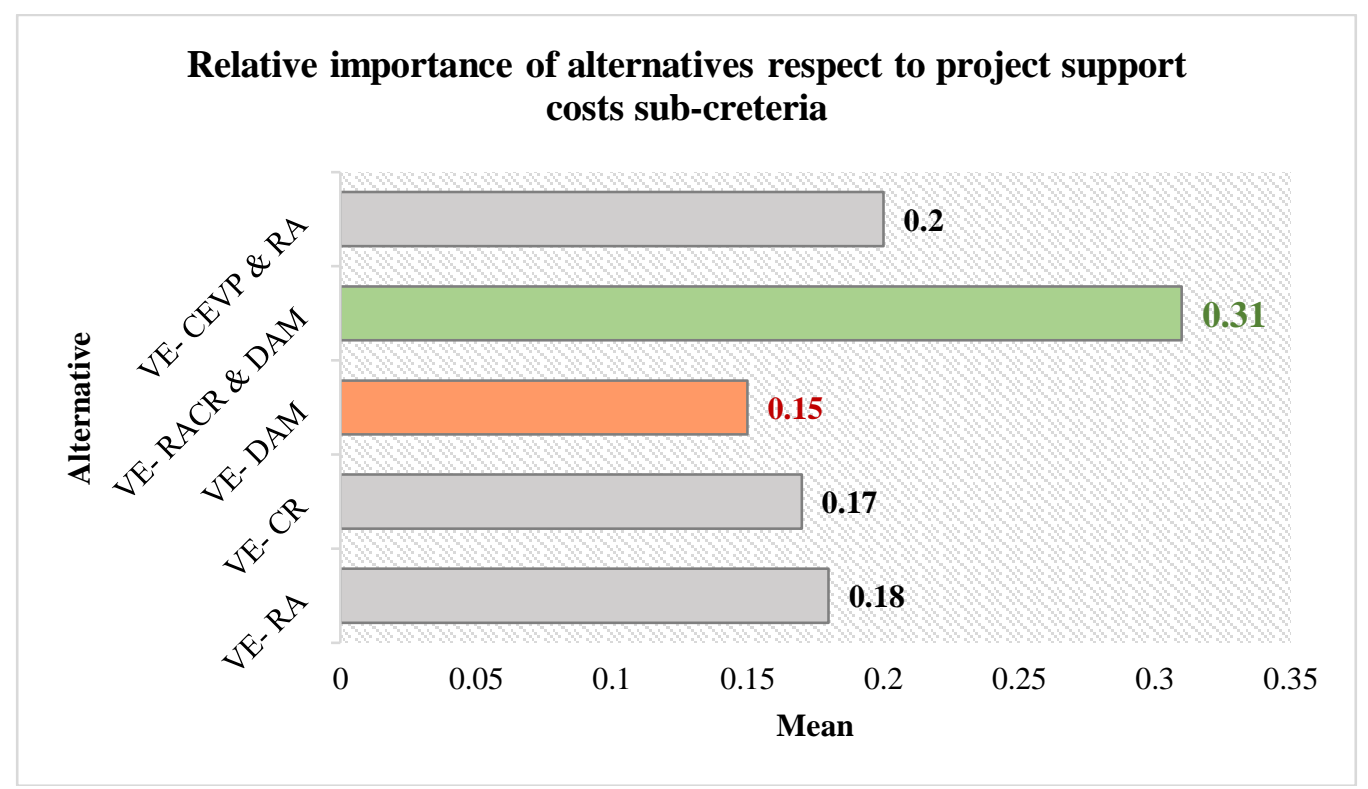

Figure 46: Relative Importance of Alts. with Respect to Support Costs

\subsubsection{Results of Alternatives with Schedule Sub-criteria}

EP3 evaluated and rated the relative importance of alternatives with respect to the Schedule sub-criteria (Project Design \& Environmental Analysis, Right-of-Way (ROW) Acquisition, Project Tender \& Construction Duration, and Project Closeout Activities Duration) using the research instrument RI5. The arithmetic means of experts' judgments for the relative importance of considered alternatives with respect of each criterion are shown in Table 26 through 29 and Figure 47 through 50. The green color of each table and figure indicates the highest rank of the best-selected alternative with respect to each Cost criterion, and the orange color indicates the lowest importance. The results indicate that the Alt.4 was ranked the most important option among others with respect to the four Schedule sub-criteria, and the Alt.3 was ranked the least importance in the Project Design \& 
Environmental Analysis, and Right-of-Way (ROW) Acquisition criterion. The Alt.2 showed the lowest importance in the Project Tender \& Construction Duration criterion. Alt. 2 and 3 share the least importance in the Project Closeout Activities Duration criterion.

In the Project Design \& Environmental Analysis criterion, as shown in Table 26 and Figure 47, the VE-RACRDAM technique was also ranked the highest relative importance with a value of 0.3 . The VE-CEVPRA was ranked the second most effective alternative (0.23), while the VE-DAM was rated the least importance technique with the ranking value of 0.13 .

Table 26: Results of Alts. with Respect to Design \& Env. Analysis

\begin{tabular}{|c|c|c|c|c|c|c|}
\hline $\begin{array}{l}\text { Project } \\
\text { Design \& } \\
\text { Environmental } \\
\text { Analysis }\end{array}$ & VE- RA & VE- CR & $\begin{array}{r}\text { VE- } \\
\text { DAM }\end{array}$ & $\begin{array}{c}\text { VE- } \\
\text { RACR } \\
\text { \& DAM }\end{array}$ & $\begin{array}{r}\text { VE- } \\
\text { CEVP } \\
\& \text { RA }\end{array}$ & Inconsistency \\
\hline Exp 20 & 0.13 & 0.14 & 0.13 & 0.33 & 0.28 & 0.01 \\
\hline $\operatorname{Exp} 8$ & 0.2 & 0.13 & 0.11 & 0.29 & 0.27 & 0.03 \\
\hline Exp 21 & 0.15 & 0.16 & 0.13 & 0.33 & 0.23 & 0.01 \\
\hline Exp 22 & 0.28 & 0.12 & 0.16 & 0.21 & 0.23 & 0.01 \\
\hline $\operatorname{Exp} 23$ & 0.19 & 0.16 & 0.1 & 0.3 & 0.25 & 0.03 \\
\hline $\operatorname{Exp} 24$ & 0.21 & 0.18 & 0.15 & 0.27 & 0.19 & 0.01 \\
\hline $\operatorname{Exp} 25$ & 0.18 & 0.17 & 0.16 & 0.27 & 0.21 & 0 \\
\hline $\operatorname{Exp} 26$ & 0.2 & 0.17 & 0.14 & 0.25 & 0.25 & 0.01 \\
\hline Exp 27 & 0.18 & 0.17 & 0.14 & 0.31 & 0.19 & 0.02 \\
\hline Exp 28 & 0.1 & 0.12 & 0.09 & 0.43 & 0.27 & 0.03 \\
\hline Exp 29 & 0.25 & 0.17 & 0.11 & 0.31 & 0.16 & 0.01 \\
\hline Mean & 0.19 & 0.15 & 0.13 & 0.3 & 0.23 & \\
\hline Minimum & 0.1 & 0.12 & 0.09 & 0.21 & 0.16 & \\
\hline Maximum & 0.28 & 0.18 & 0.16 & 0.43 & 0.28 & \\
\hline Std. Deviation & 0.05 & 0.02 & 0.02 & 0.05 & 0.04 & \\
\hline Disagreement & & & & & & 0.034 \\
\hline
\end{tabular}




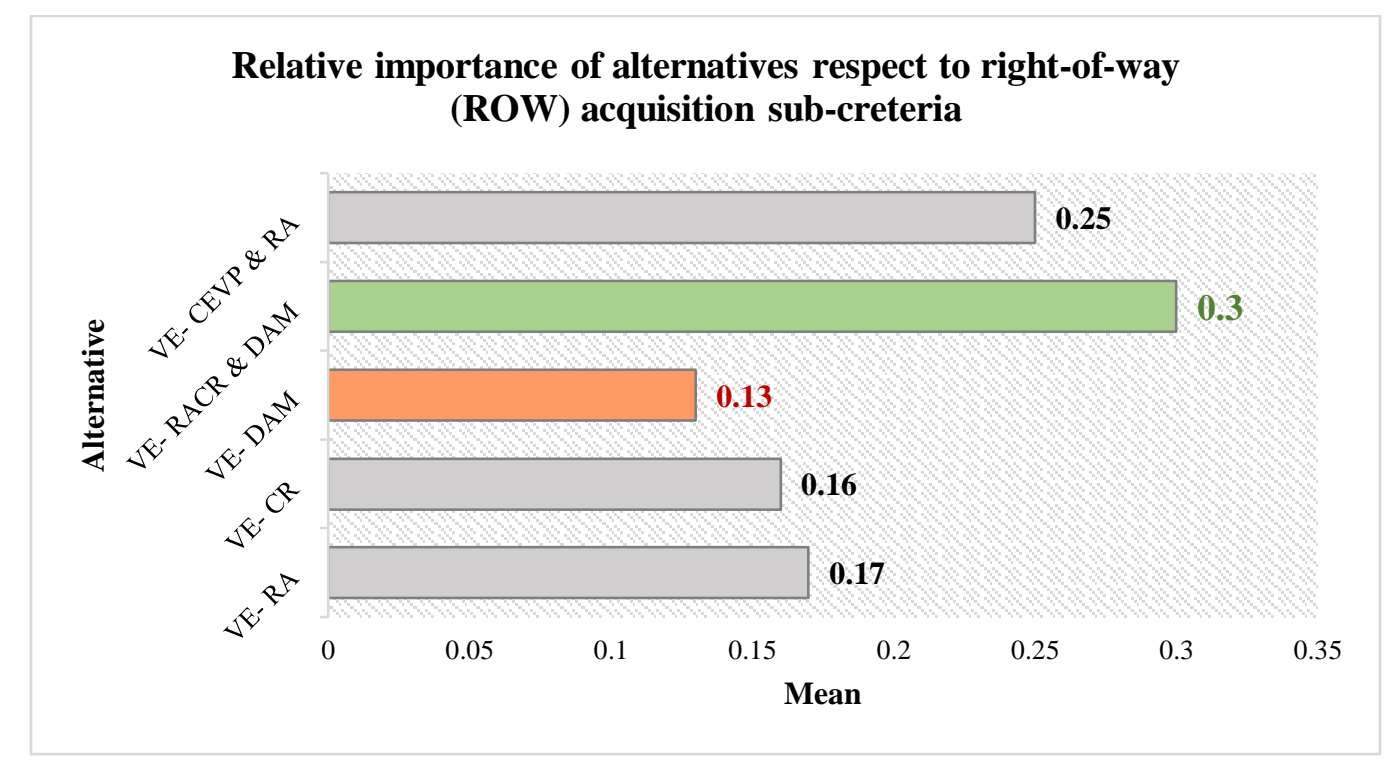

Figure 47: Relative Importance of Alts. with Respect to Design \& Env. Analysis

In the Right-of-Way (ROW) Acquisition criterion, as shown in Table 27 and Figure 48, the VE-RACRDAM technique was also ranked the highest relative importance with a value of 0.3. The VE-CEVPRA was ranked the second most effective alternative (0.25), while the VE-DAM was rated the least importance technique with the ranking value of 0.13. 
Table 27: Results of Alts. with Respect to Right-of-Way Acquisition

\begin{tabular}{|lcccccc|}
\hline $\begin{array}{l}\text { Right-of-Way } \\
\text { (ROW) } \\
\text { Acquisition }\end{array}$ & VE- RA & VE- CR & $\begin{array}{r}\text { VE- } \\
\text { DAM }\end{array}$ & $\begin{array}{r}\text { VE- } \\
\text { RACR } \\
\text { \& DAM }\end{array}$ & $\begin{array}{r}\text { VE- } \\
\text { CEVP } \\
\text { \& RA }\end{array}$ & Inconsistency \\
\hline Exp 20 & 0.14 & 0.18 & 0.16 & 0.28 & 0.23 & 0 \\
Exp 8 & 0.21 & 0.24 & 0.12 & 0.24 & 0.19 & 0.03 \\
Exp 21 & 0.11 & 0.11 & 0.1 & 0.42 & 0.26 & 0.02 \\
Exp 22 & 0.27 & 0.18 & 0.14 & 0.16 & 0.25 & 0 \\
Exp 23 & 0.16 & 0.16 & 0.11 & 0.33 & 0.23 & 0.01 \\
Exp 24 & 0.17 & 0.17 & 0.14 & 0.27 & 0.26 & 0.01 \\
Exp 25 & 0.16 & 0.14 & 0.13 & 0.33 & 0.24 & 0.01 \\
Exp 26 & 0.15 & 0.14 & 0.12 & 0.28 & 0.31 & 0.01 \\
Exp 27 & 0.14 & 0.13 & 0.12 & 0.32 & 0.29 & 0.01 \\
Exp 28 & 0.15 & 0.12 & 0.09 & 0.38 & 0.27 & 0.02 \\
Exp 29 & 0.17 & 0.15 & 0.19 & 0.32 & 0.17 & 0.02 \\
\hline Mean & 0.17 & 0.16 & 0.13 & 0.3 & 0.25 & \\
\hline Minimum & 0.11 & 0.11 & 0.09 & 0.16 & 0.17 & \\
Maximum & 0.27 & 0.24 & 0.19 & 0.42 & 0.31 & \\
Std. & 0.04 & 0.03 & 0.03 & 0.07 & 0.04 & \\
Deviation & & & & & & 0.038 \\
Disagreement & & & & & & \\
\hline
\end{tabular}

\section{Relative importance of alternatives respect to right-of-way} (ROW) acquisition sub-creteria

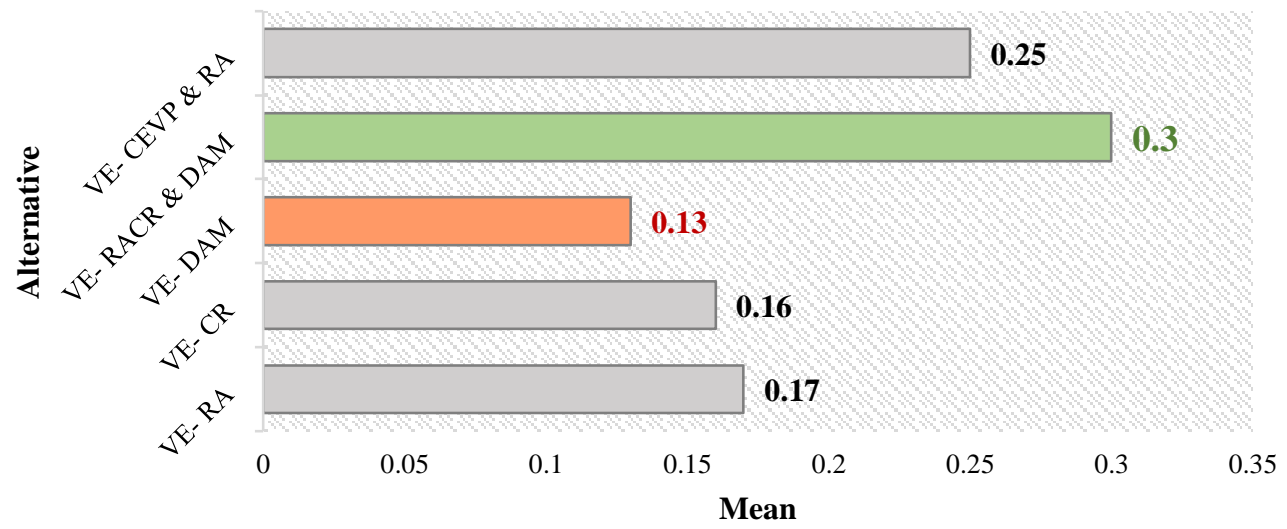

Figure 48: Relative Importance of Alts. with Respect to Right-of-Way Acquisition 
In the Project Tender \& Construction Duration criterion, as shown in Table 28 and Figure 49, the VE-RACRDAM technique was also ranked the highest relative importance with a value of 0.28 . The VE-CEVPRA was ranked the second most effective alternative (0.23), while the VE-CR was rated the least importance technique with the ranking value of 0.15 .

Table 28: Results of Alts. with Respect to Tender \& Const. Duration

\begin{tabular}{|lcccccc|}
\hline $\begin{array}{l}\text { Project } \\
\text { Tender \& } \\
\text { Construction }\end{array}$ & VE- RA & VE- CR & $\begin{array}{r}\text { VE- } \\
\text { DAM }\end{array}$ & $\begin{array}{r}\text { VE- } \\
\text { RACR } \\
\text { \& DAM }\end{array}$ & $\begin{array}{r}\text { VE- } \\
\text { CEVP } \\
\text { \& RA }\end{array}$ & Inconsistency \\
\hline Exp 20 & 0.16 & 0.16 & 0.19 & 0.25 & 0.24 & 0 \\
Exp 8 & 0.26 & 0.17 & 0.15 & 0.23 & 0.2 & 0 \\
Exp 21 & 0.14 & 0.09 & 0.21 & 0.28 & 0.28 & 0.04 \\
Exp 22 & 0.24 & 0.18 & 0.15 & 0.23 & 0.19 & 0.01 \\
Exp 23 & 0.16 & 0.14 & 0.12 & 0.36 & 0.22 & 0.04 \\
Exp 24 & 0.14 & 0.14 & 0.17 & 0.31 & 0.24 & 0.01 \\
Exp 25 & 0.2 & 0.19 & 0.19 & 0.24 & 0.19 & 0.02 \\
Exp 26 & 0.13 & 0.1 & 0.18 & 0.3 & 0.3 & 0.01 \\
Exp 27 & 0.17 & 0.14 & 0.15 & 0.32 & 0.22 & 0.01 \\
Exp 28 & 0.15 & 0.16 & 0.17 & 0.3 & 0.23 & 0.04 \\
Exp 29 & 0.15 & 0.16 & 0.16 & 0.29 & 0.24 & 0.01 \\
\hline Mean & 0.17 & 0.15 & 0.17 & 0.28 & 0.23 & \\
\hline Minimum & 0.13 & 0.09 & 0.12 & 0.23 & 0.19 & \\
Maximum & 0.26 & 0.19 & 0.21 & 0.36 & 0.3 & \\
Std. & 0.04 & 0.03 & 0.02 & 0.04 & 0.03 & \\
Deviation & & & & & & 0.031 \\
Disagreement & & & & & & \\
\hline
\end{tabular}




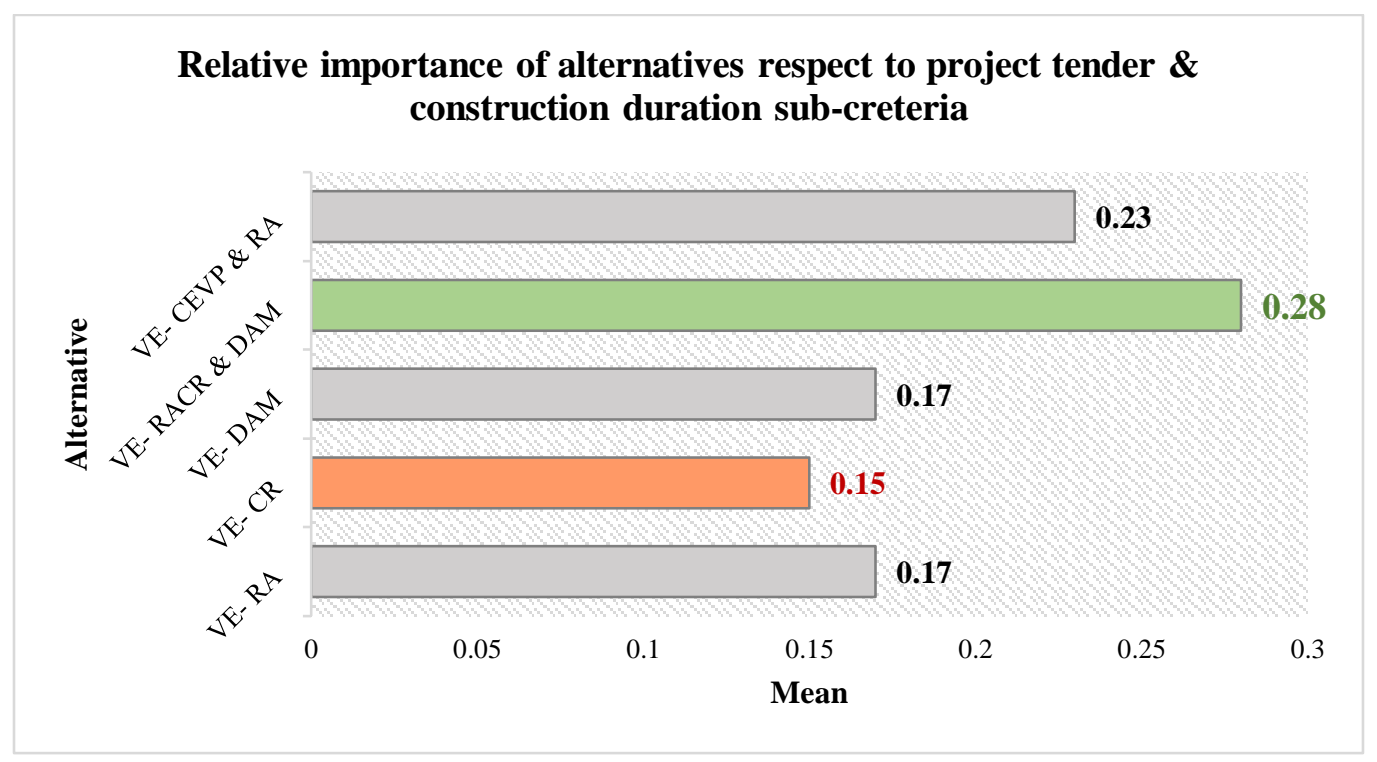

Figure 49: Relative Importance of Alts. with Respect to Tender \& Const. Duration

In the Project Closeout Activities Duration criterion, as shown in Table 29 and Figure 50, the VE-RACRDAM technique was also ranked the highest relative importance with a value of 0.26 . The VE-CEVPRA was ranked the second most effective alternative $(0.23)$, while VE-RA and VE-CR shared the least importance rank among other techniques with the value of 0.16 . 
Table 29: Results of Alts. with Respect to Closeout Activities Duration

\begin{tabular}{|lcccccc|}
\hline $\begin{array}{c}\text { Project } \\
\text { Closeout } \\
\text { Activities }\end{array}$ & VE- RA & VE- CR & $\begin{array}{c}\text { VE- } \\
\text { DAM }\end{array}$ & $\begin{array}{r}\text { VE- } \\
\text { RACR } \\
\text { \& DAM }\end{array}$ & $\begin{array}{r}\text { VE- } \\
\text { CEVP } \\
\text { \& RA }\end{array}$ & Inconsistency \\
\hline Exp 20 & 0.18 & 0.11 & 0.14 & 0.32 & 0.25 & 0 \\
Exp 8 & 0.2 & 0.2 & 0.2 & 0.2 & 0.2 & 0 \\
Exp 21 & 0.16 & 0.13 & 0.17 & 0.31 & 0.23 & 0.02 \\
Exp 22 & 0.25 & 0.2 & 0.14 & 0.18 & 0.23 & 0.01 \\
Exp 23 & 0.18 & 0.17 & 0.16 & 0.24 & 0.26 & 0.01 \\
Exp 24 & 0.18 & 0.16 & 0.19 & 0.25 & 0.23 & 0 \\
Exp 25 & 0.2 & 0.16 & 0.16 & 0.25 & 0.24 & 0.01 \\
Exp 26 & 0.21 & 0.13 & 0.14 & 0.31 & 0.21 & 0.01 \\
Exp 27 & 0.19 & 0.16 & 0.15 & 0.28 & 0.22 & 0 \\
Exp 28 & 0.18 & 0.19 & 0.17 & 0.25 & 0.22 & 0.01 \\
Exp 29 & 0.17 & 0.16 & 0.15 & 0.25 & 0.27 & 0.02 \\
\hline Mean & 0.19 & 0.16 & 0.16 & 0.26 & 0.23 & \\
\hline Minimum & 0.16 & 0.11 & 0.14 & 0.18 & 0.2 & \\
Maximum & 0.25 & 0.2 & 0.2 & 0.32 & 0.27 & \\
Std. & 0.02 & 0.03 & 0.02 & 0.04 & 0.02 & \\
Deviation & & & & & & 0.025 \\
Disagreement & & & & & & \\
\hline
\end{tabular}

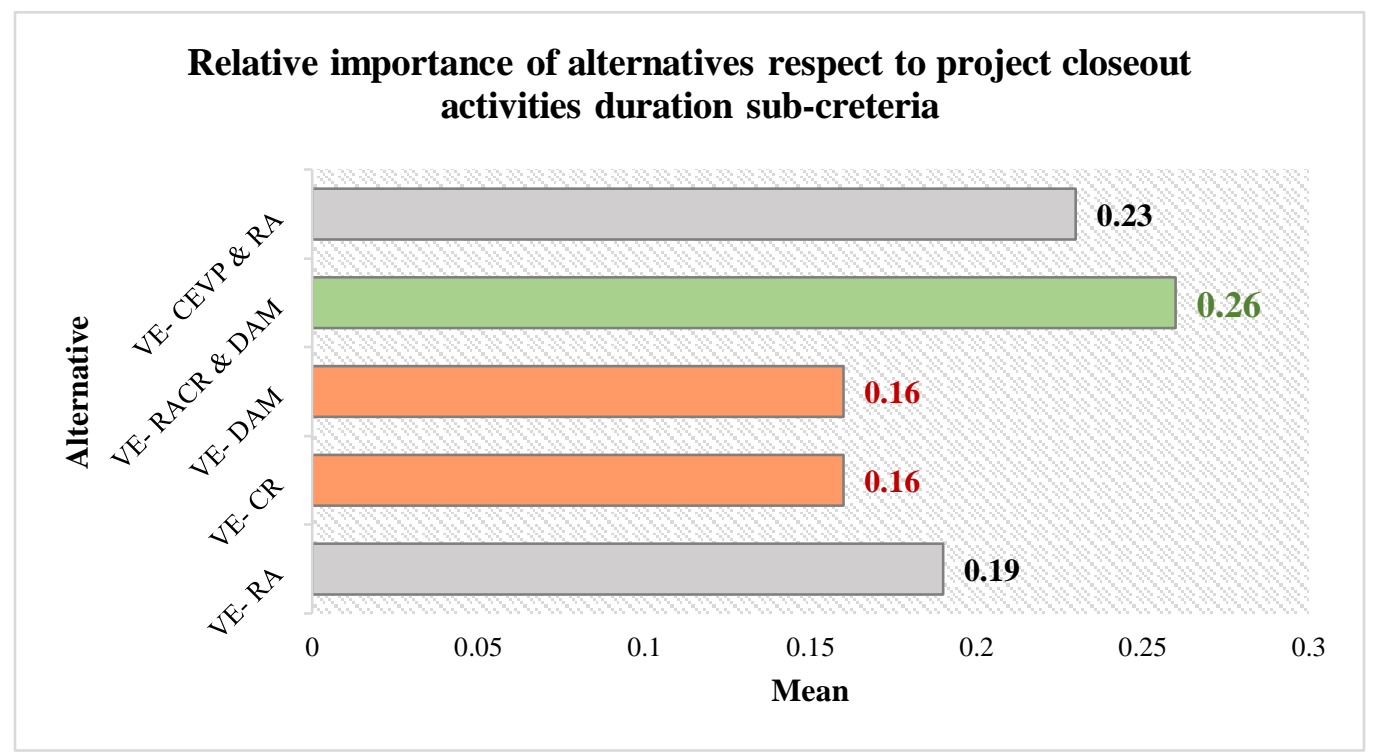

Figure 50: Relative Importance of Alts. with Respect to Closeout Activities Duration 


\subsubsection{Results of Alternatives with Risk Sub-criteria}

EP4 evaluated and rated the relative importance of alternatives with respect to the Risk sub-criteria (Identifying Project Performance Risk Impact, Project Cost Risk Impact, Project Support Costs Risk Impact, and Project Schedule Risk Impact) using the research instrument RI5. The arithmetic means of experts' judgments for the relative importance of considered alternatives with respect of each criterion are shown in Table 30 through 33 and Figure 51 through 54. The green color of each table and figure indicates the highest rank of the best-selected alternative with respect to each Risk criterion, and the orange color indicates the lowest importance. The results indicate that the Alt.4 was ranked the most important option among others with respect to the four Risk sub-criteria, and the Alt.3 was ranked the least importance in all Risk sub-criteria. Alt. 2 shared Alt. 3 in the least importance techniques in the assessment of Project Cost Risk Impact.

In the Project Performance Risk Impact criterion, as shown in Table 30 and Figure 51, the VE-RACRDAM technique was ranked the highest relative importance with a value of 0.29. The VE-CEVPRA was ranked the second most effective alternative (0.22), while the VE-DAM was rated the least importance technique with the ranking value of 0.15 . 
Table 30: Results of Alts. with Respect to Perf. Risk Impact

\begin{tabular}{|lcccccc|}
\hline $\begin{array}{l}\text { Project } \\
\text { Performance } \\
\text { Risk Impact }\end{array}$ & VE- RA & VE- CR & $\begin{array}{r}\text { VE- } \\
\text { DAM }\end{array}$ & $\begin{array}{r}\text { VE- } \\
\text { RACR } \\
\text { \& DAM }\end{array}$ & $\begin{array}{r}\text { VE- } \\
\text { CEVP } \\
\text { \& RA }\end{array}$ & Inconsistency \\
\hline Exp 5 & 0.25 & 0.15 & 0.14 & 0.32 & 0.15 & 0.03 \\
Exp 31 & 0.18 & 0.15 & 0.15 & 0.26 & 0.27 & 0.01 \\
Exp 32 & 0.13 & 0.13 & 0.17 & 0.32 & 0.26 & 0.02 \\
Exp 33 & 0.16 & 0.12 & 0.23 & 0.24 & 0.25 & 0.03 \\
Exp 34 & 0.17 & 0.13 & 0.14 & 0.26 & 0.29 & 0 \\
Exp 35 & 0.2 & 0.18 & 0.14 & 0.3 & 0.17 & 0.02 \\
Exp 36 & 0.19 & 0.15 & 0.18 & 0.28 & 0.2 & 0.04 \\
Exp 37 & 0.16 & 0.14 & 0.12 & 0.34 & 0.24 & 0.01 \\
Exp 40 & 0.15 & 0.35 & 0.09 & 0.25 & 0.15 & 0.06 \\
\hline Mean & 0.18 & 0.17 & 0.15 & 0.29 & 0.22 & \\
\hline Minimum & 0.13 & 0.12 & 0.09 & 0.24 & 0.15 & \\
Maximum & 0.25 & 0.35 & 0.23 & 0.34 & 0.29 & \\
Std. & 0.03 & 0.07 & 0.04 & 0.03 & 0.05 & \\
Deviation & & & & & & 0.041 \\
Disagreement & & & & & & \\
\hline
\end{tabular}

Relative importance of alternatives respect to project performance risk impact sub-creteria

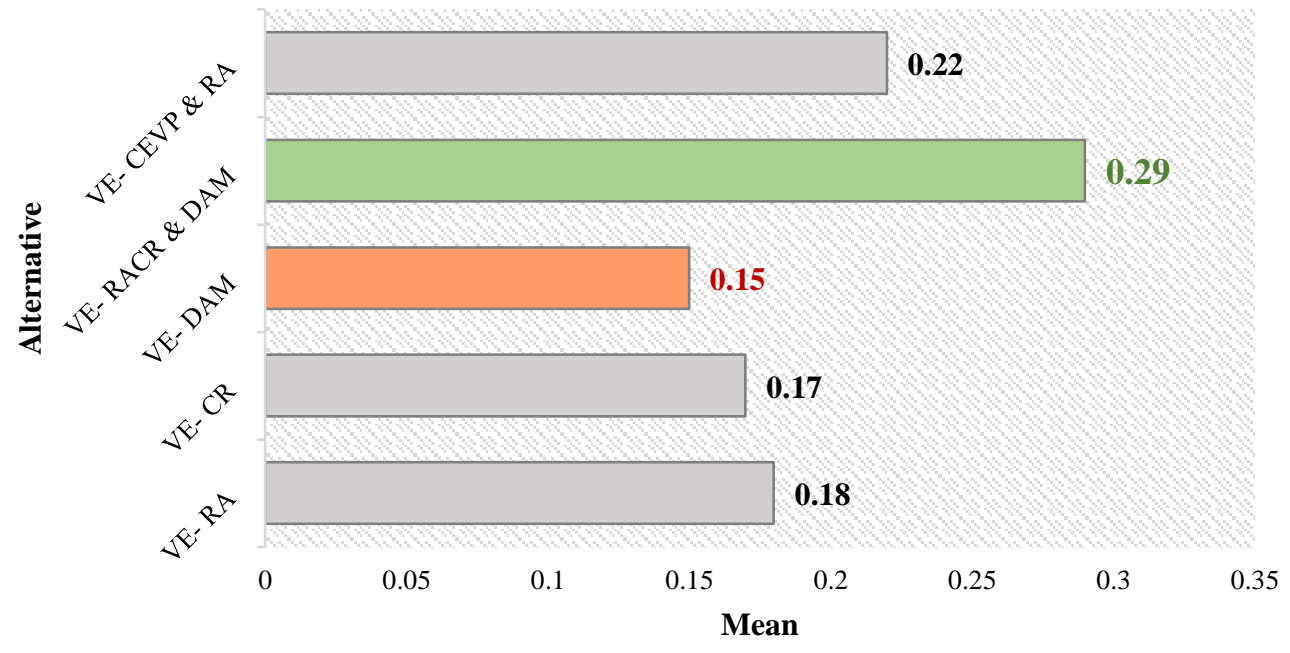

Figure 51: Relative Importance of Alts. with Respect to Perf. Risk Impact 
In the Project Cost Risk Impact criterion, as shown in Table 30 and Figure 52, the VERACRDAM technique was ranked the highest relative importance with a value of 0.27 . The VE-CEVPRA was ranked the second most effective alternative (0.24), while VE-CR and VE-DAM shared the least importance techniques with the ranking value of 0.15 .

Table 30: Results of Alts. with Respect to Cost Risk Impact

\begin{tabular}{|c|c|c|c|c|c|c|}
\hline $\begin{array}{l}\text { Project Cost } \\
\text { Risk Impact }\end{array}$ & VE- RA & VE- CR & $\begin{array}{l}\text { VE- } \\
\text { DAM }\end{array}$ & $\begin{array}{c}\text { VE- } \\
\text { RACR } \\
\text { \& DAM }\end{array}$ & $\begin{array}{r}\text { VE- } \\
\text { CEVP } \\
\text { \& RA } \\
\end{array}$ & Inconsistency \\
\hline $\operatorname{Exp} 5$ & 0.19 & 0.15 & 0.17 & 0.26 & 0.23 & 0.01 \\
\hline Exp 31 & 0.19 & 0.16 & 0.15 & 0.27 & 0.23 & 0 \\
\hline Exp 32 & 0.22 & 0.15 & 0.15 & 0.24 & 0.24 & 0 \\
\hline Exp 33 & 0.15 & 0.15 & 0.2 & 0.25 & 0.25 & 0.04 \\
\hline Exp 34 & 0.26 & 0.15 & 0.14 & 0.25 & 0.2 & 0.01 \\
\hline Exp 35 & 0.2 & 0.15 & 0.13 & 0.34 & 0.19 & 0.01 \\
\hline Exp 36 & 0.15 & 0.15 & 0.15 & 0.34 & 0.22 & 0 \\
\hline Exp 37 & 0.17 & 0.13 & 0.13 & 0.26 & 0.32 & 0.02 \\
\hline Exp 40 & 0.29 & 0.16 & 0.1 & 0.2 & 0.24 & 0.02 \\
\hline Mean & 0.2 & 0.15 & 0.15 & 0.27 & 0.24 & \\
\hline Minimum & 0.15 & 0.13 & 0.1 & 0.2 & 0.19 & \\
\hline Maximum & 0.29 & 0.16 & 0.2 & 0.34 & 0.32 & \\
\hline $\begin{array}{l}\text { Std. } \\
\text { Deviation }\end{array}$ & 0.04 & 0.01 & 0.03 & 0.04 & 0.03 & \\
\hline Disagreement & & & & & & 0.031 \\
\hline
\end{tabular}




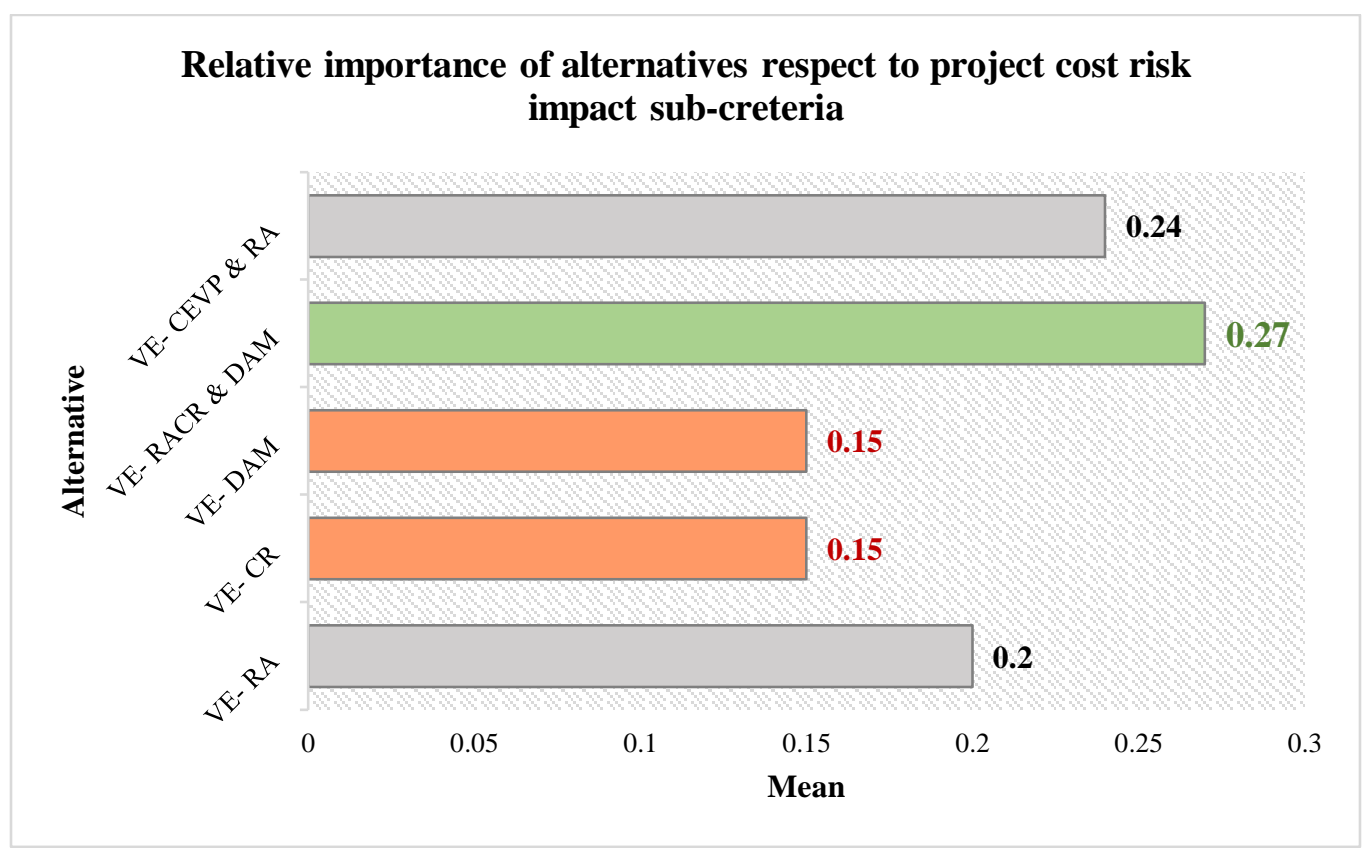

Figure 52: Relative Importance of Alts. with Respect to Cost Risk Impact

In the Project Support Cost Risk Impact criterion, as shown in Table 31 and Figure 53, the VE-RACRDAM technique was ranked the highest relative importance with a value of 0.28 . The VE-CEVPRA was ranked the second most effective alternative $(0.21)$, while the VE-DAM was rated the least importance technique with the ranking value of 0.16 . 
Table 31: Results of Alts. with Respect to Support Cost Risk Impact

\begin{tabular}{|lcccccc|}
\hline $\begin{array}{l}\text { Project } \\
\text { Support Costs } \\
\text { Risk Impact }\end{array}$ & VE- RA & VE- CR & $\begin{array}{r}\text { VE- } \\
\text { DAM }\end{array}$ & $\begin{array}{r}\text { VE- } \\
\text { RACR } \\
\text { \& DAM }\end{array}$ & $\begin{array}{r}\text { VE- } \\
\text { CEVP } \\
\text { \& RA }\end{array}$ & Inconsistency \\
\hline Exp 5 & 0.18 & 0.14 & 0.15 & 0.31 & 0.22 & 0 \\
Exp 31 & 0.19 & 0.15 & 0.14 & 0.31 & 0.21 & 0.01 \\
Exp 32 & 0.15 & 0.12 & 0.17 & 0.31 & 0.24 & 0.01 \\
Exp 33 & 0.26 & 0.13 & 0.16 & 0.2 & 0.24 & 0.05 \\
Exp 34 & 0.13 & 0.15 & 0.15 & 0.3 & 0.26 & 0.01 \\
Exp 35 & 0.16 & 0.12 & 0.15 & 0.37 & 0.2 & 0.01 \\
Exp 36 & 0.29 & 0.12 & 0.12 & 0.29 & 0.18 & 0.02 \\
Exp 37 & 0.18 & 0.13 & 0.14 & 0.31 & 0.24 & 0.01 \\
Exp 40 & 0.26 & 0.36 & 0.12 & 0.16 & 0.1 & 0.05 \\
\hline Mean & 0.2 & 0.16 & 0.14 & 0.28 & 0.21 & \\
\hline Minimum & 0.13 & 0.12 & 0.12 & 0.16 & 0.1 & \\
Maximum & 0.29 & 0.36 & 0.17 & 0.37 & 0.26 & \\
Std. & 0.05 & 0.07 & 0.02 & 0.06 & 0.05 & \\
Deviation & & & & & & 0.044 \\
Disagreement & & & & & & \\
\hline
\end{tabular}

\section{Relative importance of alternatives respect to project support costs risk impact sub-creteria}

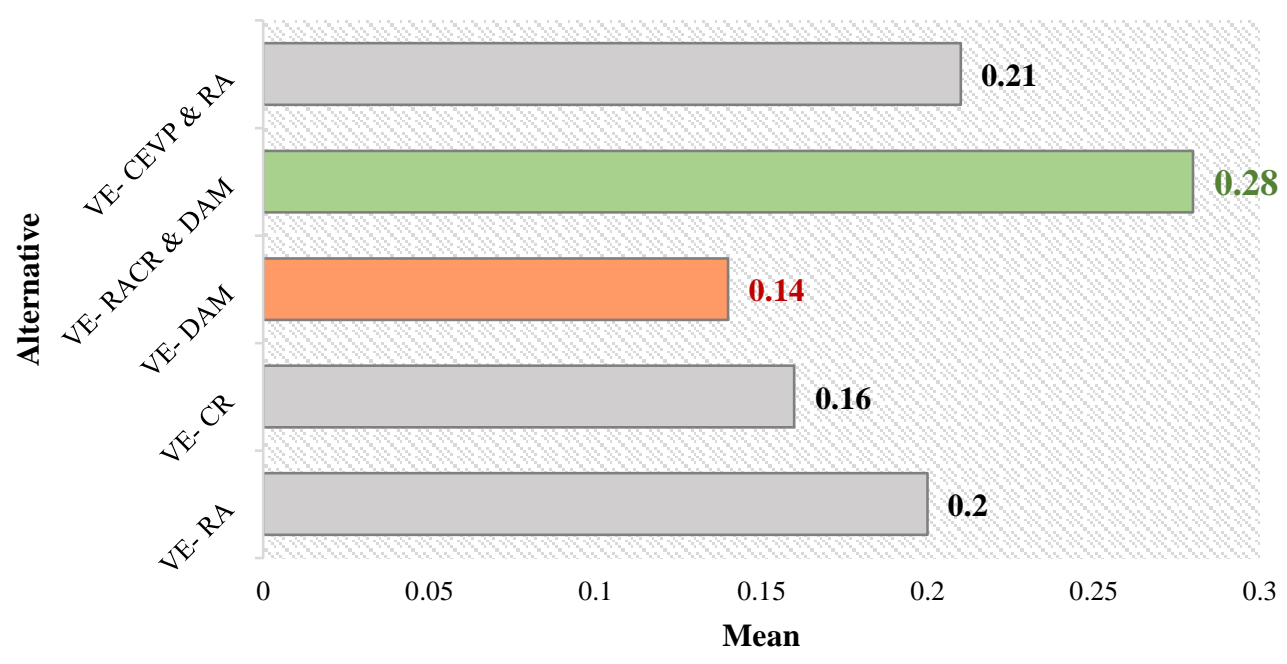

Figure 53: Relative Importance of Alts. with Respect to Support Cost Risk Impact 
In the Project Schedule Risk Impact criterion, as shown in Table 32 and Figure 54, the VE-RACRDAM technique was also ranked the highest relative importance with a value of 0.28. The VE-CEVPRA was ranked the second most effective alternative (0.27), while the VE-DAM was rated the least importance technique with the ranking value of 0.12 .

Table 32: Results of Alts. with Respect to Schedule Risk Impact

\begin{tabular}{|lcccccc|}
\hline $\begin{array}{l}\text { Project } \\
\text { Schedule Risk } \\
\text { Impact }\end{array}$ & VE- RA & VE- CR & $\begin{array}{r}\text { VE- } \\
\text { DAM }\end{array}$ & $\begin{array}{r}\text { VE- } \\
\text { RACR } \\
\text { \& DAM }\end{array}$ & $\begin{array}{r}\text { VE- } \\
\text { CEVP } \\
\text { \& RA }\end{array}$ & Inconsistency \\
\hline Exp 5 & 0.17 & 0.15 & 0.12 & 0.29 & 0.26 & 0.01 \\
Exp 31 & 0.16 & 0.12 & 0.13 & 0.26 & 0.33 & 0.02 \\
Exp 32 & 0.18 & 0.15 & 0.12 & 0.34 & 0.22 & 0.01 \\
Exp 33 & 0.13 & 0.2 & 0.13 & 0.24 & 0.3 & 0.04 \\
Exp 34 & 0.17 & 0.13 & 0.11 & 0.35 & 0.25 & 0 \\
Exp 35 & 0.12 & 0.13 & 0.14 & 0.3 & 0.32 & 0.05 \\
Exp 36 & 0.19 & 0.16 & 0.14 & 0.26 & 0.25 & 0 \\
Exp 37 & 0.17 & 0.16 & 0.15 & 0.27 & 0.24 & 0 \\
Exp 40 & 0.39 & 0.11 & 0.07 & 0.17 & 0.26 & 0.07 \\
\hline Mean & 0.19 & 0.15 & 0.12 & 0.28 & 0.27 & \\
\hline Minimum & 0.12 & 0.11 & 0.07 & 0.17 & 0.22 & \\
Maximum & 0.39 & 0.2 & 0.15 & 0.35 & 0.33 & \\
Std. & 0.07 & 0.03 & 0.02 & 0.05 & 0.04 & \\
Deviation & & & & & & 0.038 \\
Disagreement & & & & & & \\
\hline
\end{tabular}




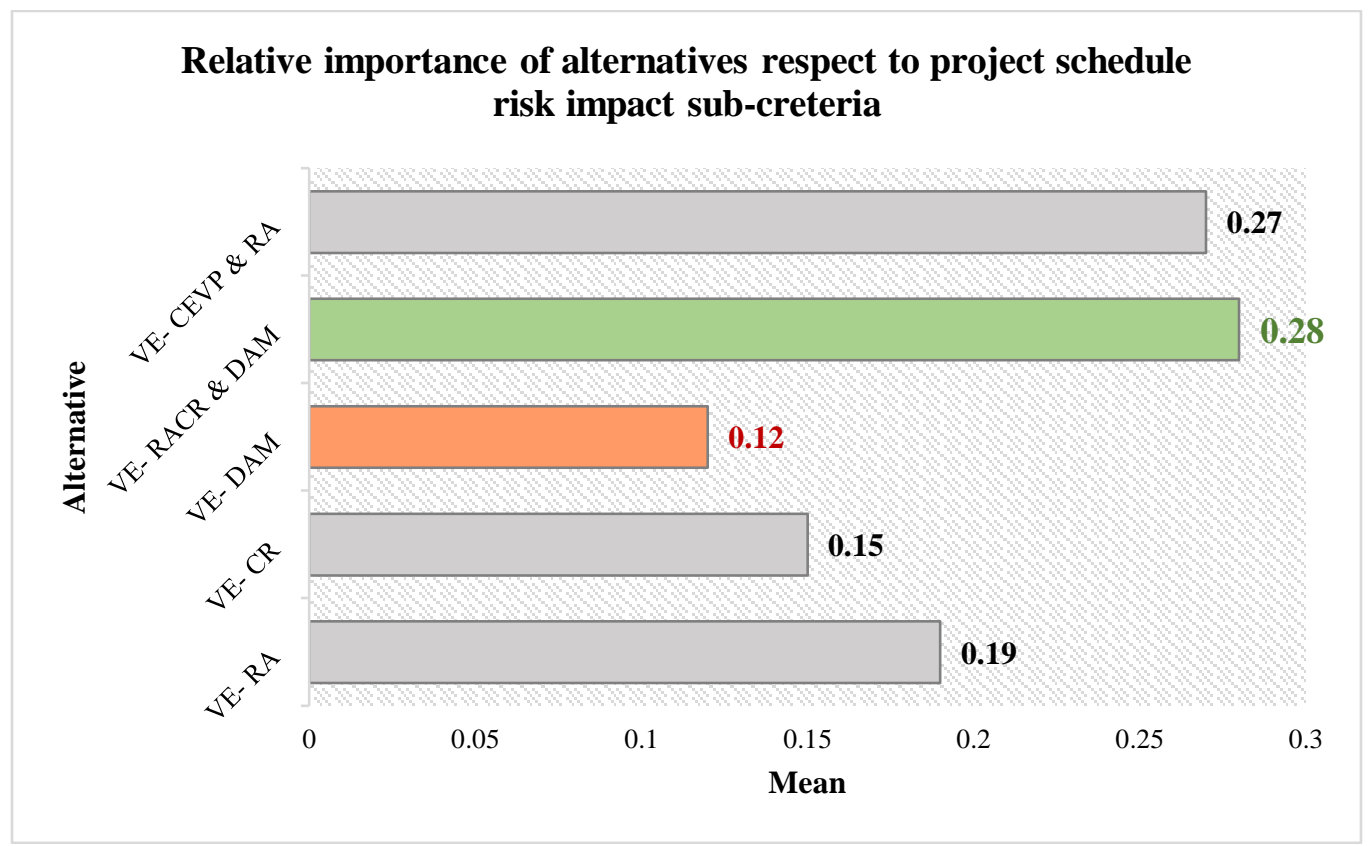

Figure 54: Relative Importance of Alts. with Respect to Schedule Risk Impact

\subsubsection{Results of Alternatives with Performance Sub-criteria}

EP5 evaluated and rated the relative importance of alternatives with respect to the Performance sub-criteria (Project Scope, Project Needed Functions, Communication and Integration Capabilities, and Stakeholder Needs) using the research instrument RI5. The arithmetic means of experts' judgments for the relative importance of considered alternatives with respect of each criterion are shown in Table 33 through 36 and Figure 55 through 58. The green color of each table and figure indicates the highest rank of the bestselected alternative with respect to each Performance criterion, and the orange color indicates the lowest importance. The results indicate that the Alt.4 was ranked the most 
important option among others with respect to the four Performance sub-criteria, and the Alt.2 was ranked the least importance in all Risk sub-criteria. Alt.5 shared Alt.2 in the least importance techniques in the assessment of Project Scope.

In the Project Scope criterion, as shown in Table 33 and Figure 55, the VE-RACRDAM technique was ranked the highest relative importance with a value of 0.26 . The VE-DAM was ranked the second most effective alternative (0.22), while VE-DAM and VE-CEVPRA shared the least importance techniques with the ranking value of 0.17 .

Table 33: Results of Alts. with Respect to Project Scope

\begin{tabular}{|lcccccc|}
\hline Project Scope & VE- RA & VE- CR & $\begin{array}{c}\text { VE- } \\
\text { DAM }\end{array}$ & $\begin{array}{c}\text { VE- } \\
\text { RACR } \\
\text { \& DAM }\end{array}$ & $\begin{array}{r}\text { VE- } \\
\text { CEVP } \\
\text { \& RA }\end{array}$ & Inconsistency \\
\hline Exp 41 & 0.2 & 0.12 & 0.17 & 0.34 & 0.18 & 0.01 \\
Exp 42 & 0.2 & 0.2 & 0.2 & 0.2 & 0.2 & 0 \\
Exp 43 & 0.16 & 0.16 & 0.23 & 0.3 & 0.15 & 0 \\
Exp 44 & 0.22 & 0.22 & 0.22 & 0.22 & 0.12 & 0 \\
Exp 45 & 0.19 & 0.14 & 0.17 & 0.28 & 0.22 & 0.03 \\
Exp 46 & 0.17 & 0.21 & 0.2 & 0.2 & 0.23 & 0.01 \\
Exp 47 & 0.2 & 0.19 & 0.21 & 0.23 & 0.17 & 0 \\
Exp 48 & 0.18 & 0.14 & 0.2 & 0.36 & 0.12 & 0.01 \\
Exp 49 & 0.19 & 0.13 & 0.34 & 0.23 & 0.11 & 0.06 \\
\hline Mean & 0.19 & 0.17 & 0.22 & 0.26 & 0.17 & \\
\hline Minimum & 0.16 & 0.12 & 0.17 & 0.2 & 0.11 & \\
Maximum & 0.22 & 0.22 & 0.34 & 0.36 & 0.23 & \\
Std. & 0.02 & 0.04 & 0.05 & 0.06 & 0.04 & \\
Deviation & & & & & & 0.04 \\
Disagreement & & & & & & \\
\hline
\end{tabular}




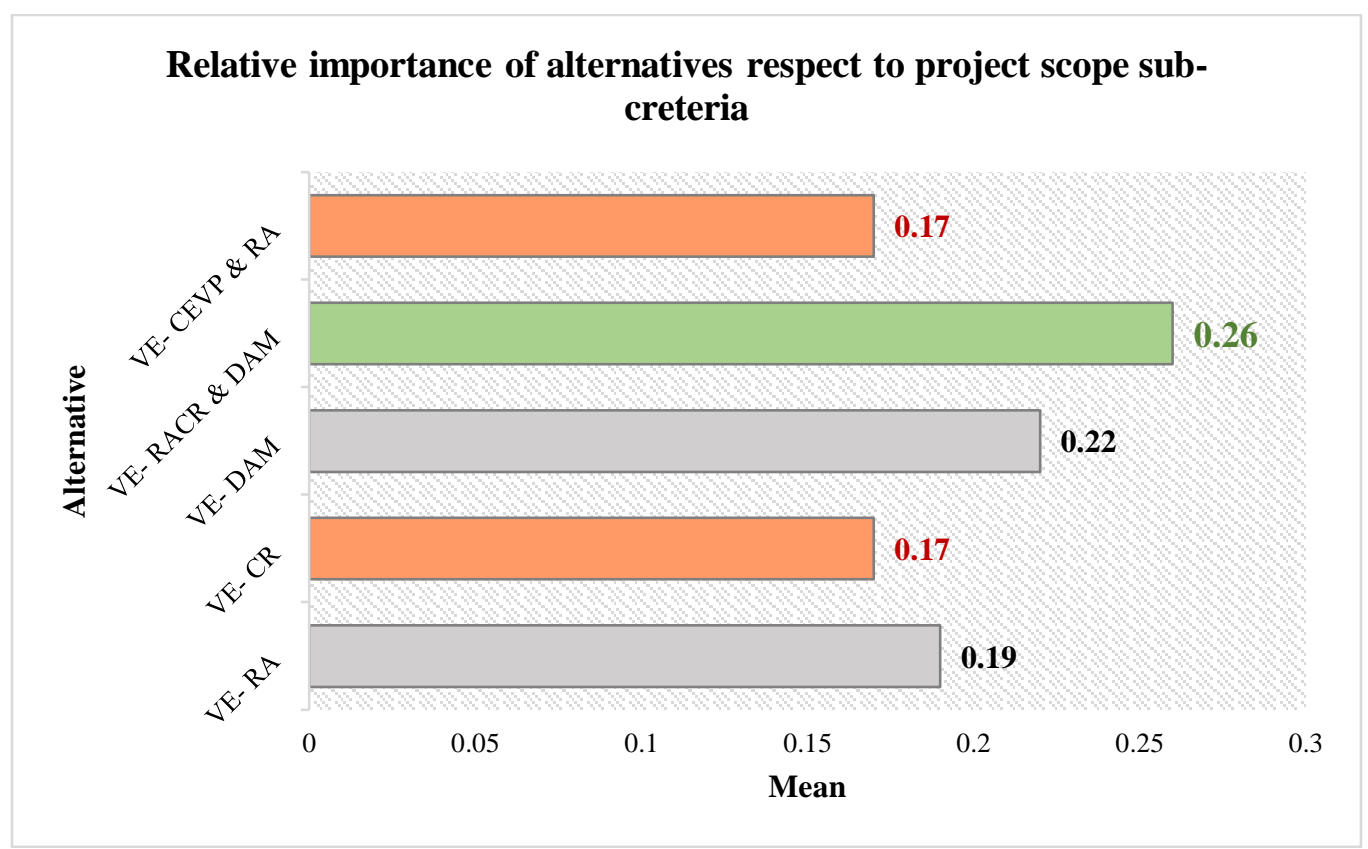

Figure 55: Relative Importance of Alts. with Respect to Project Scope

In the Project Needed Functions criterion, as shown in Table 34 and Figure 56, the VERACRDAM technique was ranked the highest relative importance with a value of 0.3 . The VE-DAM was ranked the second most effective alternative $(0.21)$, while the VE-CR was rated the least importance technique with the ranking value of 0.15 . 
Table 34: Results of Alts. with Respect to Needed Functions

\begin{tabular}{|c|c|c|c|c|c|c|}
\hline $\begin{array}{l}\quad \text { Project } \\
\text { Needed } \\
\text { Functions }\end{array}$ & VE- RA & VE- CR & $\begin{array}{r}\text { VE- } \\
\text { DAM }\end{array}$ & $\begin{array}{l}\text { VE- } \\
\text { RACR } \\
\text { \& DAM }\end{array}$ & $\begin{array}{r}\text { VE- } \\
\text { CEVP } \\
\text { \& RA } \\
\end{array}$ & Inconsistency \\
\hline Exp 41 & 0.19 & 0.16 & 0.19 & 0.29 & 0.17 & 0 \\
\hline Exp 42 & 0.2 & 0.2 & 0.2 & 0.2 & 0.2 & 0 \\
\hline Exp 43 & 0.18 & 0.15 & 0.19 & 0.3 & 0.18 & 0 \\
\hline Exp 44 & 0.13 & 0.13 & 0.18 & 0.4 & 0.15 & 0 \\
\hline $\operatorname{Exp} 45$ & 0.17 & 0.14 & 0.21 & 0.3 & 0.18 & 0 \\
\hline Exp 46 & 0.16 & 0.19 & 0.16 & 0.26 & 0.23 & 0.01 \\
\hline Exp 47 & 0.12 & 0.12 & 0.22 & 0.36 & 0.18 & 0.01 \\
\hline Exp 48 & 0.14 & 0.12 & 0.22 & 0.33 & 0.19 & 0 \\
\hline Exp 49 & 0.13 & 0.15 & 0.34 & 0.24 & 0.15 & 0.06 \\
\hline Mean & 0.16 & 0.15 & 0.21 & 0.3 & 0.18 & \\
\hline Minimum & 0.12 & 0.12 & 0.16 & 0.2 & 0.15 & \\
\hline Maximum & 0.2 & 0.2 & 0.34 & 0.4 & 0.23 & \\
\hline $\begin{array}{l}\text { Std. } \\
\text { Deviation }\end{array}$ & 0.03 & 0.03 & 0.05 & 0.06 & 0.02 & \\
\hline Disagreement & & & & & & 0.034 \\
\hline
\end{tabular}

Relative importance of alternatives respect to project needed functions sub-creteria

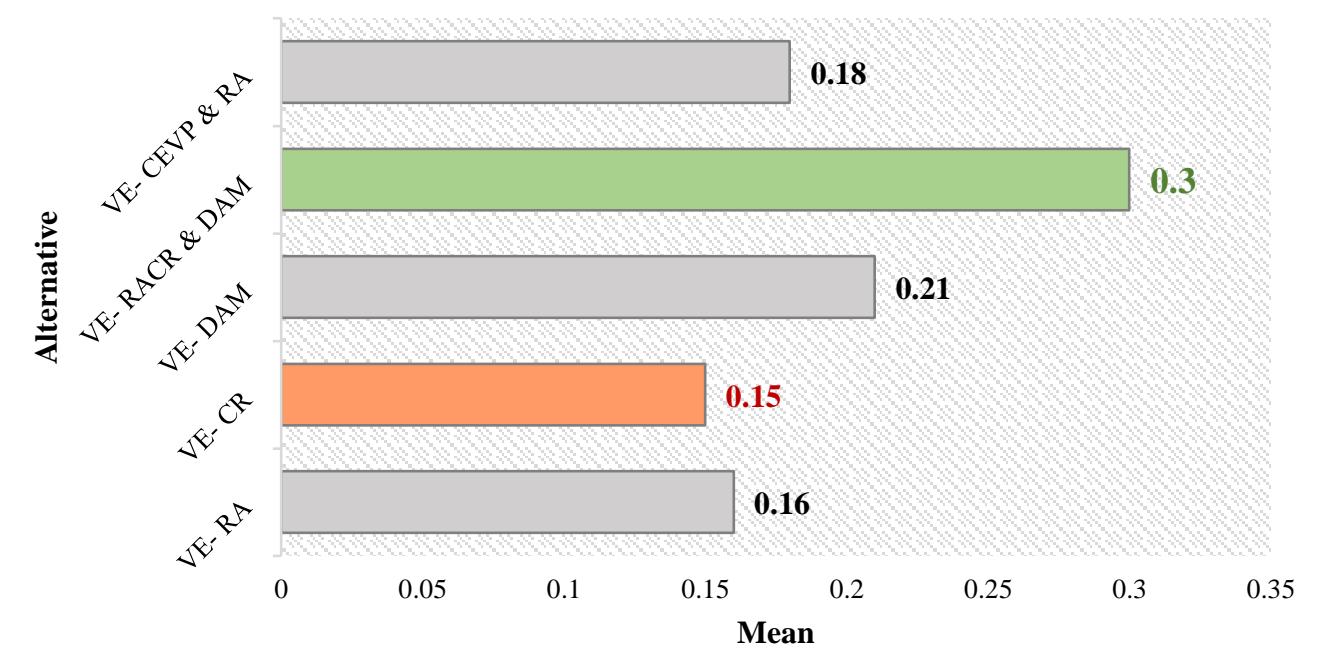

Figure 56: Relative Importance of Alts. with Respect to Needed Functions 
In the Communication and Integration Capabilities criterion, as shown in Table 35 and Figure 57, the VE-RACRDAM technique was also ranked the highest relative importance with a value of 0.3. The VE-CEVPRA was ranked the second most effective alternative (0.19), while the VE-CR was rated the least importance technique with the ranking value of 0.14 .

Table 35: Results of Alts. with Respect to Commun. and Integ. Capabilities

\begin{tabular}{|lcccccc|}
\hline $\begin{array}{l}\text { Communication } \\
\text { and Integration } \\
\text { Capabilities }\end{array}$ & VE- RA & VE- CR & $\begin{array}{r}\text { VE- } \\
\text { DAM }\end{array}$ & $\begin{array}{r}\text { VE- } \\
\text { RACR } \\
\text { \& DAM }\end{array}$ & $\begin{array}{r}\text { VE- } \\
\text { CEVP } \\
\text { \& RA }\end{array}$ & Inconsistency \\
\hline Exp 41 & 0.15 & 0.12 & 0.16 & 0.34 & 0.24 & 0.02 \\
Exp 42 & 0.17 & 0.1 & 0.16 & 0.36 & 0.21 & 0.01 \\
Exp 43 & 0.28 & 0.14 & 0.17 & 0.26 & 0.15 & 0.03 \\
Exp 44 & 0.17 & 0.11 & 0.13 & 0.37 & 0.22 & 0.01 \\
Exp 45 & 0.19 & 0.13 & 0.21 & 0.3 & 0.17 & 0.01 \\
Exp 46 & 0.3 & 0.21 & 0.11 & 0.19 & 0.2 & 0.03 \\
Exp 47 & 0.18 & 0.15 & 0.19 & 0.28 & 0.18 & 0 \\
Exp 48 & 0.2 & 0.15 & 0.19 & 0.26 & 0.2 & 0.01 \\
Exp 49 & 0.14 & 0.13 & 0.29 & 0.31 & 0.13 & 0.02 \\
\hline Mean & 0.2 & 0.14 & 0.18 & 0.3 & 0.19 & \\
\hline Minimum & 0.14 & 0.1 & 0.11 & 0.19 & 0.13 & \\
Maximum & 0.3 & 0.21 & 0.29 & 0.37 & 0.24 & \\
Std. Deviation & 0.05 & 0.03 & 0.05 & 0.05 & 0.03 & \\
Disagreement & & & & & & 0.04 \\
\hline
\end{tabular}




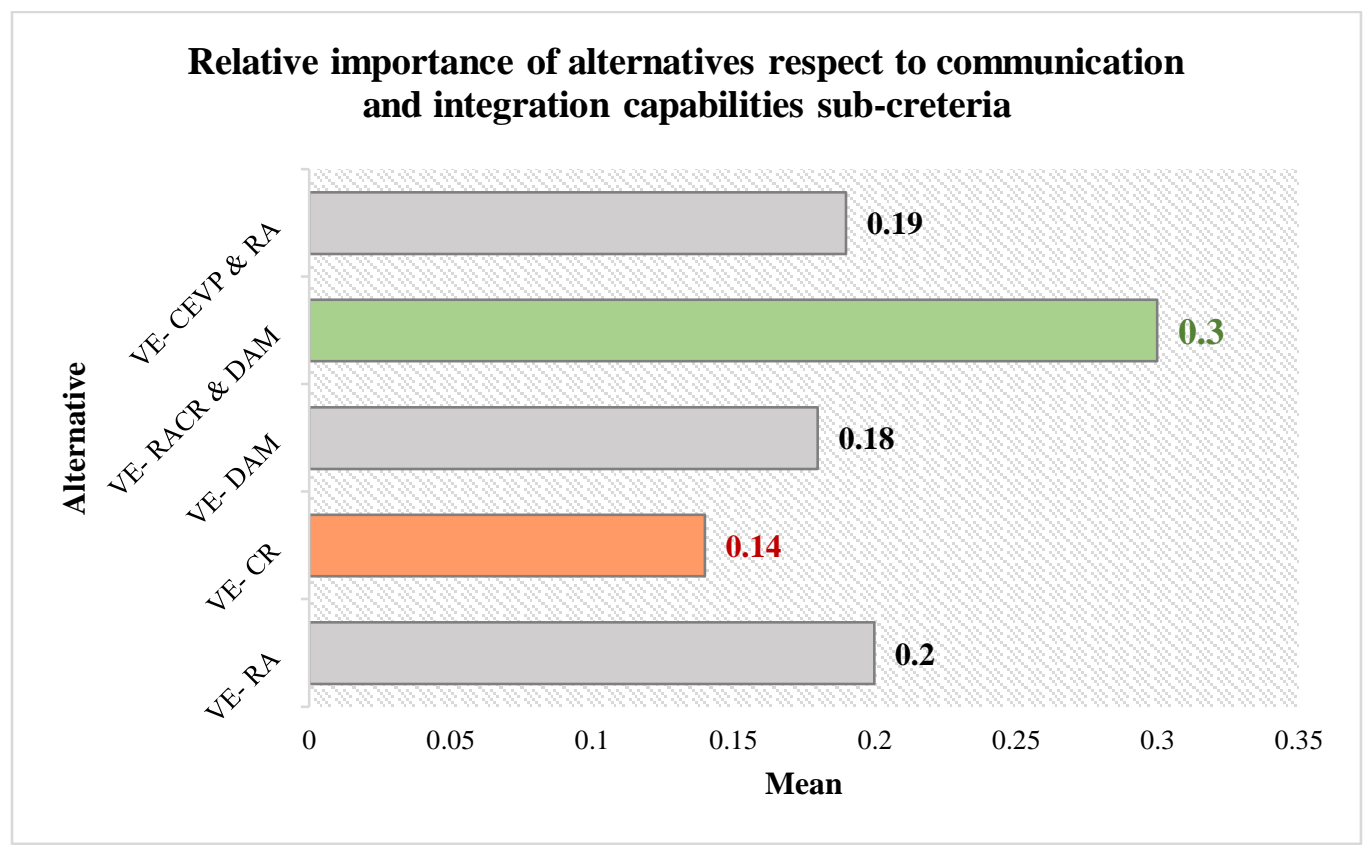

Figure 57: Relative Importance of Alts. with Respect to Commun. and Integ.

In the Stakeholder Needs criterion, as shown in Table 36 and Figure 58, the VERACRDAM technique was ranked the highest relative importance with a value of 0.28 . The VE-CEVPRA was ranked the second most effective alternative (0.21), while the VECR was rated the least importance technique with the ranking value of 0.15 . 
Table 36: Results of Alts. with Respect to Stakeholder Needs

\begin{tabular}{|lcccccc|}
\hline $\begin{array}{c}\text { Stakeholder } \\
\text { Needs }\end{array}$ & VE- RA & VE- CR & $\begin{array}{r}\text { VE- } \\
\text { DAM }\end{array}$ & $\begin{array}{r}\text { VE- } \\
\text { RACR } \\
\text { \& DAM }\end{array}$ & $\begin{array}{r}\text { VE- } \\
\text { CEVP } \\
\text { \& RA }\end{array}$ & Inconsistency \\
\hline Exp 41 & 0.18 & 0.16 & 0.18 & 0.27 & 0.21 & 0 \\
Exp 42 & 0.15 & 0.15 & 0.16 & 0.29 & 0.24 & 0.03 \\
Exp 43 & 0.14 & 0.14 & 0.21 & 0.34 & 0.16 & 0.01 \\
Exp 44 & 0.16 & 0.13 & 0.2 & 0.27 & 0.25 & 0.01 \\
Exp 45 & 0.24 & 0.14 & 0.14 & 0.24 & 0.23 & 0.02 \\
Exp 46 & 0.25 & 0.22 & 0.13 & 0.17 & 0.22 & 0.01 \\
Exp 47 & 0.16 & 0.11 & 0.17 & 0.35 & 0.21 & 0.01 \\
Exp 48 & 0.17 & 0.16 & 0.17 & 0.28 & 0.23 & 0.01 \\
Exp 49 & 0.19 & 0.13 & 0.23 & 0.32 & 0.13 & 0.04 \\
\hline Mean & 0.18 & 0.15 & 0.18 & 0.28 & 0.21 & \\
\hline Minimum & 0.14 & 0.11 & 0.13 & 0.17 & 0.13 & \\
Maximum & 0.25 & 0.22 & 0.23 & 0.35 & 0.25 & \\
Std. & 0.04 & 0.03 & 0.03 & 0.05 & 0.04 & \\
Deviation & & & & & & 0.033 \\
Disagreement & & & & & & \\
\hline
\end{tabular}

Relative importance of alternatives respect to stakeholder needs sub-creteria

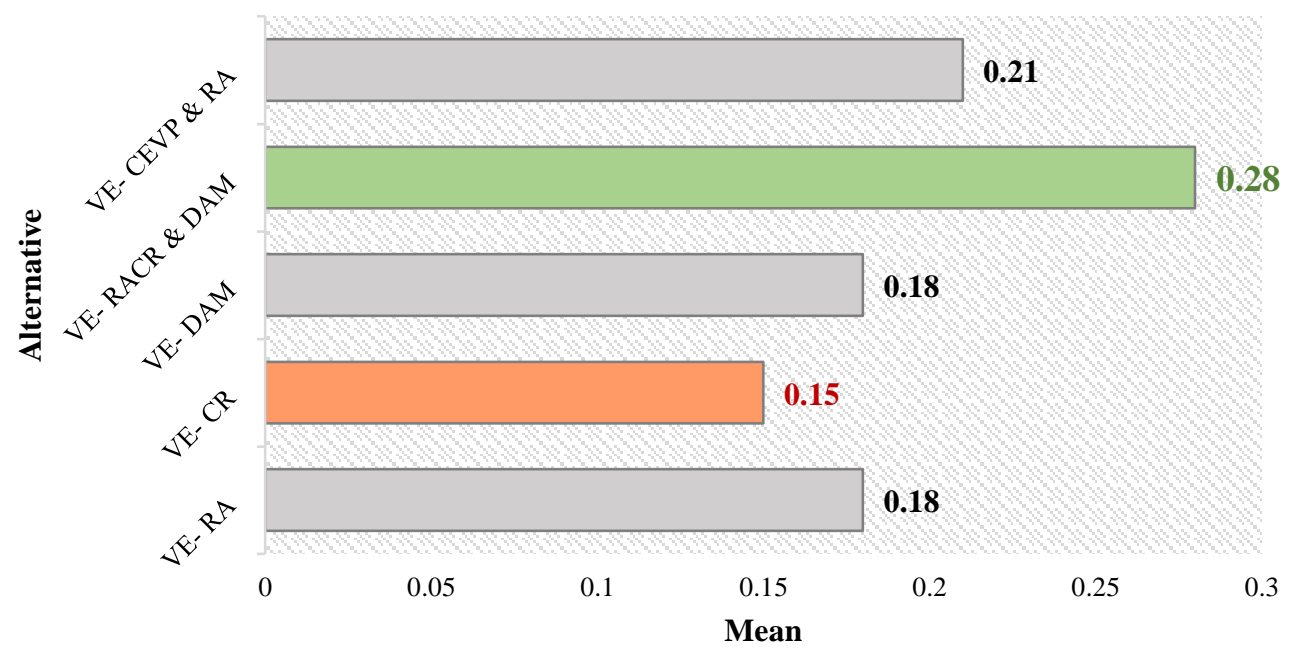

Figure 58: Relative Importance of Alts. with Respect to Stakeholder Needs 


\subsubsection{Results of Alternatives with Resources Sub-criteria}

EP6 evaluated and rated the relative importance of alternatives with respect to the Resources sub-criteria (In-house Capability, External Consultant Needs, Time Needs during using the Technique, and Project Stakeholder Involvement) using the research instrument RI5. The arithmetic means of experts' judgments for the relative importance of considered alternatives with respect of each criterion are shown in Table 37 through 40 and Figure 59 through 62 . The green color of each table and figure indicates the highest rank of the best-selected alternative with respect to each Resources criterion, and the orange color indicates the lowest importance. The results indicate that the Alt.4 was ranked the most important option among others with respect to the four Resources sub-criteria, and the Alt.1 shared Alt.4 with the same rank in In-house Capability criterion. Alt.3 and 5 showed the lowest importance in In-house Capability criterion while Alt.1 and 2 shared the least importance in the External Consultant Needs criterion. Alt.2 was ranked the least importance in Time Needs during using the Technique, and Project Stakeholder Involvement criterion. 
In the In-house Capability criterion, as shown in Table 37 and Figure 59, the VERACRDAM and VE-RA techniques were ranked the highest relative importance with a value of 0.22 . The VE-CR was ranked the second most effective alternative (0.2), while VE-DAM and VE-CEVPRA shared the least importance techniques with the ranking value of 0.18

Table 37: Results of Alts. with Respect to In-house Capability

\begin{tabular}{|lcccccc|}
\hline $\begin{array}{c}\text { In-house } \\
\text { Capability }\end{array}$ & VE- RA & VE- CR & $\begin{array}{r}\text { VE- } \\
\text { DAM }\end{array}$ & $\begin{array}{r}\text { VE- } \\
\text { RACR } \\
\text { \& DAM }\end{array}$ & $\begin{array}{r}\text { VE- } \\
\text { CEVP } \\
\text { \& RA }\end{array}$ & Inconsistency \\
\hline Exp 50 & 0.27 & 0.24 & 0.17 & 0.18 & 0.14 & 0.01 \\
Exp 44 & 0.23 & 0.26 & 0.18 & 0.18 & 0.16 & 0.01 \\
Exp 41 & 0.23 & 0.14 & 0.16 & 0.3 & 0.17 & 0.01 \\
Exp 42 & 0.17 & 0.13 & 0.19 & 0.28 & 0.24 & 0 \\
Exp 44 & 0.2 & 0.28 & 0.17 & 0.17 & 0.18 & 0.02 \\
Exp 45 & 0.22 & 0.17 & 0.2 & 0.22 & 0.19 & 0.01 \\
Exp 46 & 0.22 & 0.18 & 0.19 & 0.23 & 0.18 & 0.01 \\
\hline Mean & 0.22 & 0.2 & 0.18 & 0.22 & 0.18 & \\
\hline Minimum & 0.17 & 0.13 & 0.16 & 0.17 & 0.14 & \\
Maximum & 0.27 & 0.28 & 0.2 & 0.3 & 0.24 & \\
Std. & 0.03 & 0.06 & 0.01 & 0.05 & 0.03 & \\
Deviation & & & & & & 0.035 \\
Disagreement & & & & & & \\
\hline
\end{tabular}




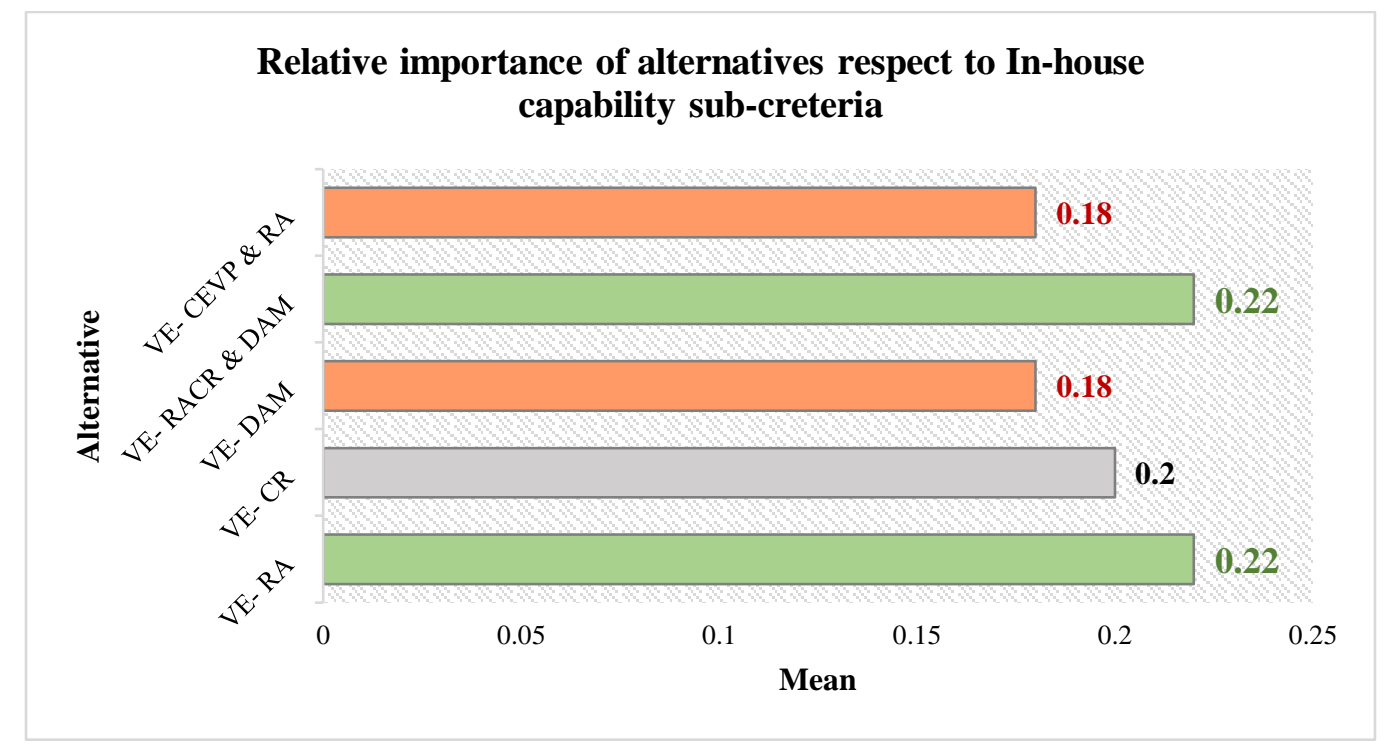

Figure 59: Relative Importance of Alts. with Respect to In-house Capability

In the External Consultant Needs criterion, as shown in Table 38 and Figure 60, the VE-RACRDAM was ranked the highest relative importance with a value of 0.29 . The VECEVPRA was ranked the second most effective alternative (0.25), while VE-RA and VECR shared the least importance techniques with the ranking value of 0.15 . 
Table 38: Results of Alts. with Respect to Ext. Consultant Needs

\begin{tabular}{|lcccccc|}
\hline $\begin{array}{c}\text { External } \\
\text { Consultant } \\
\text { Needs }\end{array}$ & VE- RA & VE- CR & $\begin{array}{r}\text { VE- } \\
\text { DAM }\end{array}$ & $\begin{array}{r}\text { VE- } \\
\text { RACR } \\
\text { \& DAM }\end{array}$ & $\begin{array}{r}\text { VE- } \\
\text { CEVP } \\
\text { \& RA }\end{array}$ & Inconsistency \\
\hline Exp 50 & 0.17 & 0.17 & 0.17 & 0.28 & 0.22 & 0 \\
Exp 44 & 0.15 & 0.13 & 0.14 & 0.29 & 0.29 & 0 \\
Exp 41 & 0.18 & 0.13 & 0.14 & 0.31 & 0.25 & 0.01 \\
Exp 42 & 0.16 & 0.15 & 0.14 & 0.29 & 0.26 & 0.01 \\
Exp 44 & 0.14 & 0.16 & 0.18 & 0.29 & 0.23 & 0.01 \\
Exp 45 & 0.14 & 0.18 & 0.15 & 0.29 & 0.24 & 0.01 \\
Exp 46 & 0.13 & 0.15 & 0.18 & 0.29 & 0.24 & 0.01 \\
\hline Mean & 0.15 & 0.15 & 0.16 & 0.29 & 0.25 & \\
\hline Minimum & 0.13 & 0.13 & 0.14 & 0.28 & 0.22 & \\
Maximum & 0.18 & 0.18 & 0.18 & 0.31 & 0.29 & \\
Std. & 0.02 & 0.02 & 0.02 & 0.01 & 0.02 & \\
Deviation & & & & & & 0.016 \\
Disagreement & & & & & & \\
\hline
\end{tabular}

\section{Relative importance of alternatives respect to external consultant needs sub-creteria}

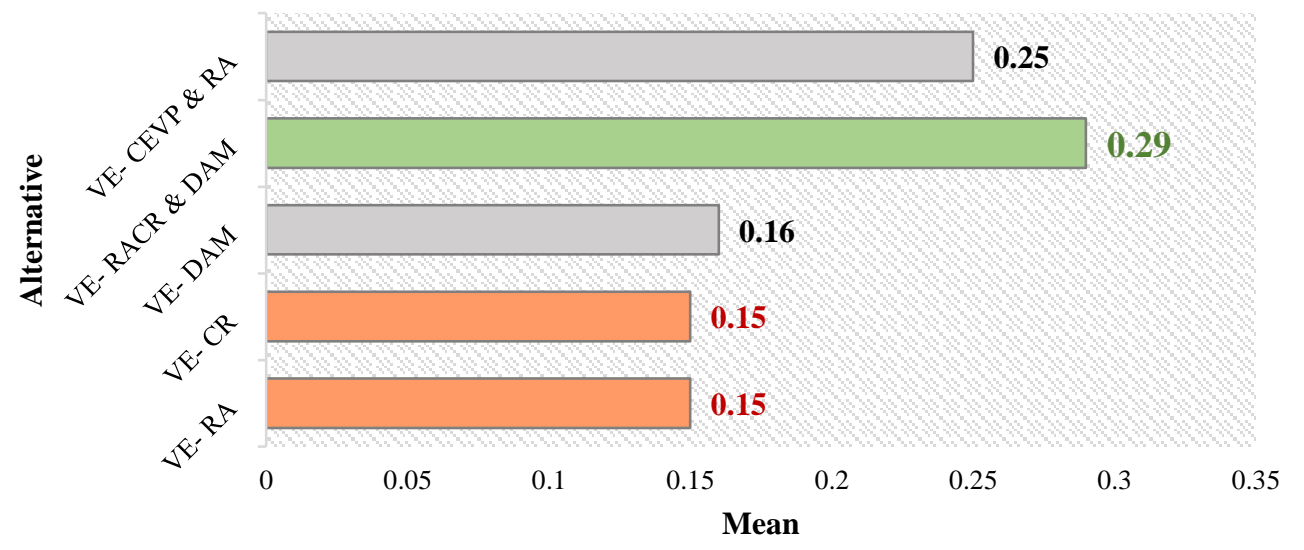

Figure 60: Relative Importance of Alts. with Respect to Ext. Consultant Needs 
In the Time Needs during using the Technique criterion, as shown in Table 39 and Figure 61, the VE-RACRDAM was ranked the highest relative importance with a value of 0.28. The VE-CEVPRA was ranked the second most effective alternative (0.24), while the VE-CR was rated the least importance technique with the ranking value of 0.15 .

Table 39: Results of Alts. with Respect to Time Needs

\begin{tabular}{|lcccccc|}
\hline $\begin{array}{c}\text { Time Needs } \\
\text { during using } \\
\text { the Technique }\end{array}$ & VE- RA & VE- CR & $\begin{array}{r}\text { VE- } \\
\text { DAM }\end{array}$ & $\begin{array}{r}\text { VE- } \\
\text { RACR } \\
\text { \& DAM }\end{array}$ & $\begin{array}{r}\text { VE- } \\
\text { CEVP } \\
\text { \& RA }\end{array}$ & Inconsistency \\
\hline Exp 50 & 0.18 & 0.14 & 0.16 & 0.26 & 0.26 & 0.03 \\
Exp 44 & 0.16 & 0.15 & 0.15 & 0.32 & 0.22 & 0.02 \\
Exp 41 & 0.18 & 0.17 & 0.15 & 0.24 & 0.27 & 0.01 \\
Exp 42 & 0.16 & 0.15 & 0.17 & 0.28 & 0.23 & 0.01 \\
Exp 44 & 0.15 & 0.15 & 0.14 & 0.3 & 0.26 & 0 \\
Exp 45 & 0.16 & 0.16 & 0.16 & 0.29 & 0.22 & 0.03 \\
Exp 46 & 0.17 & 0.15 & 0.18 & 0.29 & 0.21 & 0.01 \\
\hline Mean & 0.17 & 0.15 & 0.16 & 0.28 & 0.24 & \\
\hline Minimum & 0.15 & 0.14 & 0.14 & 0.24 & 0.21 & \\
Maximum & 0.18 & 0.17 & 0.18 & 0.32 & 0.27 & \\
Std. & 0.01 & 0.01 & 0.01 & 0.02 & 0.02 & \\
Deviation & & & & & & 0.016 \\
Disagreement & & & & & & \\
\hline
\end{tabular}




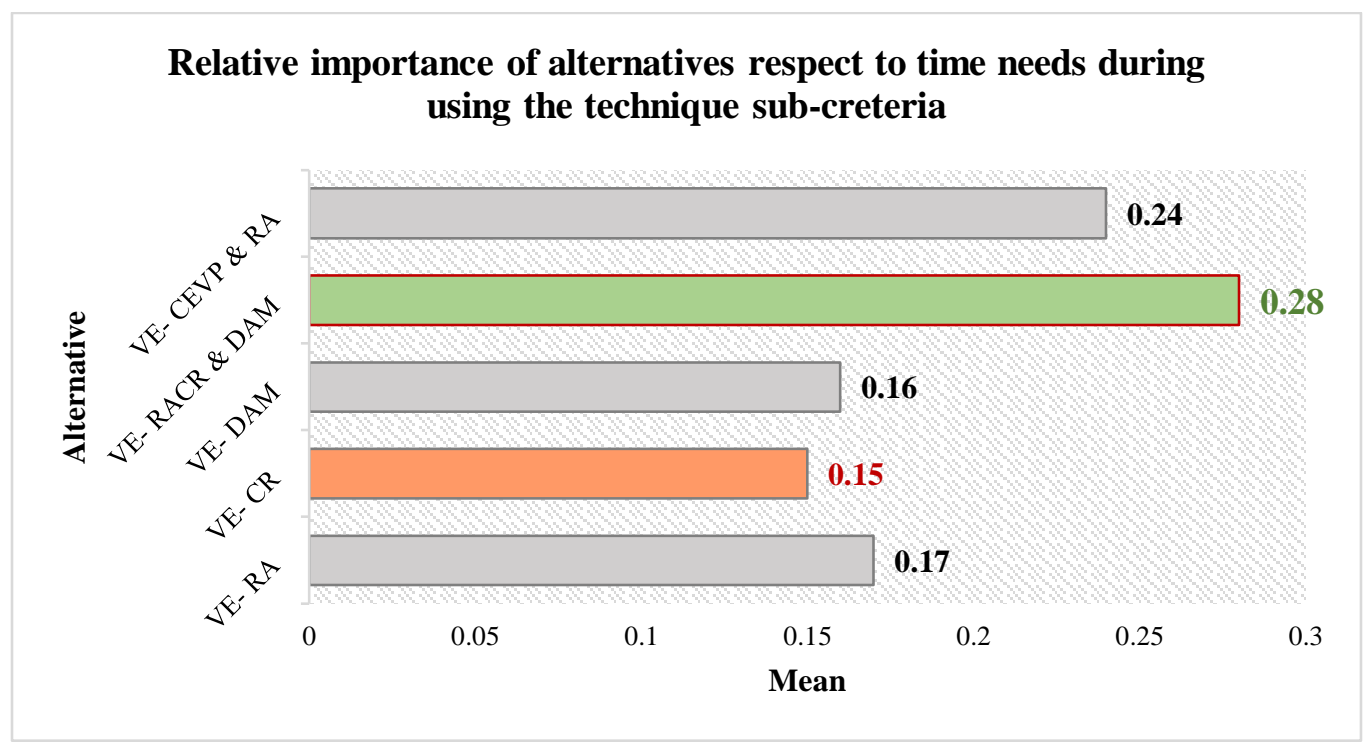

Figure 61: Relative Importance of Alts. with Respect to Time Needs

the Project Stakeholder Involvement criterion, as shown in Table 40 and Figure 62, the VE-RACRDAM was ranked the highest relative importance with a value of 0.31 . The VECEVPRA was ranked the second most effective alternative (0.21), while the VE-CR was rated the least importance technique with the ranking value of 0.14 . 
Table 40: Results of Alts. with Respect to Stakeholder Involvement

\begin{tabular}{|lcccccc|}
\hline $\begin{array}{c}\text { Project } \\
\text { Stakeholder } \\
\text { Involvement }\end{array}$ & VE- RA & VE- CR & $\begin{array}{c}\text { VE- } \\
\text { DAM }\end{array}$ & $\begin{array}{c}\text { VE- } \\
\text { RACR } \\
\text { \& DAM }\end{array}$ & $\begin{array}{r}\text { VE- } \\
\text { CEVP } \\
\text { \& RA }\end{array}$ & Inconsistency \\
\hline Exp 50 & 0.14 & 0.13 & 0.22 & 0.32 & 0.19 & 0.05 \\
Exp 44 & 0.2 & 0.11 & 0.15 & 0.26 & 0.28 & 0.06 \\
Exp 41 & 0.2 & 0.18 & 0.19 & 0.26 & 0.18 & 0 \\
Exp 42 & 0.08 & 0.06 & 0.2 & 0.44 & 0.22 & 0.06 \\
Exp 44 & 0.14 & 0.16 & 0.22 & 0.3 & 0.18 & 0.01 \\
Exp 45 & 0.13 & 0.12 & 0.14 & 0.35 & 0.25 & 0.05 \\
Exp 46 & 0.18 & 0.21 & 0.18 & 0.26 & 0.16 & 0.01 \\
\hline Mean & 0.15 & 0.14 & 0.19 & 0.31 & 0.21 & \\
\hline Minimum & 0.08 & 0.06 & 0.14 & 0.26 & 0.16 & \\
Maximum & 0.2 & 0.21 & 0.22 & 0.44 & 0.28 & \\
Std. & 0.04 & 0.05 & 0.03 & 0.06 & 0.04 & \\
Deviation & & & & & & 0.041 \\
Disagreement & & & & & & \\
\hline
\end{tabular}

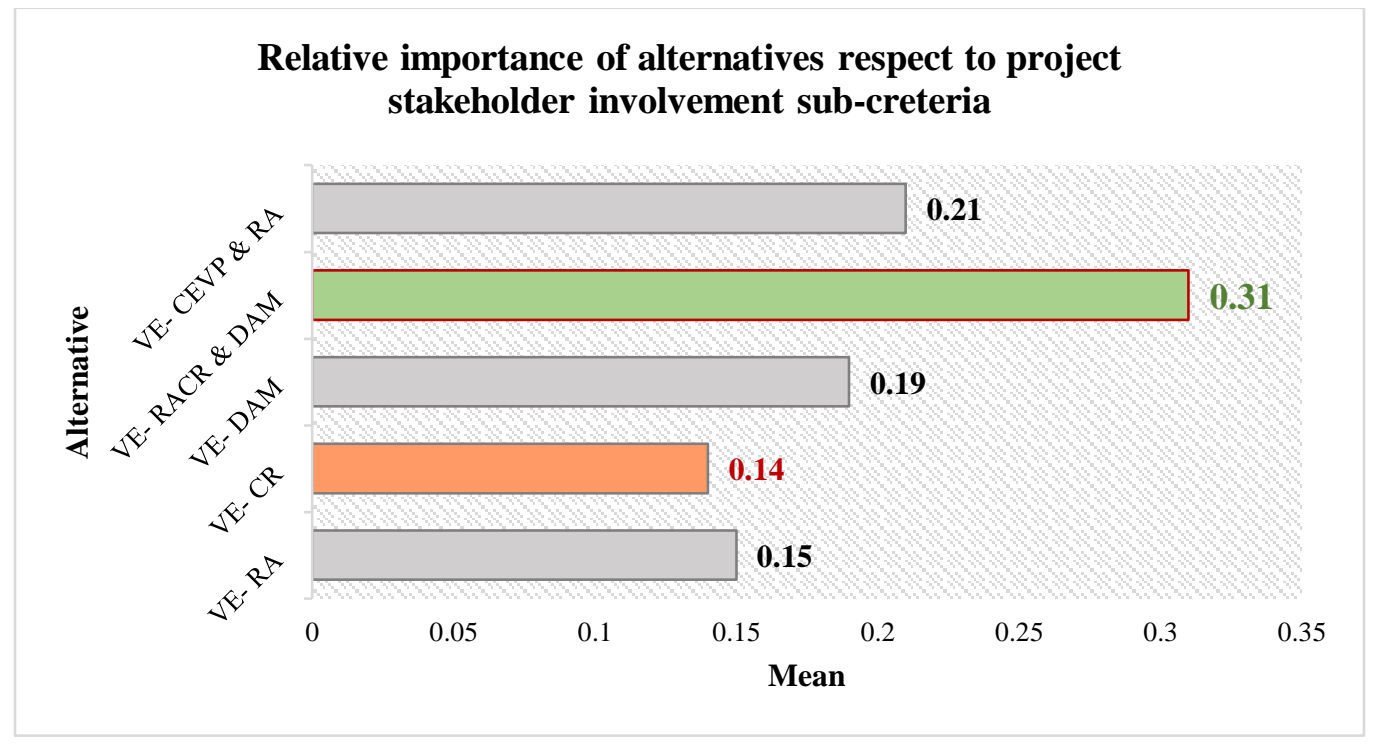

Figure 62: Relative Importance of Alts. with Respect to Stakeholder Involvement 


\subsubsection{Final Results of the Alternatives with Respect to the Mission}

This part presents the conclusion of the final five alternatives ranking (VE-RA, VECR, VE-DAM, VE-RACRDAM, and VE-CEVPRA). As shown in Table 41 and Figure 63, the VE-RACRDAM technique was ranked the most important with a value of 0.3 among others with respect to the mission. The VE-CEVPRA was the second most effective technique, and it was better than the following most effective technique, VE-RA, by only 18\%. The VE-DAM was ranked the fourth (0.16) and closed to the least importance technique, VE-CR, (0.15).

Table 41: Final Results of Alts. with Respect to Mission

\begin{tabular}{|lcccccc|c|}
\hline $\begin{array}{l}\text { Evaluating } \\
\text { Assessment } \\
\text { Techniques }\end{array}$ & VE- RA & VE- CR & VE- DAM & $\begin{array}{r}\text { VE- } \\
\text { RACR } \\
\& \text { AM }\end{array}$ & $\begin{array}{r}\text { VE- } \\
\text { CEVP } \\
\text { \& RA }\end{array}$ & Inconsistency \\
\hline Composite & 0.18 & 0.15 & 0.16 & 0.3 & 0.22 & 0.04 \\
\hline Mean & 0.18 & 0.15 & 0.16 & 0.3 & 0.22 & \\
Minimum & 0.18 & 0.15 & 0.16 & 0.3 & 0.22 & \\
Maximum & 0.18 & 0.15 & 0.16 & 0.3 & 0.22 & \\
Std. Deviation & 0 & 0 & 0 & 0 & 0 & 0 \\
Disagreement & & & & & & 0 \\
\hline
\end{tabular}




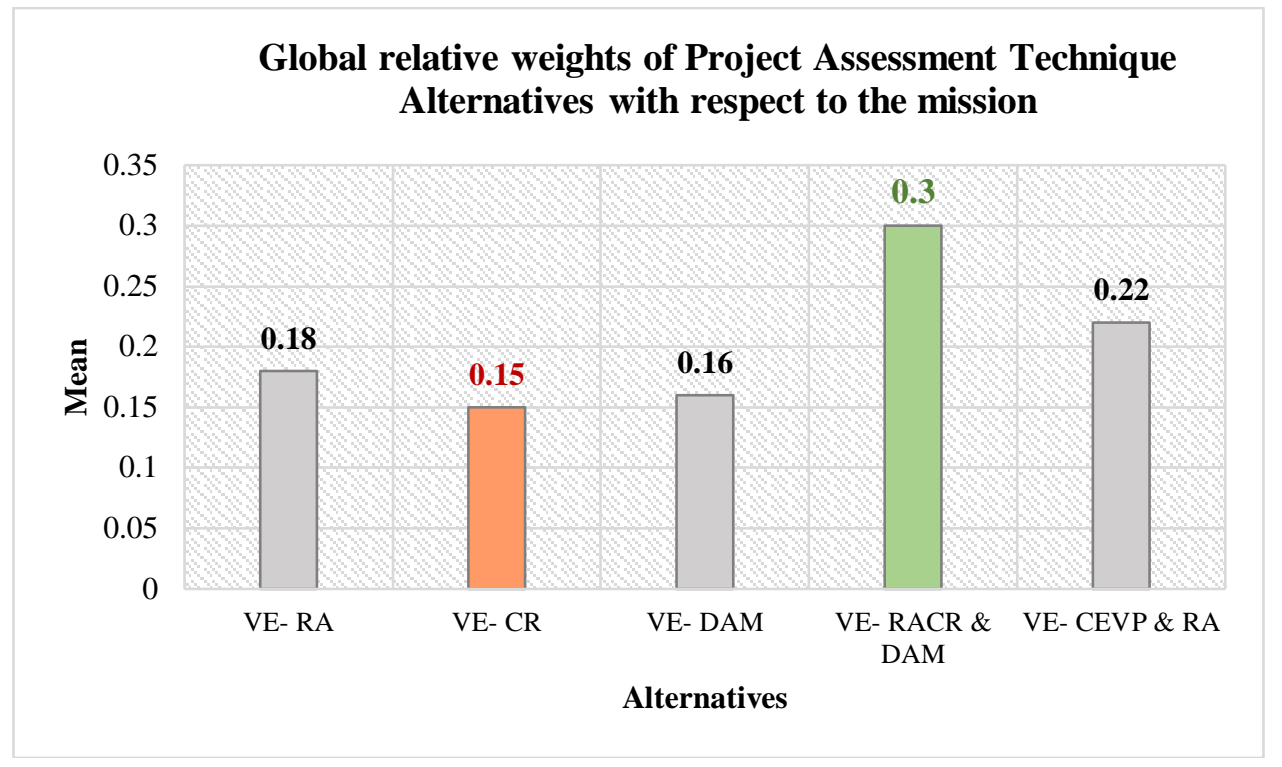

Figure 63: Alts. Ranking - Final Result

\subsubsection{Inconsistency and Disagreement}

The original inconsistency calculation also measured the inconsistency of the experts at this level. The individual inconsistency was acceptable for all alternatives with respect to each sub-criterion. All results indicate an inconsistency level less than 0.10. The disagreement at this level was measured among five alternatives with respect to the nineteen sub-criteria. All experts were considered independently to determine their effect on the final results with respect to the relative rankings of five alternatives. The HDM software showed that the final results of disagreement in this level were acceptable and within the disagreement limit $(<0.1)$. The disagreement values in this level are shown in the F-test section below, Table 42. 


\subsubsection{F-Test}

The F-test confirmed that there was no statistically significant difference among the experts in panels EP2, EP3, EP4, EP5 and EP6 regarding the Level 4 with respect to Level 3. Therefore, the null hypothesis was still rejected at 0.1. However, with S16 (In-house Capability sub-criteria) the null hypothesis could not be rejected even at the 0.1 level. As the disagreement measure was acceptable (less than 0.1) in this variable, therefore Abotah's justification regarding the F-test calculation was used [191]. The F-test and final disagreement values for each criterion are summarized in Table 42. 
Table 42: Final Results of F-test and Disagreement

\begin{tabular}{|c|c|c|c|c|c|c|}
\hline $\begin{array}{l}\text { Sub- } \\
\text { criteria (Sn) }\end{array}$ & $\sigma 2=0.01$ & $\sigma 2=0.025$ & $\sigma 2=0.05$ & $\sigma 2=0.1$ & F-value & $\begin{array}{l}\text { Disagreeme- } \\
\mathrm{nt}\end{array}$ \\
\hline S1 & 3.97 & 3.22 & 2.67 & 2.13 & 20.85 & 0.051 \\
\hline S2 & 3.97 & 3.22 & 2.67 & 2.13 & 20.38 & 0.044 \\
\hline S3 & 3.97 & 3.22 & 2.67 & 2.13 & 17.58 & 0.034 \\
\hline S4 & 3.83 & 3.13 & 2.61 & 2.09 & 24.35 & 0.034 \\
\hline S5 & 3.83 & 3.13 & 2.61 & 2.09 & 22.06 & 0.038 \\
\hline S6 & 3.83 & 3.13 & 2.61 & 2.09 & 21.63 & 0.031 \\
\hline S7 & 3.83 & 3.13 & 2.61 & 2.09 & 19.68 & 0.025 \\
\hline S8 & 3.97 & 3.22 & 2.67 & 2.13 & 8.92 & 0.041 \\
\hline S9 & 3.97 & 3.22 & 2.67 & 2.13 & 15.44 & 0.031 \\
\hline S10 & 3.97 & 3.22 & 2.67 & 2.13 & 6.93 & 0.044 \\
\hline S11 & 3.97 & 3.22 & 2.67 & 2.13 & 14.83 & 0.038 \\
\hline S12 & 3.97 & 3.22 & 2.67 & 2.13 & 5.77 & 0.04 \\
\hline S13 & 3.97 & 3.22 & 2.67 & 2.13 & 14.84 & 0.034 \\
\hline S14 & 3.97 & 3.22 & 2.67 & 2.13 & 11.11 & 0.04 \\
\hline S15 & 3.97 & 3.22 & 2.67 & 2.13 & 11.4 & 0.033 \\
\hline S16 & 4.22 & 3.38 & 2.78 & 2.19 & 1.46 & 0.035 \\
\hline S17 & 4.22 & 3.38 & 2.78 & 2.19 & 72.91 & 0.016 \\
\hline S18 & 4.22 & 3.38 & 2.78 & 2.19 & 57.23 & 0.016 \\
\hline S19 & 4.22 & 3.38 & 2.78 & 2.19 & 11.53 & 0.041 \\
\hline
\end{tabular}




\subsection{Scenario Analysis}

Using a scenarios analysis on the finalized decision model enabled us to determine the effects of changing the relative importance of the assessment criteria (Level 2) on the alternatives' rankings. Also, it tested the model's flexibility to perform the change of project decision makers assumptions, and to enable them to make informed decisions. As shown in Table 43, five cases as scenarios were designed in this research to demonstrate the difference of project decision makers' preferences or their projects' need.

Table 43: Scenarios Definition

\begin{tabular}{l|}
\multicolumn{1}{c}{ Scenario } \\
\hline Cost reduction \\
Schedule acceleration \\
Risk identification \\
Performance efficiency \\
Resources capability
\end{tabular}

Decision Makers' Preferences / Projects' Need Projects that are focused on achieving cost efficiency Projects that are focused on accelerating the project schedule Projects that are focused on identifying project risks

Projects that are focused on improving the efficiency and/or safety of project elements

Projects that are focused on enhancing the project resources capabilities

In order to find the importance of alternatives with respect to the mission, the above five scenarios were considered for sensitivity analysis by assigning a value of 0.96 for one criterion in each scenario and the other criteria with a value of 0.01 each. Before analyzing the five scenarios, the priorities of model levels were considered and calculated. The process and results are illustrated below in Table 44. 
Table 44: Distribution Values of Variations Scenarios

Scenario (Sc)

Criteria

Alternative Base

Value

Contribution

\begin{tabular}{|c|c|c|c|c|c|c|}
\hline C1 & C2 & C3 & C4 & C5 & & \\
\hline 0.21 & 0.19 & 0.23 & 0.24 & 0.14 & & \\
\hline 0.96 & 0.01 & 0.01 & 0.01 & 0.01 & Alt. 1 & 0.18 \\
\hline 0.01 & 0.96 & 0.01 & 0.01 & 0.01 & Alt. 2 & 0.15 \\
\hline 0.01 & 0.01 & 0.96 & 0.01 & 0.01 & Alt. 3 & 0.16 \\
\hline 0.01 & 0.01 & 0.01 & 0.96 & 0.01 & Alt. 4 & 0.30 \\
\hline 0.01 & 0.01 & 0.01 & 0.01 & 0.96 & Alt. 5 & 0.22 \\
\hline
\end{tabular}

\subsubsection{Cost Reduction Scenario Analysis}

In this scenario, Cost reduction was assigned as an important criterion with a value of 0.96 and the others with a value of 0.01 each (Figure 64).

Sensitivity Analysis with Respect to Cost Criterion - Scenario 1

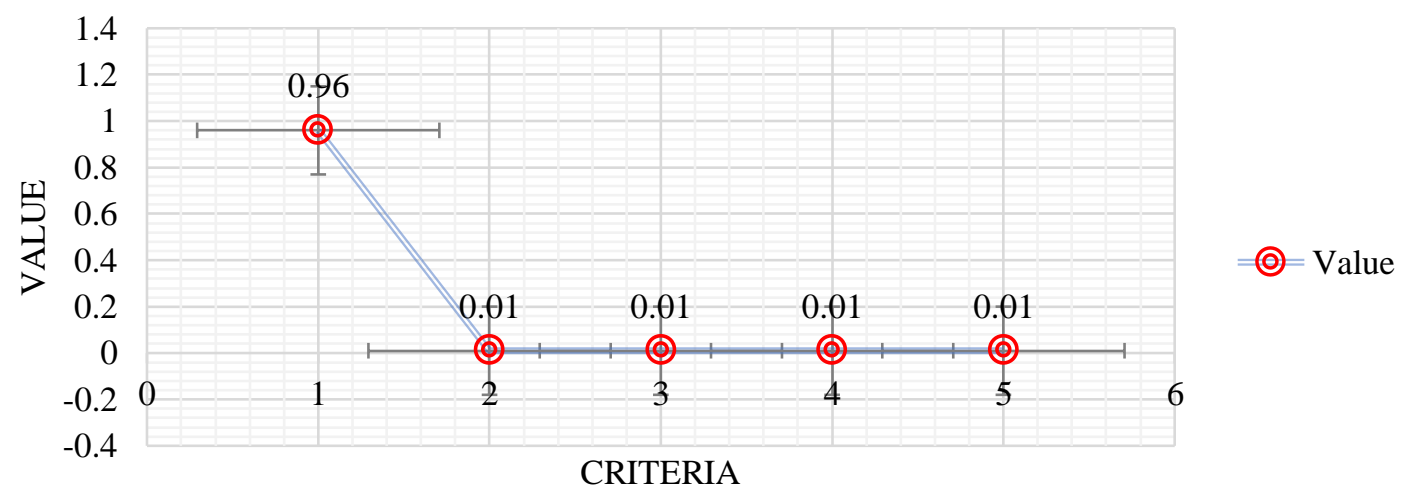

Figure 64: SA - Cost Reduction 
The results, as shown in Table 45, show that the relative importance of Cost reduction indicates the VE-RACRDAM technique as the most important alternative in Scenario 1. Therefore, the Alt 4 maintained its rank in the first position, and Alt.5 (VE-CEVPRA) stayed in the second position with a value of 0.22 .

The VE-RA technique showed strength in this scenario, and was ranked the third most effective assessment technique. VE-CR was moved from the fifth position to fourth with a variance of 0.01 between the base and sensitivity value. The VE-DAM technique returned from the fourth most important alternative in the original rank to be the least importance alternative in the new rank.

Table 45: Overall Importance of Alternatives - Scenario 1

Overal Importance of Alternatives with Respect to the Mission - Scenario 1

\begin{tabular}{|c|c|c|c|c|c|}
\hline \multirow{2}{*}{ Alternative } & \multicolumn{2}{c}{ Title } & Base Value & Oraginal Rank Sensitivity Value & New Rank \\
\hline Alt. 1 & VE-RA & 0.18 & 3 & 0.16 & 3 \\
\hline Alt. 2 & VE-CR & 0.15 & 5 & 0.14 & 4 \\
\hline Alt. 3 & VE-DAM & 0.16 & 4 & 0.13 & 5 \\
\hline Alt. 4 & VE-RACRDAM & 0.30 & 1 & 0.35 & 1 \\
\hline Alt. 5 & VE-CEVPRA & 0.22 & 2 & 0.22 & 2 \\
\hline
\end{tabular}

\subsubsection{Schedule Acceleration Scenario Analysis}

In this scenario, the Schedule acceleration was assigned as an important criterion to a value of 0.96 and others with value of 0.01 each (Figure 65). 


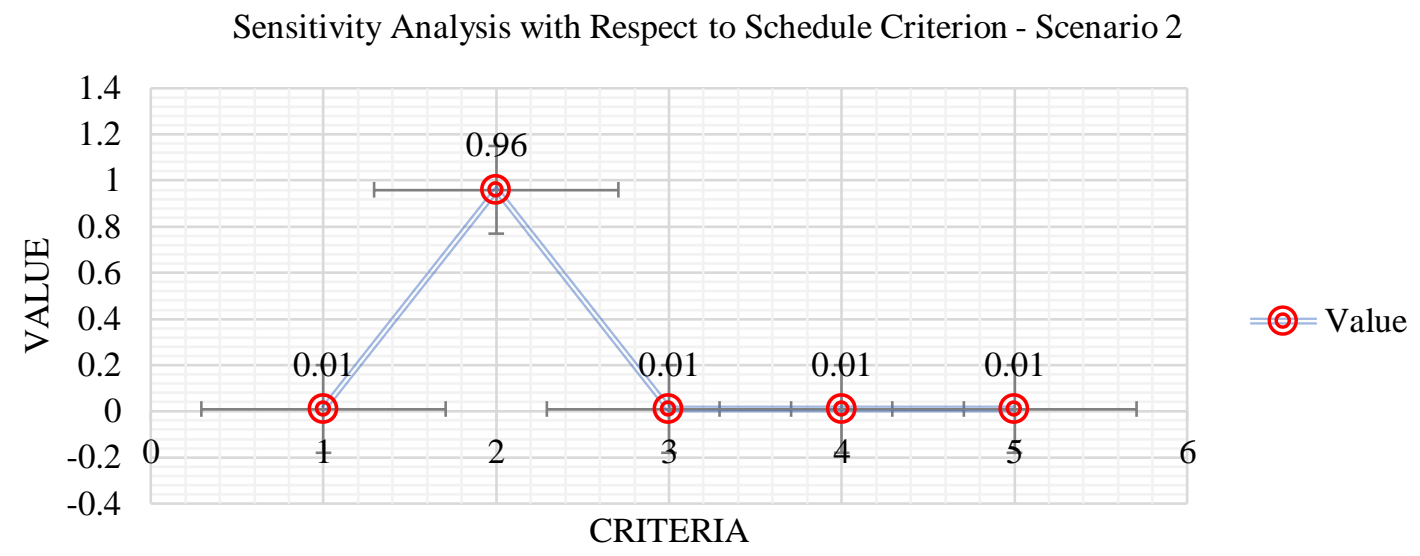

Figure 65: SA - Schedule Acceleration

As shown in Table 46, the sensitivity analysis results indicate that in Scenario 2 Alt 4, VE-RACRDAM, was still most effective assessment technique among the other alternatives. Also, Alt 5 (VE-CEVPRA) showed strength in this scenario, and was also ranked as the second most effective assessment technique. The VE-RA technique showed the same rank as before and after the sensitivity analysis with a value of 0.18 . Alt 2 and 3 switched their ranks between the fourth and fifth position, and were considered as the least important techniques in this scenario. 
Table 46: Overall Importance of Alternatives - Scenario 2

\begin{tabular}{|c|c|c|c|c|c|}
\hline \multicolumn{6}{|c|}{ Overal Importance of Alternatives with Respect to the Mission - Scenario 2} \\
\hline Alternative & Title & Base Value & Oraginal Rank & Sensitivity Value & New Rank \\
\hline Alt. 1 & VE-RA & 0.18 & 3 & 0.18 & 3 \\
\hline Alt. 2 & VE-CR & 0.15 & 5 & 0.15 & 4 \\
\hline Alt. 3 & VE-DAM & 0.16 & 4 & 0.14 & 5 \\
\hline Alt. 4 & VE-RACRDAM & 0.30 & 1 & 0.29 & 1 \\
\hline Alt. 5 & VE-CEVPRA & 0.22 & 2 & 0.23 & 2 \\
\hline
\end{tabular}

\subsubsection{Risk Identification Scenario Analysis}

In this scenario, the Risk identification was assigned as an important criterion to a value of 0.96 , and the others with value of 0.01 each (Figure 66).

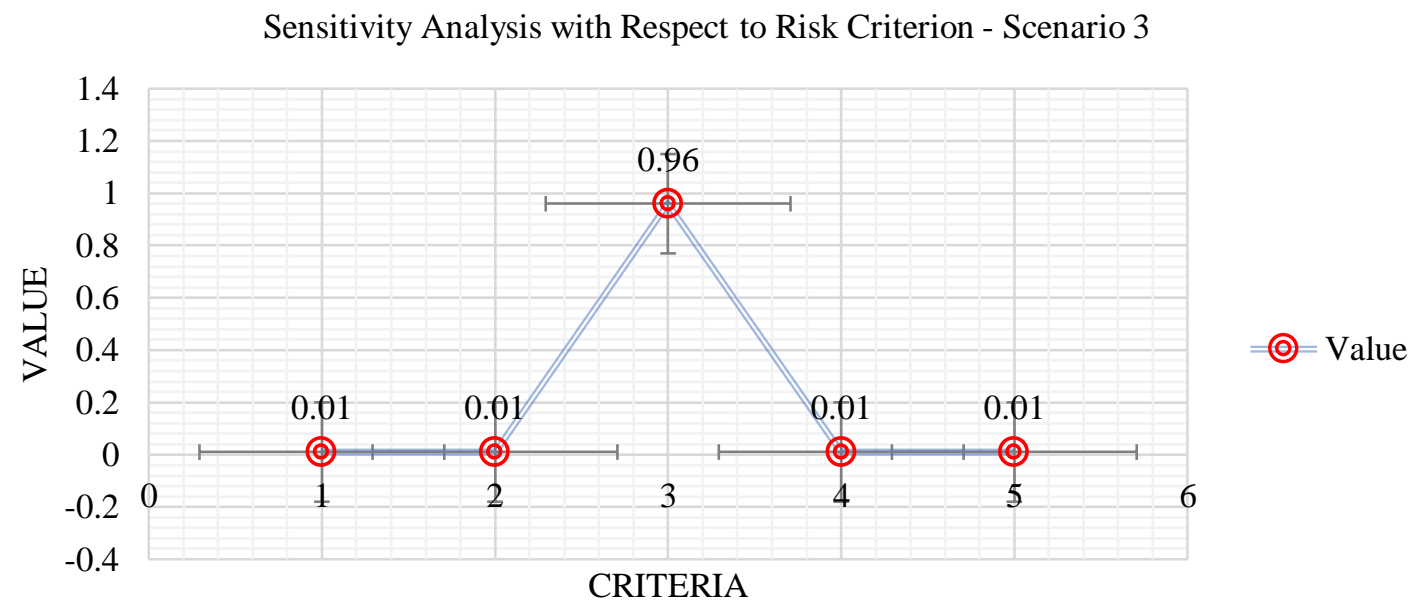

Figure 66: SA - Risk Identification

According to the results, as shown in Table 47, Scenario 3 showed that VERACRDAM, VE-CEVPRA, and VE-RA showed their strength as the most effective 
assessment techniques, and that they remained in their position (the first, second, and third, respectively). The VE-DAM technique returned from the fourth position to the last position while VE-CR jumped to the fourth with a value of 0.16 .

Table 47: Overall Importance of Alternatives - Scenario 3

Overal Importance of Alternatives with Respect to the Mission - Scenario 3

\begin{tabular}{|c|c|c|c|c|c|}
\hline \multirow{2}{*}{ Alternative } & \multicolumn{2}{c}{ Title } & Base Value & Oraginal Rank Sensitivity Value & New Rank \\
\hline Alt. 1 & VE-RA & 0.18 & 3 & 0.19 & 3 \\
\hline Alt. 2 & VE-CR & 0.15 & 5 & 0.16 & 4 \\
\hline Alt. 3 & VE-DAM & 0.16 & 4 & 0.14 & 5 \\
\hline Alt. 4 & VE-RACRDAM & 0.30 & 1 & 0.28 & 1 \\
\hline Alt. 5 & VE-CEVPRA & 0.22 & 2 & 0.24 & 2 \\
\hline
\end{tabular}

\subsubsection{Performance Efficiency Scenario Analysis}

In this scenario, the performance efficiency was assigned as an important criterion with a value of 0.96 , and the others with value of 0.01 each (Figure 67).

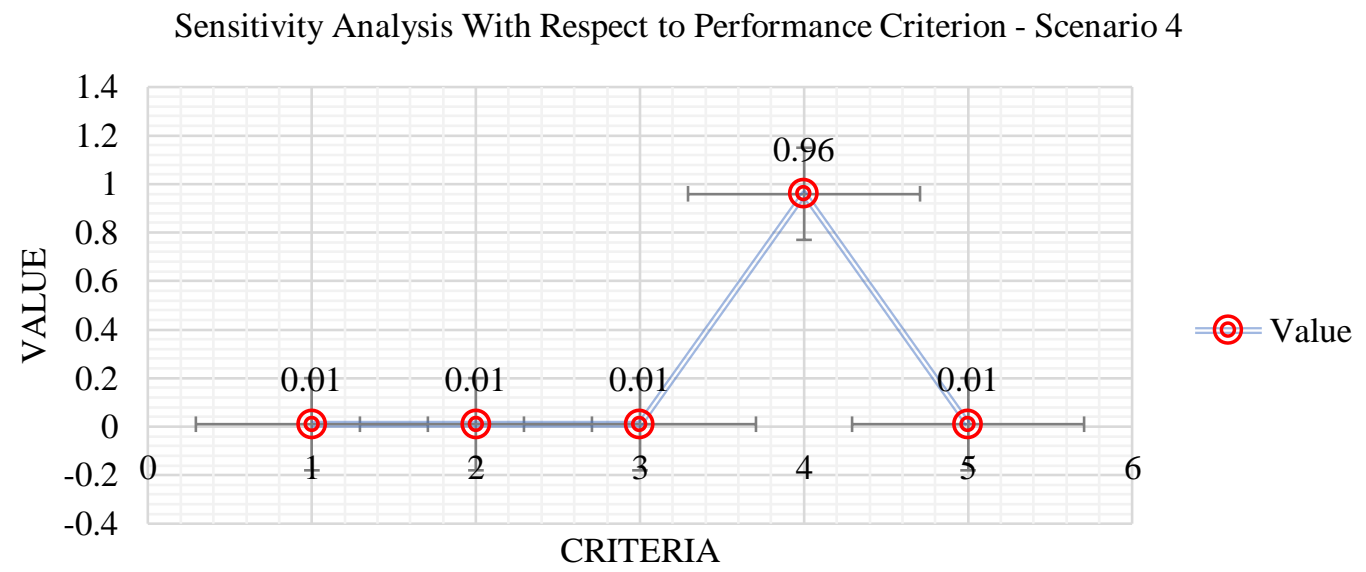

Figure 67: SA - Performance Efficiency 
Again, as shown in Table 48, the sensitivity analysis results indicate that in Scenario 4 the Alt 4, VE-RACRDAM, was still the most effective assessment technique among the other alternatives. However, it was surprising in this scenario that Alt 3 (VE-DAM) jumped to the second most effective assessment technique while Alt 5 returned to the third position with a variance of 0.01 between them in the new rank. The VE-RA technique returned to the fourth position, and VE-CR maintained its position as the least importance technique before and after the scenario analysis.

Table 48: Overall Importance of Alternatives - Scenario 4

\begin{tabular}{|c|c|c|c|c|c|}
\hline \multicolumn{6}{|c|}{ Overal Importance of Alternatives with Respect to the Mission - Scenario 4} \\
\hline Alternative & Title & Base Value & Oraginal Rank & Sensitivity Value & New Rank \\
\hline Alt. 1 & VE-RA & 0.18 & 3 & 0.18 & 4 \\
\hline Alt. 2 & VE-CR & 0.15 & 5 & 0.15 & 5 \\
\hline Alt. 3 & VE-DAM & 0.16 & 4 & 0.20 & 2 \\
\hline Alt. 4 & VE-RACRDAM & 0.30 & 1 & 0.29 & 1 \\
\hline Alt. 5 & VE-CEVPRA & 0.22 & 2 & 0.19 & 3 \\
\hline
\end{tabular}

\subsubsection{Resources Capability Scenario Analysis}

In this scenario, the Resources capability was assigned as an important criterion to a value of 0.96 , and the others with value of 0.01 each (Figure 68). 


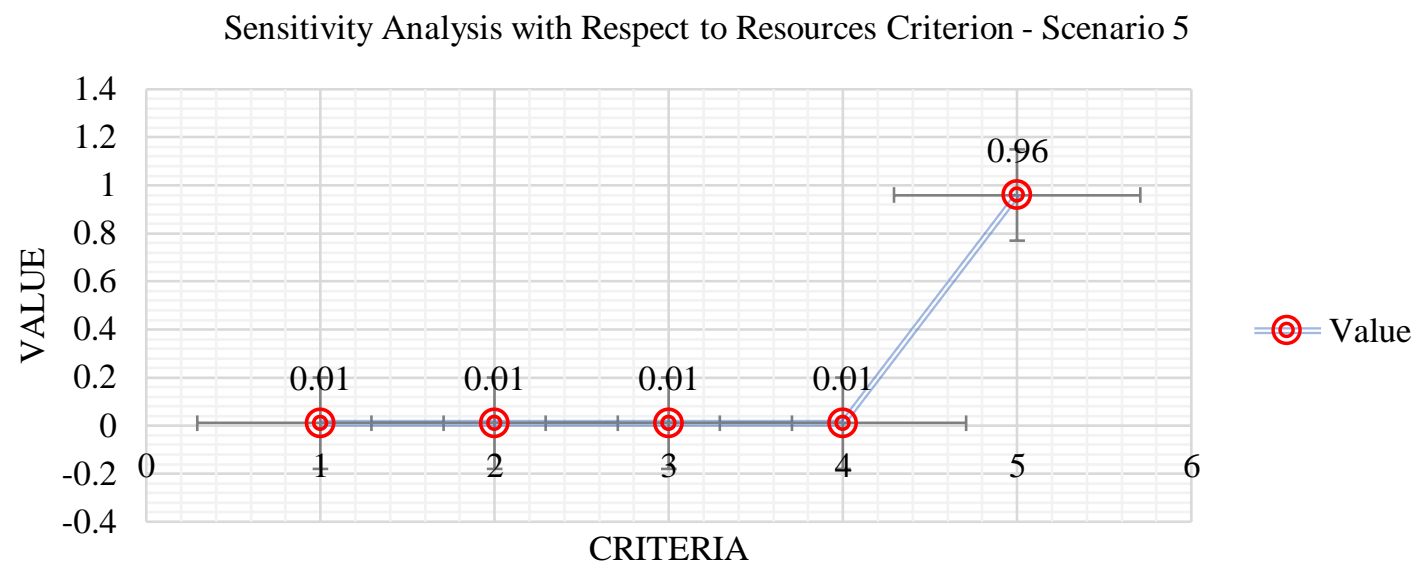

Figure 68: SA - Resources Capability

Table 49: Overall Importance of Alternatives - Scenario 5

Overal Importance of Alternatives with Respect to the Mission - Scenario 5

\begin{tabular}{|c|c|c|c|c|c|}
\hline Alternative & Title & Base Value & Oraginal Rank & Sensitivity Value & New Rank \\
\hline Alt. 1 & VE-RA & 0.18 & 3 & 0.18 & 3 \\
\hline Alt. 2 & VE-CR & 0.15 & 5 & 0.17 & 4 \\
\hline Alt. 3 & VE-DAM & 0.16 & 4 & 0.17 & 4 \\
\hline Alt. 4 & VE-RACRDAM & 0.30 & 1 & 0.26 & 1 \\
\hline Alt. 5 & VE-CEVPRA & 0.22 & 2 & 0.21 & 2 \\
\hline
\end{tabular}

According to the results, as shown in Table 49, Scenario 5 showed that VERACRDAM, VE-CEVPRA, and VE-RA showed their strength as the most effective assessment techniques, and that they are remained in their position (the first, second, and third, respectively) same as the SA outcome in $1^{\text {st }}, 2^{\text {nd }}$, and $3^{\text {rd }}$ scenarios. The VE-RA and VE-CR techniques shared their position as the lowest importance alternatives after the scenario analysis. 


\subsection{Criterion-Related Validity}

A good model or framework is usually tested by qualified experts [301]. Dissemination of the final model is essential [240]. Therefore, the survey instrument (see Appendix C-2) was designed and distributed to several experts with experience in the field of construction management and project delivery. Experts were asked to review the final model results, and to validate each criterion individually. The validation results were collected from the experts, and it was concluded by the final results that the model structure had achieved the model mission and research objective. This objective was to provide a novel approach for project managers and decision-makers to select their project techniques successfully.

The successful model contained of all the details that were validated within the five main objectives (criteria), nineteen sub-criteria, and five alternatives. Some face to face meetings and phone calls were required, and performed in order to accomplish the final model results validation process. The achievement of the final decision model provided important insights about the construction project development and delivery, particularly the requirements of public transportation projects within the scope of $\$ 100$ to $\$ 500$ million. Also, experts were asked to evaluate the generalizability of the model. Experts confirmed that the results and the model structure were appropriate and valid for general use across industries. They agreed that the model could be useful for most of the construction projects with conditional use of the project scope, project objective, and regions of project implementation. They highlighted the resources' criterion and its sub-criteria as the most important criteria that might be impacted by the change of the project scope, objective, or 
the project implementation within specific regions. For example, the final ranking of the model elements might be changed if the project scope is less than $\$ 100 \mathrm{M}$, and the project team might rank their preference technique so that it meets their knowledge and capacity.

The project objective also determined the importance of the model mission with respect to the five elements (cost, schedule, risk, performance, resources) in Level 2. This research performed the evaluation based on the achievement of value as a primary purpose for making a balance between these five elements. Some regions require an external expert to perform their projects' assessment. In this case, the resource criteria and sub-criteria weights might be changed and effect the alternatives' final rankings.

Below are some of the respondents' feedback who replied on the model's final results:

- "I like the model and would be interested in seeing more of your research work in this area. There are so many considerations and variables that go into a successful (or unsuccessful) project. Your model makes a lot of sense and addresses the key areas that need our attention. Will your research demonstrate which elements are the most critical? When you look at project failures, such as the Cover Oregon Project with Oracle, there seems to be a lack of attention to the areas described in your model (cost, schedule, stakeholder engagement, proper planning, etc.). On this particular project, over $\$ 250$ million in public funds were wasted with no tangible product or system being delivered. Perhaps your research can help to prevent this from happening in the future". 
- "I completed the survey. Thank you and keep me informed of future research. Good job on identifying these!"

- "Congratulations for your Ph.D. research on this important and useful topic, well done."

- "I'd be glad to take your survey and forward to other experts in the field."

- "Attached are the final validation results. Thank you for this opportunity and all the best to you in your research".

- "The final model looks good. I did not make any changes in the file that you sent me. The hardest thing as I mentioned to you in the past is implementation and delivery. It depends on the project purpose and needs and stakeholders and policymakers decisions. This also varies between delivery method whether Design Bid Build, Design Build, or GCCM. Hope this help and best of luck”.

- "I agree with the final judgment of the results".

- "Have reviewed the results and overall have no significant issues/problems with the outcome. Good luck to you in the future”. 

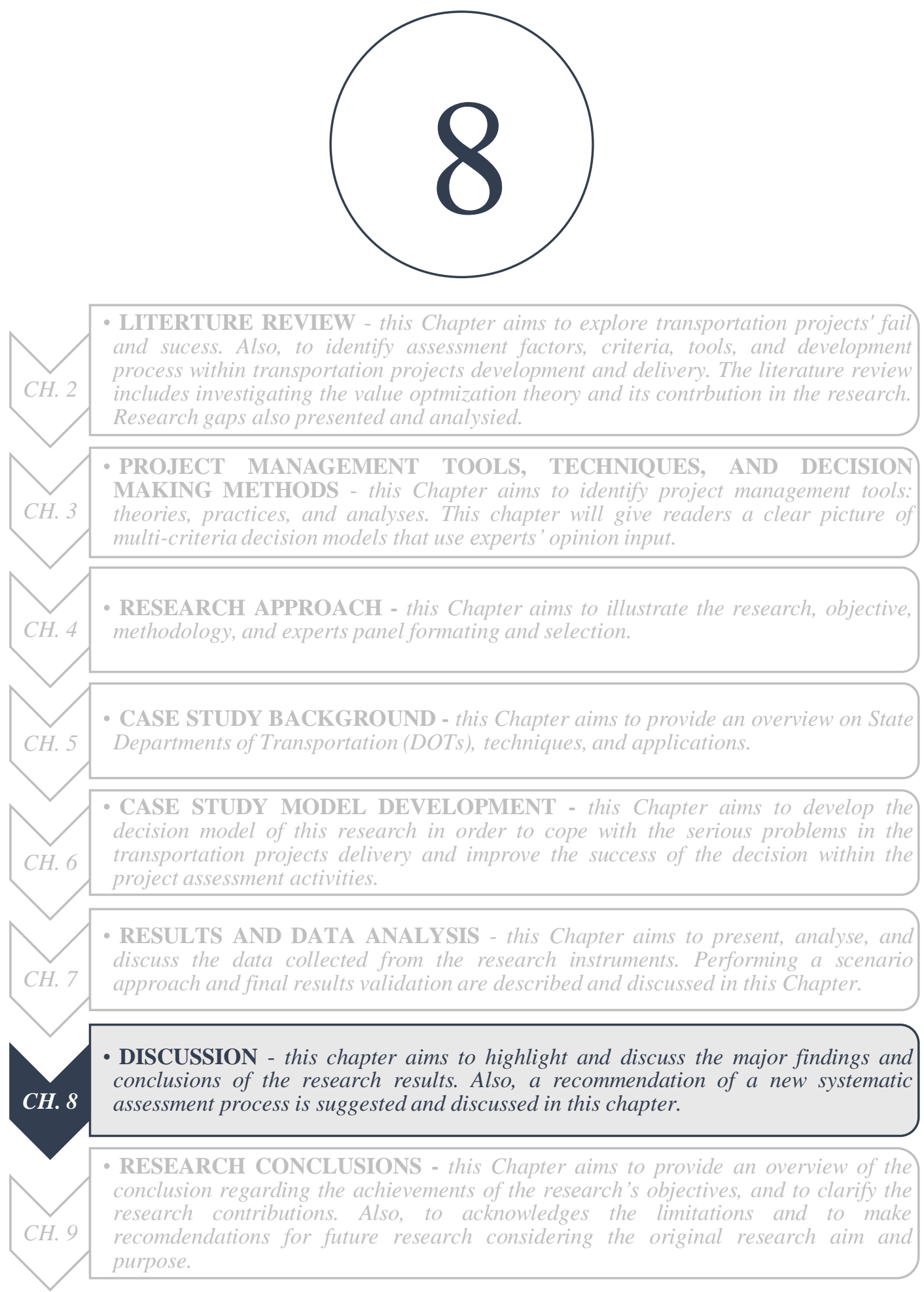


\section{CHAPTER EIGHT: DISCUSSION}

In the previous two chapters, the final decision model was constructed, validated, and quantified with minor changes that were made in order to achieve its objective. The final results were collected, validated, and discussed in the previous chapter based on the case application of State Departments of Transportation in the U.S. This chapter highlights the major findings and conclusions of the research results. Also, a recommendation for a new systematic assessment process is proposed and discussed in this chapter to answer the research Question 4, and based on the final model results.

\subsection{Data Validation}

The model objectives - criteria in Level 2, were accepted by the majority of experts from the first round, and considered as valid criteria for use in developing the model within the acceptance rate of agreement. The expert's opinions showed their $100 \%$ preference for the cost, time, and resources criteria while the risk and performance got $90 \%$.

Level 3 experts' responses were encouraging from the first round as they accepted most of the suggested sub-criteria. As presented and explained in the previous chapter, the validation rate was above $90 \%$, the majority said YES, while a few experts were suggested to reject, add, or replace some sub-criteria. 
Level 4 experts showed their interest to validate and accept all model alternatives in this level. They agreed to maintain the proposed alternatives as presented by the survey. The result rate is considered $100 \%$ acceptance.

\subsection{Data Quantification}

Performance criterion in Level 2, got the highest rank with a value of 0.24 among other criteria followed by risk, then cost, and schedule. Resources ranked the lowest importance with a value of 0.14 . The selection of Performance as the most important criterion aligns with the state DOTs strategy. State Departments of Transportation are actively researching best practices to allocate risk more effectively while achieving high performance and maximum value for transportation projects. They are seeking to improve the value of their projects through the analysis of functions by meeting or improving upon performance while reducing the total cost of ownership. Some research has been conducted on the importance of performance for project delivery [298].

About $70 \%$ of participants who participated in this level were from the construction industry, and the rest are CEOs in different sectors with a background of construction engineering. Most of them showed more interest in improving the performance of the project, which indicates that the DOTs and other construction industries are seeking to achieve high performance and maximum value for their projects.

The project needed functions criterion under the Performance was rated at the highest value followed by Stakeholder Needs criterion. The Communication and Integration 
Capabilities criterion was ranked in the third position. The Project Scope was ranked in the last position. These findings have confirmed the vision of the DOTs and other public transportation agencies for enhancing traffic operations, safety, constructability, project reliability, and minimizing Right-Of-Way and environmental impacts as priorities during the project delivery [302]. The project needed functions would also include other elements such as function, flexibility, expandability, maintainability, or reduced life-cycle cost [4]. Function analysis is the most critical task that performs by the project assessment technique.

Risk was ranked in the second importance among other criteria. The result confirms that Risk is an important factor for executive leaders after Performance and before Cost. Executive leaders in DOTs are encouraged to adopt risk assessment and management as part of their overall program delivery processes. The process would be performed by using the available guidance to examine their own programs and processes for risk management opportunities, as part of improving overall service to the public [254].

Selecting Risk as the second most important criterion confirms that the use of risk assessment activity has become more common in the delivery of transportation projects. DOTs use a specific threshold for requiring a quantitative risk assessment. This specific use for high-profile projects from $\$ 100$ million or more in capital costs for a given project. The previous research indicates that risk assessment activities are usually performing during the planning and development project phases [254]. This statement confirms that there is a general appreciation across DOTs that the management of uncertainty and risk 
can be an effective project delivery technique for control project performance, cost, and schedule.

As mentioned in the previous chapter, the outcome analysis of EP4's results under the Risk criterion indicated that the project cost risk impact was rated at the highest value while project support costs risk impact was in the last rank. This result proved that the importance of minimizing the cost risk impact on high-profile projects. Despite the notable efforts from most of the states to develop a transportation infrastructure, budget restrictions and lack of funds are some of the major challenges faced by DOTs.

This result signified the fact that the project assessment techniques cannot be effective unless they are integrated with the risk assessment tool. However, the integration of risk management with other tools into a cohesive process is not uncommon, and is found to be one of the most effective techniques available [104]. Risk assessment is a significant task that is needed during the decision-making process.

Cost criterion was selected the third most important element on evaluating the most effective project assessment technique for transportation projects development and delivery. Successful achievement of Cost criterion seems to be a subordinate objective to the experts (EP1). However, from experience, many projects have to set time and costs objectives as priorities. Failure to achieve those objectives might lead to unexpected negative impacts on project delivery. DOTs have realized substantial savings by using assessment tools combined with value engineering, these savings occur by restructuring operations and implementing cost-saving recommendations [254]. 
The outcome analysis of EP2's results indicated that Capital Cost criterion was the most important sub-criteria under the Cost, and it got the first position in the global relative weights. Project Support Costs was rated at the lowest value in the local relative weights. The Cost criterion might be an accepted rank in this research, and considered less important than Performance and Risk when been used for evaluating the most effective project assessment technique. However, decision makers in DOTs should consider that the execution of a high-profile project is not repetitive, any rework will be associated with high risk and might be very costly. They need to use a sophisticated technique to measure the project value by correlating the performance of project risk and schedule to the project costs. The technique should be performed by a systematic approach to optimize a project's cost, schedule, risk, and performance.

Schedule criterion got the fourth position after Cost and before the Resources. Despite the fact that Cost and Schedule were ranked in the third and fourth position respectively, they were still considered as the two basic criteria that could be applied to determine the success of the project [303]. This confirms that project success is associated with measuring the level of project cost reduction and schedule acceleration including other elements.

The outcome analysis of EP3's results indicated that the Project Design \& Environmental Analysis was the most important criterion under the schedule element. Project Design \& Environmental Analysis got the highest value followed by Right-of-Way (ROW) Acquisition. The Project Closeout Activities Duration showed the lowest among 
other sub-criteria under Schedule. These results confirm the importance of assessment task's duration to measure delay avoidance resulting from usage of enhanced or new innovative techniques. Also, by selecting Project Design \& Environmental Analysis as a priority element among others indicated the importance of measuring the relative degree of project schedule change throughout the delivery of a transportation project.

Resources criterion was found to be the least important for evaluating the project assessment techniques, and hence was not a very influential element among others in the objective level. EP6's results were surprised as In-house Capability criterion was rated at the highest value while External Consultant Needs showed the lowest among other subcriteria under Resources. This rank confirms that DOTs have started seriously to perform the project assessment activities in-house instead of inviting an external consultant for this purpose.

The research outcome observed the difference between the current result and our previous related work's results in 2017 [254] regarding in-house capability and external consultant needed sub-criteria. The previous survey results concluded that consultant-led studies demonstrated much higher levels of the correct applications of project assessment techniques while in-house studies did not. A very low number of state DOTs contain the internal experience and staff to perform all actions of the project assessment process. Also, the same survey indicated that many DOTs are developing internal personal, but most do not have significantly experienced internal personal for managing project assessment activities. As a result, many states tend to rely on consultant support for project assessment 
efforts, and engage in actions for management of project cost, schedule, and risks through project managers and project engineers that are assigned project delivery responsibilities. Conducting project assessment efforts tends to involve significant consultant support. The same study recommended that consultants may coordinate with DOTs to train project managers and their team for helping them to perform project assessment activities by using some innovative techniques.

This part was discussed in-depth with experts, and they confirmed that DOTs have considered the previous recommendation in the NCHRP -report 850 [289], and started to train their staff to perform project assessment activities in-house. Therefore, the findings of the current research confirm that there is a significant achievement in regarding the recommendations of the previous related work.

The combination of Risk Assessment, Constructability Review, and Decision Analysis Model with Value Engineering, into a cohesive process is not uncommon, and is found to be one of the most effective techniques available.

Experts ranked VE-RACRDAM as the most important technique among others with respect to the mission. The VE-CEVPRA was in the second most effective technique, and it was more effective than the following VE-RA. VE-DAM was ranked fourth, and close to the least importance technique, VE-CR. This confirms that project assessment tools combined with the value engineering are necessary to work as a function-oriented technique, and has proven to be an effective management tool for achieving the improved design, construction, and cost-effectiveness in various transportation assessment activities. 
Experts suggested that the selected technique should be easy to use, and the feature of populating dates need to be available during the assessment activities.

Clearly, the benefits of communication and collaboration are of great benefit to projects. These are further enhanced by providing more time in a structured environment using good technique. Therefore, the benefits could be a positive impact on the project assessment if multiple methods, such a VE, RA, CR, DAM, and others are integrated and conducted throughout the project delivery process.

Based on the findings of this research, it can be concluded that the VE-RACRDAM technique was ranked by the experts as an effective technique for measuring the success of outcomes related to the delivery of transportation projects. This technique provides a structured approach to minimize threats and maximize opportunities throughout the project delivery life cycle. 


\subsection{Recommendation of A New Systematic Project Assessment Process}

The results obtained from previous related work in 2017 [254] demonstrate different levels of performing project assessment tools in combination with each other within transportation organizations and agencies. $8 \%$ of respondents on the study survey indicated that Risk Analysis was always performed in conjunction with Value Engineering. Another $42 \%$ of respondents stated that the Risk Analysis is sometimes performed with Value Engineering or that it is determined on a case-by-case basis. About $27 \%$ of the time the Constructability Reviews are performed with the Value Engineering, and other $47 \%$ indicated that it is determined on a case-by-case.

Also, the survey results indicated the integration of some of project assessment tools with project delivery techniques and systems. For example, $100 \%$ of respondents indicated that Risk Analysis was conducted with the Design-Bid-Build project delivery technique, 92\% was Design-Build, 15\% was Early Contractor Involvement for DBB projects, 54\% was Construction Manager/General Contractor, and 31\% was Public-Private Partnerships. Respondents who conduct Constructability Review survey indicated that Design-BidBuild, Design-Build, Early Contractor Involvement for DBB projects, Construction Manager/General Contractor, and Public-Private Partnerships were 89\%, 83\%, 3\%, 10\%, and $4 \%$ respectively.

The vast majority of agencies responding to this survey deliver more than $\$ 500$ million in construction contract awards per year. The biggest challenges faced are funding, utilities, 
right-of-way, and an aging workforce. Allocations of funding to transportation agencies is mostly controlled by them with some local stakeholder involvement, and principle types of projects have been for rehabilitation of highways and bridges.

The current research was started to answer the Question 4 by using the previous workrelated data and the current research findings to suggest a systematic project assessment process. Also, the research focused on what theory, methodology, or practical experience were embedded in these approaches; how these methods can be implemented in specific industries; how likely these methods can be applied to the transportation project delivery; and provide innovative value to enhance the project performance within acceptable cost value.

The research related to investigating an acceptable assessment process indicates there are a number of opportunities to improve transportation project delivery in numerous ways by either applying completely new techniques or integrating the selected technique (VERACRDAM) in this research with establish techniques, tools, and practices, and to use its features to optimize the project value and outcome. The integration of techniques such as DBB, DB, CMGC, or PPP with VE-RACRDAM will add value to the project performance. Enhancing the assessment process with Stakeholder Analysis Tool (SAT) will encourage project teams to actively consider stakeholder positions, and think about strategies to better manage and communicate with stakeholders [289].

A stakeholder analysis will provide the required information that can be particularly valuable in the case of a change in management and to involve new staff to the project 
team. The tool is used to assess the level of interest, support, and power of a stakeholder. Integrating this tool into the assessment process will improve the communication and the negotiation within the transportation project life cycle. 

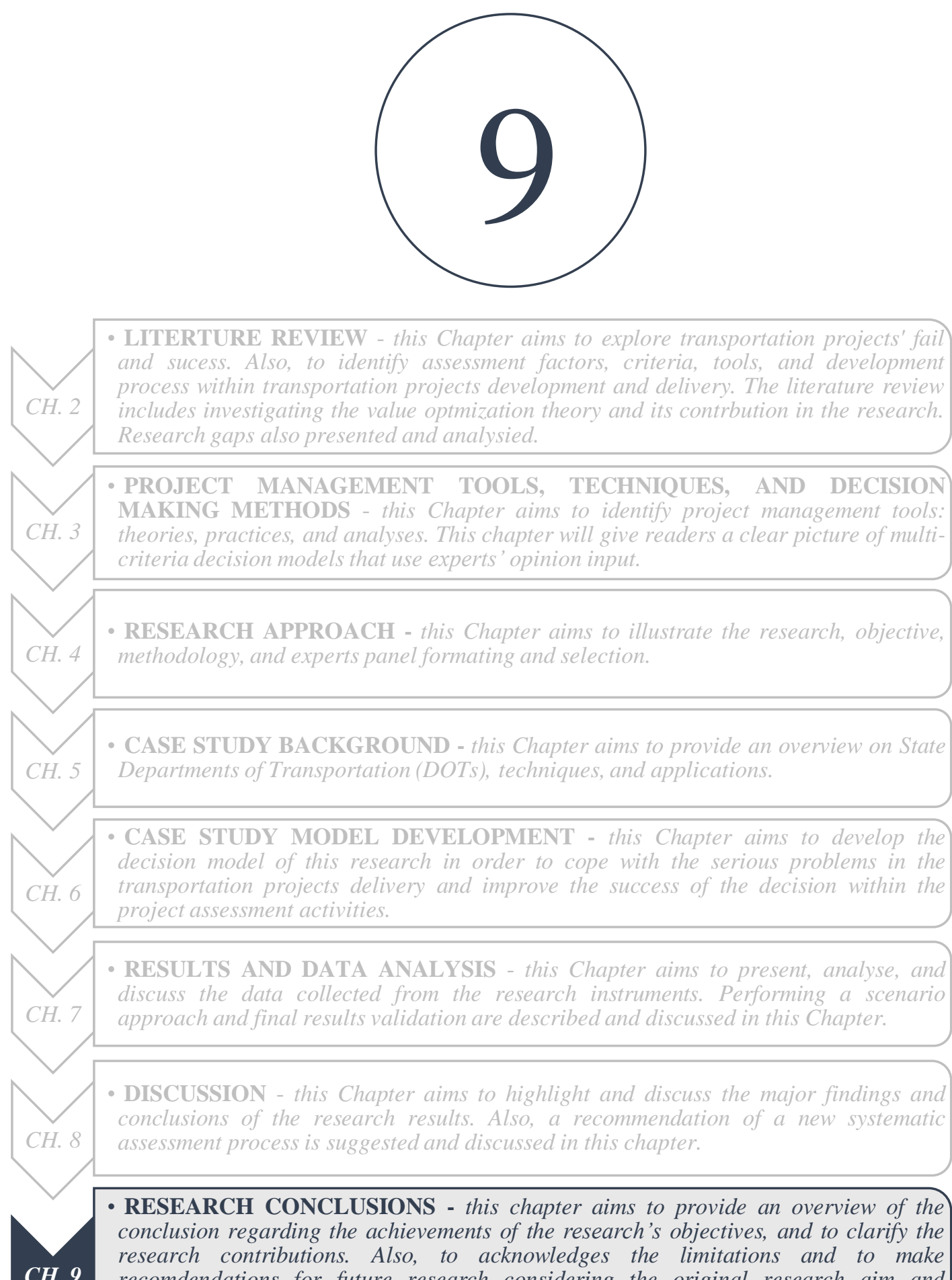

- RESEARCH CONCLUSIONS - this chapter aims to provide an overview of the conclusion regarding the achievements of the research's objectives, and to clarify the research contributions. Also, to acknowledges the limitations and to make recomdendations for future research considering the original research aim and purpose. 


\section{CHAPTER NINE: RESEARCH CONCLUSIONS}

This chapter provides an overview of the conclusion regarding the achievements of the research's objectives, and the research contributions. This chapter also acknowledges the limitations in this research. Future work has been discussed considering the original research aim and purpose.

\subsection{Conclusions and Contributions}

A comprehensive research is judged by the achievement of its aim and objective within a reasonable and defined time frame. The benefit of this research is discussed in Chapter 8. In Chapters 1, 2, 7, and 8, the research gaps were successfully identified, presented, and discussed based on the literature review and the experts' feedback. While the research questions were addressed and discussed in previous chapters, further research is still needed to extend this discussion, it is presented in this research as limitation.

The motivation of this research is the need to improve the success of transportation project development and delivery while considering the project cost and time overruns. As cited from literature [34], in transportation construction projects, all modes of transportation are under extreme budgetary and community pressure to deliver projects on time and within budget. Transportation construction projects can be complex, and most projects are large scale. Highway and bridge projects need large investments, which are 
often fraught with uncertainty and associated with higher project delivery risk. The National Cooperative Highway Research Program, state DOTs, and other transportation agencies cooperating with universities and research organizations are working hard to develop and employ dynamic project management and decision-making tools to deliver their projects on time and within budget. On time and within budget can mean different things to the transportation agencies and their customers, whether public or private [35].

The literature review discussed that the multi-criteria decision-making approach could help decision-makers to select the right solution among various potential optimal solutions in construction projects [50]. A value-based approach is needed. The drive for the selection of alternatives will be the effects of project cost and completion time [49]. A multi-criteria assessment approach is required to reach a solution with an acceptable degree of satisfaction [46]. This research identified the common use of existing innovative assessment tools, techniques, and programs within transportation projects. Then, a decision model was developed to evaluate some of these alternatives from five objectives (cost, schedule, risk, performance, and resources) including their associated sub-criteria.

A variety of criteria needs to be applied to the evaluation or selection of alternatives. As identified by literature, no ideal set of criteria has been defined by research [59]. The increase in risk and the lack of value consequences for operational decision-making, means more investigation is required to identify the relation between factors at different levels of analysis [54]. Developing a decision model to evaluate project assessment techniques could be a long process depending on the number of variables involved, and experts' availability, 
and their qualifications. This research was successful in following a balanced approach to fill in this gap by using the value optimization approach as an objective level in a multicriteria decision support model.

The literature review demonstrated that many qualitative and quantitative tools are used for project delivery within the construction industry, but no systematic analyses are implemented to complete the required actions during the project assessment activities [2][60]. In order to close this gap, this research suggested a logical approach (discussed in Chapter 8) that can be employed to improve the project delivery more successful. The research focused on what theory, methodology, or practical experience are embedded in these approaches; how these methods can be implemented in specific industry; how likely these methods can be applied to the transportation project delivery; and provide innovative value to enhance the project performance within acceptable cost value.

Also, the literature review presented that: "Design issues that negatively affect construction schedules and budgets are typically the result of a design oversight, lack of communication among the owner, designer, and contractor, or misinterpretation of specifications and plans. That is, these issues can be identified and mitigated before construction begins. For example; when factors such as design complexity, constructability, and utility work are identified, the negative impacts can be better controlled through planning and management. It is important to understand how these factors may negatively influence the construction schedule in order to manage them effectively" [304].

Therefore, this research focused on project innovative assessment tools as potential tools that can be used for optimizing the project value and outcomes during the assessment 
activity in the project development phase (design and engineering stage), see Figure 69. The assessment activity aims to assist transportation project teams in minimizing the risk and maximizing the value of their projects' delivery.

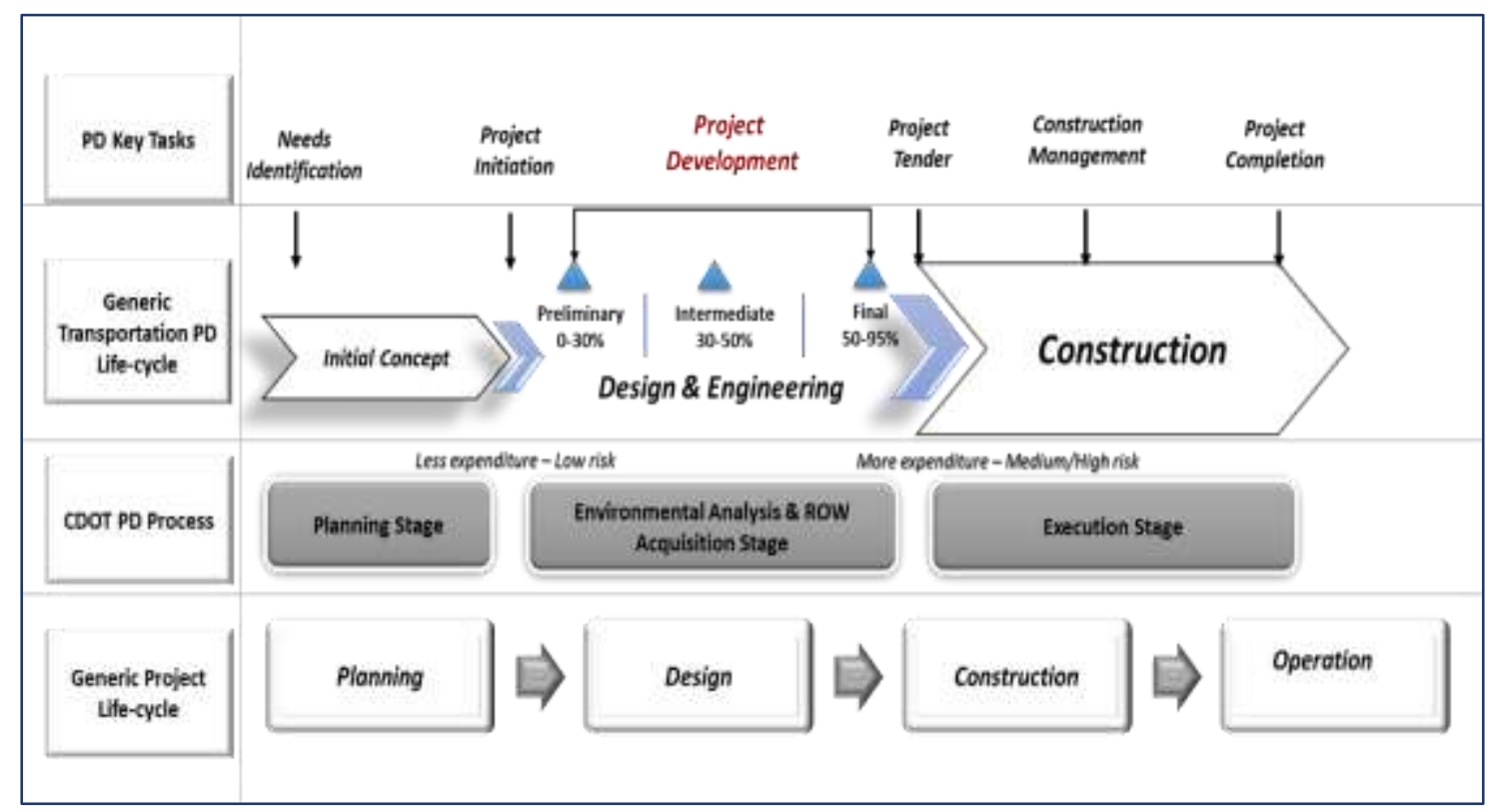

Figure 69: Project Execution Process - Adapted from Several Industries

The main contribution of this research is the development of a robust decision-making model. The developed model enables a comprehensive evaluation of project assessment techniques to assist decision makers in the transportation sector to make well-informed decisions based on the value optimization approach. The research results indicate that there is a significant opportunity to enhance the application of functional analysis in the project assessment activity by using the right technique. Doing so will likely improve the assessment process by increasing the quality of project alternatives selection. 
The research and developed decision model make other significant contributions for project management knowledge and practice, especially project development and delivery as follows:

The research findings could be pursued to improve project assessment activities where there is a close interaction between the project team, the stakeholders, and the assessment activities facilitator (external consultants) in determining a new project assessment process and identifying project needs. It is believed that the model recommends the best-ranked project delivery assessment alternative that can be used to allocate risk effectively while achieving high performance and maximum value for high-profile transportation projects.

The model can help to minimize the bias among the decision makers and the project team while evaluating and selecting the project alternatives or options. This research adds value to the project construction and delivery by offering a generalizable model to compare project management tools, methods, techniques, or practices. While a significant proportion of State DOTs perform assessment activities, there are significant inconsistencies and redundancy relative to how the assessments are conducted. However, the research and model outcome can help to determine the best option that will eliminate redundancy in project assessment activities. The research has provided a reasonable basis for future work, as well as a structured decision model for evaluating options.

The research findings were further discussed in Chapter 8. The discussion includes the practicality and acceptance of the developed decision model in the field of project development and delivery. 
Finally, the success decision model has been achieved in this research, and it offers assistance to project managers and their teams for delivering their projects more successfully.

\subsection{Limitations}

The scope of the research and the generalization of the model results are limited by the following:

The scope of this research focuses explicitly on high profile bridge and highway public projects in the transportation sector. These projects are defined as high-cost projects and are associated with higher project delivery risk (typically $\$ 100$ - $\$ 500$ million). Therefore, the scope is limited to projects that cost between $\$ 100$ and $\$ 500$ million. Also, the model was mainly developed based on the collected data from public agencies in North America, and not from the private sector or other regions.

The HDM model of this research was developed based on and limited to the value optimization framework, where different perspectives or elements might be added to extend the model' contents and its structure levels.

The developed decision model used the HDM approach. The model results are subjective because they are based on the experts' opinions. This weakness in the model can 
be minimized by using an integration approach with other model, and different methods for experts' selection.

The decision model was developed for the project development phase within the transportation industry, and covers the design and engineering stage. Other project lifecycle phases would require different techniques, as the content may differ.

\subsection{Future Work}

Decision making related to project delivery problems that involve quantitative and qualitative processes that contain several perspectives can be challenging. The HDM can be helpful in finding a useful compromise. However, the features of the optimization problem that forms the basis for generating the options should be carefully identified. The developed model in this research can be expanded to integrate other methods that help to associate a superstructure decision model for a particular project lifecycle phase. Also, the list of qualified experts can be expanded to cover other industries, and who have the experience to perform the assessment techniques within their projects' delivery. This requires identifying additional parameters that are associated with the selection process of the experts, and that may affect the accuracy of the decision model outcome.

In future research, obtaining the qualitative preferences and valuable feedback from experts provides an opportunity to develop an expert knowledgebase within the selection 
process. The knowledgebase can increase the efficiency of the decision-making process and reflect positively on the model structure.

This research was designed to be used in the project development phase. Due to research time constraints and direction, the research was focused on just this phase. Further studies are needed to develop a comprehensive decision model of project assessment techniques evaluation for all project life cycle phases.

The developed model needs to be applied in other construction industries. This model can be used to conduct a wide-range of assessment activities in further research work. The future research could produce more comprehensive evidences to support the use of HDM to help decision makers to solve project delivery issues.

Last but not least, the five value optimization elements (Cost, Schedule, Risk, Performance, and Resources) presented in the model as objectives (Level 2) could branch out as one topic of research. For further research on these criteria, it would be useful to expand the research to include other elements or factors. A wide range of elements or factors could lead to the development of one comprehensive decision model for all project lifecycle phases. Also, the expanded comprehensive multi-decision model might improve the integration of several assessment tools (alternatives), and reduce the potential redundancy in project assessment activities. 


\section{REFERENCES}

[1] J. E. Z. (GAO) Hecker, "House of Representatives FEDERAL-AID HIGHWAYS Cost and Oversight of Major Highway and Bridge Projects - Issues and Options," United States Gen. Accounitng Off., vol. 18, no. GAO-03-764T, 2003.

[2] D. Tran, C. Harper, and R. E. M. Jr, Strategic Program Delivery Methods. National Academies Press, 2017.

[3] M. Ditrani, "M ASTE R ' S THE SI S Improving Transportation Investment Decisions Through Life-Cycle Cost Analysis Comparative LCCA of Bridges," 2009.

[4] D. Bidne, A. Kirby, L. J. Luvela, B. Shattuck, S. Standley, and S. Welker, "The Value for Money Analysis : A Guide for More Effective PSC and PPP Evaluation," Natl. Counc. Public-Private Partnerships, pp. 1-59, 2012.

[5] "Value Engineering Guide, Technical Section Engineering Division Division of Highways West Virginia Department of Transportation," no. June, 2014.

[6] K. Mela, T. Tiainen, and M. Heinisuo, "Comparative study of multiple criteria decision making methods for building design," Adv. Eng. Informatics, vol. 26, no. 4, pp. 716-726, 2012.

[7] B. Flyvbjerg, M. S. Holm, and S. Buhl, "Underestimating costs in public works, error or lie?," Am. Plan. Assoc. J., vol. 68, no. 3, pp. 279-295, 2002.

[8] J. Odeck, "Cost overruns in road construction-what are their sizes and determinants?," Transp. Policy, vol. 11, no. 1, pp. 43-53, 2004.

[9] C. Bordat, B. G. McCullouch, S. Labi, and K. Sinha, "An analysis of cost overruns and time delays of INDOT projects.," 2004.

[10] P. E. D. Love, D. D. Ahiaga-Dagbui, and Z. Irani, "Cost overruns in transportation infrastructure projects: Sowing the seeds for a probabilistic theory of causation," Transp. Res. Part A Policy Pract., vol. 92, pp. 184-194, 2016.

[11] H. Lind and F. Brunes, "Explaining cost overruns in infrastructure projects: a new framework with applications to Sweden," Constr. Manag. Econ., vol. 33, no. 7, pp. 554-568, 2015.

[12] J. Odeck, M. Welde, and G. H. Volden, "The impact of external quality assurance of costs estimates on cost overruns: Empirical evidence from the norwegian road 
sector," Eur. J. Transp. Infrastruct. Res., vol. 15, no. 3, pp. 286-303, 2015.

[13] P. E. D. Love, J. Smith, I. Simpson, M. Regan, and O. Olatunji, "Understanding the landscape of overruns in transport infrastructure projects," Environ. Plan. B Plan. Des., vol. 42, no. 3, pp. 490-509, 2015.

[14] S. Verweij, I. van Meerkerk, and I. A. Korthagen, "Reasons for contract changes in implementing dutch transportation infrastructure projects: An empirical exploration," Transp. Policy, vol. 37, pp. 195-202, 2015.

[15] D. W. Chan and M. M. Kumaraswamy, "A comparative study of causes of time overruns in Hong Kong construction projects," Int. J. Proj. Manag., vol. 15, no. 1, pp. 55-63, 1997.

[16] S. A. Assaf and S. Al-Hejji, "Causes of delay in large construction projects," Int. J. Proj. Manag., vol. 24, no. 4, pp. 349-357, 2006.

[17] I. Mahamid, A. Bruland, and N. Dmaidi, "Causes of Delay in Road Construction Projects," J. Manag. Eng., vol. 28, no. 3, pp. 300-310, 2012.

[18] B. Flyvbjerg, "What you should know about megaprojects and why: An overview," Project Management Journal, vol. 45, no. 2. pp. 6-19, 2014.

[19] G. J. Sweis, R. Sweis, M. A. Rumman, R. A. Hussein, and Samer E. Dahiyat5, "Cost Overruns in Public Construction Projects: The Case of Jordan," vol. 9, pp. 134-141, 2013.

[20] Francois Buys, "FIVE CAUSES OF PROJECT DELAY AND COST OVERRUN, AND THEIR MITIGATION MEASURES," Linkedin.com, 2015. [Online]. Available: https://www.linkedin.com/pulse/five-causes-project-delay-cost-overrunmitigation-measures-buys.

[21] X. Meng, "The effect of relationship management on project performance in construction," Int. J. Proj. Manag., vol. 30, no. 2, pp. 188-198, 2012.

[22] A. M. Odeh and H. T. Battaineh, "Causes of construction delay: Traditional contracts," Int. J. Proj. Manag., vol. 20, no. 1, pp. 67-73, 2001.

[23] G. Agyekum-Mensah, A. Knight, and C. Coffey, "4Es and 4 Poles model of sustainability: Redefining sustainability in the built environment," Struct. Surv., vol. 30, no. 5, pp. 426-442, 2012.

[24] H. M. AI-Tabtabai, "CAUSES FOR DELAYS IN CONSTRUCTION PROJECTS IN KUWAIT,” vol. 15, pp. 19-37, 2002. 
[25] P. Patanakul, Y. H. Kwak, O. Zwikael, and M. Liu, "What impacts the performance of large-scale government projects?," Int. J. Proj. Manag., vol. 34, no. 3, pp. 452466, 2016.

[26] Y. Y. Chih and O. Zwikael, "Project benefit management: A conceptual framework of target benefit formulation," Int. J. Proj. Manag., vol. 33, no. 2, pp. 352-362, 2015.

[27] R. Team, "Applying Risk Analysis, Value Engineering, and Other Innovative Solutions for Project Delivery, NCHRP 19-11 project, monthly progress report, 2015.," pp. 1-32.

[28] Y. Olawale and M. Sun, "Construction project control in the UK: Current practice, existing problems and recommendations for future improvement," Int. J. Proj. Manag., vol. 33, no. 3, pp. 623-637, 2015.

[29] T. Haponava and S. Al-Jibouri, "Identifying key performance indicators for use in control of pre-project stage process in construction," Int. J. Product. Perform. Manag., vol. 58, no. 2, pp. 160-173, 2009.

[30] N. A. Ankrah and D. Proverbs, "A framework for measuring construction project performance: Overcoming key challenges of performance measurement," in 21st Annual Conference on Association of Researchers in Construction Management, ARCOM 2005, 2005, vol. 2, pp. 959-969.

[31] Beatham, "KPIs: a critical appraisal of their use in construction," Benchmarking An Int. J., vol. 11, no. 1, pp. 93-117, 2004.

[32] M. E. Bayraktar and M. Hastak, "A decision support system for selecting the optimal contracting strategy in highway work zone projects," Autom. Constr., vol. 18, no. 6, pp. 834-843, 2009.

[33] Keith R. Molenaar and Anthony D. Songer, "WEB-BASED DECISION SUPPORT SYSTEMS: CASE STUDY IN PROJECT DELIVERY," vol. 15, no. October, pp. 259-267, 2001.

[34] A. D. Biehler et al., REPORT 658 Guidebook on Risk Analysis Tools and Management Practices COOPERATIVE HIGHWAY PROGRAM. 2010.

[35] P. Management, "NCHRP WOD 137: Guidance for Transportation Project Management," no. March, 2009.

[36] W. J. Mallett and L. Luther, "Accelerating Highway and Transit Project Delivery: Issues and Options for Congress,” 2011. 
[37] F. Report, "Final Report SPR 646, Development of a decision model for selection of appropriate timely delivery techniques for highway projects, ODOT, 2007."

[38] A. Misplaced, T. Priorities, and W. Taxpayer, "Highway Boom , Budget Bust :," 2013.

[39] FMI, "U.S. Markets Construction Overview 2017, FMI (management consulting and investment banking in U.S).," 2017.

[40] J. M. Baumgarten et al., "U . S . Markets Construction Overview, FMI (management consulting and investment banking in U.S).," 2016.

[41] F. Fmi, "2019 FMI Overview (management consulting and investment banking in U.S) www.fminet.com/wp-content/uploads/2019/01/2019_Overview.pdf," 2019.

[42] T. Zayed, M. Amer, and J. Pan, "Assessing risk and uncertainty inherent in Chinese highway projects using AHP," Int. J. Proj. Manag., vol. 26, no. 4, pp. 408-419, 2008.

[43] ASCE, Infrastructure Report Card, America's Infracture Grades, https://www.infrastructurereportcard.org/americas-grades/. 2019.

[44] ASCE, "2013 Report Card for AMERICA'S INFRASTRUCTURE.," no. March, pp. 1-74, 2013.

[45] (PMI), "Capturing the Value of Project Management Through Decision Making," Pmi, 2015.

[46] J. Barry Barker et al., NCHRP Report 662 - Accelerating Transportation Project and Program Delivery: Conception to Completion. 2010.

[47] PMI, "Navigating Complexity, Book," in Project Management Institute (PMI), 2014, pp. 26-31.

[48] J. Xu, H. Zheng, Z. Zeng, S. Wu, and M. Shen, "Discrete time-cost-environment trade-off problem for large-scale construction systems with multiple modes under fuzzy uncertainty and its application to Jinping-II Hydroelectric Project," Int. J. Proj. Manag., vol. 30, no. 8, pp. 950-966, 2012.

[49] S. Monghasemi, M. Reza, M. Ali, K. Fasaee, and J. Adamowski, "Expert Systems with Applications A novel multi criteria decision making model for optimizing time - cost - quality trade-off problems in construction projects," Expert Syst. Appl., vol. 42, no. 6, pp. 3089-3104, 2015. 
[50] J. R. Schuyler, "Decision Analysis in Projects - Modeling Techniques," PMI, 1994.

[51] P. E. Russell McMurry, "TRANSPORTATION ASSET MANAGEMENT, The Georgia DOT Transportation.," 2014.

[52] D. Marcelo, C. Mandri-Perrott, S. House, and J. Z. Schwartz, "An Alternative Approach to Project Selection: The Infrastructure Prioritization Framework," no. April, 2016.

[53] D. Beale, T. Tryfonas, and M. Young, "Evaluating approaches for the next generation of difficulty and complexity assessment tools," in 2017 IEEE Technology and Engineering Management Society Conference, TEMSCON 2017, 2017, pp. 227-233.

[54] R. B. Stewart, "Value Optimization for Project and Performance Management, Book," J. Chem. Inf. Model., pp. 1689-1699, 2010.

[55] W. Ibbs, L. D. Nguyen, and S. Lee, "Quantified Impacts of Project Change," J. Prof. Issues Eng. Educ. Pract., vol. 133, no. January, pp. 45-52, 2007.

[56] C. Wimmler, G. Hejazi, E. D. O. Fernandes, C. Moreira, and S. Connors, "MultiCriteria Decision Support Methods for Renewable Energy Systems on Islands," $J$. Clean Energy Technol., vol. 3, no. 3, pp. 185-195, 2015.

[57] A. E. Dooley, D. C. Smeaton, G. W. Sheath, and S. F. Ldgard, "Application of multiple criteria decision analysis in the New Zealand agricultural industry," $J$. Multi-Criteria Decis. Anal., vol. 110, no. October 2009, pp. 79-110, 2010.

[58] R. Sonmez and Ö. H. Bettemir, "A hybrid genetic algorithm for the discrete timecost trade-off problem," Expert Syst. Appl., vol. 39, no. 13, pp. 11428-11434, 2012.

[59] M. Bertoni, "Introducing Sustainability in Value Models to Support Design Decision Making: A Systematic Review," no. May, 2017.

[60] K. Harrington, "Applying Risk Analysis, Value Engineering, and other Innovative Solutions for Project Delivery, Construction Engineer, NCHRP 11-19 VE survey comment, PHASE 1 SUMMARY REPORT, South Carolina Department of Transportation (SCDOT) harringKG@ @ scdot.org, 2015. SU,” no. January, 2016.

[61] The Louis Berger Group, Inc., "NCHRP Report 406: Desk Reference for Estimating the Indirect Effects of Proposed Transportation Projects," NCHRP Rep. 466, vol. 1, pp. 1-109, 2002.

[62] MassDOT, "Basic Financial Statements and Required Supplementary Information ( 
With Independent Auditors ' Report Thereon ),’ 2015.

[63] C. Edmondson, "Highway project delays rack up $\$ 700$ million cost overruns. http://archive.jsonline.com/newswatch/382708551.html," The Journal Sentinel, 2016.

[64] M. Alderton, “Boston's lessons learned: with a new wave of infrastructure projects underway, the U.S. city is determined to avoid the problems that cursed the "Big Dig' PM Network, 30(2).," PMI, no. 2016, pp. 14-15.

[65] P. Hallenberg, "http://www.spokesman.com/stories/2017/apr/19/newlyconstructed-sullivan-road-bridge-may-cost-sp/," 2017.

[66] R. E. Turochy, L. A. Hoel, and R. S. Doty, "Highway project cost estimating methods used in the planning stage of project development," Virginia Transp. Res. Counc., 2001.

[67] P. Overview, "Springfield Interchange Project," Interchange, pp. 1-12, 2007.

[68] C. Ahbab, "An Investigation on Time and Cost Overrun in Construction Projects," no. January, 2012.

[69] J. Reilly, M. Mcbride, D. Sangrey, D. Macdonald, and J. Brown, "The Development of CEVP-WDOT, Cost-Risk Estimating Process.," 2004.

[70] B. van Wee, "Large infrastructure projects: A review of the quality of demand forecasts and cost estimations," Environ. Plan. B Plan. Des., vol. 34, no. 4, pp. 611625, 2007.

[71] B. Flyvbjerg, M. K. Skamris holm, and S. L. Buhl, "How common and how large are cost overruns in transport infrastructure projects?," Transp. Rev., vol. 23, no. 1, pp. 71-88, 2003.

[72] D. N. Sillars, "Development of Decision Model for Selection of Appropriate Timely Delivery Techniques for Highway Projects," Transp. Res. Rec. J. Transp. Res. Board, vol. 2098, pp. 18-28, 2009.

[73] B. Mulholland and J. Christian, "Risk Assessment in Construction Schedules," J. Constr. Eng. Manag., vol. 125, no. 1, pp. 8-15, 1999.

[74] J. Wolf and M. County, "Sellwood Bridge Project, Technical Report," 2016.

[75] J. Choi, "Statement of Purpose and Interest, Memorandum," pp. 1-2, 2009. 
[76] ODOT, "Sellwood_Record_of_Decision, Federal Highway Adminstration (FHWA).pdf." 2010.

[77] S. Integrity and M. V. Safety, "Sellwood Bridge, Comparison of Alternatives, Chapter 4., Sellwood Bridge Project Draft Environmental Impact Statement," 2009.

[78] J. Schumann, "Experience, Economics, and Evolution: From Starter Lines to Growing Systems," Transp. Res. Circ., pp. 1-789, 2003.

[79] S. Monghasemi, M. R. Nikoo, M. A. Khaksar Fasaee, and J. Adamowski, "A novel multi criteria decision making model for optimizing time-cost-quality trade-off problems in construction projects," Expert Syst. Appl., vol. 42, no. 6, pp. 3089-3104, 2015.

[80] “https://en.wikipedia.org/wiki/Robertson_Tunnel\#cite_note-5.” .

[81] G.-J. Knaap, C. Ding, and L. D. Hopkins, "Do Plans Matter?: The Effects of Light Rail Plans on Land Values in Station Areas," J. Plan. Educ. Res., vol. 21, no. 1, pp. 32-39, 2001.

[82] "https://trimet.org." .

[83] K. Mela, T. Tiainen, and M. Heinisuo, "Comparative study of multiple criteria decision making methods for building design," in Advanced Engineering Informatics, 2012, vol. 26, no. 4, pp. 716-726.

[84] G. Langford and T. V Huynh, “A Methodology for Managing Complexity,” 2007.

[85] G. O. Langford, "Gap Analysis: Application to Earned Value Analysis,” 2009.

[86] O. Zwikael and J. Smyrk, "Project governance: Balancing control and trust in dealing with risk," Int. J. Proj. Manag., vol. 33, no. 4, pp. 852-862, 2015.

[87] Y. Y. Chih and O. Zwikael, "Project benefit management: A conceptual framework of target benefit formulation," Int. J. Proj. Manag., vol. 33, no. 2, pp. 352-362, 2015.

[88] A. P. Sage, "Reinventing Project Management: The Diamond Approach to Successful Growth and Innovation, by Aaron Shenhar and Dov Dvir.," Inf. Knowl. Syst. Manag., vol. 6, no. 4, p. 363, 2007.

[89] V. Analysis and F. Statutes, "CHAPTER 19 - Project Development Procedures Manual," 2013. 
[90] Highway, "MASS HIGYWAY, Project Development, Chapter 2," 2006.

[91] R. R. Venkataraman and J. K. Pinto, Cost and Value Management in Projects. 2008.

[92] J. Kenny, "Effective project management for strategic innovation and change in an organizational context," Proj. Manag. J., vol. 34, no. 1, p. 43, 2003.

[93] C. Besner and B. Hobbs, "The Perceived Value and Potential Contribution of Project Management Practices to Project Success," Proj. Manag. J., vol. 37, no. 3, pp. 3748, 2006.

[94] F. A. Mir and A. H. Pinnington, "Exploring the value of project management: Linking Project Management Performance and Project Success," Int. J. Proj. Manag., vol. 32, no. 2, pp. 202-217, 2014.

[95] D. Bryde, "Perceptions of the impact of project sponsorship practices on project success," Int. J. Proj. Manag., vol. 26, no. 8, pp. 800-809, 2008.

[96] C. . Lim and M. Z. Mohamed, "Criteria of project success: an exploratory reexamination,” Int. J. Proj. Manag., vol. 17, no. 4, pp. 243-248, 1999.

[97] C. E. M. Serra and M. Kunc, "Benefits Realisation Management and its influence on project success and on the execution of business strategies," Int. J. Proj. Manag., vol. 33, no. 1, pp. 53-66, 2015.

[98] L. D. Miles, Techniques of value analysis and engineering. Miles Value Foundation, 2015. .

[99] C. Besner and B. Hobbs, "The perceived value and potential contribution of project management practices to project success," Proj. Manag. J., vol. 37, no. 2001, pp. 37-48, 2006.

[100] A. L. C. Antoine and K. R. Molenaar, "Latent Class Analysis for Highway Design and Construction Project Categorization," Procedia Eng., vol. 145, pp. 1314-1321, 2016.

[101] I. R. Chiang and M. A. Nunez, "Strategic alignment and value maximization for IT project portfolios," Inf. Technol. Manag., vol. 14, no. 2, pp. 143-157, 2013.

[102] A. Mostafavi et al., "Risk-Based Protocol for Inspection of Transportation Construction Projects Undertaken by State Departments of Transportation," vol. 139, no. August, pp. 977-986, 2013.

[103] M. Martinsuo and P. Lehtonen, "Role of single-project management in achieving 
portfolio management efficiency," Int. J. Proj. Manag., vol. 25, no. 1, pp. 56-65, 2007.

[104] 19-11 NCHRP, "Prepared for Applying Risk Analysis, Value Engineering, and other Innovative Solutions for Project Delivery, TECHNICAL MEMORANDUM \# 2, November 2015," no. November, 2015.

[105] GDOT, "Project Management Handbook, PD Manual," 2012.

[106] ODOT, "PROJECT DELIVERY GUIDE PHASE 1: PROGRAM DEVELOPMENT," 2010.

[107] UDOT, “Project Manager Guide, Resource for UDOT Project Managers,” 2013.

[108] MDOT, “Design-Build Guidelines,” 2008.

[109] CDOT, "Project Development Process, Memorandum," 2013.

[110] VDOT, "Project Management Policy,” 2011.

[111] NJDOT, "Project Customization Guideline," 2015.

[112] NDOT, "Project Management Guidelines, Working Draft, second edition, 2010," 2010.

[113] WSDOT, "GUIDEBOOK FOR DESIGN-BUILD HIGHWAY PROJECT DEVELOPMENT," 2004.

[114] TxDOT, "Project Development Process Manual," no. July, 2014.

[115] CaltransDOT, "Caltrans Project Management Handbook, Project Processes, fifth edition," 2007.

[116] T. N. Desai, S. R. Prajapati, and H. R. Patel, "Application of value engineering to rework reduction in ship building project," MATEC Web Conf., vol. 8, pp. 1-5, 2016.

[117] T. T. Chen, T. I. Kuo, and C. S. Lin, "Value engineering applied at the construction planning stage," 2011 IEEE 18th Int. Conf. Ind. Eng. Eng. Manag., vol. Part 1, pp. 443-447, 2011.

[118] C. F. Huang, K. L. Lo, H. Y. Wang, and Y. W. Wu, "Applying value engineering to evaluate the use of concrete in an underground railway construction project," 2011 Int. Conf. Consum. Electron. Commun. Networks, CECNet 2011 - Proc., pp. 47974800, 2011. 
[119] V. Engineering and S. Final, "Value Engineering For Transportation Improvements SR 429 ( Wekiva Parkway )/ SR 417 and I-4 Interchange Value Engineering Study Final Report," vol. 429, no. 20030201, 2014.

[120] M. Baza, N. Bernard, and R. Stewart, "How VE and Decision Analysis are Improving Mobility across Borders, AASHTO Value Engineering Conference,” pp. 1-10, 2009.

[121] R. S. C. CILCH, "THE APPLICATION OF FUNCTION ANALYSIS SYSTEM TECHNIQUE FOR PROGRAM MANAGEMENT,” 2010.

[122] R. B. Stewart, C. V. S. Life, G. Brink, P. M. I. Rmp, and A. Cce, "Uncertainty Modeling in Multiple Dimensions for Value Methodology," pp. 1-18, 2012.

[123] A. Definitions, N. Region, and S. Region, "Value Engineering Program, Policy and Procedure, 05.01.030, State of Alaska DOT," 2013.

[124] A. Mohammadi and M. Tavakolan, "Construction project risk assessment using combined fuzzy and FMEA," IFSA World Congr. NAFIPS Annu. Meet. (IFSA/NAFIPS), 2013 Jt., pp. 232-237, 2013.

[125] P. G. Grabovy and A. K. Orlov, "The Overall Risk Assessment and Management: Implementation of Foreign Investment Construction Megaprojects by Russian Development Companies," Procedia Eng., vol. 153, no. 905, pp. 195-202, 2016.

[126] O. Taylan, A. O. Bafail, R. M. S. Abdulaal, and M. R. Kabli, "Construction projects selection and risk assessment by fuzzy AHP and fuzzy TOPSIS methodologies," Appl. Soft Comput. J., vol. 17, pp. 105-116, 2014.

[127] K. Molenaar, J. Diekmann, and D. Ashley, "Guide to Risk Assessment and Allocation for Highway Construction Management," p. 73, 2006.

[128] A. E. Yildiz, I. Dikmen, M. T. Birgonul, K. Ercoskun, and S. Alten, "A knowledgebased risk mapping tool for cost estimation of international construction projects," Autom. Constr., vol. 43, pp. 144-155, 2014.

[129] Nevada DOT, "Risk management and risk-based cost estimation guidelines," no. August, 2012.

[130] K. R. Molenaar, "Critical risk factors in project delivery method selection for highway projects,” no. Dbia 2010, pp. 331-340, 2012.

[131] California Department of Transportation, "Project Risk Management Handbook : A Scalable Approach,” vol. 1, no. June, 2012. 
[132] C. B. Farnsworth, M. Asce, R. O. Warr, J. E. Weidman, and D. M. Hutchings, "Effects of CM / GC Project Delivery on Managing Process Risk in Transportation Construction," vol. 142, no. 3, pp. 1-10, 2016.

[133] C. Stephen R. Pettee, PE, "Constructability Reviews-An introduction," pp. 1-31, 2010.

[134] N. Stamatiadis, P. Goodrum, M. Asce, E. Shocklee, and C. Wang, "Quantitative Analysis of State Transportation Agency' s Experience with Constructability Reviews," vol. 390, no. 2, 2014.

[135] A. A. Ezzat Othman, "Improving Building Performance through Integrating Constructability in the Design Process," Organ. Technol. Manag. Constr. An Int. J., vol. 3, no. 2, pp. 333-347, 2011.

[136] M. Hasanzadeh, Z. Tavakolirad, and P. Abbasi, "Review of affective factors on cost, time and quality of construction projects in developing countries," ICEMMS 2011 Proc. 2011 2nd IEEE Int. Conf. Emerg. Manag. Manag. Sci., pp. 858-861, 2011.

[137] INDOT, “Constructability Guide Book, ReviewProcess.” 2010.

[138] LA-DOTD, "Louisiana Department of Transportation and Development Construction Plans Quality Control / Quality Assurance," no. August, 2008.

[139] MIDOT, "PROCEDURES FOR PLAN PREPARATION, ROAD DESIGN CHAPTER 14 INDEX,” 2013.

[140] P. Goodrum, E. Shocklee, and C. Wang, "Tools for Applying Constructability Concepts to Project Development (Design) - Interim Report, Kentucky Transportation Center, College of Engineering, University of Kentucky," no. November 2012, 2012.

[141] MnDOT, "Industry Constructability Review Guidelines Office of Construction and Innovative Contracting Industry, Constructability Review Guidelines," pp. 1-6, 2010.

[142] H. Ying, "The Highway Construction Cost Control Model Based On The Improved Earned Value Method Theory," pp. 461-464, 2016.

[143] J. Reilly and J. Brown, "Management and control of cost and risk for tunneling and infrastructure projects," Tunn. Undergr. Sp. Technol., vol. 19, no. 4-5, p. 330, 2004.

[144] J. S. Shane and P. Investigator, "Risk-Based Engineers Estimate, Minnesota Department of Transportation.," no. March, 2015. 
[145] Project Management Institute, A guide to the project management body of knowledge (PMBOK ® guide). 2013.

[146] F. Minooei, N. Sobin, P. Goodrum, and K. Molenaar, "Community Outreach Tools and Strategies for Accelerated Highway Construction Projects Implementation Guide," 2016.

[147] J. Bonneson, "Development of Tools for Evaluating Safety Implications of Highway Design Decisions," vol. 7, no. 2, 2007.

[148] F. Beckers, E. Silva, N. Chiara, A. Flesch, J. Maly, and U. Stegemann, "A riskmanagement approach to a successful infrastructure project," McKinsey Work. Pap. Risk, no. 52, p. 18, 2013.

[149] H. Thamhain, "Managing risks in complex projects," Proj. Manag. J., vol. 44, no. 2, pp. 20-35, 2013.

[150] J. Fortune, D. White, K. Jugdev, and D. Walker, "Looking again at current practice in project management," Int. J. Manag. Proj. Bus., vol. 4, no. 4, pp. 553-572, 2011.

[151] R. Coombs, A. McMeekin, and R. Pybus, "Toward the development of benchmarking tools for R \& D project management," $R D$ Manag., vol. 28, no. 3, pp. 175-186, 1998.

[152] J. Sullivan et al., "Two Decades of Performance Comparisons for Design-Build, Construction Manager at Risk, and Design-Bid-Build : Quantitative Analysis of the State of Knowledge on Project Cost , Schedule , and Quality," vol. 143, no. 2017, 2017.

[153] A. Touran, D. D. Gransberg, K. R. Molenaar, K. Ghavamifar, D. J. Mason, and L. A. Fithian, A Guidebook for the Evaluation of Project Delivery Methods. TCRP Report 131. 2009.

[154] J. Walewski, G. E. Gibson, and J. Jasper, "Project Delivery Methods and Contracting Approaches Available for Implementation," vol. 7, 2001.

[155] M. El Asmar, A. S. Hanna, and W.-Y. Loh, "Evaluating Integrated Project Delivery Using the Project Quarterback Rating," J. Constr. Eng. Manag., vol. 142, no. 1, p. 04015046, 2016.

[156] D. C. Kent and B. Becerik-Gerber, "Understanding Construction Industry Experience and Attitudes toward Integrated Project Delivery," J. Constr. Eng. Manag., vol. 136, no. 8, pp. 815-825, 2010. 
[157] S. a. Austin, A. N. Baldwin, and J. L. Steele, "Improving building design through integrated planning and control," Eng. Constr. Archit. Manag., vol. 9, no. 3, pp. 249-258, 2002.

[158] B. K. Baiden, A. D. F. Price, and A. Dainty, "Looking beyond processes: Human factors in team integration," D. J. Greenwood, ed, vol. 1, no. September 2003, pp. 3-5, 2003.

[159] M. Acar, Chao Guo, and Kaifeng Yang, "Accountability When Hierarchical Authority Is Absent: Views From Public-Private Partnership Practitioners," Am. Rev. Public Adm., vol. 38, no. 1, pp. 3-23, 2008.

[160] F. Blanc-Brude, H. Goldsmith, and T. V??lil??, "A comparison of construction contract prices for traditionally procured roads and public-private partnerships," Rev. Ind. Organ., vol. 35, no. 1-2, pp. 19-40, 2009.

[161] FWA, "Accelerated Bridge Construction Manual, Federal Highway Administration," 2011.

[162] Design Build Institution of America, "Choosing a Project Delivery Method," A Des. Done Right Prim., no. April, pp. 2-3, 2015.

[163] T. Ahola, E. Laitinen, J. Kujala, and K. Wikström, "Purchasing strategies and value creation in industrial turnkey projects," Int. J. Proj. Manag., vol. 26, no. 1, pp. 8794, 2008.

[164] R. Hejne, "Public-Private Partnerships : Did a Potentially Useful Concept Sink in the "Muddle of Ideas "?," vol. 3, no. 1, 2007.

[165] S. Scott, K. R. Molenaar, D. D. Gransberg, and N. C. Smith, "Best-Value Procurement Methods for Highway Construction Projects," 2006.

[166] C. W. Ibbs, Y. H. Kwak, T. Ng, and A. M. Odabasi, "Project Delivery Systems and Project Change: Quantitative Analysis," J. Constr. Eng. Manag., vol. 129, no. 4, pp. 382-387, 2003.

[167] N. Ghaffour, T. M. Missimer, and G. L. Amy, "Technical review and evaluation of the economics of water desalination: Current and future challenges for better water supply sustainability," Desalination, vol. 309, pp. 197-207, 2013.

[168] F. Abdollahyan, "Management of value as PPM driver," Proj. Manag. Inst., 2012.

[169] Y. J. Son and J. Venkateswaran, "Hierarchical supply chain planning architecture for integrated analysis of stability and performance," Int. J. Simul. Process Model., 
vol. 3, no. 3, p. 153, 2014.

[170] D. C. WILSON, Value Engineering Applications in Transportation, COOPERATIVE, A Synthesis of Highway Practice, NCHRP 352. 2005.

[171] E. a. Ovidiu, Risk Management for Design and Construction, book. 2011.

[172] WSDOT, "Recommended AASHTO Design - Build Procurement Guide,” 2005.

[173] WSDOT, Project Risk Management Guide Part I: Guidance for WSDOT Projects Part II: Guidelines for CRA-CEVP ® Workshops, no. November. 2014.

[174] G. K. Kanji and A. Wong, "Quality culture in the construction industry," Total Qual. Manag., vol. 9, no. 4-5, pp. 133-140, 1998.

[175] P. Hoonakker, P. Carayon, and T. Loushine, "Barriers and benefits of quality management in the construction industry: An empirical study," Total Qual. Manag. Bus. Excell., vol. 21, no. 9, pp. 953-969, 2010.

[176] J. L. Burati Jr., M. F. Matthews, and S. N. Kalidindi, "Quality management in construction industry," Constr. Eng. Manag., vol. 117, no. 2, pp. 341-359, 1991.

[177] D. Arditi and H. M. Gunaydin, "Total quality management in the construction process,” Int. J. Proj. Manag., vol. 15, no. 4, pp. 235-243, 1997.

[178] WSDOT, "A MANUAL OF INSTRUCTION, The implementation of the Washington State Department of Transportation Constructability Review Process (CRP), , 2000.

[179] A. Khan, "Project Scope Management, Cost Engineering Vol. 48/No. 6," J. Constr. Eng. Manag., vol. 48, 2006.

[180] D. Nevogt, ““31 Project Management Solutions'. Hubstaff. Retrieved 3 November 2013.," 2013.

[181] A. Kastor and K. Sirakoulis, "The effectiveness of resource levelling tools for Resource Constraint Project Scheduling Problem," Int. J. Proj. Manag., vol. 27, no. 5, pp. 493-500, 2009.

[182] M. Aruldoss, "A Survey on Multi Criteria Decision Making Methods and Its Applications," Am. J. Inf. Syst., vol. 1, no. 1, pp. 31-43, 2013.

[183] S. D. Pohekar and M. Ramachandran, "Application of multi-criteria decision making to sustainable energy planning - A review," Renewable and Sustainable 
Energy Reviews, vol. 8, no. 4. pp. 365-381, 2004.

[184] K. Phan, "Innovation Measurement: A Decision Framework to Determine Innovativeness of a Company, Dissertation," 2013.

[185] D. F. Kocaoglu, “A Participative Approach to Program Evaluation," Ieee Trans. Eng. Manag., no. 3, pp. 112-118, 1983.

[186] L. Hogaboam, B. Ragel, and T. Daim, "Development of a Hierarchical Decision Model (HDM) for health technology assessment (HTA) to design and implement a new patient care database for low back pain," Proc. PICMET '14 Conf. Portl. Int. Cent. Manag. Eng. Technol. Infrastruct. Serv. Integr., pp. 3511-3517, 2014.

[187] T. Turan, M. Amer, P. Tibbot, M. Almasri, F. Al Fayez, and S. Graham, "Use of hierarchal decision modeling (HDM) for selection of graduate school for master of science degree program in engineering," PICMET Portl. Int. Cent. Manag. Eng. Technol. Proc., pp. 535-549, 2009.

[188] H. A. Alanazi, T. U. Daim, and D. F. Kocaoglu, "Identify the best alternatives to help the diffusion of teleconsultation by using the Hierarchical Decision Model (HDM)," Portl. Int. Conf. Manag. Eng. Technol., vol. 2015-Septe, pp. 422-432, 2015.

[189] B. Saatchi, L. Pham, H. Pham, C. F. Pai, and Y. Tran, "Decision model for selecting a sedan car," Technol. Manag. IT-Driven Serv. (PICMET), 2013 Proc. PICMET'13, pp. 393-400, 2013.

[190] K. Phan, "Innovation Measurement: A Decision Framework to Determine Innovativeness of a Company," pp. 1-127, 2013.

[191] R. Abotah, "Evaluation of Energy Policy Instruments for the Adoption of Renewable Energy: Case of Wind Energy in the Pacific Northwest, Dissertation," 2014.

[192] T. L. Saaty, T. Analytic, H. Process, and T. L. Saaty, "The Analytic Hierarchy Process," Education, pp. 1-11, 1980.

[193] T. L. Saaty, "Decision making with the analytic hierarchy process," Int. J. Serv. Sci., vol. 1 , no. 1 , p. 83, 2008.

[194] M. Zelany, "A concept of compromise solutions and the method of the displaced ideal," Comput. Oper. Res., vol. 1, no. 3-4, pp. 479-496, 1974.

[195] S. Opricovic and G. H. Tzeng, "Compromise solution by MCDM methods: A 
comparative analysis of VIKOR and TOPSIS," Eur. J. Oper. Res., vol. 156, no. 2 , pp. 445-455, 2004.

[196] E. Toloie and K. Majid, "Supplier Selection by Neo-TOPSIS," Appl. Math. Sci., vol. 5, no. 17, pp. 837-844, 2011.

[197] A. K. Puthanpura, R. Khalifa, and L. Chan, "Assessing emerging automotive technologies for the future," in Portland International Conference on Management of Engineering and Technology, 2015, vol. 2015-Septe, pp. 2113-2120.

[198] M. Dağdeviren, S. Yavuz, and N. Kilinç, "Weapon selection using the AHP and TOPSIS methods under fuzzy environment," Expert Syst. Appl., vol. 36, no. 4, pp. 8143-8151, 2009.

[199] K. S. S. Anupama, S. S. Gowri, B. Prabhakararao, and P. Rajesh, "Application of MADM Algorithms to Network Selection," Nternational J. Innov. Res. Electr. Electron. Instrum. Control Eng., vol. 3, no. 6, pp. 64-67, 2015.

[200] I. J. I. Engineering, "Multi-Attribute Decision Making Using Simple Additive Weighting and Weighted Product in Food Choice," Int. J. Inf. Eng. Electron. Bus., vol. 7, no. 6, pp. 8-14, 2015.

[201] H. Deng, "Multicriteria analysis with fuzzy pairwise comparison," Int. J. Approx. Reason., vol. 21, no. 3, pp. 215-231, 1999.

[202] J. Figueira, V. Mousseau, and B. Roy, "Chapter 1 ELECTRE METHODS Introduction : A brief History,” Mult. Criteria Decis. Anal. State Art Surv., pp. 1$35,2005$.

[203] R. Abu-Taha, "Multi-criteria applications in renewable energy analysis: A literature review," Technol. Manag. Energy Smart World (PICMET), 2011 Proc. PICMET '11, pp. 1-8, 2011.

[204] R. K. Gavade, "Multi-Criteria Decision Making : An overview of different selection problems and methods," Int. J. Comput. Sci. Inf. Technol., vol. 5, no. 4, pp. 56435646, 2014.

[205] H.-C. Liu, J.-X. You, X.-Y. You, and M.-M. Shan, “A novel approach for failure mode and effects analysis using combination weighting and fuzzy VIKOR method," Appl. Soft Comput., vol. 28, pp. 579-588, 2015.

[206] A. Anvari, N. Zulkifli, and O. Arghish, "Application of a modified VIKOR method for decision-making problems in lean tool selection," Int. J. Adv. Manuf. Technol., vol. 71, no. 5-8, pp. 829-841, 2014. 
[207] A. Mardani, E. K. Zavadskas, K. Govindan, A. A. Senin, and A. Jusoh, "VIKOR technique: A systematic review of the state of the art literature on methodologies and applications," Sustain., vol. 8, no. 1, pp. 1-38, 2016.

[208] Zephyris, "http://en.wikipedia.org/wiki/File:DNA_Structure\%2BKey\%2BLabelled.pn_NoB B.png,” Wikipedia.org, $2011 . \quad$ [Online]. Available: http://en.wikipedia.org/wiki/File:DNA_Structure+Key+Labelled.pn_NoBB.png.

[209] J. P. Brans, P. Vincke, and B. Mareschal, "How to select and how to rank projects: The Promethee method," Eur. J. Oper. Res., vol. 24, no. 2, pp. 228-238, 1986.

[210] J. Oberschmidt, J. Geldermann, J. Ludwig, and M. Schmehl, "Modified PROMETHEE approach for assessing energy technologies," Int. J. Energy Sect. Manag., vol. 4, no. 2, pp. 183-212, 2010.

[211] C. Yuan, S. Liu, Z. Fang, and N. Xie, "The relation between Chinese economic development and energy consumption in the different periods," Energy Policy, vol. 38, no. 9, pp. 5189-5198, 2010.

[212] D. Julong, "Introduction to Grey System Theory," J. Grey Syst., vol. 1, pp. 1-24, 1989.

[213] J. W. K. Chan and T. K. L. Tong, "Multi-criteria material selections and end-of-life product strategy: Grey relational analysis approach," Mater. Des., vol. 28, no. 5, pp. 1539-1546, 2007.

[214] L. Adelman, P. J. Sticha, and M. L. Donnell, "The role of task properties in determining the relative effectiveness of multiattribute weighting techniques," Organ. Behav. Hum. Perform., vol. 33, no. 2, pp. 243-262, 1984.

[215] M. Wang and J. Yang, "A multi-criterion experimental comparison of three multiattribute weight measurement methods," J. Multi Criteria Decis. Anal., pp. 340350, 1998.

[216] M. Bohanec, "DEXi: Program for Multi-Attribute Decision Making User' s Manual," Evaluation, no. November, pp. 1-65, 2008.

[217] M. Bohanec and V. Rajkovič, "Multi-Attribute Decision Modeling: Industrial Applications of DEX," Informatica, vol. 23, pp. 487-491, 1999.

[218] H. Mintzberg, "The rise and fall of strategic planning: Reconceiving roles for planning, plans, planners by Henry Mintzberg. New York: The Free Press.," J. Prod. Innov. Manag., vol. 13, no. 3, pp. 275-278, 1994. 
[219] B. P. Matrix, "Wisconsin Department of Transportation Guidance Matrix for Project Organization , Tools , Management , and Reporting Project Types *," 2016.

[220] CODT, "www.codot.gov/projects/contextsensitivesolutions/decision/life-cyclephases.".

[221] S. Greener, Business Research Methods, bookboon.com. Dr. Sue Greener \& Ventus Publishing ApS, 2008.

[222] C. Robson, Real World Research: A Resource for Social Scientists and PractitionerResearchers. 2002.

[223] J. Jonker and B. W. Pennink, The essence of research methodology: A concise guide for master and PhD students in management science. 2009.

[224] R. Khalifa and R. Stewart, "Survey of Value Assessment Programs within Transportation Construction Projects in U . S," PICMET (portl. Int. Cent. Manag. Eng. Technol., 2016.

[225] L. A. Rodegerdts et al., "Estimating the Life-Cycle Cost of Intersection Design," Nchrp, no. September, 2015.

[226] E. Triantaphy, "Reduction of pairwise comparisons in decision making via a duality approach, Volume 8, Issue 6 November 1999 P 299-310.” Triantaphyllou, Evangelos. "Reduction of pairwise comparisons in decision making via a duality approach.” Journal of Multicriteria Decision Analysis 8.6 (1999): 299., 1999.

[227] J. Estep, "Development of a Technology Transfer Score for Evaluating Research Proposals: Case Study of Demand Response Technologies in the Pacific Northwest, Dissertation," 2016.

[228] D. F. Kocaoglu, "A Participative Approach to Program Evaluation," Ieee Trans. Eng. Manag., no. 3, pp. 112-118, 1983.

[229] L. Chan, "Developing a Strategic Policy Choice Framework for Technological Innovation: Case of Chinese Pharmaceuticals, Dissertation," 2013.

[230] D. J. Weiss and J. Shanteau, "Empirical Assessment of Expertise," Hum. Factors J. Hum. Factors Ergon. Soc., vol. 45, no. 1, pp. 104-116, 2003.

[231] R. Neshati, "Participation in Technology Standards Development: A Decision Model for the Information and Communications Technology Industry,"” 2014.

[232] A. Alison Hubbard, "Does Consensus Imply Accuracy in Accounting Studies of 
Decision Making?," Account. Rev., vol. 60, no. 2, pp. 173-185, 1985.

[233] M. S. Abbas, "Consistency Thresholds for Hierarchical Decision Model, Engineering and Technology Management Faculty Publications and Presentations.101.," 2016.

[234] S. Zhou, "The development and evaluation of aggregation methods for group pairwise comparison judgments, Dissertation," 1996.

[235] R. L. Keeney and H. Raiffa, Decisions with multiple objectives-preferences and value tradeoffs, vol. 39, no. 2. 1993.

[236] B. S. Everitt and A. Skrondal, The Cambridge Dictionary of Statistics, vol. 53, no. 9. 2013.

[237] I. Iskin, "An Assessment Model for Energy Efficiency Program Planning in Electric Utilities: Case of Northwest U.S., Dissertation,” pp. 1-307, 2014.

[238] R. W. Saaty, "The analytic hierarchy process-what it is and how it is used," Math. Model., vol. 9, no. 3-5, pp. 161-176, 1987.

[239] Hongyi Chen and D. F. Kocaoglu, "A sensitivity analysis algorithm for hierarchical decision models,” Eur. J. Oper. Res., vol. 185, no. 1, pp. 266-288, 2008.

[240] E. C. Gibson, "A Measurement System for Science and Engineering Research Center Performance Evaluation, Dissertation,” 2016.

[241] T. A. Tran, "Strategic evaluation of university knowledge and technology transfer effectiveness, Dissertation,” p. 295, 2013.

[242] H. C. H. Chen, J. C. Ho, and D. F. Kocaoglu, "A Strategic Technology Planning Framework: A Case of Taiwan's Semiconductor Foundry Industry," IEEE Trans. Eng. Manag., vol. 56, no. 1, pp. 4-15, 2009.

[243] M. M. Lingga, "Developing a Hierarchical Decision Model to Evaluate Nuclear Power Plant Alternative Siting Technologies," 2016.

[244] A. B. Knol, P. Slottje, J. P. Van Der Sluijs, and E. Lebret, "The use of expert elicitation in environmental health impact assessment: a seven step procedure," Environ. Heal., vol. 9, no. 1, pp. 1-19, 2010.

[245] C. Okoli and S. D. Pawlowski, "The Delphi method as a research tool: an example, design considerations and applications," Inf. Manag., vol. 42, no. 1, pp. 15-29, 2004. 
[246] M. G. Morgan, "Use (and abuse) of expert elicitation in support of decision making for public policy.," Proc. Natl. Acad. Sci. U. S. A., vol. 111, no. 20, pp. 7176-84, 2014.

[247] G. F. Nemet, L. D. Anadon, and E. Verdolini, "Quantifying the Effects of Expert Selection and Elicitation Design on Experts' Confidence in Their Judgments About Future Energy Technologies," Risk Anal., no. 6, 2016.

[248] M. Rauterberg, "Tools \& Techniques Expert Opinion," Usability Resour. - TUe Tech. Univ. Eindhoven - Univ. Technol., 2003.

[249] EPA, "Overview of the Panel Formation Process at the Environmental Protection Agency Science Advisory Board," 2002.

[250] C. Pawlowski, Suzanne D, Okoli, "The Delphi Method as a Research Tool: An Example, Design Considerations and Applications 1 Introduction 2 Overview of the Delphi method," Inf. Manag., vol. 42, no. 1, pp. 15-29, 2004.

[251] M. Heindl, F. Reinisch, S. Biffl, and A. Egyed, "Value-Based Selection of Requirements Engineering Tool Support," Softw. Eng. Adv. Appl. 2006. SEAA '06. 32nd EUROMICRO Conf., pp. 266-273, 2006.

[252] P. Brinckerhoff, Guidance for Managing NEPA-Related and Other Risks in Project Delivery, Volume 1: Guide for Managing NEPA-Related and Other Risks in Project Delivery. National Academies Press, 2012.

[253] NCHRP, SYNTHESIS 455 Alternative Technical Concepts for Contract Delivery Methods, no. January. 2014.

[254] R. Khalifa and R. Stewart, "Survey of value assessment programs within transportation construction projects in U.S," in PICMET 2016 - Portland International Conference on Management of Engineering and Technology: Technology Management For Social Innovation, Proceedings, 2017, pp. 21022118.

[255] D. P. Mootanah and M. Jefferyes, "A strategy for managing project risks in value management studies.” pp. 266-274, 1998.

[256] K. David, Q, “The intergration of value management and risk management.” pp. 62$70,1995$.

[257] C. T. Hyun, "Making value engineering As An Effective Tool For Project Intergartion Using Constructability And Partnering Concepts," Save International Conference Proceedings. pp. 111-118, 1997. 
[258] V. Team, "Caltrans Value Analysis Program Overview, VALUE ANALYSIS TEAM LEADER,” 2013.

[259] NCHRP 19-11, "Applying Risk Analysis, Value Engineering, and Other Innovative Solutions for Project Delivery, Final Report," 2017.

[260] A. Bhattacherjee, R. Morphet, J. Gutiérrez Bayo, T. Nam, and T. A. Pardo, Social Science Research: Principles, Methods, and Practices, no. April 1998. 2017.

[261] A. M. Law, "How To Build Valid and Credible Simulation Models," Proc. 2008 Winter Simul. Conf., pp. 39-47, 2008.

[262] M. J. Clayton, "Delphi: a technique to harness expert opinion for critical decisionmaking tasks in education," Educ. Psychol., vol. 17, no. 4, pp. 373-386, 1997.

[263] U. A. Mahadik, "Cost Reduction in Construction Projects," vol. 3, no. September, pp. 397-400, 2015.

[264] Y. Moret and H. H. Einstein, "Construction Cost and Duration Uncertainty Model: Application to High-Speed Rail Line Project," J. Constr. Eng. Manag., vol. 142, no. 10, p. 05016010, 2016.

[265] I. M. Mahdi and K. Alreshaid, "Decision support system for selecting the proper project delivery method using analytical hierarchy process (AHP)," Int. J. Proj. Manag., vol. 23, no. 7, pp. 564-572, 2005.

[266] D. N. Ford, S. D. Anderson, A. J. Damron, R. de Las Casas, N. Gokmen, and S. T. Kuennen, "Managing Constructibility Reviews to Reduce Highway Project Durations," J. Constr. Eng. Manag., vol. 130, no. 1, pp. 33-42, 2004.

[267] Y. . Kog, D. K. . Chua, P. . Loh, and E. . Jaselskis, "Key determinants for construction schedule performance," Int. J. Proj. Manag., vol. 17, no. 6, pp. 351359, 1999.

[268] M. A. Khan, "Accelerated Bridge Construction_ Best Practices and Techniques Mohiuddin Ali Khan - Google Books." 2015.

[269] R. Lewis et al., "WSDOT Strategic Plan Accelerated Bridge Construction ( ABC ) Practice and Policy for ABC Bridge Projects Table of Contents :," pp. 1-13, 2009.

[270] A. Saeedi, S. Emami, T. L. Doolen, and B. Tang, "A decision tool for accelerated bridge construction," PCI J., vol. 58, no. 2, pp. 48-63, 2013.

[271] A. Murphy and A. Ledwith, "Manufacturing and Operations Engineering University 
of Limerick Limerick Ireland,” Manag. Res. News, vol. 30, pp. 153-166, 2007.

[272] S. Highway, "Transportation Risk Management: International Practices for Program Development and Project Delivery," no. August, 2012.

[273] K. R. Molenaar, "Guide for the Process of Managing Risk on Rapid Renewal Projects," no. January, pp. 1-4, 2014.

[274] A. Touran, D. D. Gransberg, K. R. Molenaar, and K. Ghavamifar, "Selection of project delivery method in transit: Drivers and objectives," J. Manag. Eng., vol. 27, no. 1, pp. 21-27, 2011.

[275] M. M. Kumaraswamy and S. M. Dissanayaka, "Developing a decision support system for building project procurement," Build. Environ., vol. 36, no. 3, pp. 337349, 2001.

[276] M. I. Al Khalil, "Selecting the appropriate project delivery method using AHP," Int. J. Proj. Manag., vol. 20, no. 6, p. 464, 2002.

[277] A. A. Oyetunji and S. D. Anderson, "Relative Effectiveness of Project Delivery and Contract Strategies," J. Constr. Eng. Manag., vol. 132, no. January, pp. 3-13, 2006.

[278] H.-K. Hong, J.-S. Kim, T. Kim, and B.-H. Leem, "The effect of knowledge on system integration project performance," Ind. Manag. Data Syst., vol. 108, no. 3, pp. 385-404, 2008.

[279] U. Ojiako, E. Johansen, and D. Greenwood, "A qualitative re-construction of project measurement criteria," Ind. Manag. Data Syst., vol. 108, no. 3, pp. 405-417, 2008.

[280] Mathonsi, M. D, "Factors influencing the selection of procurement systems in the South African construction industry," African J. Bus. Manag., vol. 6, no. 10, pp. 3583-3594, 2012.

[281] Z. Li, "Review of Literature on Highway Project Benefit-Cost and Tradeoff Analyses," no. 312, 2006.

[282] D. G. Peshkin, T. E. Hoerner, and K. A. Zimmerman, NCHRP Report 523: Optimal Timing of Pavement Preventive Maintenance Treatment Applications. 2004.

[283] Department of Transportation California, "CHAPTER 20 - Project Development Cost Estimates,” Proj. Dev. Proced. Man., pp. 20-3_20-20, 2014.

[284] "PROJECT DELIVERY ACCELERATION Improvements to the Project Delivery Process," no. July, 2012. 
[285] CDOT, "Right of Way, General Policies, Procedures and Information," 2016, pp. $1-11$.

[286] W. A. B. C. Initiative and A. B. C. Overview, "Accelerated Bridge Construction Table of Contents WisDOT Bridge Manual Chapter 7 - Accelerated Bridge Construction," no. July, pp. 1-40, 2015.

[287] “CDC Unified Process - Practices Guide, Project Close-out,” 2006.

[288] NJDOT, "Value Engineering Process, The New Jersey Department of Transportation," 2017.

[289] R. B. Stewart et al., "Applying Risk Analysis, Value Engineering, and Other Innovative Solutions for Project Delivery, RESEARCH REPORT 850," 2017.

[290] “Comparing In-House Staff to Consultants to Balance Workload,” 2013.

[291] M. DOT, "VALUE ANALYSIS PROGRAM MANUAL MONTANA DEPARTMENT OF TRANSPORTATION," vol. 2005, no. April, 2015.

[292] T. H. Y. Li, S. T. Ng, and M. Skitmore, "Modeling Multi-Stakeholder MultiObjective Decisions during Public Participation in Major Infrastructure and Construction Projects: A Decision Rule Approach," Am. Soc. Civ. Eng., vol. 142, no. 3, pp. 1-13, 2015.

[293] M. Abbas, "Consistency Analysis for Judgment Quantification in Hierarchical Decision Model, Dissertation," p. 200, 2016.

[294] NJDOT, “Cost Estimating Guideline,” 2017.

[295] C. M. Committee, "Constructability and Constructability Programs: White Paper By the Construction Management Committee of the ASCE Construction Division," $J$. Constr. Eng. Manag., vol. 117, no. 1, pp. 67-89, 1991.

[296] C. Behrens, D. Bassu, and H. S. Shim, "Collaborative Panel Administrator: A framework and implementation for expert Panel lifecycle management," Proc. 3rd Int. Conf. Collab. Comput. Networking, Appl. Work. Collab. 2007, pp. 408-417, 2007.

[297] A. B. Knol, P. Slottje, J. P. van der Sluijs, and E. Lebret, "The use of expert elicitation in environmental health impact assessment: a seven step procedure.," Environ. Health, vol. 9, no. 1, p. 19, 2010.

[298] M. Abbas, "Consistency Analysis for Judgment Quantification in Hierarchical 
Decision Model, Dissertation,” 2016.

[299] B. Yildiz, "Assessment of Policy Alternatives for Mitigation of Barriers to EV Adoption, Dissertation," 2018.

[300] M. M. Lingga, "Developing a Hierarchical Decision Model to Evaluate Nuclear Power Plant Alternative Siting Technologies, Dissertation," 2016.

[301] J. Swan, Practical Financial Modelling: the Development and Audit of Cash Flow Models, Book, Edition: 3rd Edition. Butterworth-Heinemann, 2015.

[302] FMI, “FMI’s Construction Outlook,” 2016.

[303] T. Haponava and S. Al-Jibouri, "Influence of process performance during the construction stage on achieving end-project goals," Constr. Manag. Econ., 2010.

[304] M. Borse and P. Khare, "Analysis of Cost and Schedule Overrun in Construction Projects," vol. 3, no. 1, pp. 383-386, 2016. 


\section{APPENDIX A: Research Instruments (RI1\& RI2)}

\section{Appendix A-1: Expert Invitation Templet - Validation}

Subject: Invitation to participate in determining criteria that contribute to the mission

Dear X,

I am a Ph.D. student in the Department of Engineering and Technology Management, at Portland State University, conducting research in Technology Management. The topic of my Ph.D. research is "Evaluating the Effectiveness of Project Assessment Techniques for Transportation Projects Development and Delivery."

I am asking you to participate in my research acting as a subject matter expert (SME) in order to evaluate my model, which is based on a Hierarchical Decision Model (HDM). Your selection as a potential participant in this expert panel was based on your expertise and knowledge in engineering, technology, and management. Also, based on your experience in evaluating, analyzing, and developing projects focused on the project management area.

As the first step of the study, I am asking you to help me finalize the initial model elements (criteria, sub-criteria, and alternatives) that contribute to the evaluation of Project Assessment Techniques for Transportation Projects Development and Delivery. The preliminary model elements have been identified from the literature review and are listed on the survey instrument that I am sending to you now.

To start the survey instrument; Please Click Here!

You will see the instructions on submitting your response after you click on the link. I would appreciate if you fill out the survey instrument at your earliest convenience

If you have any question or comment you can contact me by replying to this e-mail. Thank you, 


\section{Appendix A-2: Content Validity Survey}
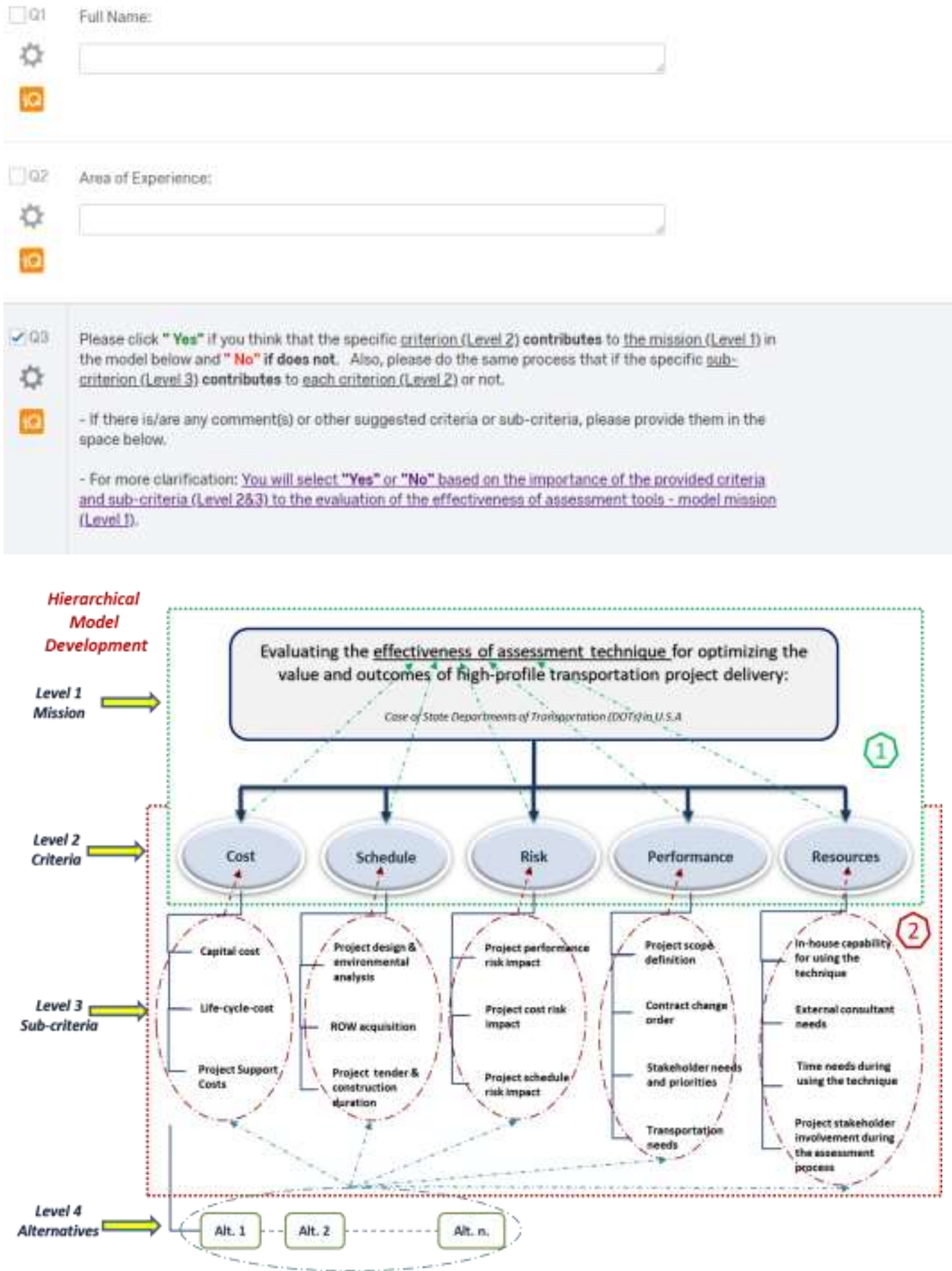


\section{APPENDIX B: Research Instruments (RI3, RI4 \& RI5)}

\section{Appendix B-1: Expert Invitation Templet - Quantification}

Subject: Data Collection for Relative Importance

Dear X,

After several rounds of data collection with the experts, we have finalized the development of the decision model that helps us Evaluating the Effectiveness of Project Assessment Techniques for Transportation Projects Development and Delivery.

The criteria, sub-criteria, and alternatives in the decision model were approved by at least two thirds of the experts.

I am now asking for quantified expert judgments about the relative importance of each model element (criteria, sub-criteria, and alternatives) in terms of its contribution to evaluate the effectiveness of project assessment techniques within transportation construction projects.

Constant sum method will be used for pairwise comparisons of the indicators to determine the importance weight of each element.

I will appreciate it if you please go to the following link for the pairwise comparisons:

Thelink:@@@@@

Note: The pairwise comparisons will not take more than 15 minutes to complete.

Regards,

First and Last Name 
Appendix B-2: Content Quantify Process - HDM Software

Model Content - HDM Software Layout

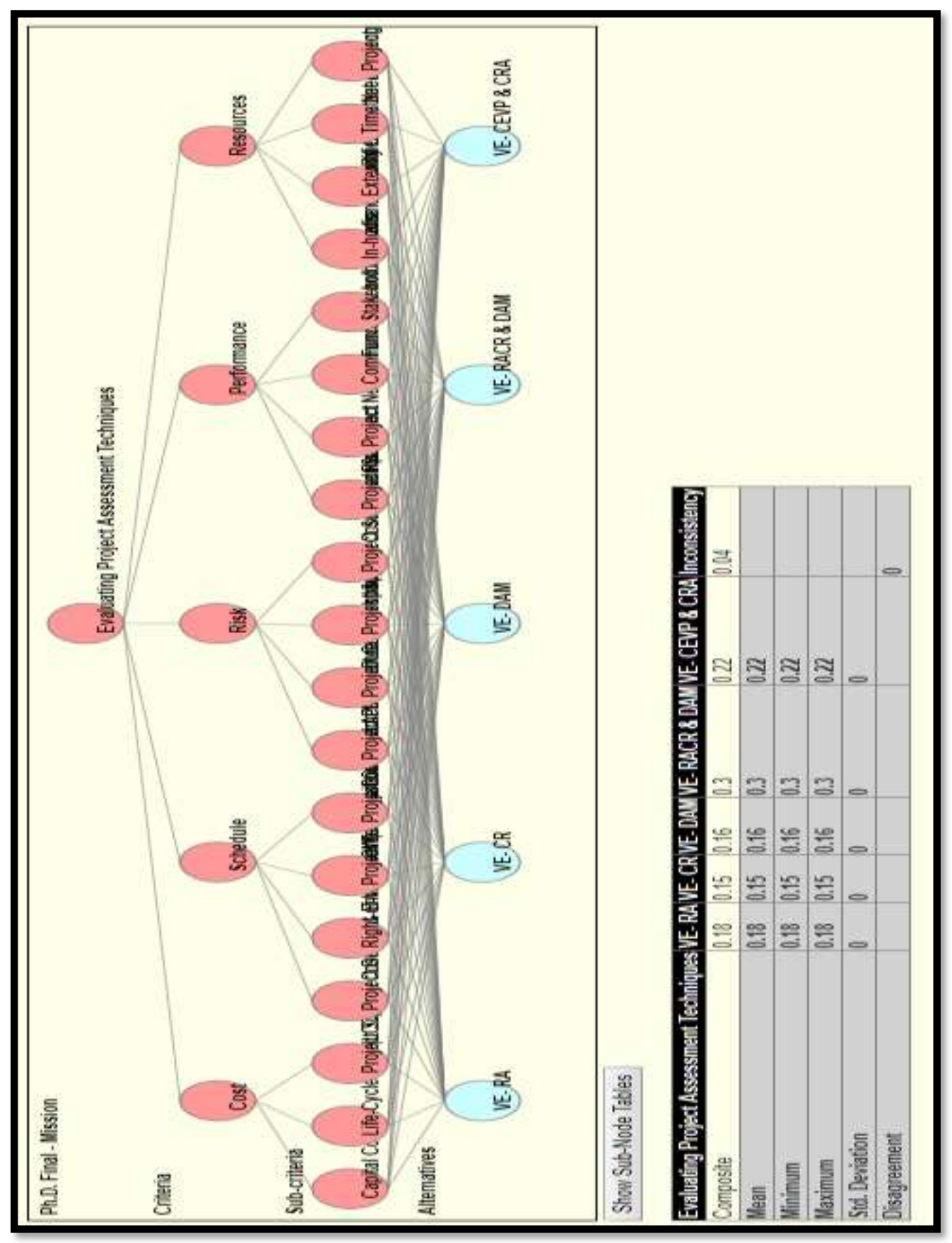


Model Level 2 Criteria Quantification - HDM Software Layout

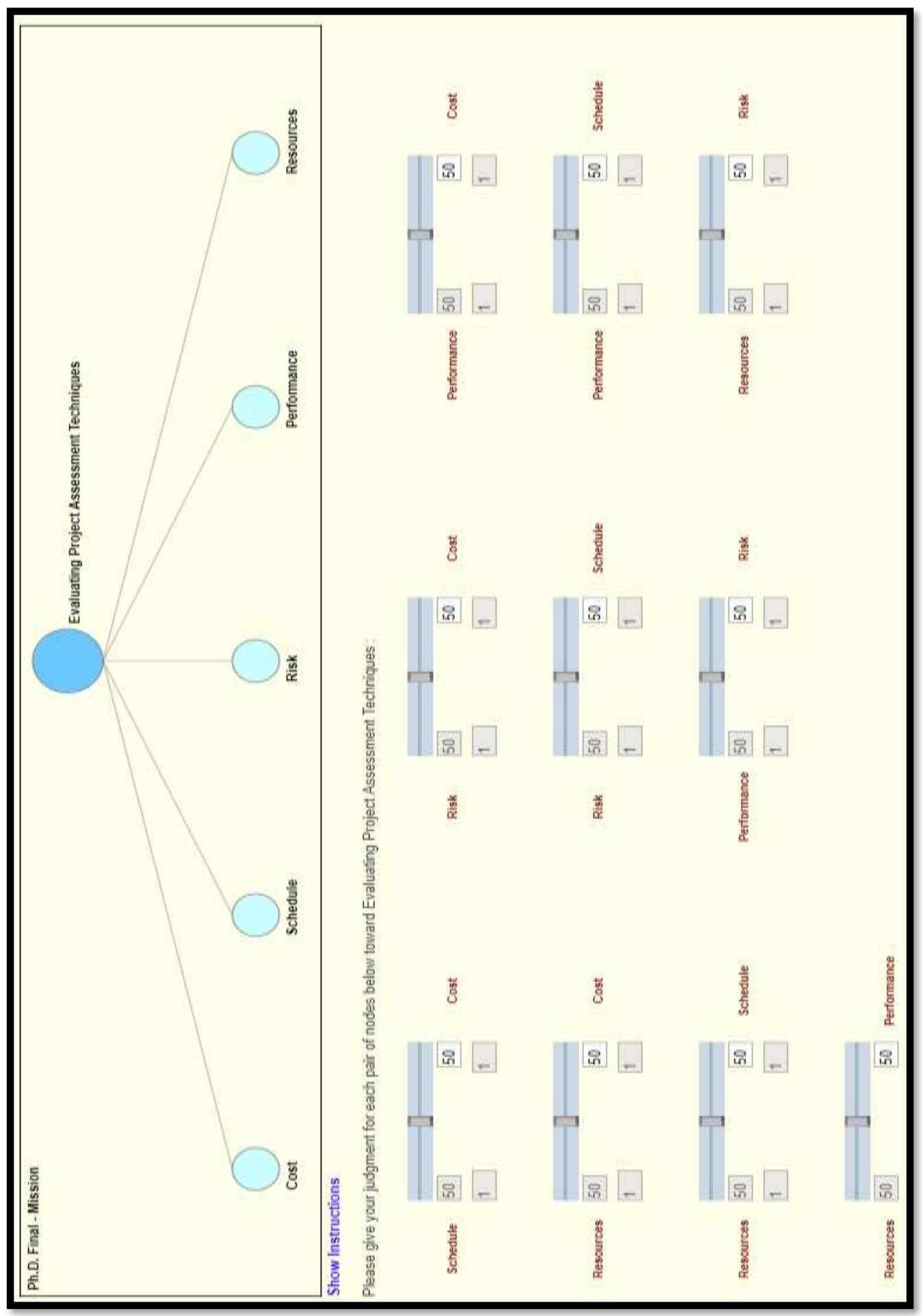


Model Level 3 (COST) Quantification - HDM Software Layout

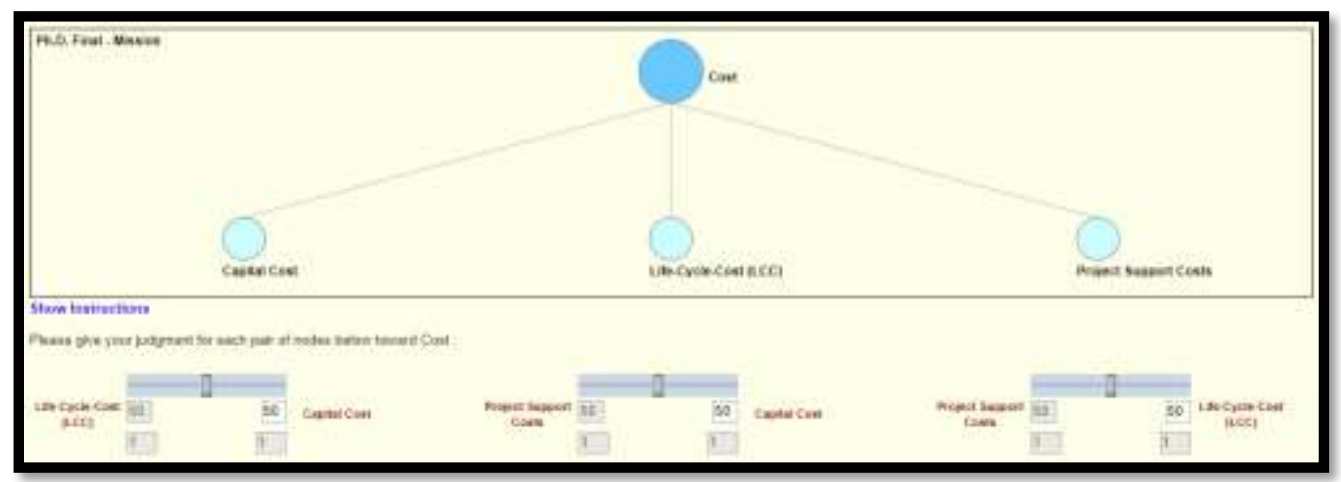

Model Level 3 (SCHEDULE) Quantification - HDM Software Layout

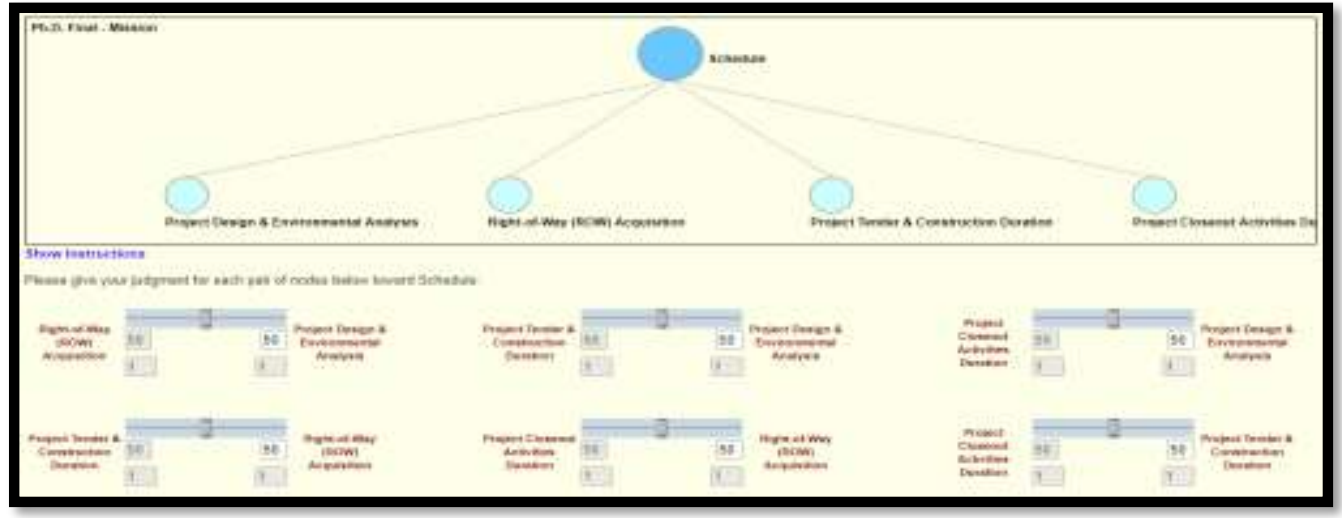

Model Level 3 (RISK) Quantification - HDM Software Layout

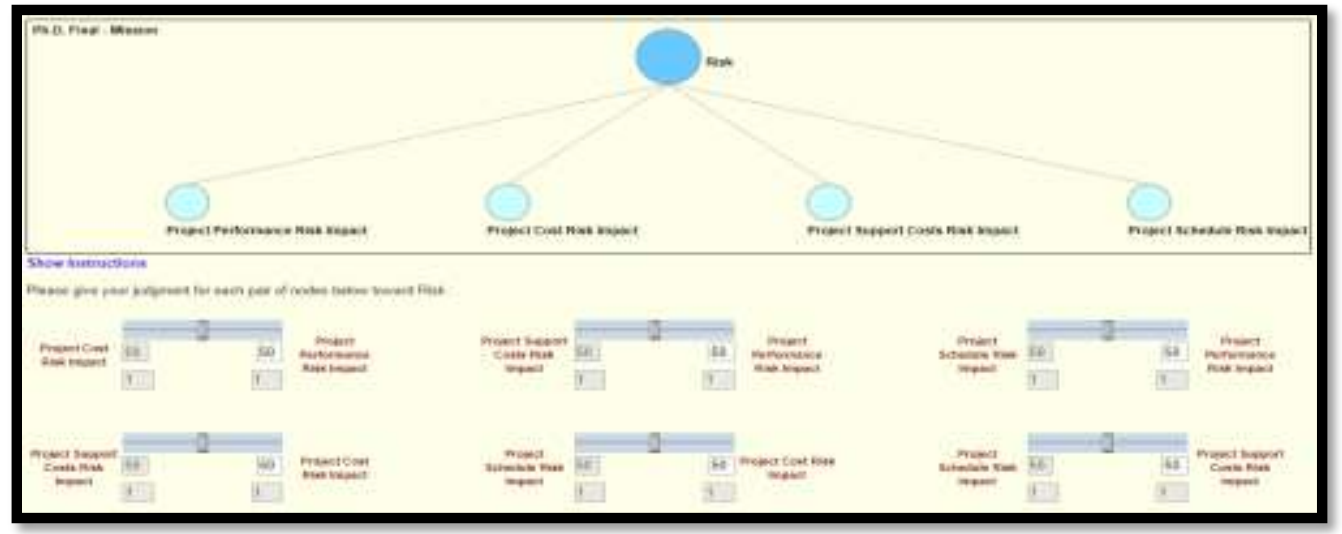


Model Level 3 (PERFORMANCE) Quantification - HDM Software Layout

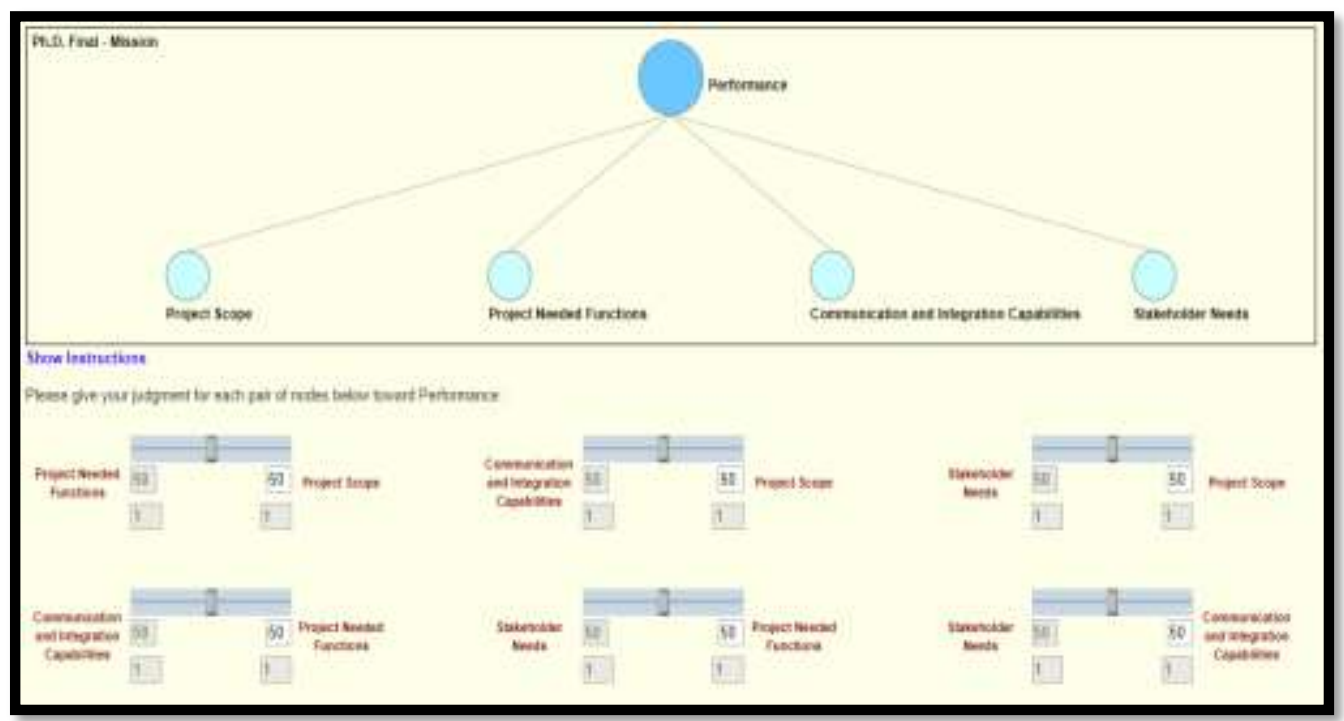

Model Level 3 (RESOURCES) Quantification - HDM Software Layout

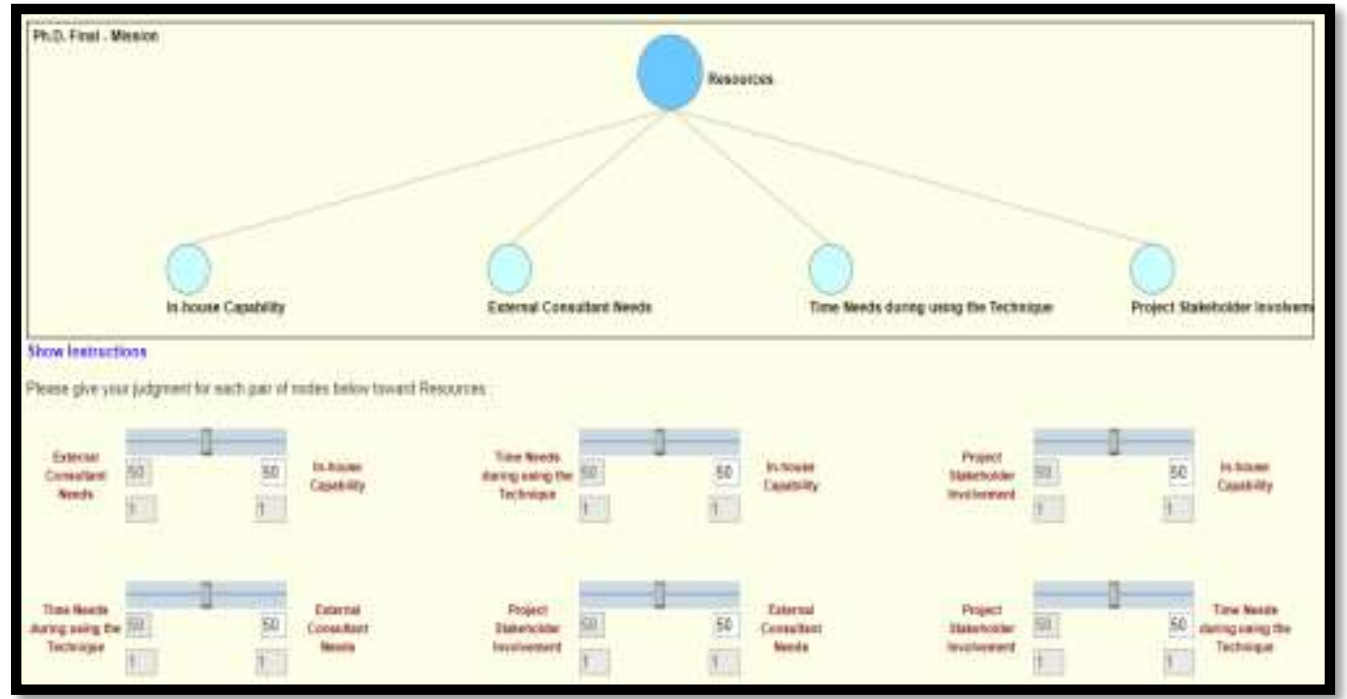


Model Level 4 Alternatives Quantification - HDM Software Layout

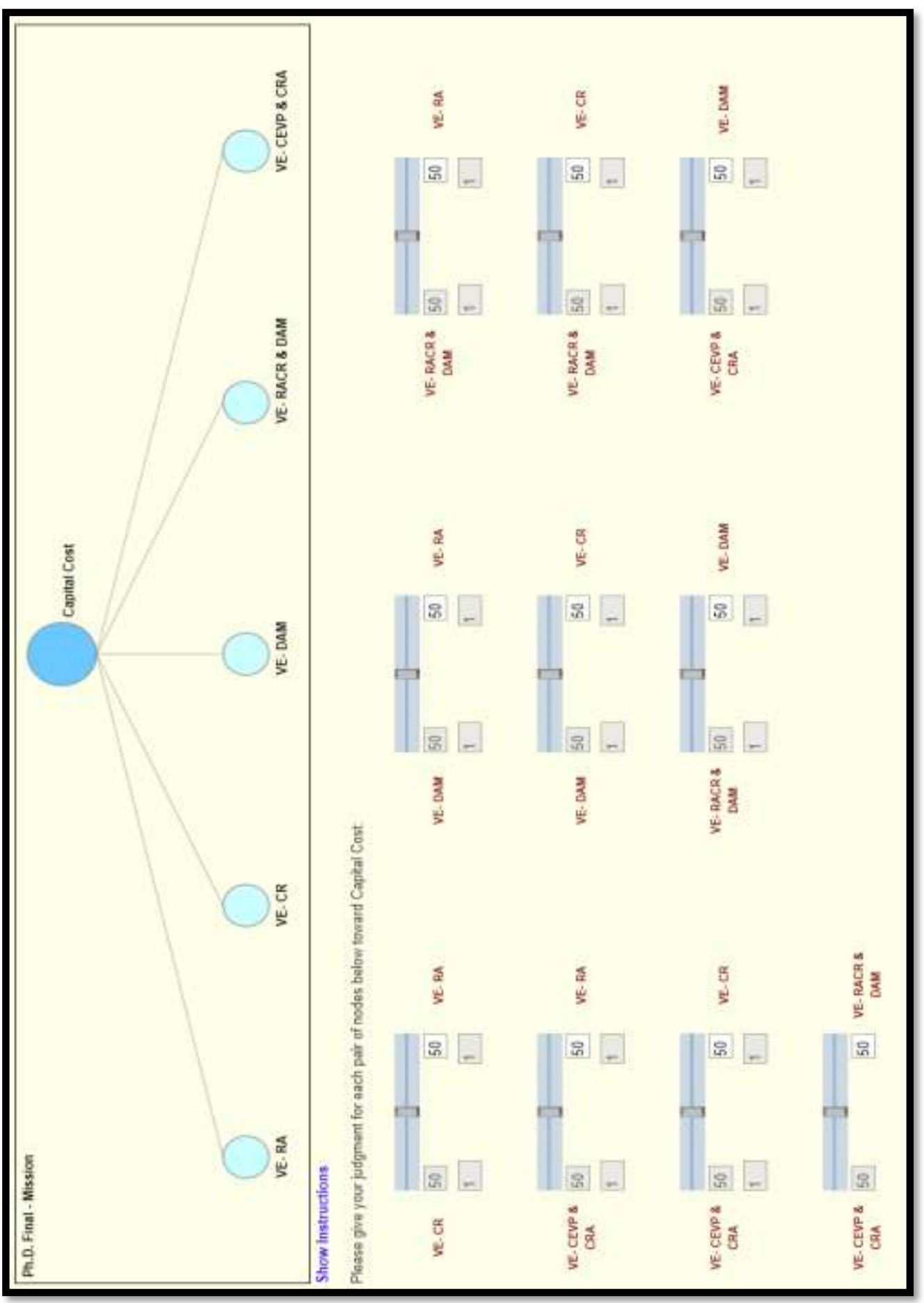




\title{
APPENDIX C: Research Instruments (RI6)
}

\section{Appendix C-1: Expert Invitation Templet - Final Results Validation}

\author{
Subject: Final Validation of the Decision Model Results
}

\section{Dear X,}

I would like to thank you for your previous efforts on my decision model.

I attached an excel spreadsheet of the final model results and will appreciate your last validation on the experts' judgment. I believe the validation will not take more than 5 minutes. Please have a look at the model weights!

All model's elements were accepted by "Yes," and please click on yes cell and select "No" by the drop-down menu of any element that you don't agree. Then, please send me your final judgment on the model results at your earliest convenience.

Regards,

First and Last Name 


\section{Appendix C-2: Survey Instrument - Final Results Validation}

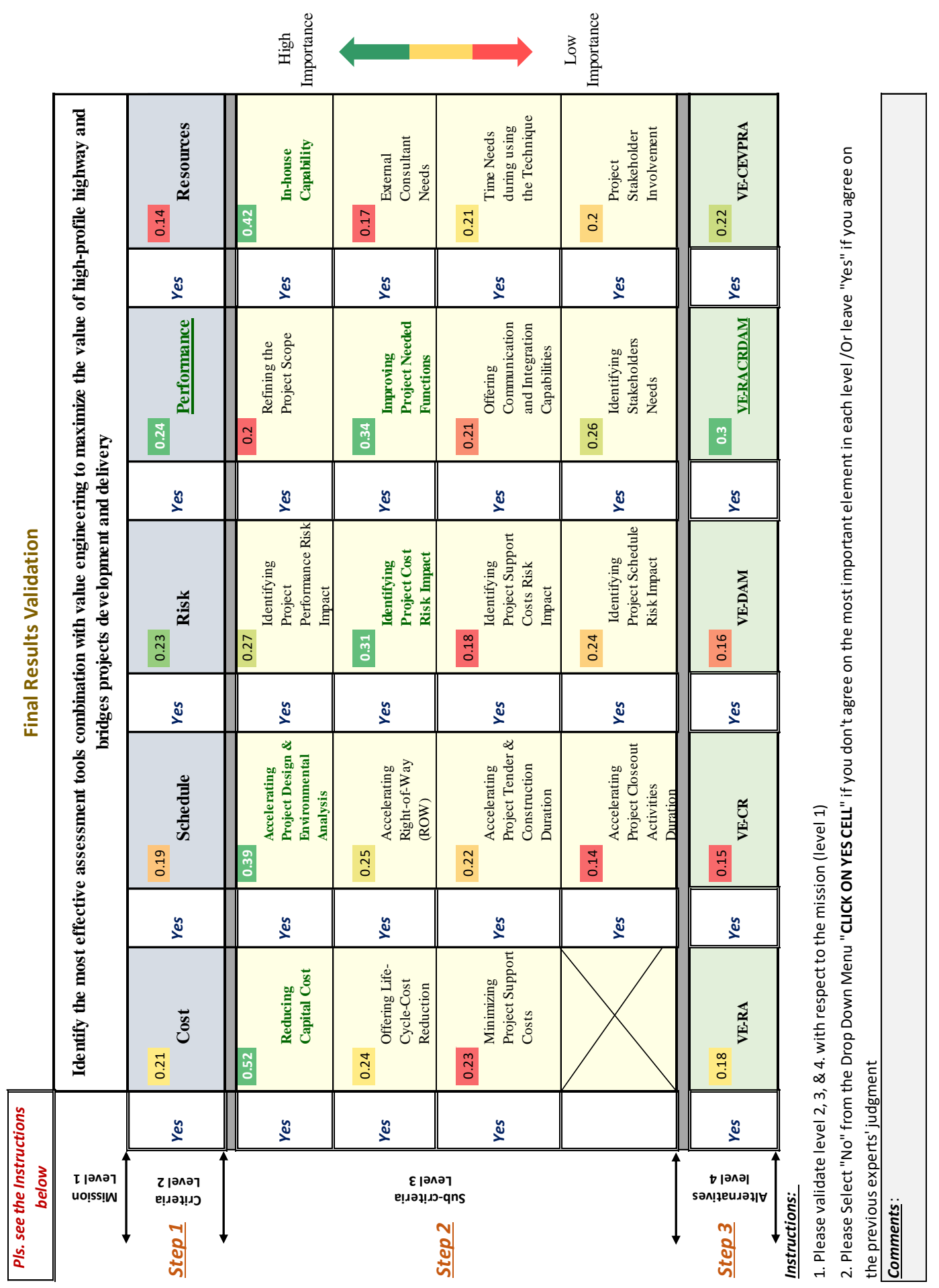

